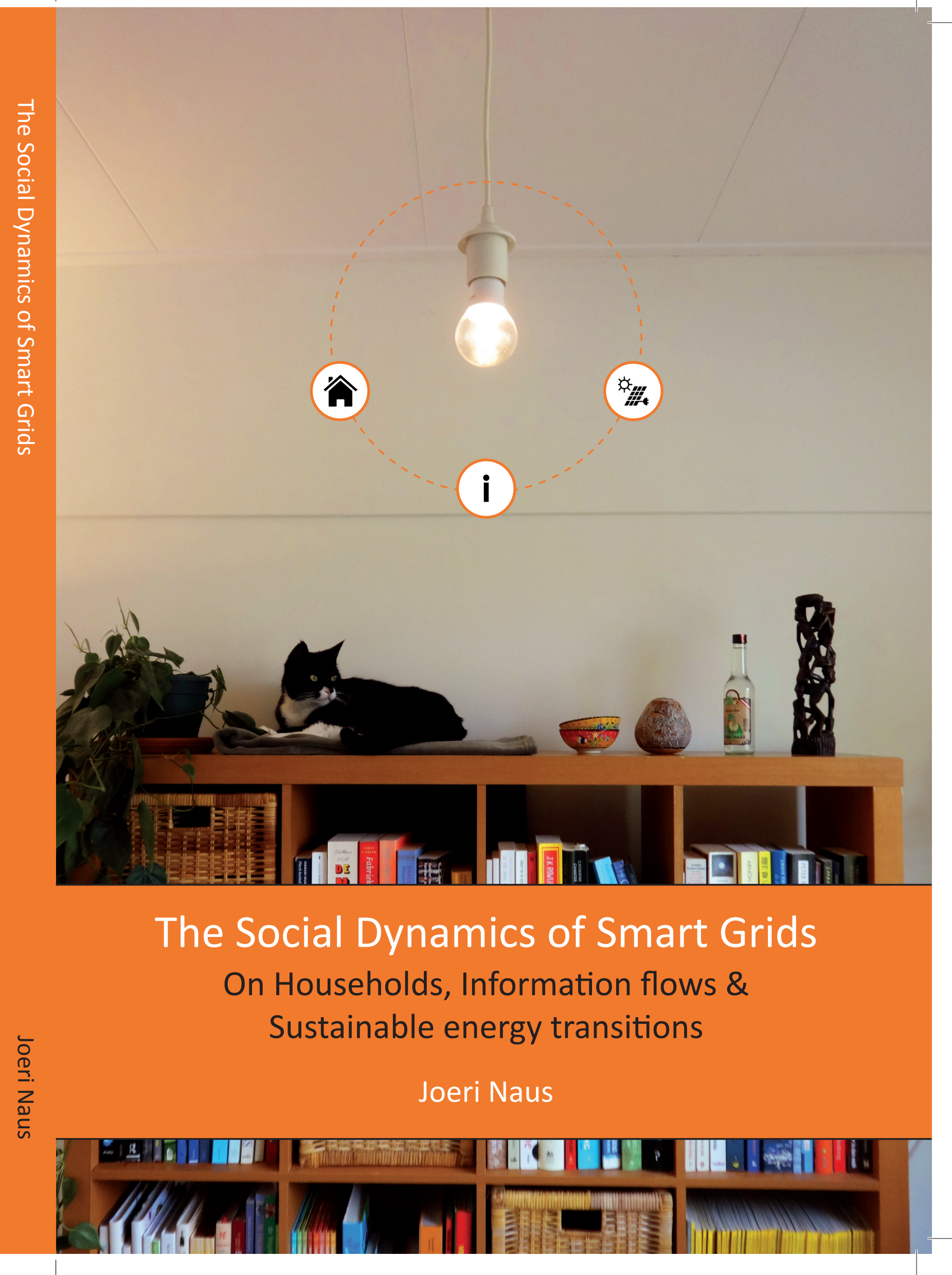




\section{Propositions}

1. The concept of 'Home Energy Management-practices' is a significant innovation in the debate on smart grids.

(this thesis)

2. The differentiation between 'informational practices' and 'information-inpractice' signifies a potential shift in the debate on Informational Governance. (this thesis)

3. The development of a generic theory of relational emergence can improve the communication and cooperation between the social sciences and the natural sciences (Elder-Vass, D., 2010. The causal power of social structures: Emergence, Structure and Agency. Cambridge University Press).

4. To emphasise the valorisation of science is to increase the need for scientific independence.

5. In twenty years from now we will see that current tendencies to reinforce the traditional powers of nation-states are unsustainable.

6. The use of monitoring technologies in sport not just promotes professionalisation, but changes the nature of sport itself.

Propositions belonging to the thesis entitled:

The Social Dynamics of Smart Grids: on Households, Information flows \& Sustainable energy transitions

Joeri Naus

Wageningen, 1 November 2017. 
The Social Dynamics of Smart Grids

on Households, Information flows \&

Sustainable energy transitions

Joeri Naus 


\section{Thesis committee}

\section{Promotor}

Prof. Dr G. Spaargaren

Personal chair at the Environmental Policy Group

Wageningen University \& Research

\section{Co-promotors}

Dr B.J.M. van Vliet

Associate Professor, Environmental Policy Group

Wageningen University \& Research

Dr H.M. van der Horst

Assistant Professor, Sociology of Consumption and Households Group

Wageningen University \& Research

\section{Other members}

Prof. Dr J. Grin, University of Amsterdam, the Netherlands

Dr T. Hargreaves, University of East Anglia, United Kingdom

Prof. Dr C.J.A.M. Termeer, Wageningen University \& Research

Dr W.J.V. Vermeulen, Utrecht University, the Netherlands

This research was conducted under the auspices of the SENSE Graduate School for Socio-Economic and Natural Sciences of the Environment. 


\title{
The Social Dynamics of Smart Grids on Households, Information flows \& Sustainable energy transitions
}

\author{
Joeri Naus
}

Thesis

submitted in fulfilment of the requirements for the joint degree of doctor at Wageningen University by authority of the Rector Magnificus Prof. Dr A.P.J. Mol, in the presence of the Thesis Committee appointed by the Academic Boards to be defended in public on Wednesday 1 November 2017 at 1.30 p.m. in the Aula. 
Joeri Naus

The Social Dynamics of Smart Grids: on Households, Information flows \& Sustainable energy transitions, 244 pages.

PhD thesis, Wageningen University \& Research, Wageningen, NL (2017)

With references, with summary in English

ISBN 978-94-6343-697-7

DOI https://doi.org/10.18174/423138 


\section{Table of contents}

Tables \& Figures................................................................................................................ vii

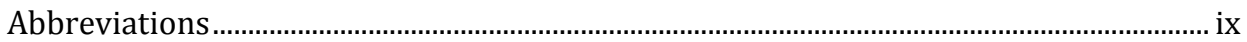

Chapter 1. General introduction ........................................................................

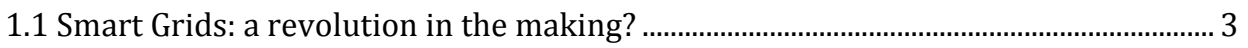

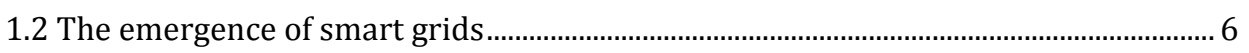

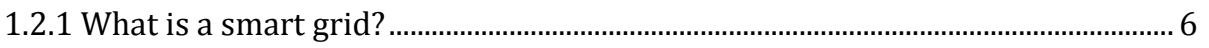

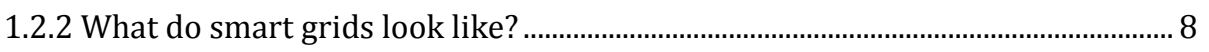

1.2.3 Where to find smart grids? ...................................................................................1

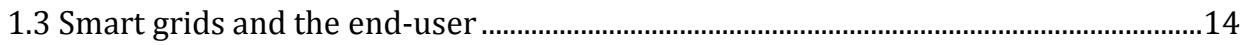

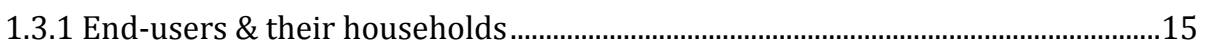

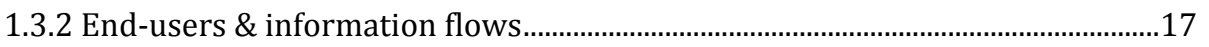

1.3.3 End-users \& the sustainable energy transition ........................................................18

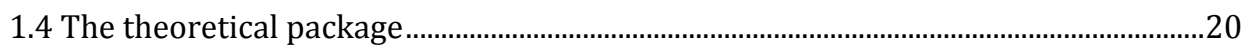

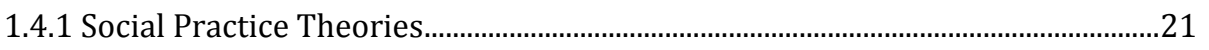

1.4.2 Informational Governance...................................................................................23

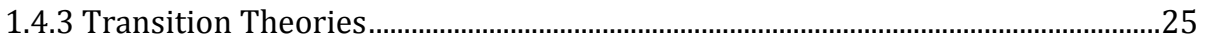

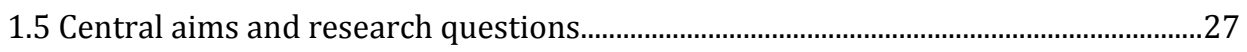

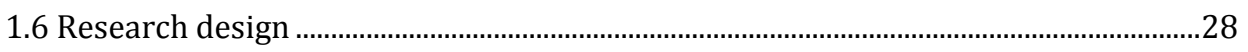

1.6.1 Practice methodologies ..........................................................................................29

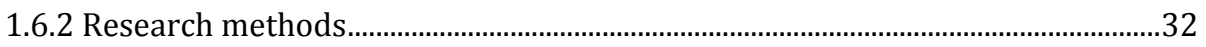

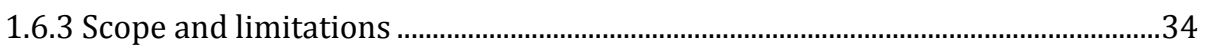

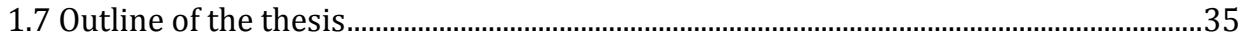

Chapter 2. Smart grids, information flows and emerging domestic

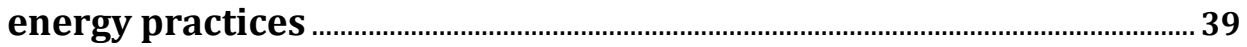

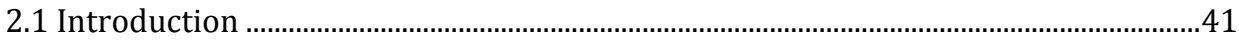

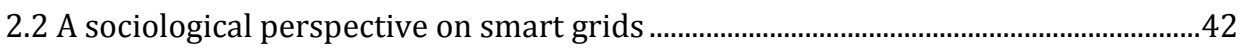

2.2.1 Households in the energy transition: A short history.............................................43

2.2.2 A sociological account of domestic energy consumption and production........45

2.3.3 A conceptual framework for studying the role of households in smart grids .46

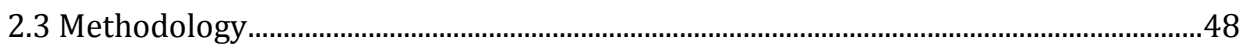

2.4 Background on smart grid development in the Netherlands......................................51

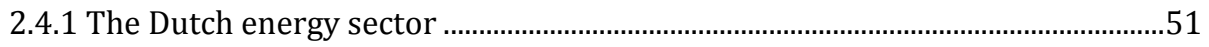

2.4.2 Implementation of smart meter and smart grid policies ........................................52 


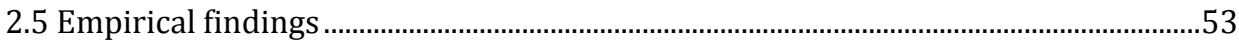

2.5.1 Information flows between household-members .................................................53

2.5.2 Information flows between households and service providers ...........................56

2.5.3 Information flows between different households ................................................59

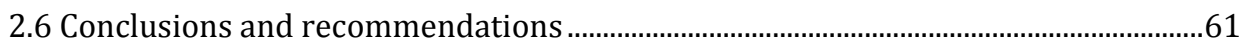

\section{Chapter 3. Households as change agents in a smart energy}

transition: On power, privacy and participation …………….......................65

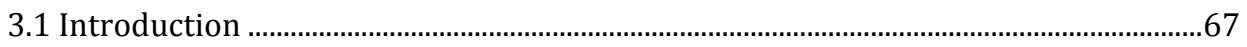

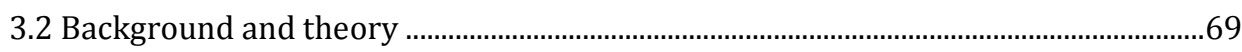

3.2.1 From 'passive' consumption towards 'active' participation? ................................69

3.2.2 Participation and transformation in the domestic environment ..........................70

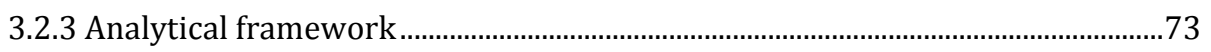

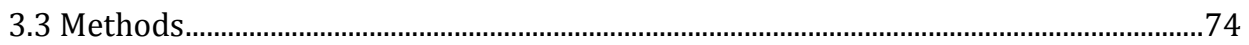

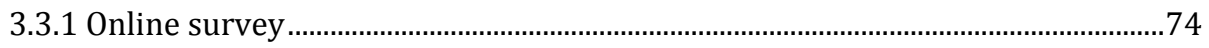

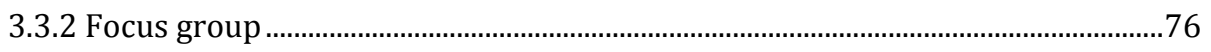

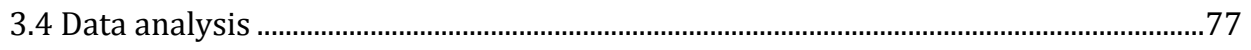

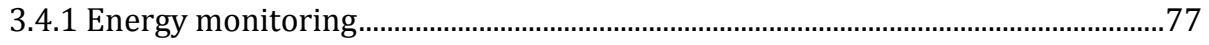

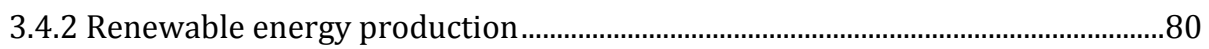

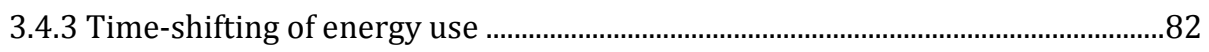

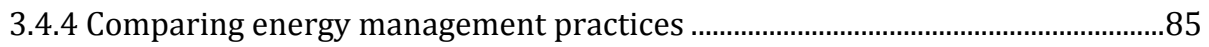

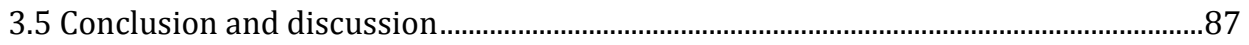

\section{Chapter 4. Accomplishing information and change in a smart grid} pilot: Linking domestic practices with policy interventions.................. 91

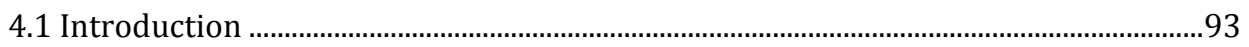

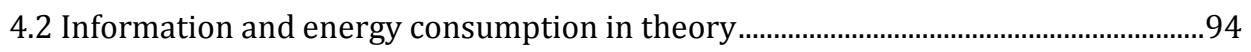

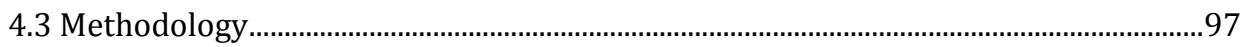

4.3.1 Case description: Smart grid pilot Lochem ...............................................................97

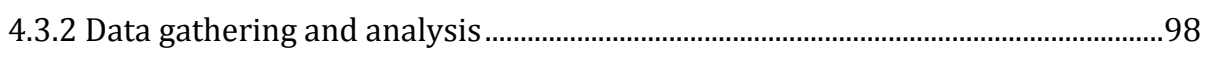

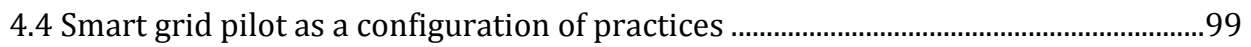

4.4.1 Community interaction practices ........................................................................ 101

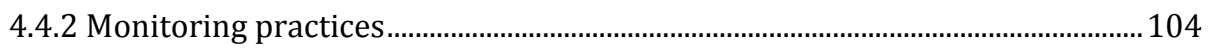

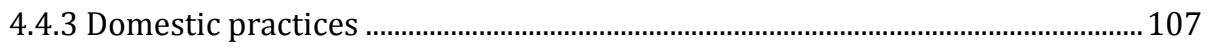

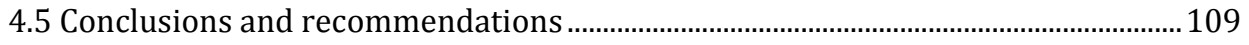




\section{Chapter 5. Governing by practices: A practice-based approach to}

sustainability transitions in smart grids

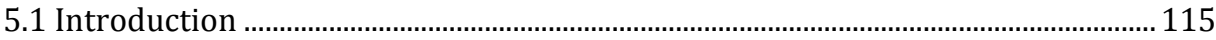

5.2 Energy transitions in theory and (policy) practice ....................................................... 116

5.3 A conceptual framework for smart grid transitions.................................................... 118

5.3.1 Identifying and positioning sets of practices for the energy transition....... 120

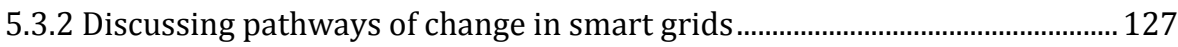

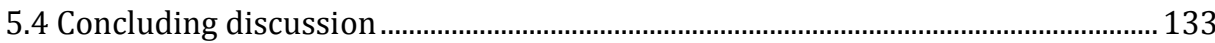

Chapter 6. Conclusions and discussion …………………………………….....137

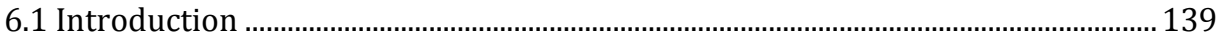

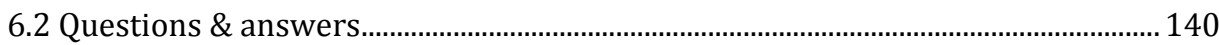

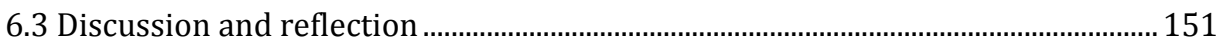

6.3.1 Coming to grips with practices and flows ........................................................... 151

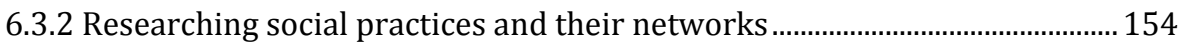

6.3.3 Approaching sustainable energy transitions ...................................................... 157

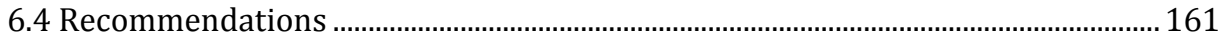

6.4.1 Recommendations for policy .................................................................................. 161

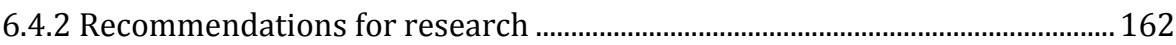

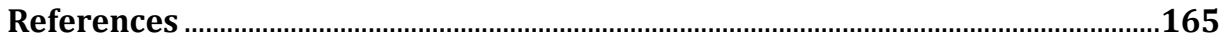

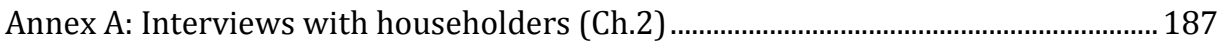

Annex B: Interviews with institutional actors (Ch.2) ........................................................ 189

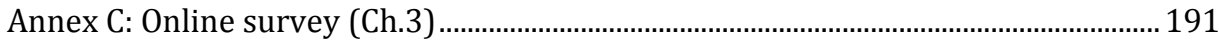

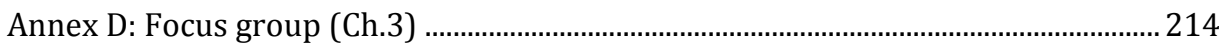

Annex E: Workshops on Energy Conservation (Ch.4) ....................................................... 216

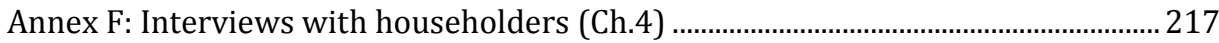

Annex G: Interviews with project organisations (Ch.4) ................................................ 221

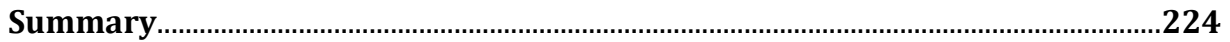

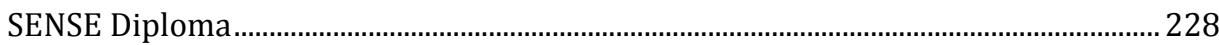

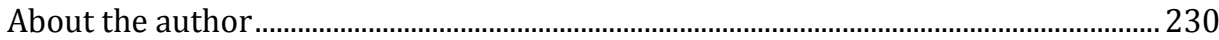

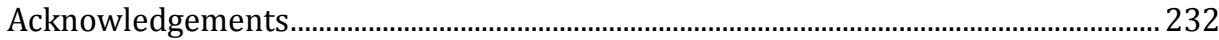




\section{Tables \& Figures}

\section{Tables}

Table 2.1: Overview of research methods.

Table 3.1: Framework for analysing householder participation in smart energy systems.

Table 5.1: Practices involved in the organisation of the home.

Table 5.2: Home Energy Management (HEM)-practices emerging in the Smart grids.

\section{Figures}

Figure 1.1: Impressions of three smart grid configurations:

1) the Super-Grid, 2) the Micro-Grid, and 3) the Smart Home.

Figure 1.2: Smart grid demonstration and deployment projects in the European Union.

Figure 1.3: Smart meter roll-out in the European Union: 1) for electricity, 2) for gas.

Figure 1.4: Connections between the research themes and the theoretical perspectives.

Figure 1.5: Research design.

Figure 2.1: Domestic energy practices.

Figure 2.2: Energy and information flows in smart grids: 1) between household-members 2) between households and service providers, and 3) between local and distant households.

Figure 3.1: Most desirable and least desirable practice arrangements as indicated by the focus group participants.

Figure 4.1: Accomplishing and using information in relation to domestic practices, monitoring practices and community interaction practices.

Figure 5.1: Emerging Home Energy Management-practices at the interface between the home and wider energy systems.

Figure 5.2: Trajectories of change for smart grid-related practices in the Context of three orders of innovation.

Figure 6.1: Conceptual framework on the interplay between households And smart energy systems. 


\title{
Abbreviations
}

\author{
ANT Actor Network Theory \\ DSM Demand-Side Management \\ ESCo Energy Service Company \\ EU European Union \\ EC European Commission \\ GPA Governing-by-Practices Approach \\ HEM Home Energy Management \\ ICT Information- and Communication Technology \\ IG Informational Governance \\ JRC Joint Research Centre (of the European Commission) \\ MLP Multi-Level Perspective \\ NGO Non-Governmental Organisation \\ OECD Organisation for Economic Co-operation and Development \\ RQ Research Question \\ SME Small and Medium-Sized Enterprises \\ SPT Social Practice Theories \\ TT Transition Theories \\ UK United Kingdom \\ USA United States of America
}




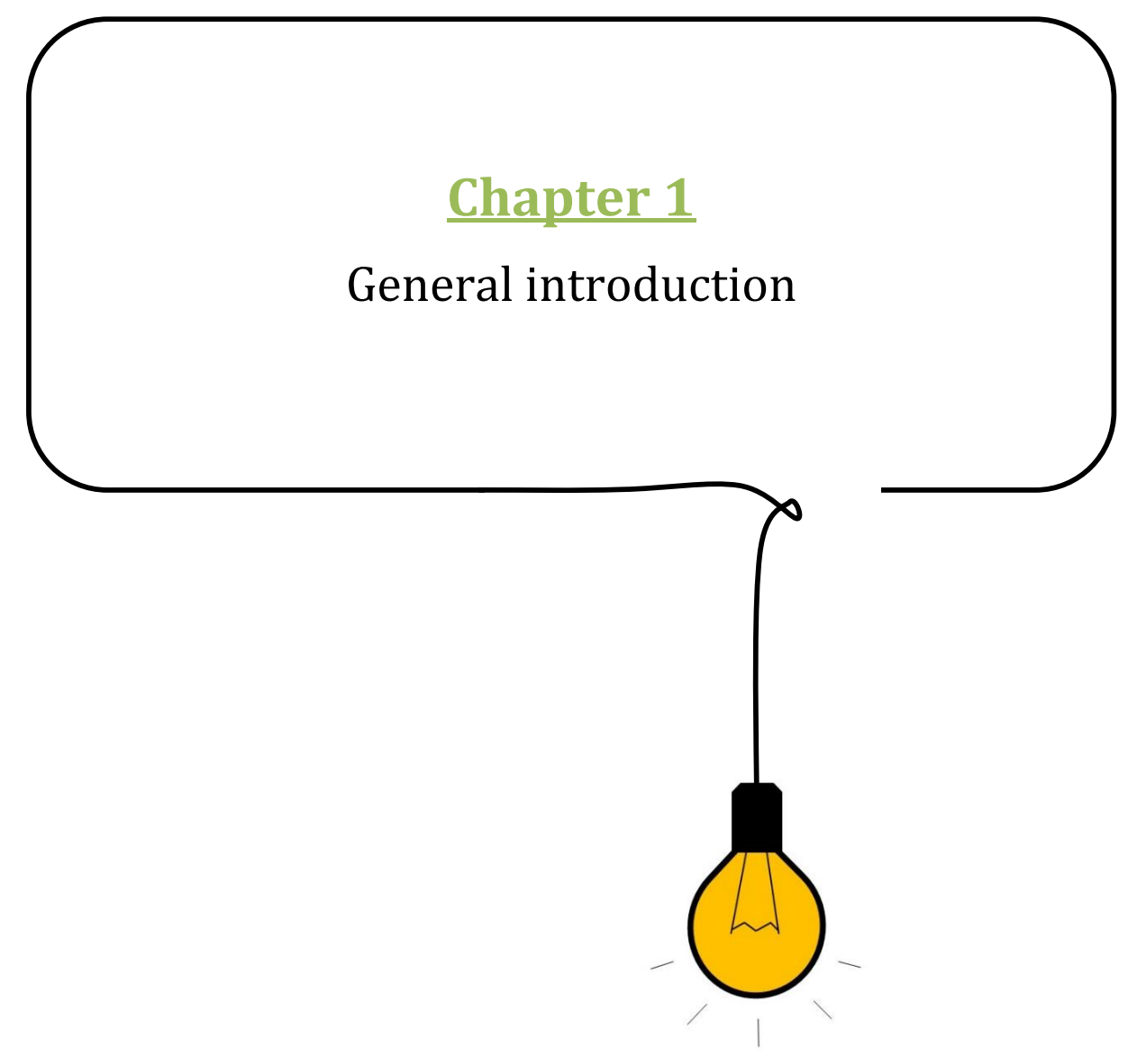

1 


\subsection{Smart Grids: a revolution in the making?}

"Do you remember where you were when you first heard of this thing called the Internet? Do you remember how this technology - email, search engines gradually took over your life, or perhaps you were born into a time when everyone was already dependent on the worldwide web? Now we have a new light-bulb moment - the introduction of the energy internet [read: the smart grid], and we will all soon come to depend on it. (...) We're not there, yet. But it's just as exciting and revolutionary. The [smart grid] is a vast network that efficiently supplies electricity to anyone anywhere. The digital age will allow such a system to be decentralized, efficient, and reliable. That's the theory, anyway." (BigThink, 2015)

This is a passage from the online knowledge forum BigThink which invites top thinkers from around the world to share their ideas on information in the Digital Age (BigThink, 2016). The passage forms the introduction to an interview about smart grids with Jeremy Rifkin, a well-known economic and social theorist. Rifkin states that the smart grid - or the Energy Internet, as it is referred to on BigThink - brings together a revolution in decentralised renewable energy and a revolution in internet-based communication. As such, the smart grid presents, according to Rifkin, "a perfect fit" between energy and the internet (Rifkin, 2015).

The idea that smart grids can revolutionise energy systems is not just a theoretical thought or a 'light-bulb moment' of an expert. Over the last decade or so, this idea has also found its way into policy and practice, which means that smart grid development is actively pursued by a wide range of actors, ranging from governments and companies to scientists and groups of citizens. Particularly interesting for this thesis is the fact that smart grids are frequently proposed as a key strategy for combatting climate change by facilitating a transition to a low-carbon economy. In the European Union, for instance, the European Commission has announced that "smart grids will be the backbone of the future decarbonised power system" (European Commission, 2011a, p2). Also in the United States (GridWise Alliance, 2016; US Department of Energy, 2016) and in China (Lin et al., 2013; Yuan et al., 2014) smart grids are intimately linked to sustainability goals.

At the same time, sustainability goals seem to be only one of many reasons for pursuing smart grid development. The passage on BigThink, for instance, refers to 'decentralisation', 'efficiency' and 'reliability' (BigThink, 2015). Also in the Netherlands, where the empirical work for this thesis is conducted, smart grids are not only seen as a strategy for combatting climate change (e.g. integrating renewable energy sources; 
reducing $\mathrm{CO}_{2}$-emissions; increasing energy efficiency), but also for fostering technological innovation, increasing cost-efficiency and enhancing the competitiveness of the Dutch energy sector (Topteam Energie, 2012).

With these kinds of goals and potential benefits in mind governments, businesses, scientists and citizens in Europe (and around the world) have started to develop, experiment with and implement smart grid technologies. By 2016 over 500 smart grid pilot projects were counted in the European Union (EU) (JRC Project Maps, 2016). Also the implementation of smart meters, a cornerstone of the future smart grid, is rapidly gathering pace. European legislation mandates that $80 \%$ of households are equipped with a smart meter by 2020 (European Commission, 2012).

Smart meters replace conventional analogue energy meters, which are now sometimes referred to as 'dumb' meters (Bullis, 2009; Pierce et al., 2008). Whereas analogue energy meters require periodic, manual readings and measure domestic energy consumption only at an aggregate level, smart meters enable the detailed recording of energy flows at household level as well as the remote and (near) real-time exchange of information between households and energy companies. These features may help energy companies reduce the costs of meter reading, and balance demand and supply in an energy system that is (increasingly) based on the production of decentralised renewable energy such as solar and wind power (Darby, 2010; Giordano et al., 2011).

Smart meters and related smart energy technologies are also expected to benefit domestic end-users; among other things, these technologies are thought to help endusers acquire more control over their energy bills, reduce carbon footprints, make use of locally produced energy, and engage in local energy trade (European Commission, 2011a; Giordano et al., 2011). Yet, from pilot projects it becomes clear that smart energy technologies do not work by themselves. While small-scale trials have indicated that savings resulting from smart meter feedback typically range between 5\% and 15\% (Darby, 2006; Faruqui et al., 2010; Fisher, 2008; Westskog et al., 2015), this may not hold for larger-scale smart meter roll-outs which lack the character and ancillary services of small-scale trials. In the Netherlands, for instance, smart meter roll-out proved to generate less than $1 \%$ of energy savings on average ${ }^{1}$ (so far) (Vringer and Dassen, 2016). Also the potential of time-shifting techniques to shift energy use to offpeak times is still largely indeterminate. Trials with dynamic pricing ${ }^{2}$ show that

\footnotetext{
1 This is significantly lower than the $3.5 \%$ that was expected by the Dutch government and that (coJlegitimized smart meter roll-out (Vringer and Dassen, 2016).

2 Dynamic pricing is a smart meter-enabled technique that introduces differentiated energy tariffs according to the specific time of the day, week or season.
} 
householders may shift between $0 \%$ and $20 \%$ of peak electricity use to off-peak times (Breukers and Mourik, 2015; Faruqui and Sergisi, 2010; Stromback et al., 2011). While this has inspired efforts to improve existing techniques, it has also given rise to more critical questions on smart meter information (Hargreaves et al., 2013b; Wallenborn et al., 2011) and dynamic pricing (Nicholls and Strengers, 2015; Powells et al., 2014) as instruments for 'Demand-Side Management' (DSM) in smart energy systems.

Besides energy savings and time-shifting also consumer acceptance has proven to be a thorny issue. In several countries around the world - including the United States, Australia, Germany and the Netherlands - consumers have contested the implementation of smart meters and related energy technologies. Reasons for objecting include suspected health risks, possible cost increases for consumers, potential invasion of consumer privacy and intensifying power imbalances between consumers and energy companies (Hess, 2014; Klopfert and Wallenborn, 2011; McKenna et al., 2012). In the Netherlands, where invasion of consumer privacy featured as the main (legal) objection to smart meters, protests by consumers and politicians resulted in substantial adaptations to smart meter legislation as well as a significant delay of smart meter roll-out (several years) (Dutch Ministry of Economic Affairs, 2014; Hoenkamp et al., 2011). With these observations in mind it seems misguided, as expressed on BigThink, to assume that "we will [simply] all soon come to depend on it" (BigThink, 2015).

More generally, it can be stated that the ways in which end-users understand and engage with smart energy systems requires further investigation. This thesis investigates these dynamics by examining the experiences and ideas of householders and energy experts in the Netherlands, while making use of and building upon three bodies of theory: Social Practice Theories, Informational Governance, and Transition Theories. To organise the research the thesis elicits three research themes that are central to understanding the interplay between end-users and smart energy systems: The 'Household' as a site of intervention and change in smart energy systems; 'Information flows' as a means of organising change in smart energy systems; and the 'Sustainable energy transition' as the long-term process of change that smart energy systems are expected to contribute to. Shedding light on these themes may help to formulate suggestions for climate and energy policy as well as for future research on end-users and smart energy systems. 


\section{Outline}

This opening chapter is organised as follows: Section 1.2 expands on the concept of smart grids and on the emergence of new energy infrastructures in Europe and the Netherlands. Next, Section 1.3 introduces the three central research themes: the Household, Information flows, and the Sustainable energy transition. Section 1.4 introduces the theories that are employed to come to grips with these themes: Social Practice Theories, Informational Governance, and Transition Theories. Section 1.5 presents the objectives and the research questions, while Section 1.6 introduces the research methodologies. Finally, Section 1.7 presents the outline of the book.

\subsection{The emergence of smart grids}

This section provides a further introduction into the world of smart grids with a focus on Europe and the Netherlands. First it discusses the concept of smart grids. Next, it considers the technical as well as the social 'design' of smart grid infrastructures. And, finally, it considers the status quo of smart grid projects in the European Union and the Netherlands.

\subsubsection{What is a smart grid?}

At a basic level the development of smart grids refers to the application of information and communication technologies (ICT) to energy systems. Examples of ICT components are network sensors, substation automation technologies, smart meters, home energy management systems and energy displays (Blumsack and Fernandez, 2012; European Commission, 2011a, 2016; US Department of Energy, 2016). The application of ICT enables two-way communication between suppliers and consumers of energy. Yet, beyond this basic sensitivity that a smart grid involves ICT and facilitates information exchange, there is no unified or agreed-upon definition (Beaulieu, 2016; Christensen et al., 2013; Wolsink, 2012). Organisations and scholars seem to emphasise different aspects depending on their specific interests and background (Blumsack and Fernandez, 2012; Clastres, 2011; Tuballa and Abundo, 2016). Some specify a limited number of core features, while others provide a long list of functionalities (Beaulieu, 2016). To discuss features of smart grids the definition provided by the European Smart Grid Task Force is helpful as a point of reference (European Commission, 2011a: p2): 
"Smart Grids [are] electricity networks that can cost efficiently integrate the behaviour and actions of all users connected to it-generators, consumers and those that do both - in order to ensure an economically efficient, sustainable power system with low losses and high levels of quality and security of supply and safety."

While this definition can be approached (and criticised) from different angles, this section lifts out three aspects that help to introduce smart grids at a general level and assist in focussing the enquiry. The first aspect concerns the focus on electricity networks. This demarcation is common, but not universal. In the Netherlands, for instance, discussions on smart grids may also refer to energy networks for gas and heat (Taskforce Intelligente Netten, 2011), corresponding with the relatively large share of natural gas in total energy demand of households (about 38\%) (ECN, 2014). ${ }^{3}$ Yet, if the trend in the Netherlands towards the reduction of gas supplies and the electrification of domestic energy consumption continues (Dutch Central Government, 2016; HIER Klimaatbureau, 2016), ${ }^{4}$ it can be expected that the discussion on smart grids also becomes more exclusively focused on electricity. This thesis is therefore primarily focused on electricity, but does not exclude other types of energy carriers in the analysis.

The second aspect that stands out from the definition is the emphasis on the behaviour and actions of users. The smart grid is perceived as an infrastructure that integrates and presumably interacts with, responds to, and depends on - the things that users do. Technical notions of smart grids frequently simplify, marginalise or leave out the role(s) of users (Beaulieu, 2016; Christensen et al., 2013). The passage on BigThink at the start of this chapter, for instance, marginalises the role of end-users by assuming that they simply "come to depend on it". Rather than actively taking part in the system, consumers are imagined to figure as passive end-users of a system designed by experts. In this thesis end-users are not construed as (essentially) active or passive. Rather, as explained in Section 1.4, they are positioned as participants in social practices.

Third, the definition reveals that smart grids may serve a variety of objectives. The objectives that are mentioned include economic efficiency, sustainability, and quality and security of supply. While these kinds of goals are common in debates on smart grids, priorities can be quite different. In the Netherlands for instance, innovation and

\footnotetext{
3 Total energy consumption includes natural gas (38\%), motor fuels (30\%), electricity (28\%), and other (3\%) (ECN, 2014).

${ }^{4} \mathrm{~A}$ key aspect in the debate on reducing gas supplies are the economic, environmental and safety risks involved in continued gas extractions in the province of Groningen, which hosts most of the natural gas reserves in the Netherlands.
} 
business opportunities are frequently emphasised as important grounds for engaging in smart grid development (TKI Urban Energy, 2016; Topteam Energie, 2012). In the USA on the other hand, energy security issues and ageing energy infrastructures play a more significant role (Coll-Mayor et al., 2007; Stephens et al., 2015). So, even though smart grids are being pursued with sustainability goals in mind, the development of these new energy infrastructures is not exclusively, and perhaps not even primarily, an environmental project.

From this discussion it can be concluded that 'smart grid' is an ambiguous and (potentially) contested concept. Even though there is a basic sensitivity regarding the central role of ICT, there are also significant differences with respect to the roles that are envisioned for end-users, and the ends to which smart grids are being deployed.

\subsubsection{What do smart grids look like?}

A factor that enhances ambiguity in smart grid development is the indeterminacy of scale. Ideas about the material infrastructures that make up a smart grid configuration may span diverse geographical units, from the micro-scale of an individual household to the macro-scale of an entire continent. Three ideal-typical representations of smart grid configurations, distilled from scientific and grey literature, can help to illustrate this (see Figure 1.1, page 10):

- The Super-Grid: This is a smart grid configuration that interconnects sites for largescale renewable energy production on a transcontinental scale. A Super-Grid in Europe, for instance, could interconnect off-shore wind parks in the North Sea region, hydropower facilities in Norway and Switzerland, biomass plants in central Europe and solar power plants in the Mediterranean (Elliott, 2013; Verbong and Geels, 2012). Significant work has already gone into the development of an offshore North Sea grid that connects e.g. Denmark, the United Kindom (UK), Germany and the Netherlands (Jay and Toonen, 2015; NorthSeaGrid, 2016).

- The Micro-Grid: This is an intermediate, more local smart grid configuration. Renewable energy production and demand-supply balancing are organised on a neighbourhood or city scale. Micro-Grids may interconnect for instance residential areas, office buildings, (small) power plants and local industries. Micro-Grids are regularly linked to the notion of 'energy communities' - groups of citizens who engage in collective forms of energy production, consumption, saving etc. (Seyfang et al., 2013; Steinheimer et al., 2012) - and the notion of 'smart cities' - wider and more integrated approaches towards the management of resource flows in urban environments (Geisler, 2013; Bulkeley et al., 2016a). LochemEnergie is an example 
of an energy community initiative in the Netherlands (LochemEnergie, 2016), and Amsterdam Smart City is an example of a smart city initiative (Amsterdam Smart City, 2016).

- The Smart Home: This is the smallest configuration of a smart grid. Households feature as stand-alone, mostly self-sufficient units that are largely independent from the main grid. Smart Homes may feed excess energy into the main grid or exchange it directly with neighbours. Smart Homes are typically equipped with a range of energy technologies, including solar PV cells, small wind turbines and heat pumps for generating electricity, electric cars with batteries for storing energy, and smart meters, smart appliances and energy displays for managing local energy flows (Markovic et al., 2012; Wilson et al., 2015). In the Netherlands the 'Enexis House' in Zwolle is an example of a Smart Home (Enexis, 2016).

The distinction between these three ideal-typical configurations is helpful as a starting point. Two remarks should be made however. The first remark concerns the mixing of infrastructural scales. Even though all three configurations are empirically traceable, as the examples above indicate, it seems unlikely that they will emerge as completely separate units. Rather, smaller configurations may become embedded into the larger ones, such that Smart Homes are part of Micro-Grids, and Micro-Grids in turn are nested in transcontinental Super-Grid infrastructures.

The second remark concerns the social organisation of smart grids. The illustrations (Figure 1.1) prioritise the technical aspects of smart grids. However, technical infrastructures like smart grids always come along with social counterparts, such that they are best perceived as socio-technical systems (Rip and Kemp, 1998; Verbong et al., 2013). Leaving aside the nature of the interactions between the technical and the social for the moment, it can be intuitively stated that each infrastructural scale produces competitive advantages for specific types of actors: prioritising the development of Super-Grid configurations puts multinational energy companies and grid operators in a favourable position (Verbong and Geels, 2012), while the development of Micro-Grids and Smart Homes opens up opportunities for the engagement of decentralised actors like municipalities, (local) businesses, citizen-led cooperatives and individual consumers (Juntunen, 2014, Wolsink, 2012). This is not to say, however, that Micro-Grids and Smart Homes necessarily empower decentralised actors like end-users. Smart Homes can just as well be designed to allow for the steering of domestic activities by 'outsiders', thereby serving the purposes of (energy) companies or governments rather than those of (individual) end-users (Bulkeley et al., 2016b; Marres, 2011, 2012; Wilson et al., 2015). 

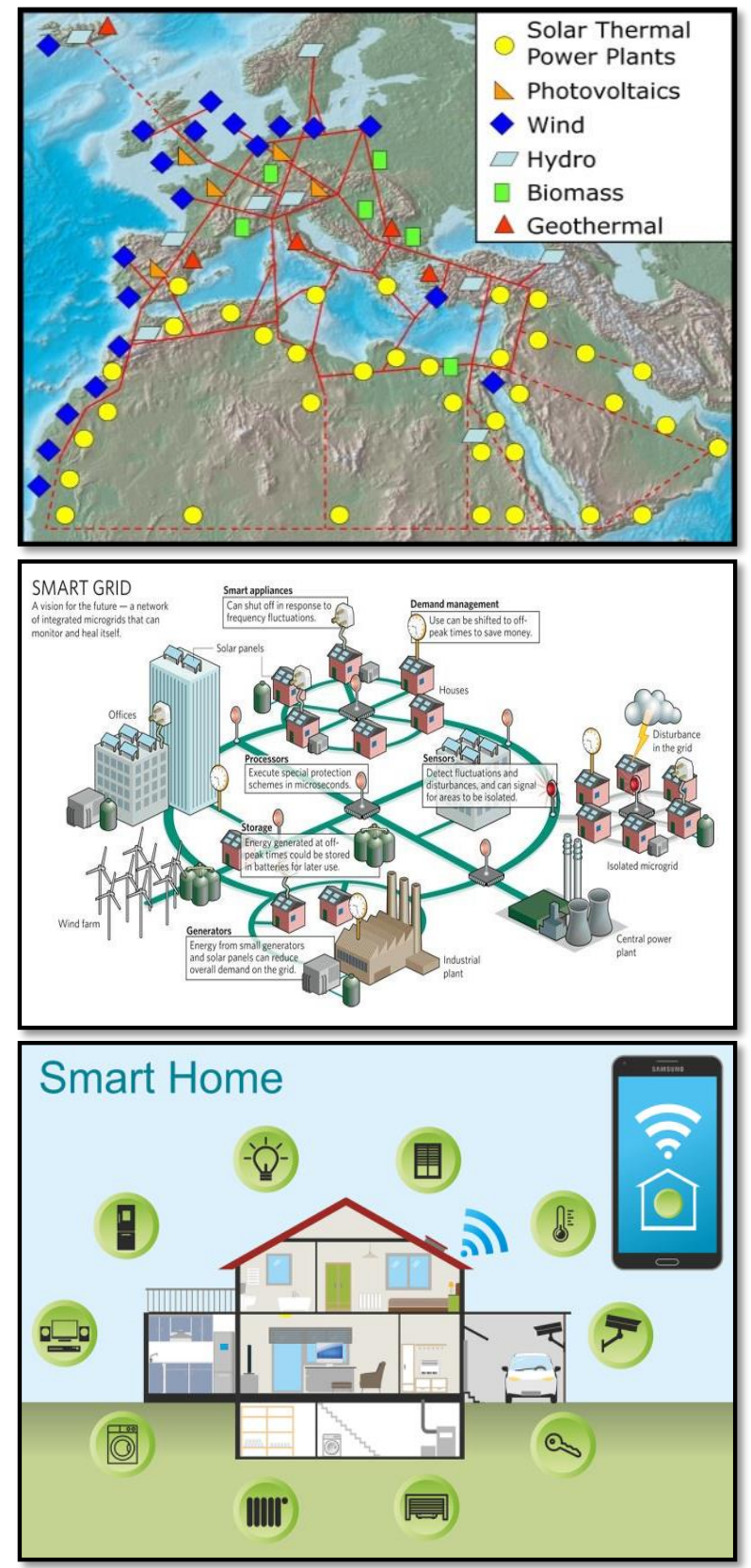

Figure 1.1: Impressions of three smart grid configurations:

1) the Super-Grid (Wikimedia, 2008),

2) the Micro-Grid (Marris, 2008),

3) the Smart Home (Pixabay, 2017). 
In sum, this section has shown that smart grid configurations are emerging at different, intertwining scales of technical and social organisation. It was argued that decentralised configurations are of particular interest since they open up a new field of possibilities for the reconfiguration of energy consumption patterns and for the engagement of new actors, like domestic end-users, municipalities and local businesses. Yet, far from providing merely positive opportunities, these new decentralised smart grid configurations also give rise to potentially new power imbalances as well as shifts in the division of responsibilities for combatting climate change.

\subsubsection{Where to find smart grids?}

To test and develop smart grid technologies there are many projects being rolled out and planned for at different levels of organisation within the European Union, from the local to the national and international level (Smart Grids Task Force, 2011). There are several ways to track smart grid development in the EU. One indication is the sums of money being invested into smart grid development. A report by the Joint Research Centre (JRC) (Giordano et al., 2011) estimated that total investment in EU smart grid projects by January 2014 would amount to $€ 3.15$ billion, while conservative estimates of investments up to 2020 would amount to $€ 56$ billion.

Another indication of smart grid development is the number of pilot projects being initiated. From 2005 onwards there has been a steady increase in the number of projects within the EU, up to a total of 459 at the start of 2014. Figure 1.2 shows that there is a concentration of smart grid projects in Denmark, the UK, the Netherlands, Belgium, Germany, France, Spain and Italy. About a third of these projects are focused on end-users (Covrig et al., 2014; JRC Project Maps, 2016). ${ }^{5}$

Similar to the general trend in Europe, there has been a steady increase in the number of projects in the Netherlands from the mid-2000s onwards. A milestone was reached in 2011 when the national Taskforce Intelligent Grids initiated 12 larger-scale 'experimental gardens' to test smart grid technologies in real-life settings. End-users and their households formed a key focus of attention in seven out of these 12 experiments (Netherlands Enterprise Agency, 2015a). By the start of 2014, 79 projects were set up (JRC Project Maps, 2016), while by the end of 2015 the number of projects amounted to 132 (Energiekaart, 2015).

5 This is an estimate based on the label "smart customer and smart home" used in the JRC inventory (JRC Project Maps, 2016). 


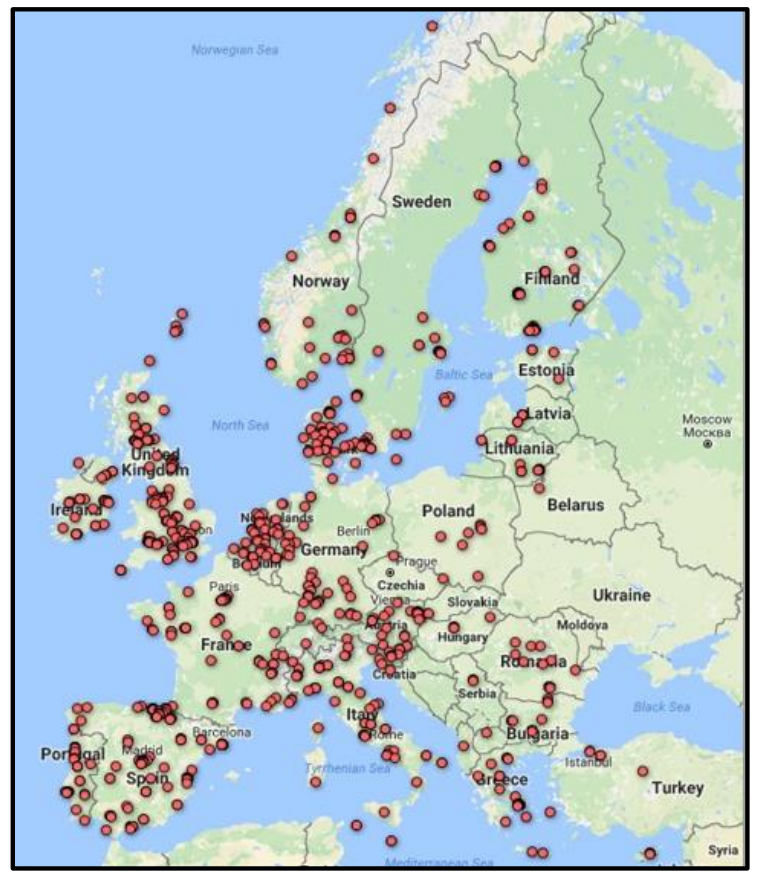

Figure 1.2: Smart grid demonstration and deployment projects in the European Union (JRC Project Maps, 2016).

A third and final indication of smart grid development is the implementation of smart meters. EU regulation mandates that by 2020 at least $80 \%$ of European households are equipped with a smart meter (European Commission, 2012). Implementation rates of smart meters differ per country. In countries like Finland, Sweden and Italy the majority of households have been equipped with a smart meter, while in countries like Belgium, Germany and Czech Republic implementation rates have been (much) slower. A key reason for this is that the national cost-benefit analyses (mandated by the EU) generated negative or ambiguous outcomes (Covrig et al., 2014). Figure 1.3 presents an overview of implementation plans for smart meters in the EU.

In the Netherlands, discussions on smart meter implementation started at a relatively early stage (mid-2000s). However, in 2009, after consumer protests had emerged, the legislative proposal that would mandate smart meter roll-out was halted in the Dutch parliament. As a consequence, smart meter standards were reconfigured and consumers were given an option to refuse the meter (Hoenkamp et al., 2011). Also large-scale roll-out was delayed for several years, and the government opted for smallscale trials and selective roll-outs before proceeding with large-scale roll-out from 2015 onwards (Dutch Ministry of Economic Affairs, 2014). 

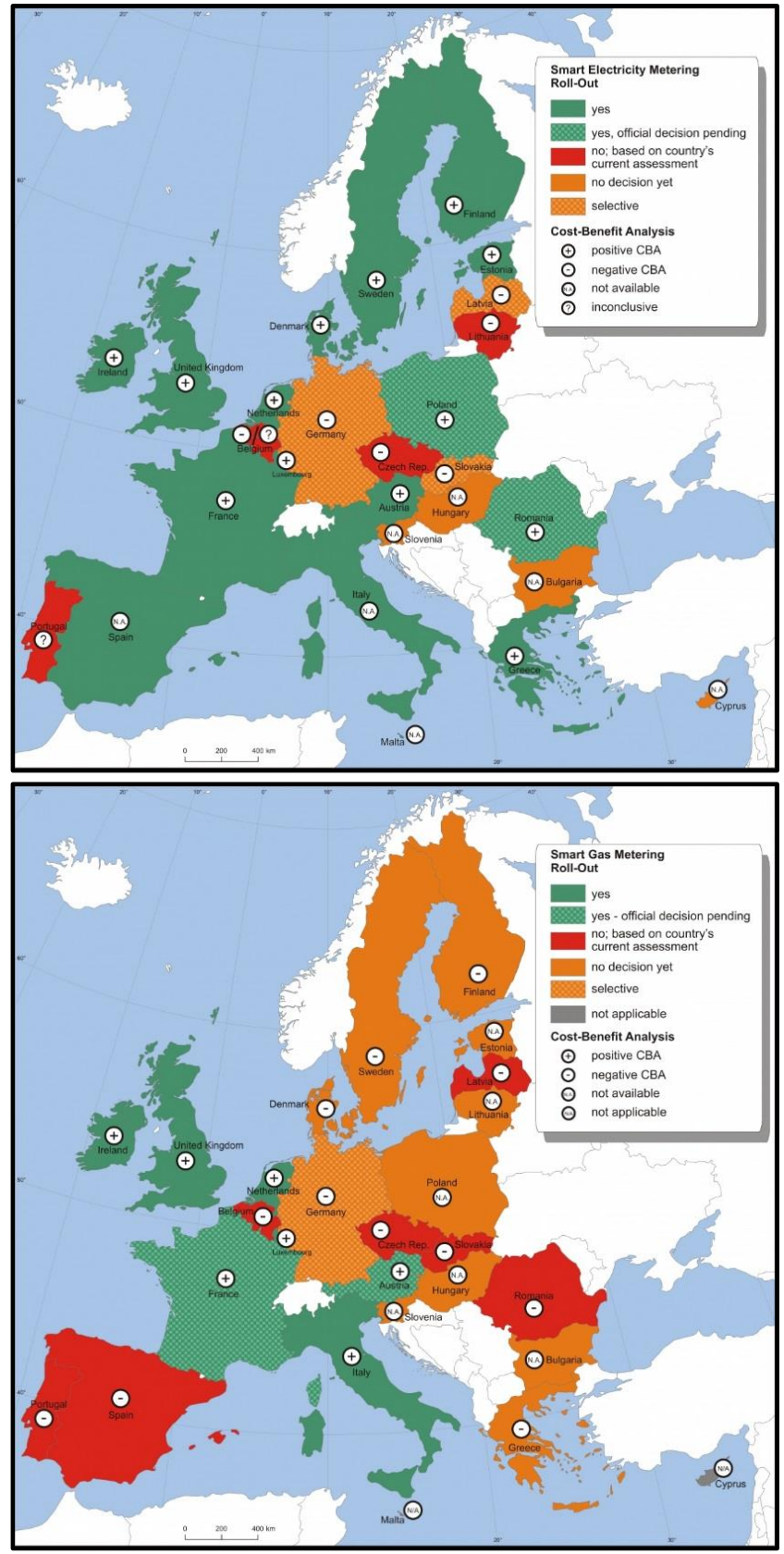

Figure 1.3: Smart meter roll-out in the European Union (JRC Smart Metering, 2016):

1) for electricity,

2) for gas. 
Together these three indicators - the size of the investments, the number of pilot projects, and the roll-out of smart meters - demonstrate that the smart grid landscape in the European Union and in the Netherlands is rapidly evolving. At the same time, it is clear that smart grid development may not transpire in an unhampered fashion. The possibility of resistance implies that the end-user is a significant source of concern to those pursuing smart grids. The end-user is the topic of the next section.

\subsection{Smart grids and the end-user}

The emergence of smart grids comes along with a growing emphasis on - and concern with - decentralised energy technologies and decentralised actors. Domestic end-users (householders) form a group of decentralised actors that is of special interest to policy makers and energy professionals (Gangale et al., 2013). In a smart grid context they feature not only as (potential) co-producers of renewable energy, but also as 'targets' of Demand-Side Management strategies (Christensen et al., 2013; European Commission, 2015a). ${ }^{6}$

However, with an energy sector that has been organised in a highly centralised way for decades, only limited experience has been build up with strategies that focus on endusers and the 'demand-side' (Rotmans, 2012; Van Vliet, 2012; Verbong et al., 2016). Moreover, in a research field that is traditionally dominated by the disciplines of engineering and economics, also the availability and use of social scientific knowledge on energy consumption is restricted (Sovacool, 2014; Wilson et al., 2015; Wolsink, 2012). As a consequence end-users are often conceived and approached in a simplistic and one-sided manner; that is, either as rational, informed decision-makers that actively manage domestic energy flows (Christensen et al., 2013; Strengers, 2013) or as deficient, uncertain and unruly 'factors' that pose a barrier to smart grid development (Beaulieu et al., 2016; Nyborg and Røpke, 2013; Skjolsvold and Lindkvist, 2015; Van Vliet, 2012).

Yet, along with a growing realisation that end-users are central to smart grid development (Gangale et al., 2013; Giordano et al., 2011; Verbong et al., 2013), there is an increasing demand for social scientific studies from the side of governments and companies (e.g. Netherlands Enterprise Agency, 2015b; Gangale et al., 2013) as well as an increasing supply of studies from the social sciences (e.g. Geelen, 2014; Kobus, 2016; Skjolsvold et al., 2015; Strengers, 2013). This thesis engages with and seeks to

\footnotetext{
${ }^{6}$ In the European Union households are responsible for about $27 \%$ of final energy consumption (European Environment Agency, 2016).
} 
contribute to this growing body of social scientific knowledge by singling out three research themes that are of central concern to research and policy on end-users and smart grids:

1. The household

2. Information flows

3. The sustainable energy transition

These three research themes help to organise and refine the focus of the thesis. Each theme is discussed in more detail below.

\subsubsection{End-users \& their households}

With the advent of smart grids, households come to serve as key sites of intervention and change in energy systems. As noted before, the household features not only as a site for renewable energy production and storage but also as a place for reconfiguring energy consumption. To get to grips with the concept of the household one may discern two ideal-typical perspectives ${ }^{7}$ that are commonly adopted in policy and research.

The first perspective conceives of the household primarily as a technical or material entity; that is, a building, a house or a smart home. In this technology-focused perspective - often adopted in engineering - households are represented as 'energy loads' that are generated by (the use of) domestic heating installations, electrical appliances, sensors, converters, etc. Energy loads are modelled and predicted based on specific sets of 'technical' and sometimes 'non-technical' parameters. The preferred option for cutting and shifting domestic energy loads is typically the installation and use of home automation technologies. Home automation is thought to avoid undesirable human interference and relieve end-users from the need to continuously engage with energy technologies. An alternative course of action is to smarten endusers and teach them how to act in accordance with the logics of the smart grid (e.g. Blumsack and Fernandez, 2012; Missaoui et al., 2014; Moreno et al., 2014; Wissner, 2011).

A second dominant understanding of the household considers primarily the human individuals who inhabit the place. Individualist perspectives - often informed by (social) psychology and (behavioural) economics - typically focus on individual or group attitudes, values, norms, preferences, motivations, beliefs, etc. When evaluating and

\footnotetext{
7 These perspectives are ideal-types in the sense that they represent standard models. The models that are presented leave out many of the nuances and varieties found in the work that is referred to. Using ideal-types is a way to clarify the differences.
} 
engaging with smart energy technologies and services, individuals are thought to draw upon a specific set of individual factors that will determine the course of action. This may result in decisions and behaviours that are either conceived as 'rational' - that is, those that are based on a (personal) costs-benefit analysis - or as 'irrational' and 'emotional' - that is, those decisions and behaviours that deviate from such an analysis. Policy strategies typically focus on providing financial incentives that alter the costbenefit analysis (e.g. new tariff structures or subsidies) or changing the cognitive resources of individuals to alter behaviours (e.g. through tailored information, education and awareness raising) (e.g. Noppers et al., 2016; Stern, 2014; Van der Werff and Steg, 2016; Webb et al., 2014).

Both the technology-focused and the individualist perspective are being criticised for a number of reasons. The technology-focused perspective for instance ignores the observation that end-users tend to use (energy) technologies in ways other than prescribed or imagined by developers (Ellsworth-Krebs et al., 2015; Ozaki and Shaw, 2014; Shove, 1998; Wallenborn et al., 2011). The individualist perspective, on the other hand, downplays the significant discrepancies between an individual's attitudes, values and awareness on the one hand, and the actual behaviours and decisions on the other (the so-called 'value-action gap') (Shove, 2010; Spaargaren, 2011).

A second problem, which concerns both perspectives, is that end-users tend to be portrayed either as passive and deficient, or as active and rational. This not only dismisses the possibility that end-users can be passive in some respects and active in others (Throndsen and Ryghaug, 2015; Verbong et al., 2016), but also ignores the fact that they employ different forms of knowledge, competence and rationality in going about their daily lives (Royston, 2014; Spaargaren, 2003; Wallenborn et al., 2011).

Finally, both perspectives disregard the fact that the social dimensions of households and (smart) energy systems are in many ways inseparable from the material and technical dimensions; whereas the technology-focused perspective tends to prioritise the technical aspects over the social aspects, individualist perspectives divorce individuals and their minds ('individual factors') from the technologies they use, the material environment in which they act, and the systems of provision on which they rely ('contextual factors') (Halkier, 2010; Shove, 2010; Spaargaren, 2011). In comparison with the individualist perspective, a more systemic perspective is needed which positions the household as part of the systems of energy provision and considers the changing interactions (or: intermediary space) between these two socio-technical systems (McMeekin and Southerton, 2012; Rohracher, 2009). 
Social Practice Theories, which form the primary body of theory in this thesis, promise to deal with the social and the technical aspects of households and smart grids in a more balanced and refined manner than the technological and individualist perspectives outlined here. Before introducing Social Practice Theories in Section 1.4.1, this section continues with the two remaining research themes.

\subsubsection{End-users \& information flows}

Information technologies and information flows are part and parcel of smart energy systems. Among other things they allow for the detailed recording of energy flows at household level, for the exchange of information between households and energy providers, and for the remote control of electric appliances. In this sense, information technologies and the information flows they generate are expected to act as an enabler and medium of change in smart energy systems. This role cannot be taken-for-granted however, as the following two points help to illustrate.

The first point relates to the handling of information by end-users. A key promise behind the introduction of smart metering technologies is that it provides end-users with an increased awareness of and insight into (domestic) energy consumption and production (European Commission, 2011a; Darby, 2010). Based on this newly acquired insight end-users are expected to control energy flows and save energy. Yet, as indicated before, several studies show that smart meter trials and roll-outs generate only limited energy savings, that energy savings are not always sustained over time, and that smart meter information is no longer interesting or relevant after an initial period of more intensive use (Darby, 2006; Hargreaves et al., 2013b; Vringer and Dassen, 2016; Westskog et al., 2015). While this has led to attempts to improve the quality of visualisation and feedback methods (e.g. D'Oca et al., 2014; Pierce et al., 2008) it has also generated more fundamental questions on the logic of information handling that is implied in smart meter implementation. The basic logic can be depicted as follows (Wilhite and Ling, 1995: p150):

"Increased feedback $\rightarrow$ Increase in awareness or knowledge $\rightarrow$ Changes in energy-use behaviour $\rightarrow$ Decrease in consumption"

Two aspects in this logic are particularly problematic. The first concerns the linearity of the model; that is, the stepwise, cause-and-effect approach in which information (or: feedback) serves as a starting point for change, and in which energy savings increase as a function of information. However, it has been shown that more information does not necessarily lead to more awareness and more energy savings (Hargreaves et al., 2013b; Strengers, 2013; Wallenborn et al., 2011). The second critique concerns the 
rationalist undertones of the model. End-users are conceived as more or less rational actors who calculate and manage domestic energy flows with the help of smart meter information. To do so is to ignore the collective and material aspects of energy consumption (Shove et al., 2012; Spaargaren, 2011), and to underestimate the difficulties of steering consumption patterns in a desired direction (Bell et al., 2015; Christensen et al., 2013; Ozaki and Shaw, 2014).

Next to the handling of information, also the disclosure of information is a point of concern when considering the role of end-users in smart energy systems. In countries like the USA, Germany and the Netherlands the implementation of smart meters has led to consumer protests with critical questions being posed to governments about the erosion of consumer privacy and autonomy (Cavoukian et al., 2010; Cuijpers and Koops, 2008; Hess, 2014). Smart metering technologies have shown to pose a threat to consumer privacy because they can reveal intimate details of everyday life like eating routines, sleeping patterns and whereabouts to outsiders (Cavoukian et al., 2010; McKenna et al., 2012). Smart energy technologies have also been linked to new forms of discipline. By opening-up activities in the private sphere, either directly through the remote control of smart appliances or more indirectly through the promotion of selfdiscipline, end-users become exposed to the influence of public or commercial enterprises (Bulkeley et al., 2016b; Graham, 1998; Kester, 2016; Marres, 2011). While initially overlooked or underestimated by authorities in charge of smart meter roll-out, it has become clear from these debates that smart grid programs that are designed in a one-sided and unreflective manner are likely to be met with resistance (Fell et al., 2015; Van den Burg et al., 2003; Wolsink, 2012).

To better understand information handling and information disclosure in a smart grid context this thesis draws upon Social Practice Theories and Informational Governance. As a theory that is specifically focused on environmental governance in the Information Age (see Section 1.4), Informational Governance can help analyse the role of information flows in smart energy systems.

\subsubsection{End-users \& the sustainable energy transition}

The development of smart grids is often seen as the next (big) step in the sustainable energy transition. The sustainable energy transition, in this case, refers to the long-term structural shift from centralised and carbon-intensive energy systems towards more decentralised, renewable energy based systems (Verbong and Loorbach, 2012; World Energy Council, 2014). Among other things, smart grids are expected to facilitate the integration of vast amounts of decentralised renewables in the energy system. Yet, the 
relation between smart energy systems and the sustainable energy transition may not be straightforward. Two points help to illustrate this.

The first point concerns the changing character of the energy transition. From the 1980s and 1990s onwards the centralised, state-owned energy grids that were built in post-war Europe have been subject to various trends and policies that have significantly changed the social and technical organisation of energy systems. These include deregulation, privatisation, the self-organisation of local actors (Guy et al., 2001; Rohracher, 2009; Van Vliet, 2012) as well as internationalisation (Nilsson, 2012; Verbong and Geels, 2010). The result is a more fragmented, liberalised energy market in which end-users no longer act as 'captive consumers' but increasingly as (active) 'coproducers' (or: prosumers) who can choose from different energy providers and from different (green and grey) energy resources (Marvin and Guy, 1997; Spaargaren, 2011; Van Vliet, 2002). The development of smart grids builds upon many of these longerterm trends (Verbong and Geels, 2012), but is also likely to affect the energy transition in significant ways. In particular, smart grid development implies a deeper and more widespread engagement of end-users in the energy transition. However, structural engagements with end-users have been largely absent (Laes et al., 2014; Rotmans, 2012), while the policy instruments that are conventionally used to target end-users (e.g. information campaigns, financial incentives) seem inadequate (Geels et al., 2015; Van der Loo and Loorbach, 2012). Another issue that comes along with end-user engagement concerns the (possible) shift in responsibility for change from systemic actors (governments and companies) to end-users. With systemic actors being responsible for the development of centralised energy systems based on fossil fuels, it can be questioned to what extent this constitutes a legitimate and desirable move (Bertolo et al., 2016; Halkier, 2010; Marres, 2012; Throndsen and Ryghaug, 2015).

The second point of discussion concerns the directionality of smart grid development. As apparent from the discussion on the concept of smart grids (Section 1.2), it is questionable to what extent smart grid development is actually oriented towards and contributing to sustainability. Climate goals are only one among many objectives that motivate smart grid development (Stephens et al., 2013; Stephens et al, 2015; Verbong and Geels, 2012). The same is true for the development of smart homes; rather than being restricted to energy, the smart home seems to be a catch-all phrase that embraces all kinds of domestic ICT-developments, including developments in entertainment, health, comfort and safety (Nyborg and Røpke, 2011; Wilson et al., 2015). Finally, there is a concern that a reductive focus on time-shifting (or: flexibility) may leave energy demanding lifestyles unquestioned and divert attention from actual reductions in energy demand (Røpke and Christensen, 2012; Shove, 2003; Strengers, 2013). These 
observations cast doubt on the alignment of smart grid development with the energy and sustainability goals of the energy transition, as formulated in national and international policy.

To shed more light on the changing character of the energy transition and the directionality of smart grid development the thesis draws upon Social Practice Theories and Transition Theories. As a body of theory that specialises in sustainability transitions, Transition Theories can help to consider the relations between smart grid development and the long-term dynamics of sustainable energy transitions. The next section provides an introduction into the main bodies of theory for interpreting smart grid development.

\subsection{The theoretical package}

In seeking to come to grips with end-users and smart grids this thesis employs three bodies of theory: Social Practice Theories (SPT), Informational Governance (IG) and Transition Theories (TT). The theories form a kind of 'natural match' with the three research themes identified in the previous section: Social Practice Theories are often used to analyse consumption processes, including energy consumption in households (e.g. Halkier, 2010; Shove et al., 2012; Spaargaren, 2011), Informational Governance is primarily concerned with the dynamics and governance of information flows (e.g. Mol, 2008; Soma et al., 2016a, 2016b), and Transition Theories deal first and foremost with sustainability transitions, including the sustainable energy transition (e.g. Geels, 2002; Rip and Kemp, 1998; Smith et al., 2010). Figure 1.4 shows how the themes and the theories are connected.

Social Practice Theories serve as the primary frame of reference. As a diverse body of theory SPT is not only being developed as an analytical theory in the field of sociology, but also as an ontology 8 in the field of philosophy (Schatzki, 2002, 2010). With the premise that it provides a more generic account of (human) existence, SPT may help shed light on all kinds of social phenomena in the world, not only on consumption processes in households, but also on the dynamics of information flows and on sustainable energy transitions. Informational Governance and Transition Theories, in turn, provide conceptual resources and frames of reference to support the analysis on the themes of information flows and sustainable energy transitions. Each theory is introduced in more detail below.

${ }^{8}$ An ontology is concerned with the nature and relations of being (Merriam-Webster Dictionary, 2016). 


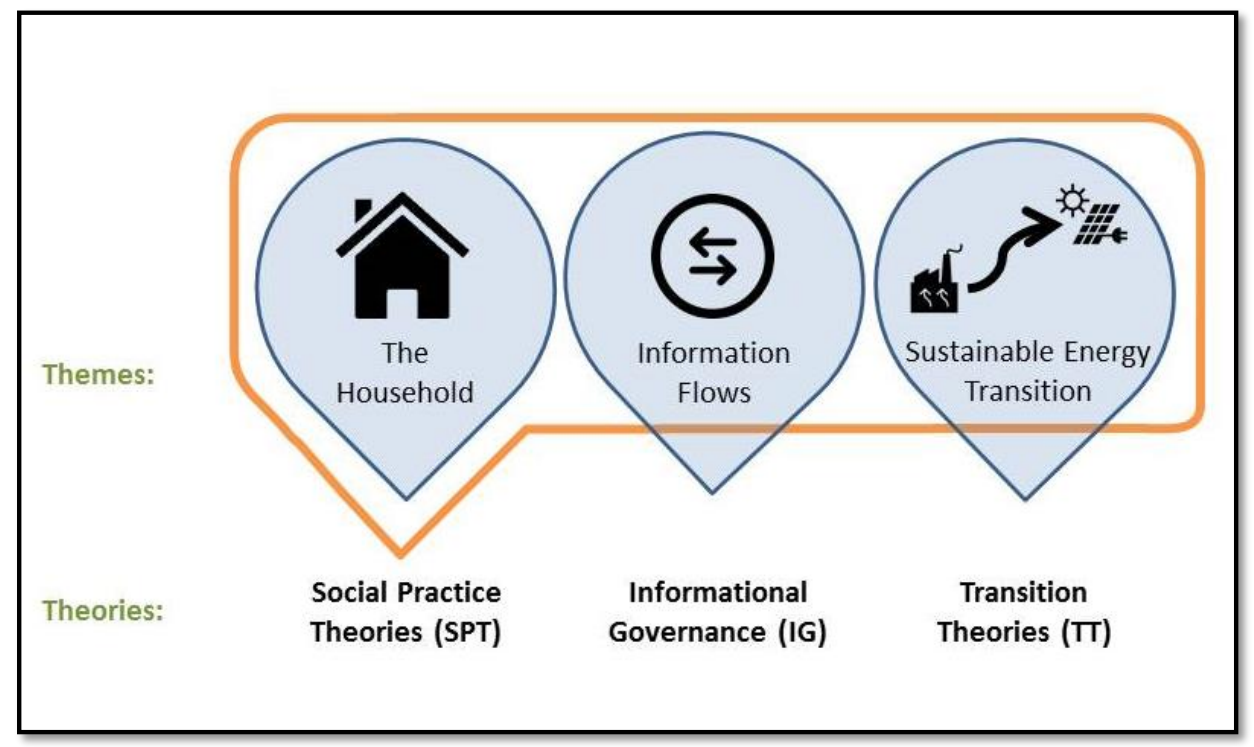

Figure 1.4: Connections between the research themes and the theoretical perspectives.

\subsubsection{Social Practice Theories}

Social Practice Theories (SPT) single out 'practices' as the entities to put centre stage. In a basic sense, a practice can be defined as a "routinized type of behaviour" (Reckwitz, 2002: p249) or as an "organised nexus of actions" (Schatzki, 2002: p71). With the focus on routinized behaviours or organised actions, SPT promotes a particular view of energy consumption. That is, it considers energy consumption as an outcome of everyday practices, such as cooking dinner, driving a car, watching TV, having a shower etc. Energy, in other words, is not so much consumed for its own sake, but it is used in the process of performing such practices (Shove and Walker, 2014; Spaargaren, 2011). Accordingly, the organisation and the performance of social practices are at the centre of analytical attention.

To put social practices centre stage is to differ from other social theoretical accounts. Individualist accounts like (social) psychology and economics, for instance, concentrate on individuals and their minds. Structuralist accounts in sociology such as functionalism and (neo-)institutionalism on the other hand prioritise social structures such as norms, discourses, systems and institutions (Giddens, 1984; Reckwitz, 2002; Schatzki, 2002). Social Practice Theories, instead, hold that it is the instantaneous interplay between agency and structure - the practice - that forms the appropriate 'level' of analysis (Giddens, 1984). 
Individuals (end-users), therefore, are not seen as free agents who willingly choose and act in a social vacuum or in reference to a set of external factors (individualism). Vis-àvis individualist accounts, SPT involves not only a decentring of individuals and their minds (Reckwitz, 2002), but also an increased appreciation of the practical, routinelike character of human activity (Reckwitz, 2002; Warde, 2005) and a promotion of the role of material entities (Nicolini, 2012; Schatzki, 2002). Individuals are also not seen as norm-followers who (blindly) subject to social structures (structuralism) (Nicolini, 2012; Shove, 2010; Spaargaren, 2011). Instead they feature as 'participants' in, or 'carriers' of, social practices (Reckwitz, 2002; Shove et al., 2012).

SPT is not a unified or uniform theory however; it represents a range of theories from diverse social scientific disciplines that have been brought together in what has been labelled the "practice turn in contemporary social theory" (Schatzki et al., 2001). SPT is being developed both as a general sociological and philosophical theory (e.g. Bourdieu, 1977; Giddens, 1984; Reckwitz, 2002; Schatzki, 2002) and as a more specialised theory in the research field of sustainable consumption (e.g. Halkier, 2010; Shove et al., 2012; Shove and Spurling, 2013; Spaargaren et al., 2016; Strengers and Maller, 2014; Warde, 2005, 2014).

Social Practice Theories differ in various respects, including in the definitions of practices that are used, in the kind of activities that are considered to be practices, and in the components of practices that are discerned (Nicolini, 2012). Especially the division of practices into (organisational) components or elements is subject to considerable debate. Reckwitz (2002: p249), for instance, discerns "forms of bodily activities, forms of mental activities, things and their use, a background knowledge in the form of understanding, know-how, states of emotion and motivational knowledge". In an account that is more convenient for empirical investigation Shove et al. (2012) discern meanings, competences and materials as the three basic elements of practices. Finally, in his ontological account, Schatzki (2002, 2016) distinguishes four organisational components of practices: practical understandings, rules, teleo-affective structures and general understandings. Schatzki also makes a distinction between practices - the "nexus of doings and sayings" - and material arrangements - the "interconnected human bodies, organisms, artefacts and things" - that practices are inherently linked to (Schatzki, 2016a, 2016b). ${ }^{9}$

In spite of the significant differences between the theories, there are also sufficient commonalities to justify the use of the term (Social) Practice Theories: most - if not all

${ }^{9}$ Schatzki therefore proposes using the term 'practice-arrangement bundles' instead of just practices. 
- theories understand practices as fundamentally social (non-individual) in character; they consider the material as part of or as inherently tied to practices; and they view social phenomena as sets of, aspects of, or rooted in practices (Schatzki, 2016a; Shove et al., 2012; Spaargaren, 2011). Referring to practices as 'social' means several things: that practices are (widely) shared it the sense of being performed by multiple (groups of) people in space and time; that practices and/or their components have been collectively and historically formed (Shove et al., 2012); and finally, that participation (of individuals) in practices implies an immersion into the giant network of practices that constitutes social life (Schatzki, 2002).

SPT is increasingly used for analysing the emergence of smart energy systems. The field is rapidly growing with contributions focusing on smart metering practices (Hargreaves et al., 2010, 2013b; Pullinger et al., 2014; Wallenborn et al., 2011), on domestic practices that involve energy consumption (Bell et al., 2015; Doyle and Davies, 2013; Royston, 2014; Strengers, 2011a, 2012, 2013), on the flexibility of everyday practices (Higginson et al., 2014; Nicholls and Strengers, 2015; Powells et al, 2014; Walker, 2014), on the energy impacts of smart homes (Røpke and Christensen; 2012; Wilson et al., 2014), on the (imagined) roles of householders in smart grids (Christensen et al., 2013; Goulden et al., 2014), and, finally, on smart grid development as a form of governmentality (Bulkeley et al., 2016b). The chapters in this thesis draw upon much of this work.

In sum, Social Practice Theories represent a diverse body of theory which has found fertile ground in the research field of sustainable consumption. SPT has increasingly come to serve a sociological alternative for individualist and structuralist accounts of (energy) consumption, which focus on end-users and social structures respectively. With respect to households and smart grids, SPT stipulates a focus on the organised activities (practices) that constitute the household and the smart grid.

\subsubsection{Informational Governance}

Informational Governance (IG) is a governance theory that seeks to address the transformative role of information flows in present-day society. Information flows refer to the exchange of information, data and knowledge in a general sense (Mol, 2008). IG promotes a view of environmental governance in which information becomes an increasingly important driving force behind social and environmental transformation. To a significant degree this capacity derives from enhanced possibilities for collecting, processing and using (environmental) information through 
monitoring technologies and other ICT (Mol, 2006, 2008; Soma et al., 2016a, 2016b; Termeer and Bruinsma, 2016).

As a monitoring technology that is characteristic for the new possibilities that are emerging, smart meters are considered to hold positive, emancipatory potentials for consumers as well as potentially negative impacts. On the positive side, they allow consumers to engage in monitoring practices which strengthen their potential to influence infrastructural change. This concerns not only reflexive self-monitoring, but also the counter-surveillance of energy companies. If, however, smart meters are deployed (exclusively) to the benefit of energy companies or governments, they can also be used to subject consumers to new regimes of surveillance and social control (Mol, 2008; Van den Burg et al., 2003).

The notion of Informational Governance was coined by Mol (2006) to outline a new agenda for social scientific research on environmental issues. According to Mol, Informational Governance represents a mode of environmental governance that is essentially different from other or more conventional modes, primarily those that rely on state power and authoritative resources. In the informational mode of governance, by contrast, information is the most crucial resource and power is distributed between a variety of actors and networks (e.g. state, market, civil society) (Mol, 2006, 2008).

IG is informed by the work of Castells $(1996,2009)$ on the Information Age and the rise of the Network Society. Castells differentiates between the "space of flows" - the abstracted, globalised space-time that is based on real-time interaction at a distance and the "space of places" - the time and space of local, face-to-face interactions that people are accustomed to (Castells, 1996, 2009). Yet, where Castells stresses the detrimental effects of the space of flows on the environment, and sees opportunities for place-based resistance only, IG (also) emphasizes the possibilities for environmental reform in and through the space of flows. The space of flows, Mol argues, opens up new opportunities for the articulation of an environmental rationality - a form of rationality that is, according to the thesis of Ecological Modernisation (Mol et al., 2009; Mol and Spaargaren, 2000), increasingly differentiated from economic and political rationalities. Expressions of this environmental rationality in the space of flows include the emergence of eco-labelling and certification schemes, new environmental monitoring techniques and reporting programs, and international conventions on public access to environmental information (Mol, 2006, 2008).

IG is still a relatively new theory. Application and development has, until recently, been restricted to the fields of citizen-based monitoring (Van den Burg, 2006; Van den Burg et al., 2003) and marine environmental governance (Hoefnagel et al., 2013; Toonen and 
Lindeboom, 2015; Toonen and Mol, 2013). New work has been brought together in a special issue entitled Informational governance and environmental sustainability (Soma et al., 2016a). Drawing on a diversity of other social scientific perspectives the special issue discusses various aspects that are relevant to Informational Governance, among other things; the construction of environmental information (Lehtonen et al., 2016; Opdam et al., 2016), the use and effects of new ICT and social media (Stevens et al., 2016; Termeer and Bruinsma, 2016), the development of transparency and accountability mechanisms in environmental governance (Cook et al., 2016; Gupta and Mason, 2016) and the role of information in institutional change (Lamers et al., 2016a; Bailey et al., 2016).

In short it can be stated that Informational Governance represents both a theory of environmental governance as well as a mode of governance. It seeks to capture both the bright and the dark sides of information in order to improve forms of governance with respect to their social and ecological dimensions. In relation to smart grid development, IG can help to analyse the gathering, processing and use of information flows as part of the new infrastructural networks that are emerging.

\subsubsection{Transition Theories}

Transition Theories (TT) are primarily concerned with 'sustainability transitions' fundamental changes in societal systems that result in more sustainable modes of production and consumption. TT understands transitions as complex, multidimensional, and long-term processes of transformation (Geels, 2011; Markard et al., 2012). A key premise of TT is that societal systems like transport, health, food and energy systems, are conceived as socio-technical systems. The social and the technical stand in a recursive, co-evolutionary relationship such that "technology is shaped by social, economic and political forces [while] technologies and technology systems shape human relations and societies" (Rip and Kemp, 1998: p328). Sustainability transitions, accordingly, involve technological change along with changes in institutions and user practices.

A second key characteristic of sustainability transitions is that they are goal-oriented; they are transitions towards sustainability. While actors involved in the transition might disagree on what sustainability means, and how it is best achieved, such a normative purpose is inherent to the process (Geels, 2011; Markard et al., 2012). Goalorientation or directionality is also an important aspect in the governance of sustainability transitions (Grin et al., 2010; Smith et al., 2005). 
Similar to SPT, the term Transition Theories refers to a diversity of theories and management approaches within science and technology studies that come together in the study of sustainability transitions. These include Strategic Niche Management (Kemp et al., 1998; Schot and Geels, 2008), the Multi-Level Perspective (Rip and Kemp, 1998; Geels, 2002; Geels and Schot, 2007; Smith et al., 2010), Transition Management (Loorbach and Rotmans, 2010; Voß et al., 2009), Complex Systems Theory (Rotmans and Loorbach, 2009) and the Governance Approach (Grin, 2010; Grin et al., 2011).

Even though there is considerable diversity within these approaches, the Multi-Level Perspective (MLP) offers a shared, integrative framework and a platform for discussion between various strands of TT (Geels, 2010, 2011). The MLP distinguishes three interacting levels: the regime, the niche and the landscape. Regimes refer to dominant, institutionalised assemblages of technologies, actors, practices, rules, beliefs, expectations etc. (the meso-level), niches refer to shielded spaces for innovation (the micro-level), and the landscape refers to a relatively stable exogenous environment that is not directly influenced by the other levels (the macro-level).

Transitions are understood as outcomes of alignments between developments at niche, regime and landscape levels (Geels, 2002; Geels and Schot, 2007; Rip and Kemp, 1998; Smith et al., 2010). Alignments can follow distinct evolutionary patterns that are referred to as transition pathways (Geels and Schot, 2007; Smith et al., 2005). Geels and Schot (2007) distinguish four types of pathways: transformation, substitution, reconfiguration, and de- and re-alignment. These differ in the timing and nature of the interactions between the three levels. The transformation pathway, for instance, is characterised by, incremental adaptations in the regime as a result of moderate landscape pressure and immature niches. The substitution pathway, on the other hand, is characterised by disruptive change as a result of suddenly high landscape pressure combined with sufficiently developed niches.

The MLP is applied and discussed in a wide range of scholarly work (e.g. Geels et al., 2012; Grin et al., 2010; Smith et al., 2010; Spaargaren et al., 2012; Verbong and Loorbach, 2012). However, aside from the diversity of studies on national and international energy transitions more generally, there are only few that deal with smart energy systems specifically. Studies that draw on TT to understand smart grid development focus on transition pathways for smart grid development (Foxon, 2013; Verbong and Geels, 2010, 2012), on the role of users in smart energy systems (Bosmans, 2013; Verbong et al., 2013), on the influence of ICT firms entering the energy domain (Erlinghagen and Markard, 2012) and on the interconnections between smart grid development and climate change objectives (Stephens et al., 2013, 2015). 
In sum, Transition Theories represent a diverse set of theories and management approaches in which the MLP has come to serve as a common point of reference. TT seeks to understand and enhance (technological) transitions towards sustainability by studying niche, regime and landscape interactions. Seeing sustainable energy transitions with the help of TT is to see the complex, multidimensional and long-term character of the transition as well as the different pathways of change describing how and what kind of transitions (may) unfold.

\section{$\underline{\text { To conclude }}$}

The discussion above makes clear that Social Practice Theories, Informational Governance and Transition Theories share an interest in sustainability, but also differ in significant ways: the theories specialise in different aspects of environmental issues (respectively: consumption; production; governance), they discern different units of analysis (respectively: social practices; information flows/networks; interacting levels) and they seem to make different ontological assumptions (the 'flat ontology' of SPT vs. the 'levelled ontologies' of TT and IG). ${ }^{10}$ Therefore, caution should be exercised when combining theoretical insights or conceptual elements in the analysis. Doing so, however, may help to bring the theories into dialogue, to explicate the synergies and differences and to reflect on (core) theoretical assumptions.

\subsection{Central aims and research questions}

The central aims of this thesis are:

a. To contribute to a better understanding of the social dynamics of smart energy systems, with a focus on the transformations taking place in and around the households of end-users;

b. To develop concepts and analytical tools for studying these dynamics and transformations;

c. To formulate suggestions for the governance of sustainable energy transitions that involve smart energy systems.

\footnotetext{
10 In SPT the 'flat ontology' refers to the idea that all practices are situated on a single level of existence (Schatzki, 2016a). TT, on the other hand, differentiates between niche-regime-landscape levels (Geels 2002), while IG differentiates between the space of places and the space of flows (Mol, 2008).
} 
The central research questions of this thesis are:

1. How can we conceptualise the interplay between households and smart energy systems?

2. How do householders deal with new information flows in a context of emerging smart energy systems?

3. What are the implications of this analysis for (the governance of) householder participation in sustainable energy transitions that are enabled by smart energy systems?

\subsection{Research design}

Finding answers to the research questions requires systematic enquiry in the form of a research design. A research design is a roadmap that specifies what and how different procedures and methods are applied during the research process (Kumar, 2014). Figure 1.5 presents the research design that organises this thesis. It shows the connections between the research questions, the methods and the chapters of the thesis (note: Research question 2 is divided over two different chapters). The figure also displays the vantage points from which each of the chapters consider the research themes: Chapter Two presents a general outlook on the three themes. Chapters Three, Four and Five each start from a more specific angle.

This thesis makes use of several research methods. The specific method or set of methods varies per chapter. Chapter Two makes use of semi-structured interviews with end-users and energy experts to explore the use and effects of new information flows as part of smart grid development. Chapter Three combines a quantitative survey with a focus group discussion in order to understand how privacy and autonomy concerns of end-users interfere with end-user participation in emerging smart grids. Chapter Four combines participant observation of workshop sessions with end-user interviews to consider the role of information in changing domestic consumption practices. Finally, Chapter Five is a theoretical chapter which investigates householdlevel sustainable energy transitions in the context of smart grids.

Even though Figure 1.5 is useful as an initial point of orientation, its rigour should not be overstated; each chapter has a unique set of features and priorities. ${ }^{11}$ For instance, Chapter Two and Chapter Five prioritise conceptual development, while Chapter Three

\footnotetext{
11 This is a consequence of writing an article based-thesis in which the chapters have been designed as journal articles.
} 
and Chapter Four provide more room for empirical analysis. There is also diversity in research approaches. Data gathering for Chapter Three, for instance, starts from a more predefined theoretical format, whereas Chapter Four is more explicitly rooted in empirics.

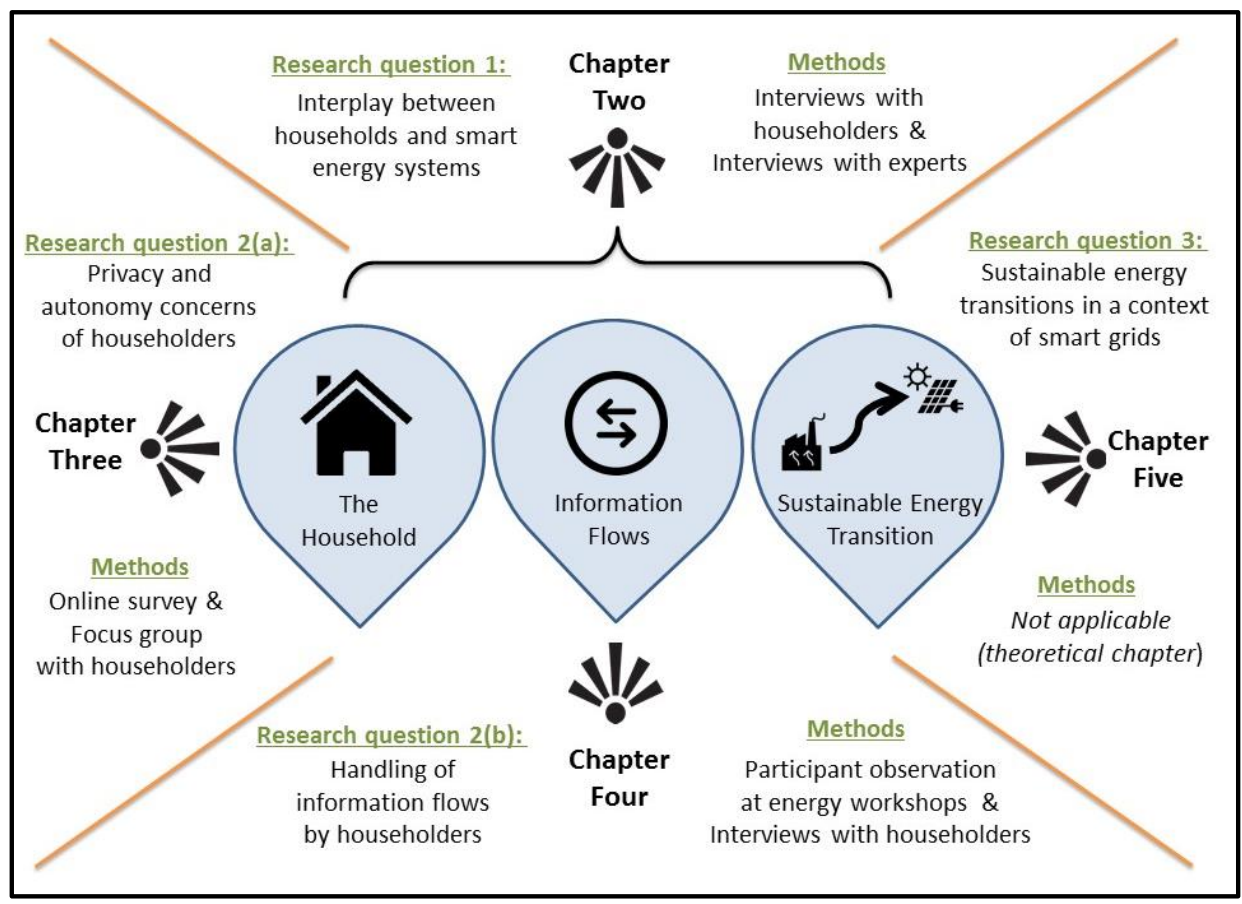

Figure 1.5: Research design.

This section first considers the use of methodologies for studying social practices. Next, the research methods are explicated. Finally, a note is added on the scope and limitations of the research.

\subsubsection{Practice methodologies}

This thesis takes Social Practice Theories as the primary starting point for studying the research themes. What this means, first and foremost, is that social practices feature as the primary units of analysis. As mentioned before, a focus on practices comes along with a move away from explanatory frameworks such as social psychology and neoclassical economics that explain social phenomena in reference to the motives and actions of individual agents, a research strategy that has been labelled "methodological individualism" (Halkier and Jensen, 2011; Schatzki, 2002). 
Yet, what constitutes a proper practice-methodology that serves as an alternative for methodological individualism is still not entirely clear. Until recently at least, empirical research into practices has been characterised by a "methodological muddling through" (Bueger, 2012: p403) with scholars drawing upon different research traditions. In the latest years, however, more and more effort is being directed at the examination and development of specific practice-methodologies (e.g. Browne et al., 2013; Bueger, 2012; Nicolini, 2012; Schatzki, 2016b; Shove et al., 2012). At a minimum, what seems to be required for studying practices is the use of practice-ontological concepts to understand and describe the social world (Schatzki, 2016b). This section specifies five other methodological considerations and explicates how the work in this thesis engages with these points.

The first methodological point concerns the use of an analytical divide between practices-as-entities and practices-as-performances (Schatzki, 1996; Shove et al., 2012; Warde, 2005). Practices-as-entities refer to the composition of practices and to the (social) organisation of practices in space and time. Practices-as-performances refer to the actual deed, the practicing, the enactment. Whilst this thesis does not explicitly employ these terms, it can be stated that Chapters Two, Three and Five consider practices in their 'capacity' as entities, whereas Chapter Two and especially Chapter Four also explicate performances.

A second point concerns the dissecting of practices (as entities) into practice components. In the field of sustainable consumption various scholars have outlined sets of practice elements that can be used as an analytical tool: Warde (2005), for instance, differentiates between procedures, understandings and engagements. Gram-Hanssen (2010) distinguishes between know-how and embodied habits, institutionalised knowledge, engagements, and technologies. And Shove et al. (2012) discern competences, materials and meanings. These schemes serve as hands-on alternatives to the complex (ontological) schemes proposed by Schatzki (2002) and Reckwitz (2002). This thesis does not adopt a specific outline of practice elements. Instead, it uses these outlines as sensitizing schemes to consider what practices might involve, thereby leaving considerable room for complexity. Chapter Five, however, specifically engages with the distinctions made by Schatzki ${ }^{12}$ in order to think about sustainability transitions.

\footnotetext{
12 Schatki (2002) discerns between practices and arrangements, where practices are composed of practical understandings, rules, teleo-affective structures and general understandings. Arrangements refer to human bodies, organisms, artefacts and things.
} 
The third methodological consideration concerns the techniques of zooming in and zooming out, as proposed by Nicolini (2012). Zooming in refers to investigations into practices-as-performances, while zooming out refers to investigations into the relationships between practices in space and time. Zooming out embraces a variety of analytical moves to consider the wider practice-network, including considerations of how the same practice is performed in different locations, how practices have been historically formed, and how practices interconnect in real-time (Nicolini, 2012). Wider networks of practices (or: systems of practices) are increasingly recognized as an important field of research (Macrorie et al., 2015; Shove et al., 2012, 2015; Watson, 2012). Among other things, the zoomed out modus allows practice theorists to account for large(r)-scale phenomena, next to the small-small scale phenomena that are usually studied (Schatzki, 2016b; Spaargaren et al., 2016). This thesis considers various types of practice networks and their interrelations, including those that make up households and those that make up smart energy systems (all chapters). It also considers information flows as a specific type of interconnection between practices (Chapter Four).

A fourth methodological issue is the differentiation and labelling of practices. There are different strategies for carrying out this task. A researcher might, for instance, use the labelling schemes of practitioners (Røpke, 2009; Shove et al., 2012), first engage in practices and then start differentiating based on empirical observations (Nicolini, 2012), or start from an analytical interest in specific resources and label practices accordingly, e.g. food practices, energy practices, waste practices (Halkier and Jensen, 2011; Spaargaren, 2011). In this thesis the differentiation and labelling of practices mostly, but not exclusively, follows from an analytical interest in the use of energy and information flows.

A final methodological issue is the use of specific research methods to research social practices. Nicolini (2012) argues for the need to develop a coherent "theory-method package" on the basis of ethnographic research methods like participant observation and shadowing. Bueger (2012) makes a similar argument, but considers interviews and document analysis as back-up strategy for situations in which participant observation is not possible, for instance when access to the field is difficult, or when investigating (historical) practices that cannot be directly observed. Hitchings (2012) and Browne et al. $(2013,2014)$ on the other hand, suggest that a wider variety of qualitative and also quantitative methods can be used to investigate practices. In their view methods like interviews, surveys and focus groups, used on their own or as part of a mixed methodology, may reveal aspects of practices that remain hidden from view when only relying on detailed ethnographies - e.g. distribution patterns of practices 
across a population (e.g. quantitative survey), historical shifts in the configuration of practices (e.g. document analysis) and the diversity of meanings, understandings and considerations that is part of practices (e.g. qualitative interviews, focus groups). In line with the latter suggestion, this thesis makes use of several research methods to investigate practices in and around the household. As apparent from Figure 1.5, the specific method or set of methods varies per chapter.

\subsubsection{Research methods}

This section explicates the methods for data collection and analysis: interviews, a focus group, an online survey and participant observation. Further details are provided in the respective chapters.

\section{$\underline{\text { Interviews }}$}

Chapters Two, Four and Five make use of several sets of interviews. Interviews were conducted face-to-face, with the exception of two expert interviews that were conducted by telephone. The interviews took the form of semi-structured interviews. Semi-structured interviews have a predetermined order in questions or topics that are discussed, but also some degree of flexibility both in terms of questioning and in terms of responding (Kumar, 2014; Longhurst, 2003). This allows the researcher to focus the conversation on topics that are of analytical interest, while at the same time leaving room for other issues to emerge. Early interviews were leaning towards the unstructured end of the spectrum, while later interviews moved more towards the structured end.

For Chapter Two, five interviews were conducted with end-users who participated in a smart meter trial by a consumer organisation (November - December 2012; Annex A). These end-users were purposefully selected to explore the use of smart meters. In addition, ten interviews were conducted with experts in the energy domain (August 2011 - January 2013; Annex B). Interviewees included energy providers, grid operators, consultancy firms, consumer organisations and a government agency. Interviewees were selected on the basis of recommendations by researchers and (earlier) interviewees. The main purpose was to get information on the smart meter roll-out in the Netherlands and to obtain opinions on smart grid development and the role of end-users.

For Chapter Four, 21 interviews were conducted with end-users who took part in, or had come in contact with, a smart grid pilot in the Dutch town of Lochem (October 2014; Annex F). The interviews included demonstrations of domestic consumption 
practices and the use of smart meters. Interviewees were purposefully selected based on the recommendations of a contact person at the local energy cooperative. The primary aim was to acquire an in-depth understanding of the use of energy-related information. Additionally, eight interviews were conducted with organisations participating in the smart grid project in Lochem (September - October 2014; Annex G). Interviewees included (former) board members of the local energy cooperative, a researcher at a technical university and two employees of service providers. The primary aim was to acquire a better contextual understanding of the smart grid project and the local energy cooperative.

All interviews were audiotaped (with the exception of one). Interviews with end-users were fully transcribed and coded in coordination with the analytical categories specified in the respective chapters. Expert interviews were drawn upon selectively.

\section{Online survey}

Chapter Three makes use of an online survey. Survey designs allow for a quantitative description of trends, relations, opinions (etc.) within a population (Creswell, 2013; Field, 2013). In this case the survey was used to obtain quantitative measures of participation and interest in smart grid-related practices, and to test the effects of privacy and autonomy concerns.

The survey was designed in Qualtrics, an online survey tool. It was advertised through the digital newsletters of iNSnet, a Dutch non-profit organisation, and made accessible through a link on their website (August - September 2013). iNSnet publishes news and essays on environmental issues on their own website (duurzaamnieuws.nl). This route was chosen because participation in the survey required some familiarity with the topics of energy and sustainability. Familiarity was also expected to increase response rates (participation was pro bono). In the end 212 valid responses were obtained.

The survey consisted of 68 questions with 152 items in total. Questions were multiplechoice. There was also room for respondents to make comments or explain their choices. Various images were added to clarify the subject matter. SPSS Statistics was used for statistical analysis of the data. Annex C presents the survey (in Dutch). Procedures and outcomes are presented in Chapter Three.

\section{Focus group}

The survey was complemented with a focus group as part of a mixed methods design for Chapter Three. Focus groups are similar to interviews in that they generate open responses of participants in their own words. At the same time they are different from 
interviews in that they introduce group interaction (Longhurst, 2003; Kumar, 2014). The group dynamics allowed for the collective rather than the individual construction of (ideas on) smart energy futures.

The focus group was conducted on a weekday evening in Utrecht, the Netherlands (April 2014). It involved 12 participants who had expressed their interest in the focus group after filling in the online survey. The focus group comprised several rounds of discussion. Sub-groups of three or four participants were formed to discuss the specific themes that were introduced by the researchers. The focus group was finalised with a plenary session in which participants reported back to the group. Conversations were recorded and transcribed. Coding was done in ATLAS.ti, a tool for qualitative data analysis. Annex D shows the slides with questions for discussion that were provided to the participants (in Dutch).

\section{Participant observation}

In addition to semi-structured interviews, Chapter Four makes use of participant observation in a series of workshops on energy conservation, which was organised as part of the smart grid pilot in Lochem. Among other things, participant observation allows researchers to obtain a holistic understanding of a phenomenon or social interaction, to observe non-verbal communication, and to get a feel for how things are organised and prioritised (Kawulich, 2005). In this case, participant observation was used to acquire an in-depth understanding of the process of information handling and sharing. It also helped to obtain a contextual understanding of the smart grid pilot.

Observations were made during 13 workshop sessions on energy conservation (9), electric mobility (3) and wind energy (1) (June 2013 - October 2014). The workshops were organised by a project leader at the local energy cooperative and attended by a varying group of 6 to 18 end-users. In return for access to the workshop series, the researcher agreed to assist in organising the workshops, in facilitating the discussions and sending around notes. The notes of the workshops were also used for the data analysis. This took the form of descriptions of the workshops series in general and of situations within the workshops sessions on energy conservation more specifically. Annex E provides an overview of the workshop sessions on energy conservation.

\subsubsection{Scope and limitations}

The research aims and the research questions of this thesis are to a significant extent of a conceptual nature. The primary ambition is to acquire a better (qualitative) understanding of the relevant social dynamics, rather than to obtain a representative 
(quantitative) picture of particular groups of individuals. To obtain a close understanding of the relevant dynamics the thesis has primarily selected, observed and inquired end-users who have acquired some experience with smart energy technologies ('frontrunners').

The Netherlands was selected as the site for research for a number of reasons. First, the country offered ample opportunities for investigation with various smart grid projects being developed, many of which included households (Energiekaart, 2015; Netherlands Enterprise Agency, 2015b). Second, as mentioned before, the Netherlands provides a particularly interesting case for investigating the role of information given the public and political resistance that emerged in relation to smart meter roll-out (Dutch Ministry of Economic Affairs, 2014; Hoenkamp et al., 2011). And thirdly, there are also pragmatic reasons: language does not pose a (significant) constraint; access to sites and to information sources is relatively easy; and travelling and accommodation costs are relatively low.

While it is difficult to give a precise indication of the scope, it is clear that the relevance of the thesis extends beyond the site(s) of investigation and beyond the Netherlands. As apparent from this introductory chapter, smart grid development is in many ways an affair that cuts across the boundaries of individual (European) nation states, cities and municipalities. From a practice theoretical perspective, moreover, practices and networks thereof provide a more immediate and relevant context to the things taking place than do nation states. The spatial, administrative and cultural specificities of nation states, in other words, might not be more significant to the dynamics of practices than any other local or global 'force', at least not by definition.

Nevertheless, some bias in the ideas and imagery stemming from the selection of sites, people, documents (and theories) seems inevitable. Potential biases are addressed as much as possible by explicating relevant policy contexts and local situations, and by linking findings to national and international literature on the topic.

\subsection{Outline of the thesis}

This introduction has provided a broad picture of developments, ideas and problems surrounding the emergence of smart grids. It has also singled out three themes that are of particular interest to the thesis: Households, Information flows and the Sustainable energy transition. Each of the four main chapters deals with these three central themes from a different vantage point (Figure 1.5). 
Chapter Two outlines a conceptual framework for understanding the interrelations between households and emerging smart grids. Using Social Practice Theories and Informational Governance, it postulates that the household can be understood as a set of interconnected domestic practices. Energy functions as a resource to many domestic practices, and it is consumed as part of performing these practices. The chapter also argues that, with the advent of smart grids, the relation between the household and the energy system is changing, and that this process can be studied by discerning three sets of energy and information flows: flows within households, flows between households, and flows between households and service providers. Together these practices and flows constitute a basic conceptual framework. In the second half of the chapter the use of this framework is illustrated with the help of data from an initial set of exploratory interviews with and end-users and energy experts. The conceptual framework also informs subsequent chapters; each chapter highlights, elaborates on or revisits specific conceptual elements.

Chapter Three examines the privacy and autonomy concerns of end-users in relation to their participation in smart grids. More specifically, it seeks to better understand the nature of privacy and autonomy concerns and, secondly, to consider the significance of these concerns with respect to three types of practices that are typical for smart energy systems: energy monitoring, co-production of energy and time-shifting of energy demand. These practices are referred to as energy management practices. To investigate the matter, Chapter Three presents a scheme that relates the energy management practices to three social arrangements - private arrangements, horizontal arrangements and vertical arrangements - implying different forms of cooperation and information disclosure between households, associations of households and service providers. An online questionnaire and a focus group help to identify possibilities for cooperation as well as important points of concern. The outcomes also help to shed light on the concepts of privacy and autonomy.

Chapter Four studies the reconfiguration of domestic practices as a result of new information flows. The chapter starts by adopting an understanding of information as a practical accomplishment; that is, as something that requires work and occurs in and through practice. Subsequently it tracks the dynamics of information in a pilot project where end-users could obtain first-hand experience with smart energy technologies. Based on participant observation in a series of energy-workshops and interviews and house tours with end-users the chapter singles out three categories of practices that resonate with the particularities of the pilot project: community interaction practices, monitoring practices and domestic practices. On the basis of concrete situations the analysis explicates how information is accomplished in each of these practices, how 
information moves between such practices and how this affects domestic practices. The understanding of information and change resulting from this has implications not only for pilot projects, but also for smart grid-related policy interventions more broadly.

Chapter Five sketches out a practice-based approach to smart grid research and governance. While relying primarily on Social Practice Theories, the approach also draws on insights from Transition Theories, which have become influential in understanding and governing sustainability transitions. The chapter highlights three aspects that are central to the new approach. The first is the locus of change. It is argued that it is the interface between the household and the energy grid that becomes of central concern, and that this interface consists of a distinct set of Home Energy Management-practices (HEM-practices) which organise energy flows at the decentralised level of households. The second aspect is the mechanism of change. Change in the case of smart energy systems involves the emergence of new HEMpractices, the reconfiguration of established (individual) practices, and the linking and delinking of networks of practices. The third and final aspect is the directionality of change. The chapter argues that for smart grid development to contribute to the sustainability goals of the energy transition, it is important to attend to the directionality of HEM-practices. Taken together, these aspects form the outline of a practice-based approach that can help to rethink and improve smart grid research and governance.

Finally, Chapter Six takes an overarching view and draws general conclusions. The chapter starts by synthesising the findings of the chapters and providing answers to the central research questions. After that it presents a theoretical and methodological discussion of the research process and its outcomes. The thesis ends with a set of recommendations for future policy and research on smart grids and end-users. 


\section{Chapter 2}

\section{Smart grids, Information flows \& Emerging domestic energy practices}

This chapter has been published as: Naus J, Spaargaren G, Van Vliet BJM and Van der Horst HM (2014) Smart grids, information flows and emerging domestic energy practices. Energy Policy 68: 436-446. The publication has been edited to integrate it as a chapter in this thesis. 


\section{.}




\subsection{Introduction}

Over the past decades highly centralised and fossil fuel-based systems have been the dominant form of energy production and consumption in most OECD countries. Although centralised systems are likely to remain important in the future, we are also witnessing a partial shift towards more distributed configurations that make use of low carbon alternatives. This systemic shift towards a decentralised and more sustainable energy future represents one possible pathway in what is often called the 'energy transition' (Jefferson, 2008; Verbong and Loorbach, 2012). ${ }^{13}$

New opportunities to accelerate a sustainable energy transition seem to arise with the advent of smart grids and smart meters in the European Union (EU) and elsewhere. A smart grid can be defined as "a socio-technical network characterised by the active management of both information and energy flows, in order to control practices of distributed generation, storage, consumption and flexible demand" (Wolsink, 2012: p824). Smart meters generally figure as key components of a smart grid. These digital successors of 'dumb' analogue energy meters enable the detailed monitoring of energy consumption (and production) within households, as well as the two-way exchange of energy and information flows between households and energy providers (Darby, 2010; European Commission, 2011a).

So far, the cultural framing of smart energy technologies has been mainly positive. 'Efficiency', 'flexibility', 'new markets', 'citizen participation' and 'transparency' are key terms figuring in this frame. In a similar manner, the EU has forwarded smart grids as the 'backbone of the future decarbonised power system' (European Commission, 2011a).

In recent years societal implementation has gained momentum through the roll-out of smart meters and the deployment of small and medium scale smart grid pilots. However, when measured against the positive framing and high expectations, smart grids are still in an early stage of development, and there are - as yet - no signs of the centralised and fossil fuel-based regime becoming redundant or even being seriously challenged (Stephens et al., 2013; Verbong et al., 2013; Wolsink, 2012). Furthermore, the introduction of smart meters in people's homes has raised critical questions regarding consumer privacy, increasing control of energy companies over their customers, and potentially dangerous electromagnetic radiation (Beyea, 2010;

\footnotetext{
13 Verbong and Loorbach (2012, p6) refer to transitions as "large-scale transformations within society or important subsystems during which the structure of the societal system fundamentally changes".
} 
Cavoukian et al., 2010; Hess, 2014). Progress towards a low carbon future therefore remains highly uncertain.

Along with societal implementation, scientific research on the use and effects of smart energy technologies is rapidly growing. There are still only few studies, however, that focus on the role of households in smart grids and on the impacts of distributed energy generation on the (everyday) lives of residents (Christensen et al., 2013; Strengers, 2013; Verbong et al., 2013; Wallenborn et al., 2011). Accordingly, this paper seeks to contribute to a better scientific understanding and a more encompassing policy debate on the crucially important roles of households in smart grids. Which changes in domestic energy practices can we expect to emerge? And to what extent do smart grids affect the social relations within, and between households as well as between households and institutional actors? We intend to answer these research questions, first, by developing a conceptual framework for analysing the changing and newly emerging energy practices ${ }^{14}$ and social relations in and around the household, and second, by explicating the role of (energy) information flows in the reconfiguration of these practices and relationships. With the help of stakeholder interviews and workshop observations in the Netherlands we subsequently seek to illustrate - and acquire more insight into - the dynamics of change that are at play.

\section{$\underline{\text { Outline }}$}

The next section discusses the conceptual framework that we derive from 'practice theory', as developed in sociology, and 'informational governance' in particular. It also specifies our research questions. Section 2.3 describes the research methods, while Section 2.4 touches upon the development of smart grids in the Netherlands. The empirical findings from our interviews and workshops are outlined in Section 2.5. Finally, Section 2.6 presents the conclusions and recommendations.

\subsection{A sociological perspective on smart grids}

In his influential 'Information Age trilogy' (Castells, 1996-1998) sociologist Manuel Castells makes a powerful argument for understanding the development and diffusion of new information flows and systems as distinguishing features of today's network society. Building on Castell's work, Mol (2008) formulated the concept of 'informational governance'. Mol thereby postulates the idea that "information is fundamentally restructuring processes, institutions and practices of environmental

\footnotetext{
${ }^{14}$ Note that, for analytical purposes, we use 'energy practices' as a general term to refer to any practice that involves the production, distribution or consumption of energy.
} 
governance" (Mol, 2008: p83). As a governance perspective, informational governance highlights the modes of strategic steering by a variety of actors and networks, made possible by the latest generation of ICT. The informational mode of governance thereby departs from more conventional modes that are largely based on authoritative resources and state power (Mol, 2006).

Building upon the general notion of informational governance we develop a framework for analysing the role of information flows in smart grids. We show how these information flows are used by householders when they perform a number of domestic energy practices. First, a short review is presented on the role of households in the historical development of energy configurations. 2.1.

\subsubsection{Households in the energy transition: A short history}

The positions of households vis-à-vis energy providers (and their energy grids) have significantly changed over time. In order to better understand the current situation of households and smart grids, we present a brief overview of some basic trends and shifts.

Since the 1920s governments in Europe and the USA have been involved in the construction of national high voltage lines and regional distribution grids. The majority of households became connected to these government-controlled networks. Households, by and large, assumed the role of passive end-users or captive consumers (Spaargaren, 2003).

This changed with the emergence of modern environmentalism in the early 1970s, when energy production and consumption became focal points for environmental governance. In conflicts over 'nuclear and coal' versus 'renewables', a shared understanding emerged on the need for energy saving and a long term transition in the organisation of energy systems (Mol et al., 2009; Spaargaren, 2003).

As for the non-industrial, domestic consumption of energy, residents have been assigned increasingly active roles in the implementation of ambitious energy saving policies. EU, national and local governments have sought to support residents through public awareness campaigns and a range of subsidies and (eco-)tax policies (Mol et al., 2009; Spaargaren, 2003).

From the late 1980s onwards, demand side management (DSM) strategies were developed to "avoid environmentally and economically expensive supply investment by managing both the load and timing of demand placed on networks through the implementation of energy (...) efficiency measures" (Marvin et al., 1999b: p128). DSM 
strategies thus seek to balance energy supply and demand, rather than maximising supply capacity, e.g. through the introduction of network flexibility, interactive control, participant users and micro profiling (Marvin et al., 1999a). This has led to new forms of inclusion of households in the networks and infrastructures of energy provision. In contrast to these mainstream developments, specialised NGO's and grass-root movements have initiated local, off-grid energy systems in several countries as an alternative to utility-led provisioning (Seyfang et al., 2013).

Over the last two decades, the huge gap between mainstream strategies and grass-root alternatives has, to some extent at least, been narrowed down. Germany serves as a key example here, with former activists and now green party politicians taking the lead in organising the 'Ausstieg' from nuclear energy provision towards local renewables (Jacobsson and Lauber, 2006). Furthermore, the combined introduction of DSM strategies and energy liberalisation policies has resulted in a differentiation of the roles of domestic energy consumers towards energy providers. With the support of (new) intermediary organisations, some households, for instance, have strategically united their stakes and responsibilities by setting up renewable energy cooperatives (Marvin and Medd, 2004; Spaargaren and Mol, 2008).

More recently, the concept of smart grids has gained popularity. With intelligent monitoring and steering systems as important elements, smart grids are expected to facilitate the up-take of an increasing share of intermittent renewable energy resources in the overall energy provision (Verbong and Loorbach, 2012). As for the future of energy systems, two different scenarios seem to be possible. In a scenario of radical centralisation, the outcome will be a (transnational) 'supergrid' in which the role of households tends to be marginal. At the other end of the extreme we find a scenario of radical decentralisation. In this scenario smart grids develop as a set of interconnected, largely self-governing micro-grids in which (groups of) households become increasingly self-sufficient and self-regulating (Verbong and Loorbach, 2012; Stephens et al., 2013; Wolsink, 2012).

This short review shows that the role of households - as citizens, consumers and activists - in the energy grid (Van Vliet, 2012) has been discussed well before the introduction of smart grids. The advent of smart energy technologies, however, adds new dimensions to the debate on consumer involvement. The social sciences in general, and (environmental) sociology in particular, can make an important contribution to understanding the role of households as social actors in (smart) grids. 


\subsubsection{A sociological account of domestic energy consumption and production}

Most social scientific studies on the role of residents in the energy transition focus on the perceptions and behavioural changes of residents as individuals. These 'individualist models', used in social-psychological and economic studies in particular, have been criticised for their neglect of context and their reliance on rational, conscious decision making (Shove, 2010).

While sharing a concern for a more contextual approach, sociological analyses make different assessments - or highlight different aspects - of the role of (social and material) 'structures' in shaping domestic consumption and production. Some studies emphasise the (need for) the empowerment of householders vis-à-vis energy providers. They show how more sustainable, local energy configurations and information exchange can combine a higher climate performance with better social positioning of community-based actors and organisations (Seyfang and Haxeltine, 2012; Verbong et al., 2013; Wolsink, 2012). Others - inspired by Michel Foucault (Foucault, 1995) in particular - accentuate the new, more fine-grained and encompassing forms of surveillance and disciplinary power exercised over residents. They demonstrate how smart energy technologies and information gathering by providers and authorities can be used to strengthen utility control 'behind the (energy) meter', to condition and classify the actions of residents, and to further marginalise the power of low income households (Graham, 1998; Hargreaves, 2010; Marres, 2011). Conversely, consumers can also develop 'counter-surveillance' strategies when these technologies enable the disclosure of information about energy provisioning (Van den Burg et al., 2003).

Since about a decade, theories of social practice have become more prominent in the field of domestic energy consumption. In comparison with the perspectives discussed above, practice-based approaches direct more attention to the shared, routinized and embedded nature of everyday consumption practices. They also emphasise that domestic energy routines and activities are generally more complex and hard-togovern than often suggested or expected by policy-makers and energy providers (Gram-Hanssen, 2010; Shove et al., 2012; Strengers, 2012).

When developing our conceptual framework in the next subsection, we seek to connect to this stream of practice literature. Such an approach allows us to investigate the detailed dynamics of the activities and interactions taking place in (situated) domestic and local settings, while not losing sight of the broader context of systems of energy provision (Spaargaren and Van Vliet, 2000). Building upon practice theories as developed by Giddens (1984) and Schatzki (2002) in particular, we seek to analyse 
both the enabling ('bright') and constraining ('dark') sides of the structures, policies, social relations and networks implied in energy provisioning (Southerton et al., 2004; Spaargaren, 2011).

\subsubsection{A conceptual framework for studying the role of households in smart grids}

Our conceptual framework contains three main components: the household, the (smart) grid and information flows. They will be introduced consecutively.

\section{The household}

Rather than a single entity consisting of material objects and human beings, the household can be better understood as a set of different - yet interdependent - subsystems that fulfil specific domestic tasks (Gregson et al., 2007; Shove, 2003). In other words, there are more or less specialised systems involved in e.g. doing the laundry, for showering, for cooking and eating, for communicating. When 'in action' these subsystems can be referred to in terms of a series of (routine) social practices, i.e. doing the laundry, making dinner, watching TV. (Figure 2.1) depicts a number of domestic energy practices (in the circles) that are of special relevance in the context of smart grids. These practices are performed by human agents who communicate about different elements of practices (speech bubbles), and who make use of technological objects, machines, energy and information flows that connect them to wider technological infrastructures delivering energy, water, data etc. (Cowan, 1983; Otnes, 1988). In short, we depict households as hybrids of objects and people, which are implied in the (routine) performance of a series of interconnected practices reproduced in the domestic arena with the help of energy as a key resource.

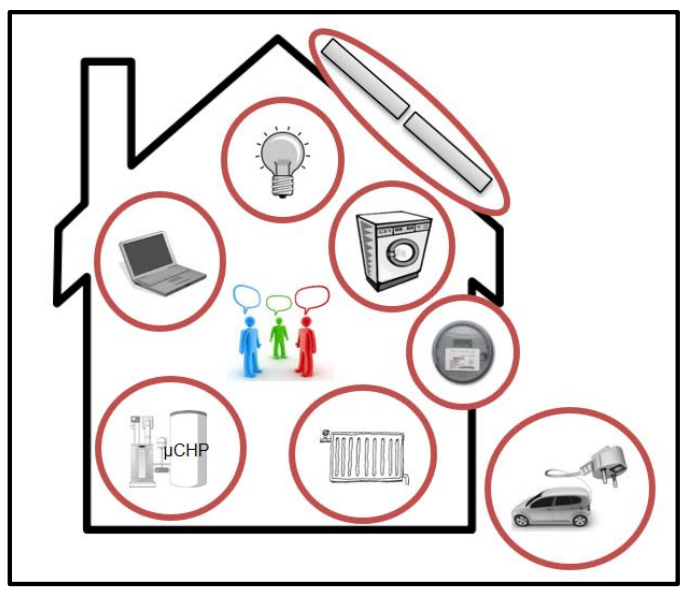

Figure 2.1: Domestic energy practices. 


\section{The (smart) energy grid}

In order to understand how changes in domestic energy practices are connected to the development of smart grids, we add the 'energy grid' as a second component to our framework. Similar to the household, the grid can be understood as a socio-material system composed of e.g. infrastructures, technological objects, human actors and conduct.

As depicted in (Figure 2.2), we distinguish - for analytical purposes - three types of social relations that residents engage in: those with co-residents (e.g. children, spouse, room-mates), those with private and public service providers (e.g. grid-operators, energy providers and technology developers) and those with local and distant (other) households (e.g. neighbours, social networks). It is in and through the performance of (energy) practices that relationships between actors are consolidated or become reconfigured (Shove et al., 2012). Thus, we depict the energy grid as a series of interconnected domestic and institutional energy practices in which residents and service providers continuously create and re-create mutual relationships of power, autonomy and dependence.

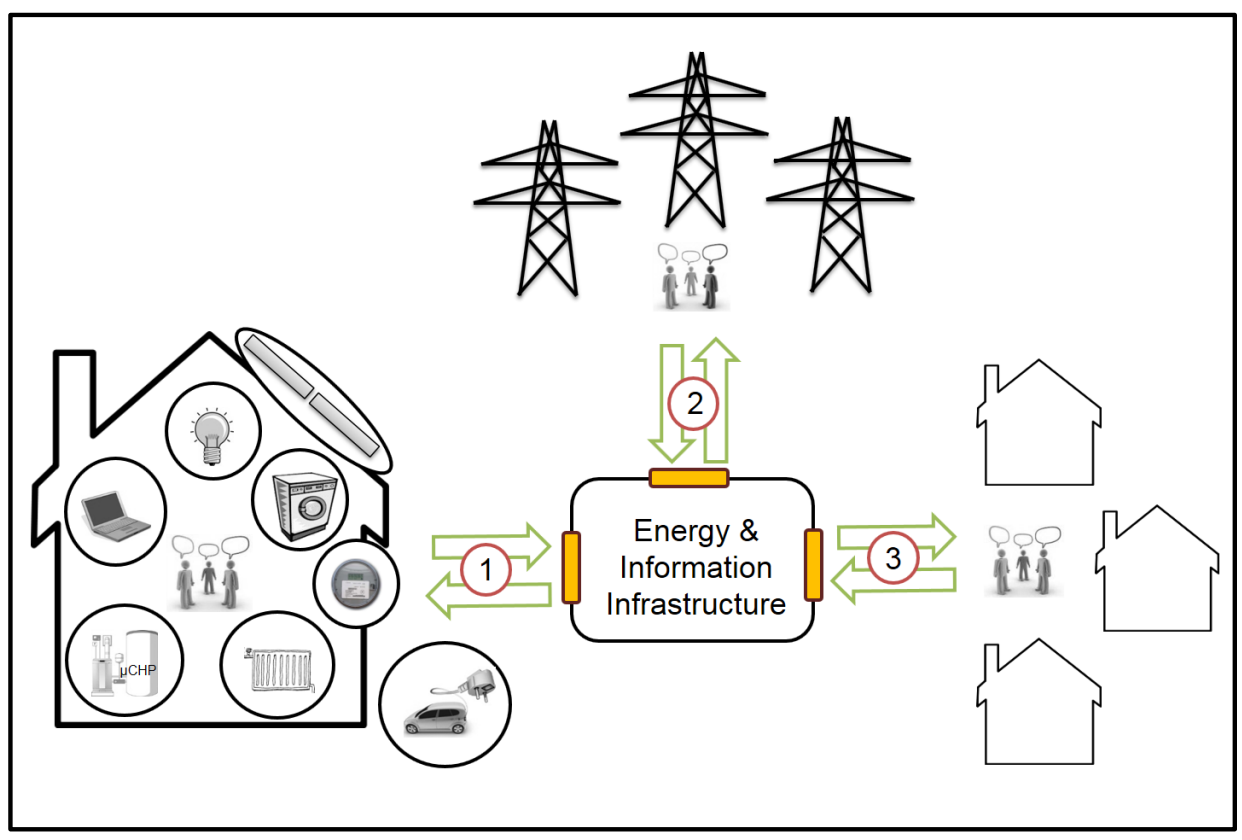

Figure 2.2: Energy and information flows in smart grids: (1) between householdmembers (2) between households and service providers, and (3) between local and distant households. 


\section{Information flows}

Following Castells and scholars of informational governance (Mol, 2008; Van den Burg, 2006) we identify information flows as the third and final component of the framework. The term 'information flows' is employed as a sociological concept to refer to diverse forms of data, information and knowledge exchange (Mol, 2008) between actors in the energy grid. In line with the three types of social relations distinguished above, Figure 2.2 also differentiates between three categories of information flows. The first category of flows is largely generated and used by residents within the context of the household. The second category pertains to the interactions between households and their energy service providers. Finally, the third category of information flows relates to the interactions between households and other local and/or distant households. So, whereas the first category of information flows is largely contained within the 'private' sphere of the home, the other two flows refer to information exchange with actors operating in the (sometimes public) realm 'outside' the household. Again, speech-bubbles are used in Fig. 2 to indicate the fact that people (may) actively communicate about and reflect upon the energy practices that are performed, both inside and outside the household.

With the help of this conceptual framework connecting energy practices, social relations and information flows in the context of smart grids, we are able to specify our main research questions as follows:

- What kind of changes in domestic energy practices are connected to the generation and use of the different smart grid information flows?

- How do the new information flows affect social and power relations within households, between households, and between households and institutional actors?

\subsection{Methodology}

To answer the research questions we have used a mixed-method approach for data gathering in the Netherlands. The Netherlands provides a particularly interesting venue, first because of the significant delay in smart meter implementation resulting from public concerns over consumer privacy (Hoenkamp et al., 2011), and second because of the widespread emergence of local energy cooperatives in recent years (Schwencke, 2012). In Section 2.4.1 we further document the specific case of the Netherlands in the context of the international discourse on smart grids. 
A mixed-method approach was adopted to document the different information flows involved in smart grids and their effects on social relations within households and between households and other actors. Table 2.1 lists the methods used and their contributions to the different categories of information flows distinguished.

Table 2.1: Overview of research methods.

\begin{tabular}{|l|l|l|l|}
\hline Method & Timing & $\begin{array}{l}\text { Primary category of } \\
\text { Information flows }\end{array}$ & $\begin{array}{l}\text { Contribution to } \\
\text { sub-section(s) }\end{array}$ \\
\hline $\begin{array}{l}\text { Interviews with } \\
\text { householders }\end{array}$ & $\begin{array}{l}\text { Apr. 2012 \& } \\
\text { Nov. - Dec. } 2012\end{array}$ & $\begin{array}{l}\text { Between household- } \\
\text { members }\end{array}$ & $2.5 .1 ; 2.5 .2 ; 2.5 .3$ \\
\hline $\begin{array}{l}\text { Interviews with } \\
\text { institutional } \\
\text { actors }\end{array}$ & $\begin{array}{l}\text { Aug. 2011 - Jan. } \\
2013\end{array}$ & $\begin{array}{l}\text { Between households and } \\
\text { energy service providers }\end{array}$ & $2.5 .2 ; 2.5 .3$ \\
\hline $\begin{array}{l}\text { Observations at } \\
\text { workshops }\end{array}$ & June - Sept. 2013 & $\begin{array}{l}\text { Between local and distant } \\
\text { households }\end{array}$ & 2.5 .3 \\
\hline
\end{tabular}

First, an orientating householder interview was conducted (Apr. 2012) with Ms. Visser, who was pre-testing monitoring equipment for a project by a Dutch environmental NGO together with a number of colleagues. The first set of tools that she tested consisted of an online portal that measures in-home temperatures and electricity consumption, among others things. The second set of tools that she tested included a brick-like device with a display that changes colour when moving above or below average consumption levels. The 5-min interval data recorded by this device could be uploaded to her PC.

Later, four semi-structured interviews were conducted (Nov.- Dec. 2012) with residents sampled from 45 households which participated in a one-year smart meter trial. All 45 participants in this trial were selected by a Dutch consumer organisation after they had responded to a call in their (home) magazine. At the end of this trial, six residents participated in a group discussion arranged by the consumer organisation and a grid-operator (partner in the project). All six participants were approached for an individual follow-up interview. In the end, four interviews were conducted.

Two interviewees, Ms. Dijkstra and Ms. Martens, initially received a monthly email with daily consumption statistics and the digital image of a (coloured) house that compared present consumption levels against the levels of preceding months. After six months this email was replaced by an online portal, providing access to daily consumption 
statistics, historical overviews and a comparison with average consumption levels in the neighbourhood. The other two interviewees, Mr. Kuipers and Mr. Peters, had access to a wall-display that recorded real-time energy consumption, provided overviews of consumption over time, and could be used to set overall reduction targets.

All interviews with residents lasted between 1 and $2 \mathrm{~h}$. They focused on a number of specific points in time, starting from the moment of kick-off, and then zooming in on specified moments of monitoring during the trial. Also the interactions with family, friends and neighbours in different phases of the process were discussed.

The semi-structured format of the interviews was considered suitable, given the explorative character of the study. The interviews provided guidance on the topics, but left substantial room for manoeuvre for both the interviewer and the interviewee. Annex A summarises some key characteristics of the residents, their households and the smart meter equipment they used. Pseudonyms are used to protect their identities. Alongside the interviews with residents, ten semi-structured interviews were conducted (Aug. 2011-Jan. 2013) with various institutional actors (Annex B). The interviews took place with individual employees of energy service providers (3), gridoperators (2), public consultancy firms (2), consumer organisations (2) and a government agency (1). Interviewees were selected in the initial phase based on the recommendations of two social scientists specialised in energy systems, and during later phases with the help of recommendations provided by the interviewees. The interviews lasted between 1 and $2.5 \mathrm{~h}$ and had an explorative character as well. Interview topics included the roles and activities of the organisation in the energy sector, their expectations of - and involvement with - smart meters and smart grids, the roles of residents, and the process of smart meter roll-out in the Netherlands.

Finally, participant observations were made during four workshops (June-Sept 2013) organised by 'LochemEnergie', a local energy cooperative established by inhabitants of the (rural) Dutch municipality of Lochem. The cooperative is a central player in 'Smart Grid Lochem', a prominent pilot project (2012-2015) funded by the Dutch government. During the workshops residents discussed various aspects of domestic energy consumption and production, and generated input for the design of the smart grid project. Observational research at the workshops allowed the researcher to acquire first-hand information on the discussions among residents and on the interactions between residents and institutional actors. The workshops signified the start of two separate workshop series. ${ }^{15}$ The 'Energy saving workshop' series involved 19 and 14

\footnotetext{
15 The authors are conducting a longitudinal study on these workshop series.
} 
participants, respectively. The 'Electric mobility workshop' series involved 11 and 10 participants. In both series, participants were asked to attend subsequent workshops. Some attended both series.

Data collection in the workshops relied on minutes of the meeting and notes taken by the researcher. Interviews with residents and institutional actors were recorded and transcribed. The quotations presented in the analysis are translations by the authors.

Given the mixed-method design and the small sample sizes used in our research, serious limitations exist with respect to the generalizability of the empirical results. The aim of our research, however, is not to make a comprehensive assessment of smart grid development in the Netherlands, but instead to explore, document and discuss the different categories of information flows and their impact on the social and power relations discerned in the conceptual framework.

\subsection{Background on smart grid development in the Netherlands}

Before presenting the findings from the interviews and observations, we use this section to describe the societal scene against which our empirical findings come about. We first address those developments in the Dutch energy sector that we consider relevant to the analysis of smart grids and emerging domestic energy practices, and then go on to outline the implementation process of smart energy technologies.

\subsubsection{The Dutch energy sector}

Like many EU countries, the Netherlands has pursued a liberalisation policy in the energy field from the 1990s onwards. In 2004 this resulted in an official split-up of the former semi-governmental utilities into private energy providers and semigovernmental grid operators (Van Vliet, 2012). The most recent political achievement in the energy policy concerns the 'Energy-Agreement for Sustainable Growth', in which more than 40 organisations from the government sector, the market and civil society agree to work towards a "wholly sustainable supply system in 2050". The Agreement includes an aim to save $1.5 \%$ on total energy consumption annually, a renewable energy target of $14 \%$ by 2020 (compared to $4.4 \%$ in 2013), and a tax-relief for renewable energy generated by local cooperative initiatives (Social Economic Council, 2013).

From 2011 onwards, there has been a rapid increase in the number of local renewable energy businesses. Over 300 initiatives were (unofficially) registered by the end of 2013. Membership-based cooperatives constitute a particularly popular legal form of 
renewable energy business in the Netherlands. These new cooperatives are different from wind cooperatives established primarily in the 1990s, among other things, because they aim for (self-) provisioning to the members of the cooperative, instead of feeding the electricity into the grid and receiving a financial return on investment (Schwencke, 2012).

Along with the establishment of local renewable energy businesses, and cooperatives in particular, institutional players are developing new decentralised services. For instance Greenchoice, a green energy provider, is increasingly participating in decentralised initiatives as an administrator and intermediary. Alliander, a Dutch grid operator, is positioning itself as a facilitator of self-provisioning initiatives (Schwencke, 2012).

\subsubsection{Implementation of smart meter and smart grid policies}

EU policy requires that $80 \%$ of European households have a smart meter installed by 2020. Although the Dutch government started planning for smart meter roll-out at an early stage, it encountered a severe setback when several civil society organisations and members of parliament voiced their concerns over consumer privacy and security. They primarily questioned the mandatory acceptance of the smart meter, its vulnerability to cyber-crime, and the potential for the detailed tracking of domestic electricity consumption (15-min intervals) by grid-operators and energy providers. In 2009, the Dutch Senate therefore requested a revision of the smart meter bill. Successive regulatory measures have abolished the mandatory acceptance, established a bi-monthly transfer of energy data (by default), and entitled residents to bi-monthly overviews of energy use (Dutch Central Government, 2013; Hoenkamp et al., 2011). ${ }^{16}$ Small scale roll-out, moreover, was delayed until 2012, while large-scale deployment was (re-)scheduled from 2014 onwards (Dutch Central Government, 2013).

Parallel to the smart meter roll-out, a range of (real-life) smart grid pilots has been initiated in the Netherlands. These pilots experiment with new tariff structures and smart appliances to provide (more) 'flexibility' in energy production and consumption. New tariff structures can take various forms, including high tariffs at times of extraordinary high demand (critical peak pricing), various timeslots with pre-fixed tariffs (time-of-use pricing) and highly dynamic tariffs (real-time pricing). Smart

\footnotetext{
${ }^{16}$ Smart meter implementation has led to protests in other countries as well. McKenna et al. (2012) report on a 'Big Brother Award' granted to the German energy company Yello Strom, and on political turmoil in the UK about a smart meter option that enables utilities to remotely cut off energy supply to non-paying customers. Hess (2014) details (other) forms of opposition around the world, including in the US.
} 
appliances can be switched on/off remotely to shift consumption over time. Examples of smart appliances include washing machines, refrigerators, heat-pumps and the batteries of electric cars (Hakvoort and Huygen, 2012). As an outcome of a smart grid innovation program, set up by the Dutch government, 12 larger smart grid pilots have started in 2012. Seven of these pilots - including Smart Grid Lochem - involve residential buildings (Netherlands Enterprise Agency, 2013).

In short, the development of smart energy technologies in the Netherlands has been slowed down in terms of political support, after privacy concerns were raised by different actors in society. Within the market and in civil society, nevertheless, both profit and non-profit actors are actively debating and experimenting with new smart technologies and their projected impacts on future energy networks, relationships and practices.

\subsection{Empirical findings}

In line with the conceptual framework and the research questions, our findings address the role of smart grid information flows in reconfiguring domestic energy practices and social relations. We separately turn to the three categories of information flows outlined in the conceptual framework. For all three flows, we first present the results on the changes they bring to energy practices, followed by a sub-section reporting on the perceived impacts on social relations.

\subsubsection{Information flows between household-members}

\section{Changes in energy practices}

The interviews with residents reveal some clear differences between householders with respect to the monitoring practices made possible by smart grid technologies.

Ms. Dijkstra and Ms. Martens, who initially received a monthly e-mail, did not develop an elaborate monitoring practice. They explained that this was due to the long time lapse between the moments of actual energy use and the moments of feedback, as well as because of the aggregate scale at which the information was provided. Ms. Dijkstra stated that she "could not conclude much" from the daily statistics as she was unable to remember exactly what happened on the specific days. The occurrence of "totally unexplainable peaks" resulted in a general disinterest in the statistics. Her monitoring practice was therefore soon confined to a quick glance at the coloured picture providing a comparison with the preceding month. After a few months, she reported, the energy e-mail got "submerged" in the continuous flow of daily e-mails and was no 
longer given any particular attention. Whereas the replacement of the email by an online portal, after six months, did not revive Ms. Dijkstra's interest, it made Ms. Martens "immediately log in three times". However, her interest quickly faded again when she experienced that it did not contain much new information and therefore "did not make (her) much smarter".

Mr. Kuipers and Mr. Peters, who received a wall-display, painted a different picture. Their smart metering activities comprised a much wider variety of actions and generated more positive emotions, especially at the start of the trial. Mr. Peters described the display as "encouraging" and "challenging". He stated that he "examined everything on it", including his "consumption baseline" and "consumption peaks". In a similar fashion Mr. Kuipers reported that he used to switch on and off all kinds of electric devices in the first few days. After ten seconds he and his family members could see the result on the wall-display: "when you switch on a device .... the water heater or the washing machine or whatever ... then you can see, gee!".

After the initial phase of experimentation, the monitoring practice got established as a more 'modest' routine. Mr. Kuipers reported that he continued to check the display for indoor temperatures, but also to monitor progress towards the reduction target of $10 \%$ that he had set at the beginning of the trial. Occasionally this inspired him to "quickly look further" and he would still discover "other stuff". Mr. Peters, on the other hand, "scaled down to monthly monitoring" by downloading the data to his PC. He experienced this as "much less of a burden" than the daily interactions with the display.

These findings suggest that the emergence of new monitoring practices depends not only on the particular form in which energy data can be accessed, but also on the creative selection and interpretation by residents. Furthermore, it indicates that smart meters may not produce a constant flow of information, nor a practice that remains stable over time. Nonetheless, the interviewees reported a variety of changes in their consumption practices.

Shortly after the installation of the wall-display Mr. Peters and his wife adjusted their routine of lighting their living room in the evenings. After a short discussion, they agreed to use "the (light) switch in the corner, instead of (the one) next to the door". This way of lighting was considered less energy intensive, but not less comfortable. Mr. Peters explained that, after the initial change, it became a firmly established routine: "it becomes inscribed into your behaviour, even when you do not monitor that intensely anymore".

Later on in the trial, Mr. Peters substituted his water-bed for a box-spring and he replaced his old central heating boiler by a smaller and more efficient one. He explained 
that "because of the display you are more aware of the effects that you create" and that "energy consumption levels start to play a more prominent role" in such decisions. On the other hand, these substitutions involved other considerations as well. The waterbed had been punctured and was considered irreparable, while the maintenance contract on the old boiler had expired for some years.

Ms. Martens developed a new routine for charging electric appliances, already before the start of the smart meter trial. She used to check the energy being produced by her solar panels on a meter in her attic. In line with the monitoring practice she started charging appliances like her electric toothbrush and a small vacuum cleaner: "at this moment (2 p.m.) all kinds of stuff is being charged... Until 3 p.m. That's when I have to switch them off." Her estimation was that other people may find this re-scheduling of energy practices a bit peculiar: "I am the kind of idiot who ... starts doing all kind of things when those panels produce (energy)." However, the positive emotions seemed to overcome the more negative thoughts: "You become a bit of a slave of your solar panels, so I have to restrain myself a bit. But I like it so much! Because now it is clean, and it is my own energy!".

Rather than presenting a direct causal relation between the new information flows and the modification of consumption practices, the examples show instances in which (new) monitoring practices have contributed to the reconfiguration of the energy consumption practices as they are performed by householders.

\section{Changes in social relations}

Domestic energy practices are often performed together with, or in the presence of, other members of the household. Interviewees report on many new interactions which emerge as a result of monitoring practices.

Ms. Visser revealed that she confronted her teenage son with information that she had retrieved from her PC. While pointing at a graph presenting 5-min energy consumption levels of the day before, she commented: "This (peak) is, I think, my son, who returns home in the evening and turns on the microwave." Being troubled by the lack of certainty, she decided to question her son: "We have asked him: what are you doing here? But he is not interested and not really eager to think along." Perhaps related to the failed attempt at engaging her son in this way, Ms. Visser later added that she prefers commenting on actually displayed behaviour to using monitored energy data.

Ms. Dijkstra has been struggling to engage her children in energy saving practices as well. She sensed that her continuous attempts to make sure that her children are not wasting energy might be "very annoying for everyone". Nevertheless, she wished for a 
more comprehensive tool to check upon her children, because her efforts did not produce the desired effects: "Perhaps my son has been using the computer all day, downloading stuff ... I would love to know details, so that I can point out to him: look at how much (energy) you've been using!"

The efforts of Mr. Kuipers have been more fruitful. He reported that his son got interested and, at some point, regularly examined the wall-display: "It was finally a touchscreen that he was allowed to touch, haha." Although Mr. Kuipers felt that "a classical division of roles" may be reinforced in this way - with the men in charge of the "electronic toys" - he has also seen the tables turning: "At 6 p.m. it (the thermostat) switches to a higher temperature. So, when I return home at 5.30 p.m., I feel somewhat uncomfortable. So, yes, then I complain a bit. But then she (his wife) replies: It was you who wanted to save money!"

These examples show that new information flows can produce shared commitments to save energy among family members, but also introduce new modes of surveillance, between the sexes or between the generations.

\subsubsection{Information flows between households and service providers}

\section{Changes in energy practices}

Interviews with residents and institutional actors show that smart meters and smart grids also open up a range of opportunities for information exchange between households and energy service providers.

An employee of a grid-operator indicated that smart meters should, at a minimum, be able to measure more precisely "how much (energy) goes in and out of a house". This would not only enable providers to produce more accurate energy bills, but could also help operators to visualise and control energy distribution in the future smart grid. Having installed mainly analogue meters at this point, the employee felt that they had been "operating the grid as a blind man" so far.

An employee of an established energy provider rather highlighted the market opportunities for new information-based energy services. Especially the demand for the company's (automated) "monitoring applications" and "action-oriented advice" seemed to be quickly rising. According to the employee, more and more energy providers are stepping into this kind of business, as they have realised that "there is more money to be earned with giving pro-active advice and assisting consumers in their efforts to save energy", then with more conventional provisioning tasks. 
Mr. Peters and Ms. Dijkstra, however, indicated that they see no direct need for additional advice. Mr. Peters commented that he "already dived into (his) energy use" extensively. Instead of asking someone else, he has a preference for "sorting things out" on his own. In similar vein, Ms. Dijkstra wondered how it would contribute to what she already knows, having implemented "all those ... tips about more thrifty (ways of) living" listed in magazines and newspapers. She argued that unsolicited advice could even upset some people: "That's all very nice, but who is going to pay?"

Besides advice, energy companies have also been developing new projects around smart appliances. An employee of an energy provider noted that there is "ample interest" among residents for smart washing machines that the company seeks to test in a pilot project. The fact that these washing machines can be programmed by residents based on weather forecasts and dynamic energy tariffs ensures, according to the employee, that laundry practices will be "more profitable than in a normal situation".

Modifications in the timing of domestic routines, however, may not always be convenient or desirable. Ms. Visser indicated that she is "sufficiently stubborn" to resist possible (outside) interventions in her laundry practices. Alluding to the normative elements involved in a possible transfer of control over this practice, she commented: "I want to remain free to decide on what is good and what is not". An employee of a consumer organisation made a similar appeal to the autonomy of the household. By stating that residents "are certainly not going to wait until 11(p.m.) to put a pizza in the oven or a ready-to-serve meal in the microwave" the employee pointed to complications in adjusting firmly established life rhythms.

Providing households with information (or commands) on the 'optimal' way of performing domestic tasks may thus be more problematic than sometimes expected. Existing monitoring practices, established life-rhythms, and ideas about the appropriate locus of control seem to condition the enactment of new monitoring and scheduling tasks by service providers.

\section{Changes in social relations}

The preceding analysis indicates that households and institutional players are adopting new roles, and form new relationships, with the advent of smart grids. New forms of control over energy practices by 'outside' actors are resisted since they would imply a transfer of power from the households to the energy company. 
Relationships are also being reconfigured though the exchange of new information flows. This has become apparent in debates over consumer privacy that figured prominently in political discussions on the roll-out of smart meters in the Netherlands. In reflecting on the debate, an employee of a consumer organisation posited that the information disclosed through smart meters not only creates a feeling that "big brother is watching you", but also becomes a resource for providers, thereby "strengthening the control of the energy market" over its consumers. With consumers having "no choice" but to accept the new meter and the 15-min reading frequency, issues of 'choice' and 'control' thus emerged more strongly as sources of conflict.

According to an employee of a grid-operator, many institutional actors questioned the "actual privacy impacts". Considering the detailed information that can be extracted from mobile phones and internet-based social networks, the employee described smart meter information as "not very exciting".

A government official viewed the matter in a different light, arguing that the Dutch smart meter policy contained a number of "bad tastes". That is, it incorporated ideas, such as the mandatory acceptance of the smart meters, and a policy process that the official considered inconsistent with principles of "building a joint vision with stakeholders of all kinds". On the same issue, but in a different wording, an employee of a consumer organisation revolted against the "arrogant and patronising ways" in which companies and governments sometimes "interfere with people's lives". Rather than an isolated dispute, the Dutch privacy debate thus seemed to signify a wider societal discontent with governmental decision-making.

Although opportunities for disclosing information about energy provisioning to consumers have generally received less attention in the public debate, various interviewees stressed the importance of this issue. An employee of an energy provider, for instance, defined "the interests of the consumer" in a smart grid not only in terms of "insight into (domestic) energy consumption" and "having low-priced energy", but also in terms of "transparency". In elaborating on this, the employee pictured "a more active consumer" who had acquired "more insight into production and supply" and "more influence in the energy market" with the help of a wall-display.

Consumer organisations also recognised this potential form of 'counter-surveillance' by consumers. One employee remarked that consumers could significantly benefit from smart meters that measure "the spikes and dips and trends" in power supply. Another employee remarked that the improved disclosure of information about energy distribution and supply could help them to further "unravel the world of energy". 
Thus, new information flows generated in smart grids can be used for different purposes and be contested or appreciated by different actors. Information, then, plays an important role in redefining the relationships between households and energy providers by drawing attention to issues of choice, (counter) surveillance and domestic privacy and autonomy.

\subsubsection{Information flows between different households}

\section{Changes in energy practices}

The interviews and the workshops show that, along with the development of smart energy technologies, various new interactions among households are emerging. The different situations that Mr. Peters, Mr. Kuipers, and Ms. Visser describe are illustrative in this regard.

Mr. Peters explained that, some years ago, he and his neighbours used to compare annual energy bills. The timing of this routine was directly connected to the occasion that neighbouring households received their bills, "all at the same time, pretty punctual". At a certain point, when Mr. Peters's bill appeared to "stand out" against the others, this prompted a joint effort to search for options to lower his energy use. After the liberalisation of energy supply, however, he experienced that comparing energy bills became more difficult, as neighbours selected different energy providers and received their energy bills at different times.

Mr. Kuipers, by contrast, reported that he only started discussing energy matters with peers after the installation of the wall-display in his living room. The device frequently attracted the attention of visitors: "When people come over, it (the display) gets noticed." Hence, Mr. Kuipers regularly demonstrated the workings of the display to his visitors: "I think it is nice to show it to them (...) Then you turn on the TV or the halogen lamp, and you immediately see the energy use rising. Everyone is keen to see that." The wall-display thus seemed to enable and inspire new interactions among peers as a result of its direct visibility in the home.

Ms. Visser points to a slightly different possibility for peer interaction, when discussing the smart meter project that she was developing together with her colleagues at the environmental NGO. One of the software-packages being tested included "a module" to enrol participants into an "internet community". This online community would allow participants to "share experiences" and to "help each other" reduce energy consumption based on smart meter data. Smart meters thus also offer an opportunity to share information online, between peers that were not necessarily connected before. 
The workshops organised by the local energy cooperative LochemEnergie illustrated yet another type of interaction between households. The participants in this workshop agreed to strive for "a net zero energy use" for each household meaning that - in the future - local renewable energy production should fully offset domestic consumption. To measure progress towards achieving this goal, a "benchmark" exercise was initiated in which smart meters and other monitoring tools provide the means to compare energy data from the different households over time. While initially relying on fairly aggregate energy data, the participants were also considering the development of a more fine-grained system, including a "bonus" and "malus" scheme for households that do, or do not, "help to prevent peak loads in the (local) network". Administrating (individual) contributions to the prevention of peak loads would only be possible with the help of detailed monitoring data from the local (smart) grid.

These findings illustrate several, more or less distinct forms of information sharing between households in smart energy environments. Some involve direct face-to-face interactions between residents in domestic and local settings, while others encompass online interactions between widely dispersed sites and households.

\section{Changes in social relations}

The interviews and workshop series also bring to light that practices of information sharing are, to a considerable extent, shaped by existing relationships among households and between households and institutional actors.

In discussions on the smart meter project of the environmental NGO, as discussed above, the issue of 'access to smart meter data' came up as an important topic. Although Ms. Visser and her colleagues considered the online community to be "a promising system" for communication and discussion "among consumers", they decided to exclude the data-module from the project. The fact that this particular module would make "behavioural information" accessible not only to other households, but also to project partners such as the provider of solar panels, was identified as a threat to the success of the project. Although Ms. Visser stated that she did not find the disclosure of information very problematic herself - as long as one is "transparent" about who has access to the information - the possible "interference of commercial interests with domestic affairs" was deemed undesirable.

Social relations assumed a prominent role in workshop discussions by LochemEnergie as well. Participants indicated that "future generations", "human bonding", "solidarity" and "joint action" provided important grounds for them to join the workshop and to step into the energy cooperative. At the same time, this commitment to take action as 
a collective also seems to be motivated by the conviction that "public authorities and businesses fail to make progress" in terms of realising a more sustainable energy future. The workshop series, and the cooperative at large, can thus equally be understood as an effort of households to acquire a more autonomous position vis-à-vis established players in the energy sector.

Largely in line with this, an employee of a grid-operator argues that "citizens will be more independent in their energy management in the future". Interviewees from the energy sector do, however, not anticipate a future in which (groups of) citizens become fully autonomous. Instead, an employee of a service provider postulates that the "citizen-amateurism" that characterises these local initiatives, is in need of regulation and professional support: "Citizens are not going to account for grid stability. They are just going to do whatever they like; a windmill here and something there. That's not possible with an open end." In similar vein, an employee of an energy provider observes "a lack of knowledge" among non-energy sector parties, for instance regarding "the roles of the different players" in the energy sector and "the way in which information should be handled" in smart grid systems.

In sum, citizens at the local level are discovering and exploring new ways to cooperate in smart energy environments while running into all kind of social and technical issues that need to be addressed. Meanwhile, institutional players emphasise the limits to non-expert based forms of energy-governance and argue that new opportunities are opening up for institutional actors to establish functional linkages to the decentral initiatives. In this process, the governance of information flows emerges as a central concern.

\subsection{Conclusions and recommendations}

In this paper we set out to acquire a better understanding of the (active) role of households in (co-)shaping smart grid environments. We introduced a conceptual framework focusing on three categories of information flows to be used in the context of three types of relationships emerging in smart grids. The conceptual model is employed to analyse the processes through which established (carbon intensive) energy practices are being reconfigured or replaced by new, more sustainable domestic energy practices. Our empirical work highlighted some of the ways in which (Dutch) residents and providers start making use of new information flows and smart grid technologies. This is set against a societal and policy background that is supportive on the future use of smart grid technologies, without developing strong policies that are directed at the implementation and governance of new, more 
sustainable and decentralised energy configurations. Two tentative conclusions, and answers to our research questions (Section 2.2.3), can be drawn from our explorative analysis.

First, new information flows provided to households do not automatically result in the development of more sustainable domestic energy practices. The main reason for this is the fact that, time and again, existing life-world rationalities of residents turn out to be decisive for the (non-)uptake and use of new information flows. We documented instances in which residents dismiss 'smart info', for example when the information cannot readily be accessed, when it is not deemed relevant for distinctive consumption practices, or when the changes they bring do not fit into the organisation of the household. Discussions with residents also suggest that initial enthusiasm for performing smart metering practices tend to diminish over time, or can even fade away altogether. However, we also reported on instances in which smart metering was taken up by residents, setting in motion processes of change that were conceived as structural and more sustainable. A range of motivations and considerations were shown to be relevant, including saving money, creating transparency, enjoying sustainable consumption and participating in new forms of solidarity among householders.

Smart grid technologies and information flows thus do not bring about reconfigurations in domestic energy practices in linear and predictable ways. Instead, they seem to result from dynamic and situated interactions between domestic actors and 'external' actors on the one hand, and between domestic actors and new (information) technologies on the other. These findings resonate with earlier findings by e.g. Hargreaves et al. (2013b), Marres (2011) and Strengers (2013). What we add to the existing literature however, is the insight that smart grid practices of householders are shaped by their 'horizontal' and 'vertical' relationships with other actors involved in the smart energy production and consumption. Horizontal forms of energy-cooperation present a challenge to the established centralised energy configurations. Service providers seem to be aware of the need to (re)connect to these new networks in the near future. More research needs to be done on the diverse forms of centralised-decentralised collaboration and the new modes of institutionalisation of cooperative energy practices as carried out by nonprofessionals.

Second, we conclude that smart grid innovations do not only produce energy, but also new or reconfigured social relations. We documented different changes in relationships that were affected by discussions and conflicts pertaining to 
'transparency', 'access', 'privacy' and 'autonomy'. The analysis reveals that residents are fending-off some information flows to other households or energy companies, while using other information flows to build shared commitments. In the Netherlands, smart meter implementation has encountered severe resistance by (groups of) residents who defend their privacy and autonomy against what they regard as new modes of surveillance and commercial strategies of energy companies. Our research however, shows that the issues at stake are broader than privacy as commonly conceived. New social or power relations in smart grids also refer to new forms of surveillance between parents and children within the household, to forms of countersurveillance in which households gain more control over energy-providers, and to the potential for the establishment of new social ties between households in decentralised and cooperative networks. These new, often unexplored and ill-specified relationships of autonomy and dependency deserve further research.

Although the research methodology does not allow for the formulation of strong and direct policy recommendations, we would argue, based on the results, for the need to adopt a differentiated account of households, energy practices and information flows in the context of emerging smart grid configurations. Against the present state of affairs, moreover, it seems sensible for decision makers to concentrate on creating fertile conditions for the emergence of more sustainable practices, for instance through the endorsement of citizen-cooperatives and by enhancing access to advisory services. This should initiate and facilitate discussions about, and experiments with, new types of relationships between centralised and decentralised ('old' and 'new') actors, and further support promising forms of decentralised cooperation and professionalisation. 


\section{Chapter 3}

Households as Change Agents in a Smart Energy Transition:

On Power, Privacy and Participation

This chapter has been published as: Naus J, Van Vliet BJM and Hendriksen A (2015) Households as change agents in a Dutch smart energy transition: On power, privacy and participation. Energy research \& social science 9: 125-136. The publication has been edited to integrate it as a chapter in this thesis. 
$-$ 


\subsection{Introduction}

With the effects of climate change becoming ever more apparent and with economies that are still largely based on the use of fossil fuels, there is a pressing need for industrialised societies to reconsider the ways in which they produce, distribute and consume energy. As pressure has been mounting over the past decades, government bodies at different levels have formulated targets to promote a transition to a lowcarbon economy. The European Union (EU), for instance, has put in place targets to cut greenhouse gas emissions by $20 \%$ in 2020 and by $40 \%$ in 2030 (European Commission, 2014). To achieve these targets the development of intelligent energy systems, or smart grids, has been endorsed as a key strategy. Smart grids are expected to promote the utilisation of renewable energy sources and to improve energy management through detailed monitoring and intensive two-way communication between sites of production and consumption (European Commission, 2011a; Giordano et al., 2011).

Particularly notable is that in smart grid development, and in visions of low-carbon transitions in general, households are increasingly positioned as active participants with a responsibility to act as 'change agents' (Strengers, 2012). Gangale et al. (2013), for instance, observe a growing focus on 'consumer engagement' and 'consumer empowerment' in many European smart grid pilot projects. But also beyond smart grid pilots, scholars find a flourishing of - and at times increasing appreciation for grassroot initiatives in which citizen-groups themselves are promoting more sustainable ways of producing and consuming energy (Ornetzeder and Rohracher, 2013; Seyfang et al., 2013). It is therefore not surprising to find a rapidly developing body of literature around 'participation methods' (Jolivet and Heiskanen, 2010), 'consumer-inclusive innovation strategies' (Hegger et al., 2011), and the role of 'smart users' (Goulden et al., 2014; Verbong et al., 2013).

At the same time, these and other scholars are posing critical questions regarding the active and transformative role of households. First of all, notions of participation and engagement may feature as discursive frames, rather than being applied in actual practice. In a study on infrastructure planning Cotton and Devine-Wright (2012: p1) find that network operators, in spite of employing a "rhetoric of deliberative engagement", are lacking "a clear rationale and effective means to incorporate citizen perspectives". In studies on smart grid development, Wolsink (2012) and Goulden et al. (2014) note that opportunities for increased autonomy of householders and local groups are being negated by developments at regime level where established players have firmly rooted smart grids in the conventional centralised paradigm. 
A second issue of concern revolves around imagined possibilities for the 'rational' and 'effective' use of smart energy technologies in households. Wallenborn et al. (2011) and Hargreaves et al. (2013b) show that monitoring tools, in spite of the promise to increase householder control over the energy bill, are often of limited value in achieving significant reductions in energy consumption. Important reasons include a lack of prior experience with energy issues, a lack of sustained interest in energyrelated information, and difficulties and trade-offs in changing daily routines. According to Marres (2012), the observation of such barriers has given rise to the idea that domestic engagements with energy must be 'made easy'. However, this results in design choices that intentionally assign tasks and responsibilities to home automation technologies, thus requiring householders to do or change very little.

A third and final set of questions pertains to forms of public resistance against the implementation of smart meters and renewable energy technologies. Gawel et al. (2013) note that Germany, with its exemplary role in the deployment of small-scale renewable energy technologies, is experiencing growing discontent with the guaranteed feed-in tariff which is argued to increase energy bills. In relation to smart meter deployment in the USA, Europe and Australia, Hess (2014) lists a diversity of cases where public protest emerged around suspected health impacts of electromagnetic radiation, the potential for householder-surveillance by companies and governments, and the misuse of private information.

This paper seeks to contribute to these discussions by drawing up a framework for analysing householder participation and by examining how Dutch householders see themselves participating in a future smart energy system. More specifically, we investigate how the decisions of householders to participate in new production and consumption practices are shaped by social and power relations that come along with smart grid development: In what socio-technical arrangements do householders feel confident to act as change agents? And, on the other hand, in what arrangements do they run into privacy and autonomy problems that can thwart such engagements?

\section{Outline}

Section 3.2 presents the background, theoretical orientation and analytical framework. The framework discerns three energy management practices that come along with smart grid development and three social arrangements which involve different ways of distributing control over the conduct of these practices. Section 3.3 provides methodological details about the online survey and the focus group discussion that were conducted for this study. We selected a group of householders from the Netherlands who have some experience with - and understanding of - renewable 
energy generation, smart meters and new energy initiatives. The data analysis, presented in Section 3.4, revolves around the three energy management practices specified in the framework: energy monitoring, renewable energy production and time-shifting. Finally, Section 3.5 assembles and discusses the main outcomes.

\subsection{Background and theory}

This section develops the analytical framework that guides our analysis of householder participation in smart energy systems. Particular emphasis is placed upon the distribution of control between householders and other actors. In the construction of this framework, we first consider in more detail how households have come into the position of being seen as change agents (Section 3.2.1) and then show how a social practice approach informs our study of householder participation (Section 3.2.2).

\subsubsection{From 'passive' consumption towards 'active' participation?}

In the period after World-War II many industrialised countries invested heavily in the deployment of large-scale electricity grids. These state-owned networks were designed to transport fossil-fuel based electricity from centralised production plants to decentralised energy consumers, including households, thereby changing the existing paradigm in which self-provisioning was the dominant form. Over time, this has created a state of play in which governments and large-scale energy producers are responsible for system maintenance and change (Spaargaren, 2003). Households, on the other hand, were typically configured as 'passive end-users' or 'captive consumers' who are dependent on monolithic and distant energy providers (Spaargaren and Van Vliet, 2000). Energy consumption got institutionalised as a largely taken-for-granted and inconspicuous aspect of everyday life (Burgess and Nye, 2008; Christensen et al., 2013).

Though the centralised design of energy networks and the taken-for-granted status of energy consumption still characterise much of the present-day situation, there have also been significant changes from the 1980s onwards. Processes of liberalisation, privatisation and environmental activism have given rise to more fragmented, competitive energy networks with a diversity of energy providers, new intermediary organisations and new roles for households (Guy et al., 2001; Southerton et al., 2004). Households were given a choice between different energy providers and between different energy sources, and some started to produce energy on their own. Arguably, such developments yield new and more active roles for householders in systems of energy provision (Van Vliet, 2012). 
More recently, ideas around a low-carbon energy transition have inspired further change processes. For the purpose of this paper, we want to mention two here. First, in several Western European countries there has been a sharp increase in the number of citizen-led initiatives around renewable energy generation and conservation (REScoop, 2014; Seyfang et al., 2013). In the Netherlands, more specifically, estimates for civil-society based renewable energy initiatives range from a few dozen in 2007 up to nearly 500 in 2014 (Boon and Dieperink, 2014; HierOpgewekt, 2014). Second, as a largely parallel trajectory, governments and businesses in these countries have been preparing the ground for the development of smart energy systems. In the EU over 450 smart grid pilots are registered by 2014, with a particularly high spatial concentration in the UK, Denmark, Belgium and the Netherlands (JRC Project Maps, 2016). Also the roll-out of smart meters has been ongoing, with an EU mandate to have $80 \%$ of European households equipped by 2020 (European Commission, 2011a). In the Netherlands, however, there was a set-back of several years after the legislative proposal for the mandatory acceptance of the new meter was rejected by the Dutch Senate on grounds of consumer privacy protection (Hoenkamp et al., 2011).

Though citizen-led energy initiatives and government or business-led smart grid development follow rather different transition pathways, they are also bound to influence each other as they encounter the home. Moreover, it is not uncommon for citizen-initiatives to use information technologies (e.g. web-based communication platforms), nor are ideas around householder cooperation alien to smart grid development (e.g. in local micro-grids). Of particular importance here is the fact that both developments give rise to new forms of cooperation and control; householders acquire new opportunities to cooperate and share information with each other and, at the same time, they are provided with new possibilities to outsource tasks and disclose information to service providers. In line with the differentiation of horizontal and vertical forms of cooperation presented in Naus et al. (2014), we refer to these processes as a horizontal opening-up and a vertical opening-up of the household, respectively. This will be further addressed in the next sections.

\subsubsection{Participation and transformation in the domestic environment}

In analysing householder participation in systems of energy production and consumption we draw on theories of social practice (Reckwitz, 2002; Schatzki, 2002). Over the past years, these theories have received increased recognition and consideration in studies on domestic energy consumption (Gram-Hanssen, 2010; Shove et al., 2012; Spaargaren, 2011). Though significant diversity among practiceapproaches exists, there is also common ground in that they position 'social practices' 
(such as cooking, laundering and driving a car) rather than individuals, their minds or their collective norms as the central units of analysis. In doing so, practice-approaches draw attention to the social and material context of human conduct, its embeddedness in everyday life and its thoroughly shared nature.

In this paper we adopt an understanding of social practice as 'a bundle of activity' or 'an organised nexus of doings and sayings' (Schatzki, 2002). Everyday life, then, can be understood as a web of interwoven practices that are loosely or more tightly interconnected in time and space (Shove et al., 2012). Against this background, the advent of smart energy systems can be understood as encompassing the transformation of established domestic practices and the emergence of new ones in the web of everyday life (Naus et al., 2014). While acknowledging that most domestic practices that involve energy are not about energy use per se (e.g. showering, cooking) (Shove et al., 2012; Strengers, 2013), the practices being considered here (energy monitoring, renewable energy production, time-shifting) are much more explicitly about energy. We therefore refer to these practices as 'energy management practices'. ${ }^{17}$

The remainder of this section lays the groundwork for combining an analysis of energy management practices with ideas around the horizontal and vertical opening-up of the household. Three conceptualisations are important here:

The first concerns the understanding of participation in theories of practice. While participation is more conventionally associated with public involvement in political decision-making, through a lens of practice-theory it entails the participation of human 'carriers' in social practices (Strengers, 2013; Reckwitz, 2002). Such a conceptualisation not only decentres the individual, but also signifies that practices connect householders to the outside world in general, and to energy infrastructures specifically. As Strengers (2013: p56) explains: "when people participate in everyday practices that consume energy ... they simultaneously draw on and reproduce the structural features of an energy system". A key implication of this connection is that householders always 'actively' participate in energy systems, though not necessarily consciously or deliberately. Yet, over the past few decades the home has also become a more explicit site for environmental action by citizens. In a process that Marres (2012) describes as the 'domestication of citizenship', the domestic environment increasingly

\footnotetext{
17 It can be discussed whether the identified energy management practices can be understood as practices in their own right. We come back to this point in the discussion (Section 3.5).
} 
comes to function as a substitute for protest in public spaces and participation in public decision-making processes.

A second, closely connected point concerns the role of the home as a meaningful space. A present-day (western) home is commonly understood as a private space where householders determine what happens, or as privacy-theorist Solove (2008: p58-59) finds, "a castle where the individual enjoy(s) freedom from government intrusion", can find "peace of mind, cultivate intimate relationships, and engage in personal activities of self-development". The domestic environment thus provides specific social meaning to the practices that take place within it. As such, Shove et al. (2012) argues that the home can serve as a 'means of association' between practices: “Concepts of privacy and propriety are important for what happens where, and hence for the range of practices likely to be reproduced in any space" (Shove et al., 2012: p84). On the other hand, it is also clear that privacy, propriety and autonomy are not fixed needs or preconditions. The contrast between the 'private' homes of today and the pre-17th-century homes that typically consisted of large, open and multi-purpose spaces, illustrates the dynamic nature of such conceptions (Solove, 2008).

A third and final point concerns the role of meaning in the transformation of practices. In line with Shove et al. (2012), we understand transformation as the reconfiguration and withering away of existing practices and the emergence and elaboration of novel ones. While there are many ways in which (the web of) practices may change (e.g. the appropriation of new technologies, the application of new skills), this paper pays particular attention to the ways in which existing social and power relations shape the uptake of new energy management practices. The idea here is that established practices structure what is deemed logical, needed, meaningful and desirable (Reckwitz, 2002). So, an important question becomes: how do forms of cooperation and meanings of privacy and autonomy contained in established practices shape participation in new energy management practices?

These three points can be summarized as follows:

- While householders have always participated in energy systems through their practices, consciously or not, the home is also becoming a more explicit site for environmental participation.

- The dominant understanding of the home as a private and autonomous place is a pervasive but ultimately malleable social construction.

- Forms of cooperation and meanings of privacy and autonomy invested in existing practices can serve as a frame of reference for thinking about participation in smart energy systems. 


\subsubsection{Analytical framework}

Based on the previous sections, this section draws up an analytical framework that guides our empirical analysis. The framework, outlined in Table 3.1, is structured around three energy management practices (energy monitoring, renewable energy production and time-shifting) that come along with the advent of smart energy systems, and three social arrangements (private, horizontal and vertical) that correspond with the horizontal and vertical opening-up of the household. Table 3.1 also contains nine practice arrangements $(3 \times 3)$ that result from combining energy management practices and social arrangements.

Table 3.1: Framework for analysing householder participation in smart energy systems.

\begin{tabular}{|c|c|c|c|c|}
\hline & & \multicolumn{3}{|c|}{ SOCIAL ARRANGEMENTS } \\
\hline & & Private & Horizontal & Vertical \\
\hline \multirow{3}{*}{$\begin{array}{c}\text { ENERGY } \\
\text { MANAGEMENT } \\
\text { PRACTICES }\end{array}$} & $\begin{array}{c}\text { Energy } \\
\text { monitoring }\end{array}$ & $\begin{array}{c}\text { Self- } \\
\text { monitoring }\end{array}$ & $\begin{array}{c}\text { Information } \\
\text { sharing* }\end{array}$ & $\begin{array}{c}\text { Feedback \& } \\
\text { advice* }^{*}\end{array}$ \\
\hline & $\begin{array}{c}\text { Renewable } \\
\text { energy } \\
\text { production }\end{array}$ & $\begin{array}{l}\text { Domestic } \\
\text { production }\end{array}$ & $\begin{array}{c}\text { Collective } \\
\text { production* }\end{array}$ & $\begin{array}{l}\text { Large-scale } \\
\text { production }\end{array}$ \\
\hline & $\begin{array}{l}\text { Time-shifting } \\
\text { of energy use }\end{array}$ & $\begin{array}{c}\text { Domestic } \\
\text { time-shifting }\end{array}$ & $\begin{array}{l}\text { Communal } \\
\text { time-shifting }\end{array}$ & $\begin{array}{l}\text { Demand } \\
\text { control* }^{*}\end{array}$ \\
\hline
\end{tabular}

* Four initial practice arrangements (included in the online survey)

Breaking down smart grid participation into multiple energy management practices and social arrangements seems sensible given earlier research. Strengers (2013: p12), for instance, observes that "characteristics of energy systems can enrol and un-enrol householders in energy-making practices". Hargreaves (2012), furthermore, finds that resistance of householders against real-time energy displays "did not usually represent a wholesale rejection, but rather a resistance to carbon governmentality in relation to some aspects of daily practice". Finally, Solove (2002: p1129) makes clear that privacy "should be understood as part of practices, rather than as a separate abstract conception". 18

\footnotetext{
${ }^{18}$ In Solove's account 'practices' refer more loosely to customs, activities and traditions.
} 
Whilst the framework of Table 3.1 guides our empirical analysis in Section 3.4, it should be noted that this study started with the identification of four practice arrangements that we considered particularly interesting with regard to emergence of smart energy systems: information sharing, feedback \& advice, collective production and demand control (in Table 3.1 these are indicated with ${ }^{*}$ ).

After the first round of data gathering (online survey-see Section 3.3), however, we reckoned that it was more insightful and productive to position these four practice arrangements in a broader framework that could contrast horizontal and vertical arrangements with private arrangements. As such, Table 3.1 was constructed and used for the second round of data gathering (focus group-see Section 3.3).

\subsection{Methods}

For this study we combined two methods: an online survey (Section 3.3.1) and a focus group discussion (Section 3.3.2). These methods are complementary in the sense that the survey provides largely quantitative data and elicits individual responses, whereas the focus group generates qualitative data and allows for an open and interactive discussion between participants.

It was decided to purposely select householders who can be expected to have some knowledge about and experience with renewable energy generation, smart meters and energy initiatives. This alleviates difficulties involved in discussing socio-technical systems that are, for the most part, yet to be developed. It also enables the examination of participation among a group of householders that is often considered unproblematic; people for whom energy and sustainability already matters.

On the other hand, the specific backgrounds of the respondents also imply that any generalisations should be made with care. The survey data reveal that, compared to Dutch averages, there is a gender imbalance (relatively more men), a particularly high level of education, a relatively high number of homeowners and particularly high income levels (CBS, 2013). ${ }^{19}$

\subsubsection{Online survey}

The survey was circulated in August and September 2013 through announcements in three consecutive newsletters of duurzaamnieuws.nl, a Dutch website established by

\footnotetext{
${ }^{19}$ Survey respondents: $73.5 \%$ men, $43.5 \%$ university level, $81.9 \%$ home-owners, $67 \%$ over 1.5 times modal. Dutch averages: $49.5 \%$ men, $12.2 \%$ university level, $56.2 \%$ home-owners, $28.7 \%$ over 1.5 times modal (CBS, 2013).
} 
the non-profit organisation iNSnet for publishing news items and essays on a diversity of environmental issues. ${ }^{20}$ The survey consisted of 68 questions with a total of 152 items (Annex C1). Images were added to illustrate the subject matter and to help respondents envision possible energy futures. In addition to multiple-choice questions, there was room for the respondents to explain their choices. The survey generated 212 valid responses, with 171 respondents completing the full survey.

As explained in Section 3.2.3, the survey included questions on four practice arrangements: information sharing, feedback \& advice, collective energy production and demand control. Questions on these practices were divided over several items. Feedback \& advice, for instance, consists of four items assessing the openness of respondents to specific new forms of service provision, including getting assistance in making energy use transparent and receiving tailored advertisements. All constructs and items on these practice arrangements are listed in Annex C2.

Besides considering the results that individual items generated, we also examined (in SPSS) whether choices on the four practice arrangements are predisposed by privacy considerations in other domains of life. To this end two constructs, horizontal privacy and vertical privacy, were assembled which tie in with the horizontal and vertical arrangements of Table 3.1. Horizontal privacy, as a construct, consists of five preassembled items asking respondents whether they are generally open to friends and acquaintances about, for instance, political preferences and income levels. Items on vertical privacy asked respondents whether privacy is a consideration when signing up for, for instance, the digital public transportation card and the electronic health record. Both privacy constructs and their items are listed in Annex C2.

As a final step, we tested correlations between the items and constructs on practice arrangements on the one hand, and the privacy constructs on the other. To do this, every respondent was given a score on each item and, correspondingly, on each construct. ${ }^{21}$ After that, the scores of the respondents were divided into two groups; one with a relatively low score and one with a relatively high score..$^{22}$

\footnotetext{
${ }^{20}$ http://www.duurzaamnieuws.nl/ and http://www.insnet.eu/

${ }^{21}$ Internal consistency of the constructs was measured with Cronbach's alpha. The six construct used in the analysis showed sufficient consistency with alpha values between 0.5 and 0.8 (see Annex C4) (Field, 2013).

22 Whether a respondent is in the high or low score group depends on its position in the overall score distribution of the construct. While in theory this would result in two groups of equal size (rank cases: $\mathrm{n}$ $=2$ ), this is not usually the case, as possible scores are limited (e.g. between 0 and 8) and a unique score (e.g. 4) is included in one group only, either high or low. See Annex C5 for an example. Division into more than two groups would lead to group sizes that are too small to work with.
} 
Finally, 2-sided Pearson Chi-square tests were used to measure correlations between groups with high and low scores. For example, high and low scores on feedback \& advice were tested against high and low scores on vertical privacy. The procedure is schematically presented in Annex C3. Results of the correlation tests are presented in Annex C4.

\subsubsection{Focus group}

The focus group took place in April 2014 and involved 12 participants ( 8 men, 4 women) who had provided their contact details at the end of the survey. Discussions were specifically designed to validate Table 3.1 and acquire a better understanding of the different categories. The focus group included three rounds of discussion and lasted for $2.5 \mathrm{~h}$ in total. All discussions were recorded, transcribed and coded (in ATLAS.ti).

After a short introduction to the discussion themes, the researchers divided the participants into sub-groups. In round 1 each group was invited to discuss a different 'energy theme', corresponding to the energy management practices identified in Table 3.1: energy monitoring, renewable energy production and time-shifting. Each group received a number of questions to guide the discussion (Annex D): How are you currently involved with this theme? What possibilities do you identify for 2020 in terms of organising this theme? Which parties are needed for this? And what are the main advantages and disadvantages?

For round 2 the researchers introduced three 'organisational forms', analogous to the three social arrangements of Table 3.1: by myself (private), with other householders (horizontal) and with a service provider (vertical). Participants were then divided into new sub-groups, with each group including a representative of each initial group in round 1. The following questions were provided: What are the implications of this organisational form for (a) the exchange of information, (b) autonomy and control, and (c) societal involvement?

Finally, in round 3 group representatives presented the main outcomes of the subgroup discussions, while researchers and other participants were allowed to comment. To conclude the session, each participant was asked to make a final judgement regarding the most desirable and least desirable organisational form for each energy theme. The outcomes of this exercise were shortly discussed in a plenary debate. 


\subsection{Data analysis}

This section presents our empirical examination of householder participation in a smart energy transition. The analysis is guided by the framework (Table 3.1) around three energy management practices and three social arrangements. Sections 3.4.1 3.4.3 each evaluate a different energy management practice on the basis of both survey and focus group data. Rather than detailing the everyday context in which the (new) practices take place - as is more customary in practice-based research - the analysis concentrates on explicating the ways in which householder decisions to participate in these practices are shaped by social and power relations: what practice arrangements, horizontal and vertical, support their engagement in a sustainable energy transition? And what arrangements give rise to privacy and autonomy concerns that can obstruct such engagements? Section 3.4.4 examines similarities and differences between the three energy management practices. Finally, in Section 3.5 we present the main findings and reflect on the interrelations between power, privacy and practice-based research.

\subsubsection{Energy monitoring}

The survey reveals that many of the householders have already adopted monitoring practices to keep track of their own energy consumption. 95\% of the respondents read their annual energy bill. Furthermore, $26 \%$ take energy meter readings every month, while $25 \%$ do this at least every week. Other tools that householders have used for energy monitoring include a device-specific energy meter (42\%), an energy consumption test on the internet (33\%) and an energy performance advice drawn up by a professional advisor $(25 \%)$.

With this experience respondents are also eager to explore new forms of monitoring that can extend existing practices: $64 \%(+19 \%$ more tentatively) welcome the assistance of experts in sorting out smart meter data, 52\% (+28\% tentatively) are open to tailored energy saving tips, $70 \%(+15 \%$ tentatively) are positive about receiving notifications in case of unusual energy use, and $28 \%(+34 \%$ tentatively) are open to tailored advertisements. Especially consumer organisations (72\%), environmental organisations (70\%) and energy providers (58\%) seem to be in a good position to provide these services. Environmental and consumer organisations are positively evaluated for their non-profit character and their commitment to the subject, while energy providers are often seen as more familiar and capable parties. Commercial third parties (10\%) and smart meter manufacturers (18\%) are much less favoured. 
Both the survey and the focus group discussion expose that privacy, propriety and power are important considerations for householders when thinking about smart metering and new advisory practices. Among the survey respondents with an analogue energy meter $(74 \%)$, a noteworthy $32 \%$ would refuse a smart meter or has actually refused it when the meter was presented to them. These respondents express their concern about a lack of ownership over their data, the consequences for their privacy, and the fairness of new net-metering arrangements enabled by the introduction of smart meters. Respondents who are not interested in new forms of energy advice state similar things; they are afraid of being watched, they oppose the use of smart meter data "for commercial purposes" or they prefer interpreting smart meter data themselves.

Further confirmation on the importance of privacy considerations is found in the correlation tests (Annex C4) where horizontal privacy and vertical privacy both prove to predispose a householder's openness to feedback \& advice. That is, those householders who are generally more private towards friends and acquaintances (horizontal), or more private towards governments and companies (vertical), tend to be less open to new feedback and advisory practices by third parties. While the correlation with vertical privacy can reasonably be expected, the strong correlation with horizontal privacy seems somewhat counter-intuitive. A possible explanation is that these forms of privacy are mutually reinforcing. This hypothesis could not be proven statistically, however.

The focus group provided more detail but also more ambiguity to this picture. On the one hand, participants argued that householders should not be overly suspicious about information disclosure through smart meters. They felt that that, to some extent, "privacy has already disappeared" with the widespread use of social media. On the other hand, deliberations on consumer privacy surfaced already at the start of the discussion and participants agreed on the need to carefully assess and regulate the use of smart meter information. One of the participants explained:

"[Energy providers] all want to give us the impression that they are thinking along with us. . . That's positive in the sense that they are better able to see where the [energy] peaks are, so they can resolve things. But they can also see, for example, that Mr. X has been using the same hair dryer so many times that it is not working properly anymore. Then they will send him an advertisement saying: buy a new one! Surely they are going to extend the scope."

The use of smart meter information for what is considered to be a public benefit (balancing demand and supply) is thus seen in a different light than the use of the same 
information for commercial purposes. But, as one of the participants argued, even information that is intended for the public good can be detrimental to personal freedom and reputation:

"I have nothing to hide. It is just that connections will be made between different databases. That will result in a profile... For many that profile will be just fine, but for a small minority this profile will mark them as terrorists! Simply because [they can see]: here I have bought some chemical fertiliser and there I do something that requires a lot of energy."

Smart meter information then becomes part of much wider discussions on privacy and security. This embeddedness in broader societal debates not only complicates measures that try to deal with smart meter privacy in an isolated fashion, but, importantly, also suggest that energy monitoring practices are evaluated in the light of broader understandings of privacy.

Similar to feedback and advisory practices, opportunities for information sharing with other householders are initially met with enthusiasm. Many survey respondents have engaged in information sharing practices before, for instance by comparing energy consumption levels with family members (57\%) or with neighbours (34\%). It may therefore not be surprising to find that many respondents would share their energyperformance through social media, with family and friends (60\%) and with neighbours (59\%) in case they were asked to do so. Furthermore, 69\% would enrol in a local energy-saving program, while participation in an online discussion forum (51\%) or an energy saving competition (32\%) is less appealing. As opposed to expert advice, citizen-led initiatives are praised for the absence of a profit-orientation and for the possibility of "generating innovative ideas". On the other hand, they are also perceived as problematic precisely because of the expected lack of expertise, and the time and effort required to organise such initiatives. Social and spatial proximity seem to make local initiatives particularly attractive.

Largely in line with these findings, focus group participants concluded that a major advantage of information sharing practices is the fact that such practices are voluntary and "originate from the users". This is thought to take away the obligation to disclose information, as with the smart meter, and the threat of using information for commercial or administrative purposes.

Yet, in spite the positive evaluations, practices of information sharing are subject to privacy considerations as well. Correlation tests based on survey data point out that dispositions on horizontal privacy negatively affect a householder's inclination to share energy performances through social media. The specific group of peers to share this 
information with seems important here as other forms of information sharing remain unaffected by this measure of horizontal privacy.

Also focus group participants started constructing social constraints around information sharing after initial enthusiasm had settled. Illustrative is a conversation in which participants considered digital applications to remind householders of the environmental impacts of energy consumption:

Participant 1: "The ideal situation, I think, is that everyone has a [carbon] footprint [that is visualised] near the front door of their house. Then everyone can see: this is how I did today"

Researcher: "Visible for others as well or. .."

Participant 2: (laughing) "A big cross; misbehaving household!" (laughing)

Participant 1: (laughing) "No, not on the outside! No, no. Only when you enter your house... Only for yourself."

The potential for social judgement that comes along with information sharing is thus seen as an undesirable side-effect or even limiting feature to such practices, especially for those householders with a relatively high carbon footprint. It reveals that, like vertical information disclosure, also participation in horizontal information sharing is strongly influenced by ideas about what is private and what is (or should be) public.

\subsubsection{Renewable energy production}

Survey data show that participation in energy production practices is exceptionally high among respondents: $60 \%$ are engaged in domestic energy production (mostly by means of solar panels), while $14.5 \%$ participate in some form of collective energy production.

In the focus group, participants made clear that their engagement in energy production practices is strongly coupled to a desire of becoming more independent from the conventional fossil-fuel based energy system. According to the participants a decentralised system brings energy production closer to the "sphere of influence" of householders. As such, a decentralised energy system is posited as the positive counterpart of the vertically organised system that is dominant today. However, rather than functioning as a driver of change from the outset, one of the participants has experienced that the desire to become autonomous is something that needs to grow: 
"Many people, when they have started to produce, want to become autonomous ... There is a tendency [to think]: Now that I am producing my own electricity, I want to do good things with it, and I want to produce as much energy as possible on my own."

This suggests that participation in decentralised production practices can generate a process of sense-making and subsequently result in the adoption of goals of 'autonomy' or 'independence', rather than the other way around. A similar dynamic can be observed in the following example, where the installation of solar panels made one of the focus group participants reconsider the merits of its visual appearance:

"I have a few solar panels. They are somewhat more visible than I had anticipated. But now I really don't mind anymore. In fact, to be honest, I really like to show other people: I understand what is at stake here!"

The solar panels thus transformed from being something that is preferably hidden from the view to something that serves as a status symbol. The point is that ideals of autonomy, cooperation and engagement are as much shaped by participating in practices of energy production as they inspire such participation.

Furthermore, the focus group demonstrated that aspirations to become more autonomous as a household, or as a group of households, coincide with an increasingly critical view of government policies. Especially when collective energy generation is concerned, Dutch policies on renewable energy are considered to impede innovation through demanding administrative procedures and unfavourable financial incentives. A participant who has been involved in the application procedure for a collectively financed wind turbine got frustrated by the difficulties of obtaining governmental approval for the project:

"Even when you have submitted and approved everything. . .[the government argues that] the wind turbine should be light-green instead of dark-green. Then you need to do it all over again! Another six years! By the time you have a turbine up and running, the system is out-dated. 'Progressive insights' they call it. . Just go and built it!"

The Dutch government is thus thought to keep a firm grip on renewable energy development, where more freedom to develop horizontal arrangements is considered desirable.

Even though collective production practices are seen as a second best option that becomes relevant especially when it is technically infeasible or financially "not profitable or smart" to start producing energy at home, many survey respondents 
indicate that they are open to cooperate with other households in the near future. Generally, collective arrangements are valued for their affordability, the lower financial risks compared to domestic production and their "orientation towards cooperation". More critical respondents emphasise the lack of control over such an arrangement or state that they are "not the community type".

Of the three collective production arrangements set out in the survey, the local energy cooperative appears to be most appealing; 68\% evaluate this arrangement positively $(+15 \%$ are somewhat more cautious). With $63 \%$ participation in a large-scale production facility is nearly as attractive $(+17 \%$ is more cautions). Finally, respondents seem most hesitant to engage in individual arrangements with friends or neighbours; only $46 \%$ are positive towards this arrangement ( $+25 \%$ are more cautious). As regards the local energy cooperative, respondents appreciate especially the spatial proximity, the "social cohesion" that it can create and the more professional, business-like character compared to arrangements with friends or acquaintances. Others doubt the profitability, expertise and financial risks, especially compared to large-scale projects. Arrangements with friends, finally, are appreciated for the "personal contact" and the "absence of commercial interests". On the other hand, several respondents worry about conflict situations that can arise in the absence of formal rules and with "a lack of authority over someone else's roof".

More than the previous outcomes indicate, the correlation tests (Annex C4) show that horizontal privacy functions as a key concern in relation to collective energy production; respondents who are generally more private towards friends and acquaintances are comparatively less inclined to engage in collective production practices. At a more detailed level, the tests show that dispositions on horizontal privacy impede participation in arrangements with friends and in large-scale arrangements, while this is not the case for local energy cooperatives. This not only underlines the good position of local energy cooperatives, but also suggests that such local configurations provide a middle way between arrangements that are perceived either as too personal (arrangements with friends) or as too distant (large-scale arrangements). Finally, in the light of the forgoing analysis which highlighted autonomy rather than privacy considerations, these outcomes suggests a tight coupling between understandings of privacy and autonomy.

\subsubsection{Time-shifting of energy use}

Timing is key to many domestic practices that involve the use of energy. The one way in which the Dutch energy sector traditionally has been able to influence the timing of 
these practices is through the application of high and low tariffs for day and night time electricity use. In the focus group discussion, one of the participants explained how these differentiated tariffs affect the timing of her laundry practice:

"I only switch on the laundry machine at night, not during the day. . . because at night I get electricity at a lower rate."

This example illustrates a routine that has become common practice in many Dutch households. Yet, when another participant in the focus group concludes that "price" is the leading motive for time-shifting, the quoted participant is quick to explain how this routine emerged from a shared understanding of resource scarcity when she was still living at her parent's place:

"You know, back in the days we barely had any electricity at home. So for me, that is just the way things go. . I d do not really feel better or anything, but that's just the way you do it."

This demonstrates how the effectiveness of financial incentive schemes to shift specific energy practices is tied up with a context in which energy matters and in which it makes sense to do so.

Processes of sense-making are also important in the design and selection of new timeshifting technologies. The survey reveals that the prospect of new demand control strategies that could promote the use of renewables elicits mixed responses. When presented with a choice between different tariff structures $20 \%$ of the respondents select a fixed electricity price, $52 \%$ opt for multiple tariff blocks per day, and $17 \%$ go for real-time pricing. ${ }^{23}$ The fixed tariff is seen as a "no-nonsense" option that is particularly relevant for householders that cannot readily adjust the timing of consumption practices. Real-time pricing is considered most "honest" and "transparent" by proponents, while opponents construe this mechanism as "complicated", "opaque" and "a new means for the provider to make profit". Multiple tariff blocks, finally, seem to provide a practical middle ground, being more "understandable" and "manageable" than real-time pricing, while still putting householders "in a position to influence energy consumption".

Questions on the application of - and control distribution over - smart washing machines generated varied responses as well. 30\% of the respondents opt for full control over the timing of this laundry practice, $35 \%$ allow the energy provider to preselect options, while $17 \%$ allow the energy provider to decide on the timing within self-

23 The remaining $12 \%$ do not know. 
defined limits. ${ }^{24}$ Respondents who selected the 'full control' option value the "freedom of choice" or do not entrust energy providers with this task. The correlation tests (Annex C4) confirm the importance of autonomy/privacy considerations; both vertical privacy and horizontal privacy are shown to negatively affect the attribution of control to service providers.

Finally, a notable $63 \%$ of the respondents are open to the application of temporary limits to energy demand in case this fosters the deployment of renewables. Of the remaining $27 \%$ that rejected such a limit initially, 39\% would reconsider when allowed to set additional requirements. Respondents mention a wide range of requirements including the possibility to exclude times of the day or practices that are deemed "essential", an obligation to provide early notifications and "proof of environmental gains", and a guarantee to not use the mechanism "to the advantage of customers that generate most profit".

The focus group discussions provided a more contextual picture of when privacy and autonomy concerns come to the fore. Rather than considering demand control strategies in the abstract, participants conceived of such strategies as particularly sensible in reference to (future) decentralised energy systems in which the "risks and benefits are in the hands of the decentralised producer". The logic of matching demand and supply, then, is much more in the interest of the householder. Nevertheless, the participants also argued that the involvement of (centralised) service providers would still be necessary and desirable to make the system work.

One participant summarised this point as follows:

"So, on the one hand we have decentralised energy production, on the other we need centralised control of smart meters. Only in the centre you can bring all those decentralised things together. . Someone needs to know what is happening and where it is happening."

So, rather than being enrolled in a vertical model that would prioritise the goals of service providers, or in a system that would put full responsibility on householders, the participants outlined a future in which both parties share control over and responsibility for time-shifting.

While focus group participants responded positively to the idea of collectively organising timing-shifting practices, as an alternative to centralised control by service providers, they were also quick to identify a number of socially undesirable

\footnotetext{
${ }^{24}$ Of the other respondents $15 \%$ do not want smart washing machine and $3 \%$ do not know.
} 
implications. One participant illustrated the type of drawbacks that peer-involvement can elicit:

"You can also see it as an invasion of your privacy. Someone is going to meddle in. You might experience some sort of social pressure on the way you do your housekeeping."

As this can be counter-productive, the participants thought of measures to guard households against such peer-pressure. They imagined, for instance, arrangements in which "user-patterns" are only visible at an aggregate level, and arrangements in which "contributions to a common goal" are optional rather than imposed. While such privacy measures may alleviate peer pressure, they also condition the possibilities for horizontal cooperation around time-shifting.

\subsubsection{Comparing energy management practices}

The previous sub-sections have singled out specific energy management practices. Yet, the analyses already suggest that there are parallels between evaluations of different future practice arrangements. The prominence of such parallels is substantiated by the concluding focus group session in which every participant was asked to indicate, for each energy management practice, the social arrangement that he or she considers most and least desirable. Figure 3.1 presents the outcomes of this session.

What stands out most from Figure 3.1 is that, for all practices, vertical arrangements that centre on service providers are seen as least desirable. Focus group participants argued that service providers are not logical partners to cooperate with. Their goals, according to one of the participants, do not align well with a sustainable energy transition:

"As far as I am concerned, a service provider is a for-profit organisation. . .

This is primarily about sustainable energy, not about profit-making."

A sustainable energy transition, participants contended, requires not only alternative forms of cooperation but also a departure from the existing centralised system that does not allow householders to exercise much influence on the future course of development. A participant who has been experimenting with renewable energy technologies at home further illustrated this point:

"The scale of things. . has only been expanding. The consequence is that all kinds of responsibilities have been taken away from us, the people. Now, a counter-movement is emerging... We just need to take it back from the service providers. We need to take matters into our own hands again." 

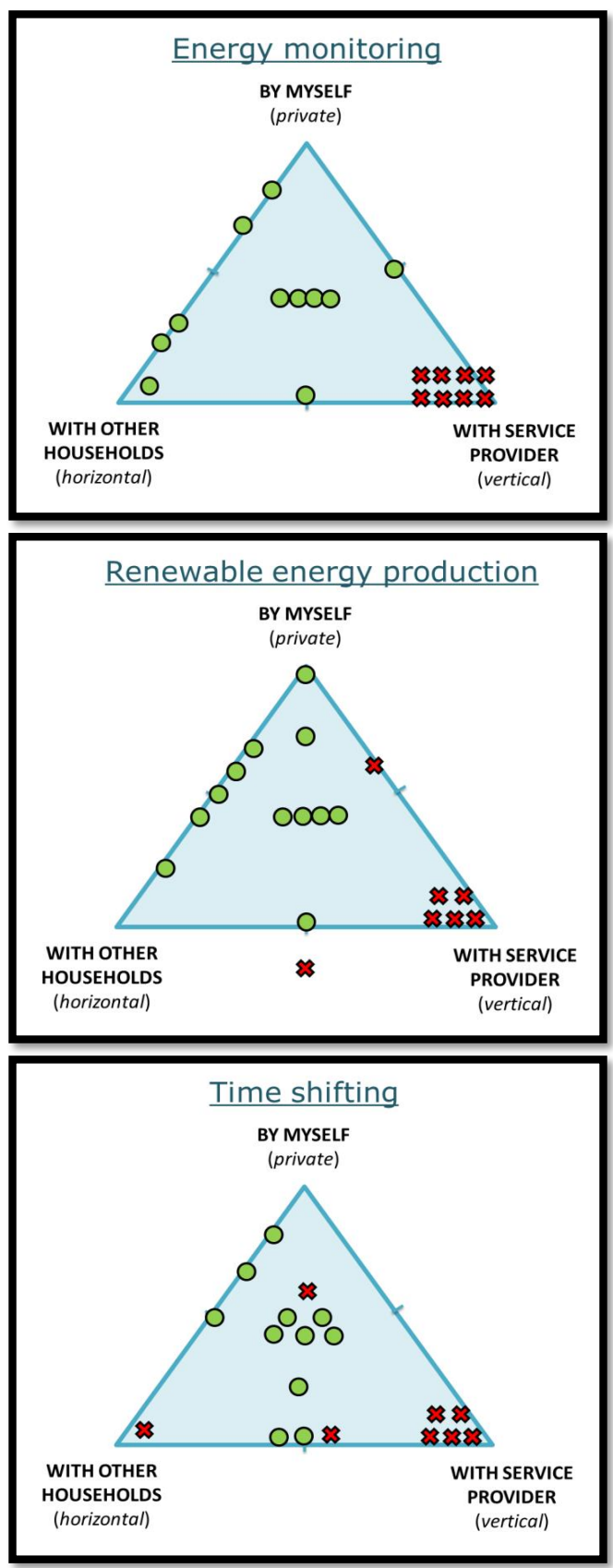

Figure 3.1: Most desirable (green dots) and least desirable (red crosses) practice arrangements as indicated by the focus group participants. (Note: each dot or cross represents a choice by an individual participant; participants were asked to make their selection in each other's presence). 
This critical stance towards conventional service providers and the search for decentralised alternatives also clarifies the more favourable evaluations of privately and horizontally organised arrangements in Figure 3.1. Though there is little agreement on the most desirable type of alternative arrangement, participants seem to be looking for arrangements in which parties share control and responsibility, rather than for more 'extreme' arrangements in which power is concentrated in the hands of private households or collectives of households.

The concentration of positively evaluated arrangements in the centre of the triangles, moreover, implies that the participants did not foresee a future in which service providers become obsolete. Instead, one of the participants anticipated a role for service providers in facilitating interchanges between households:

"For me the reason to keep considering service providers is a financial one. If you have the ambition to become energy neutral, then you need to have an element of exchange. And if you exchange, you need an institution to organise that."

Such a facilitating role, they argued, requires "another type of service provider" that better understands how to "work based on the power of people". So, rather than outright antipathy towards service providers and striving for radical autonomy, focus group participants were looking for "a new balance" that allows for more decentralised and democratic control over energy production and consumption. In thinking about this new balance the contrast between the prevailing centralised paradigm and alternative decentralised systems provided a shared frame of reference that cut across energy management practices.

\subsection{Conclusion and discussion}

The central aim of this paper was to better understand how social relations and new forms of cooperation shape the participation of householders in a future smart energy system. In doing so, we outlined an analytical framework that differentiates three emerging energy management practices (energy monitoring, renewable energy production and time-shifting) and three social arrangements (private, horizontal and vertical) that involve different ways of distributing control over these practices. To elucidate the dynamics involved in deciding on practice participation we examined the considerations and decisions of Dutch householders who already have some experience with sustainable energy practices. 
Though engagement in and interest for decentralised renewable energy production has been growing sharply over the last years, the results presented in this paper may not be representative for considerably wider groups in Dutch society. The insistence on autonomy, for instance, is unlikely to be so prevalent and consequential among other social groups. At the same time, the commitment of many respondents to environmental improvement may also have offset some privacy and autonomy concerns that would thrive otherwise. Comparisons with other groups in Dutch society, or with social groups in other countries, could therefore enrich the findings presented here.

Overall, we found that the householders that took part in this study are eager to enhance existing energy management practices with new forms of cooperation, vertically (with service providers) as well as horizontally (with fellow-householders). However, far from 'simply' engaging, it was shown how their participation in new monitoring, production and time-shifting practices is shaped, impeded or even obstructed by autonomy and privacy considerations. The survey demonstrated the significance of such considerations in relation to smart metering services and demand control strategies by service providers, and in relation to information sharing and collective energy production with fellow-householders. Regarding collective energy production, it was particularly interesting to see that local energy cooperatives provided a middle ground between forms of cooperation that are considered either as too personal or as too distant. Furthermore, the survey showed how conceptions of horizontal and vertical privacy that span multiple domains of life are employed by householders when considering participation in new energy management practices. However, there were also cases that complicated the distinctions between horizontal and vertical privacy, and second, between privacy and autonomy more broadly. Future research could further disentangle interrelations between these cross-cutting concepts and their relation to specific energy management practices.

The focus group discussion added insight into the ways in which householders construct boundaries around what is appropriate to share or co-manage with fellowhouseholders. Even though participants were clearly more inclined to cooperate horizontally than vertically, it was shown how, on second thought, practices of information sharing became subject to discussions about peer pressure, surveillance and conflict situations. The idea of sharing responsibility for balancing local energy demand and supply elicited similar reflections.

Furthermore, the focus group revealed strong connections between (desired) practice arrangements. For the participants it made most sense to think about time-shifting in 
relation to domestic or collective energy production and both centralised and decentralised energy monitoring. Moreover, largely irrespective of the energy management practice under consideration, participants agreed on the need to move away from forms of cooperation with service providers that are associated with a unsustainable and profit-oriented regime. For many participants this has been an important reason to start exploring alternative private and horizontal arrangements that are closer to their sphere of influence. As such, the analytical distinction between horizontal and vertical social arrangements proved to closely resemble the frame of reference used by participants for thinking about smart grid participation.

At the same time, the prospect of a decentralised smart energy system in which both householders and service providers assume new roles exposed the limitations of this distinction. In line with earlier findings by e.g. Wolsink (2012) and Goulden et al. (2014), this research emphasises the importance of such decentralised systems in opening up spaces for renegotiating existing relationships and finding new, more balanced combinations of private, horizontal and vertical arrangements. For households, the re-arrangement of practices in decentralised smart energy systems thus involves a multifaceted process of acquiring more control over energy production, distribution and consumption and, simultaneously, opening up to new forms of control over domestic practices by others. This underlines the context dependence and malleability of privacy and autonomy understandings as postulated by Solove (2008).

To finish, we would like to raise two points of discussion. The first concerns the match between a practice approach and the employment of survey and focus group methods. Though these methods proved to be instructive in distilling how social and power relations shape householder decisions to participate in new practices, it is also clear that such an approach operates at the fringes of what is generally conceived as practicebased research. That is, rather than taking practices as the overarching units of investigation, these methods rely to a significant extent on individual and collective viewpoints of respondents. Yet, in both cases we started from, and posed questions about, actually performed practices. Moreover, as Bartiaux (2008) shows with an analysis of large-scale survey data and Goulden et al. (2014) with a series of focus groups, there is room to explore the use of these methods to aid understanding of the dynamics of (sustainable) practices.

Second, in retrospect, the interconnectedness of the examined energy management practices elicits a reconsideration of the idea to understand energy monitoring, renewable energy production and time-shifting as more or less discrete practices. They may be better conceptualised as an emergent 'bundle of practices' (Schatzki, 2002; 
Shove et al., 2012) or as a distributed set of tasks (Gram-Hanssen, 2010) that together make up a practice of domestic energy management. An interesting line of research, then, is to examine the coupling of these practices or tasks in different decentralised arrangements. Findings in this paper suggest that engagement in renewable energy production can be a starting point for developing a context in which energy starts to matter more and in which new incentives to adopt other sustainable practices make more sense, also to households who lack the particular knowledge and experience of the participants in this study. In any case, this requires rules and forms of governance that enable rather than constrain the emergence and spreading of innovative practice arrangements. 


\section{Chapter 4}

\section{Accomplishing information and change in a smart grid pilot: linking domestic practices with policy interventions}

This chapter has been published as: Naus J and Van der Horst HM (2017) Accomplishing information and change in a smart grid pilot: Linking domestic practices with policy interventions. Environment and Planning: Politics and Space 35: 379-396. The publication has been edited to integrate it as a chapter in this thesis. 


\begin{abstract}
-
\end{abstract}




\subsection{Introduction}

Smart metering technologies have become a cornerstone of European policies that aim to reduce the climate impacts of energy consumption (European Commission, 2011a). Unlike conventional analogue energy meters, digital smart meters enable detailed monitoring and exchange of energy consumption and production data. According to the European Commission smart metering technologies should...

"Foster greater consumption awareness ... and improved customer information, in order to allow consumers to modify their behaviour according to price and load signals and related information." (European Commission, 2011b: p5)

Many scholars have questioned this logic, including those employing a practice theoretical perspective. Practice scholars have problematised assumptions that consumers suffer from an information deficit, that fact-based information provides a starting point for more rational behaviour and that heightened awareness will guide energy consumption in more sustainable directions (Halkier, 2010; Hargreaves et al., 2013b; Strengers, 2013). In response, practice scholars have drawn attention to the material entanglement of energy consumption, the routinised and conventional nature of domestic activities that involve energy use, the increasing and seemingly nonnegotiable standards of living that these activities uphold, and accordingly the complexities involved in consciously steering energy and carbon-intensive practices (Bulkeley et al., 2016b; Gram-Hanssen, 2010; Shove et al., 2012).

Yet, in emphasising complexity and in concentrating efforts on explicating the 'internal' dynamics of domestic practices, practice research has backgrounded the role of information (Shove, 2010; Strengers, 2013), while the possibilities for policy intervention have only recently become a more explicit focus of attention (Sahakian and Wilhite, 2014; Strengers and Maller, 2014). Practice scholars might thus lose sight of the potential of new information flows in bringing about environmental reform (Mol, 2006) and miss out on the opportunity to make this literature relevant to policy makers who are concerned with smart energy technologies and sustainability transitions.

The aim of this article is to explore the potential of practice theories in understanding the interrelations between policy interventions, information flows and (changes in) domestic practices. We do so through a case study of a smart grid pilot in the Netherlands where energy-information was attributed a central role. For analysing the smart grid pilot, we formulated the following research questions: When and how is information accomplished in the context of the pilot project? And when and how is 
information put-to-work in the context of domestic practices? Based on the answers to these questions, we make suggestions for the improvement of smart grid interventions.

\section{Outline}

First, section 4.2 provides a brief account of theories on information and energy consumption by contrasting a psychological perspective, as a more mainstream approach, with practice theoretical approaches. Section 4.3 introduces the smart grid pilot project and spells out the methods of data gathering and analysis. In section 4.4, we analyse when and how householders in the pilot setting accomplish and act upon energy-information. Finally, section 4.5 assembles the main findings and discusses the implications for policy and research.

\subsection{Information and energy consumption in theory}

Policy debates on sustainable consumption are typically informed by mainstream economics and psychology (Shove, 2010; Spaargaren, 2011). In the economic literature, information - or lack thereof - mostly figures as a factor that might disturb rational action. The analysis of information in the psychological tradition leaves more room for complexity. A review of the psychology of household energy conservation by Steg (2008) reveals that most of the work in psychology concentrates on improving consumer awareness and motivation through 'informational strategies' (Steg, 2008: p4450); that is, strategies that focus on information provisioning and consumer education. While traditional public information campaigns have proven to be largely ineffective, it is suggested that new informational strategies such as social marketing methods and smart meter feedback hold more potential because they allow for the tailoring of information to the needs of specific individuals or consumer groups (Steg, 2008).

Smart metering research that follows this line of investigation has been primarily concerned with the identification of the most appealing, accessible and effective consumer interfaces to visualise energy-information (D'Oca et al., 2014; Fischer, 2008; Webb et al., 2014). In focusing on informational strategies, however, psychological research may have insufficient attention for 'structural strategies' (Steg, 2008: p4450) that increase the attractiveness of adopting energy saving behaviours and the ability of consumers to enact pro-environmental attitudes and values. Structural strategies focus on the improvement of contextual factors, e.g. physical infrastructures, household income levels, laws and regulations, and the provisioning of smart products and services (Steg, 2008; Van der Werff et al., 2016). 
While agreeing on the need to bring contextual elements into the analysis, socialpractice scholars have criticised psychological accounts of behaviour change and the policy strategies informed by it. In what is labelled the 'individualist paradigm', Spaargaren (2011) has argued that awareness is a weak predictor of enacted behaviour and that individual attitudes and choices are preconfigured by systems of provision. With the term 'ABC-paradigm' (Attitude, Behaviour, Choice), Shove (2010) has criticised mainstream approaches for incorrectly treating context as a set of external variables, and for bypassing more significant questions around changing cultures of living and thinking. Finally, Hargreaves et al. (2013b) and Strengers (2013) refer to the 'information deficit model' in questioning the linear relation that is assumed between the provisioning of information (cause) and the adoption of energy saving behaviours (effect).

Practice theoretical perspectives serve as a sociological alternative for understanding the dynamics of energy consumption. Instead of concentrating on individuals and/or contextual factors, this line of investigation exposes the middle ground between agency and structure by positioning social practices at the heart of social scientific enquiry (Giddens, 1984). Reckwitz provides an often cited definition of a social practice:

"A 'practice' is a routinized type of behaviour which consists of several elements, interconnected to one other: forms of bodily activities, forms of mental activities, 'things' and their use, a background knowledge in the form of understanding, know-how, states of emotion and motivational knowledge." (Reckwitz, 2002: p249)

A practice (e.g. doing the laundry, having dinner, heating the home) thus involves a variegated set of elements which together constitute the practice. Shove et al. (2012) have suggested using a shortlist of three elements for studying the dynamics of practices: materials, meanings and competences. In our empirical analysis, we adopt this sensitivity of practices consisting of heterogeneous elements, as suggested by both authors, without pre-empting what the relevant elements might be.

Besides the specification of practice-elements, there are several other important debates on the use of practice theories. For the scope of this article, we would like to mention three. The first concerns the priority that is granted to routines. It seems that, even though the routine mode of conduct is characteristic of many domestic practices that involve energy use (Shove, 2010; Spaargaren, 2011), Reckwitz' definition of practices is overly focused on routine. In everyday life, people constantly adapt, improvise and experiment (Warde, 2005) and they move back and forth between routine and more reflexive modes of conduct (Halkier, 2010; Southerton, 2013). 
Reflexivity becomes particularly relevant of course when considering interventions, like a smart grid pilot, that are specifically designed to elicit reflection and change on the part of consumers.

The second debate concerns the role of information. It seems that the dismissal of the information deficit model in practice literature is being accompanied by a shift away from energy feedback. Instead, scholars have identified other forms of feedback that are (more) significant in consumption practices, e.g. 'social feedback' that is conveyed by friends, neighbours or family members, 'material feedback' that is built into the design of homes and devices, and 'embodied feedback' that involves sensory experiences such as smelling, hearing and seeing (Foulds et al., 2014; Strengers, 2013). More specifically, analyses have directed attention to the role of non-visual, bodily senses in getting to know new ways of doing (Wallenborn and Wilhite, 2014), and to the role of experience-based know-how in monitoring and managing domestic heat flows (Royston, 2014).

While it is clearly important to recognise multiple forms of feedback and knowledge, this move away from energy feedback may also result in a limited consideration of the potential of new information flows in transforming (the governance of) production and consumption practices (Mol, 2006; Soma et al., 2016b; Van den Burg et al., 2003). This article therefore reconsiders the role of energy-information and brings it back into the centre of the analysis. In doing so, we make two analytical moves. First, we follow Orlikowski's conceptualisation of knowledge (Orlikowski, 2002: p252) in understanding energy-information not as something that is 'out there', ready to be implemented (as in mainstream accounts of information), but as dynamically accomplished, handled and put-to-work in and through situated practice. Smart meter data, for instance, require an active engagement with the smart meter to become known as information. And second, we consider energy-information as a broader concept than energy feedback, which is associated with smart meters. Energyinformation may also result from conversation for instance.

The third debate concerns interconnections between practices. With the majority of practice-based studies, so far, being focused on the dynamics of singular (domestic) consumption practices, there has been less attention for the ways in which practices interconnect and form larger systems or configurations of practices (Macrorie et al., 2014, 2015; Spaargaren et al., 2016; Watson, 2012). There is, however, an emerging literature that is specifically engaging with this matter. This includes analyses of the ways in which consumption practices form bundles and complexes (Shove et al., 2012), analyses of the interconnections that are formed by material infrastructures like road 
networks and energy grids (Shove et al., 2015), and analyses of the interconnections between consumption practices and the steering efforts of policy makers, industries and civil society organisations (Lamers and van der Duim, 2016; Spurling and McMeekin, 2015; Strengers et al., 2015).

Discussions on steering are an important part of the literature on interconnections. A key insight in this regard is to view policy-making and planning 'as practices in their own right, and as arrangements that are part of rather than outside the ongoing flux of daily life' (Shove et al., 2015: p284). In line with this understanding of policy, we see the smart grid project as a set of intervention practices - or policy-initiated practices that stand in a dynamic relation to the domestic practices in which it seeks to intervene. Through the analysis of the pilot project, moreover, we explore the role of information flows in establishing potentially important connections between policy-initiated practices and domestic practices.

\subsection{Methodology}

The smart grid pilot project 'Intelligent grid in sustainable Lochem' (the Netherlands) (Locamation, 2011) provided an opportunity for investigating the ways in which energy-information is accomplished and put-to-work in a real-life setting. This section first describes the project in some more detail. Afterwards, it explicates the procedures of data gathering and analysis.

\subsubsection{Case description: Smart grid pilot Lochem}

Lochem is a small town (about 14,000 inhabitants) located in a rural area in the eastern part of the Netherlands. The pilot in Lochem was initiated in 2012 as part of a threeyear funding programme for smart grids by the Dutch government. The project was spearheaded by a research consortium comprised of a grid operator, two engineering companies, a technical university and a local energy cooperative. During the project, various novel energy technologies were deployed and tested, including substation automation technologies, intelligent charging stations for electric vehicles, solar energy technologies (PV) and smart meters (Locamation, 2011).

A distinctive feature of the pilot project is the central role that was attributed to LochemEnergie, a citizen-based energy cooperative established in 2011. The goal of LochemEnergie is to accelerate a local energy transition by producing renewable energy for its members (Locamation, 2011). LochemEnergie is widely held to be a bestpractice case with respect to local energy initiatives (Hoppe et al., 2015). In the pilot, 
the cooperative acted as a mediator between the households (about 125) and the other parties participating in the project.

To participate in the project, households were required to engage in decentralised energy production - either by installing privately owned solar PV panels on their own house or by renting a set of panels at a collectively owned solar park installed on top of the town hall. Households also received a smart meter to record energy data, a separate 'energy data box' to gather and process the data, and various internet-based applications to make the data accessible. This allowed householders to obtain data on domestic and collective solar energy production, as well as on electricity and gas consumption, both in real-time and over specified periods of time, e.g. days, weeks and months.

The cooperative also encouraged project participants to join two workshop series, one on the theme of 'energy conservation' and one on the theme of 'electric mobility'. The workshops were organised by the cooperative and generally took place on a bi-monthly basis at the offices of the cooperative.

\subsubsection{Data gathering and analysis}

We analyse the ways in which energy-information is accomplished and put-to-work by looking at situated performances of practices. In general, when trying to capture situated performances, it is preferable to make use of in situ observation and/or shadowing techniques (Nicolini, 2013). In this case, however, we made use of participant observation in workshops, which comprised active involvement on the part of the researcher, and second, of interviews and house tours, which largely rely on post hoc accounts of practices by individuals. We think these methods serve as a practical and appropriate alternative, when taking into account the demands of workshop facilitation, and the private setting of the home, respectively.

First, we made observations during a series of nine Workshops on Energy Conservation (WEC 1-9) in the period between June 2013 and October 2014 (see Annex E). The workshops were attended by a varying group of 6 to 18 participants, mostly but not exclusively middle-aged and senior men. In exchange for access to the workshop series, one of the researchers actively contributed to the meetings by taking up organisational tasks prior to the meetings, by facilitating discussions during the meetings, and by distributing meeting notes afterwards. For the analysis of the workshops, we relied on minutes taken during the meetings.

Second, we conducted a set of 21 interviews with householders in Lochem in October 2014. Interviewees were recruited through the workshop series and through the 
personal and professional networks of a contact person at the cooperative. While this did not allow for a rigid selection procedure, we obtained a variegated picture by interviewing Workshop Participants (WP 1-10), Project Participants who were not involved in the workshops (PP 1-7) as well as Non-Participating householders who were not involved in the smart grid project (NP 1-4). Annex F lists interviewee details. The interviews took place at the homes of the interviewees and lasted between 45 and 90 minutes. They consisted of three parts: part 1 examined (personal) interest in the smart grid project and in LochemEnergie, part 2 zoomed in on laundry, heating and lighting practices, and part 3 focused on renewable energy production, energy monitoring and electric mobility. For the second and third part, interviewees were asked to give a demonstration on site (house tour). Conversations were audiotaped and transcribed.

In a first round of analysing the interview transcripts and workshop minutes, we highlighted all passages in which energy-information played a role. In a second round, when a useful set of distinctions was found (see section 'Smart grid pilot as a configuration of practices'), the data were reanalysed and categorised. For the presentation of the findings in the next section, we selected a diversity of ways in which energy-information was accomplished and put-to-work.

\subsection{Smart grid pilot as a configuration of practices}

As can be understood from the case description, the smart grid pilot consisted of a diverse set of activities including the installation of monitoring devices, the organisation of a workshop series and an appeal on participants to change their domestic ways of doing. To consider these activities and the role of energy-information with the help of practice theories, we describe the project as a configuration of practices and specify three categories of practices that reflect the specificities of the pilot project:

- Practices in which project participants come together and interact with each other, such as workshop meetings, information evenings and demonstrations. We refer to these practices as community interaction practices. These kinds of practices are typically discussed in the literature on community energy and grass-root innovation (e.g. Ornetzeder and Rohracher, 2013; Seyfang and Haxeltine, 2012). We find that community interaction practices closely resemble the character of interaction rituals (Collins, 2004; Spaargaren, 2011) in that they involve feelings of membership as well as a mutual focus of attention.

- Practices that involve the use of energy monitoring tools, including smart meters, online applications and manual metering devices. We refer to these practices as 
monitoring practices. Such practices figure prominently as pathways for change in the mainstream literature on smart meter feedback (e.g. D'Oca et al., 2014; Webb et al., 2014) and also in the pilot project under consideration. We observe, however, that monitoring may increase a householder's knowledge of energy production and consumption without directly or necessarily effectuating change.

- Practices that involve energy use in the process of getting comfortable or getting things done in and around the home, such as heating, lighting and doing the laundry. We refer to these practices as domestic practices. Domestic practices are frequently discussed in practice-based studies of energy consumption (e.g. Shove et al., 2012; Strengers, 2013). We find that, despite the apparent obduracy of domestic practices, there are also particular situations in which energy-information contributes to change.

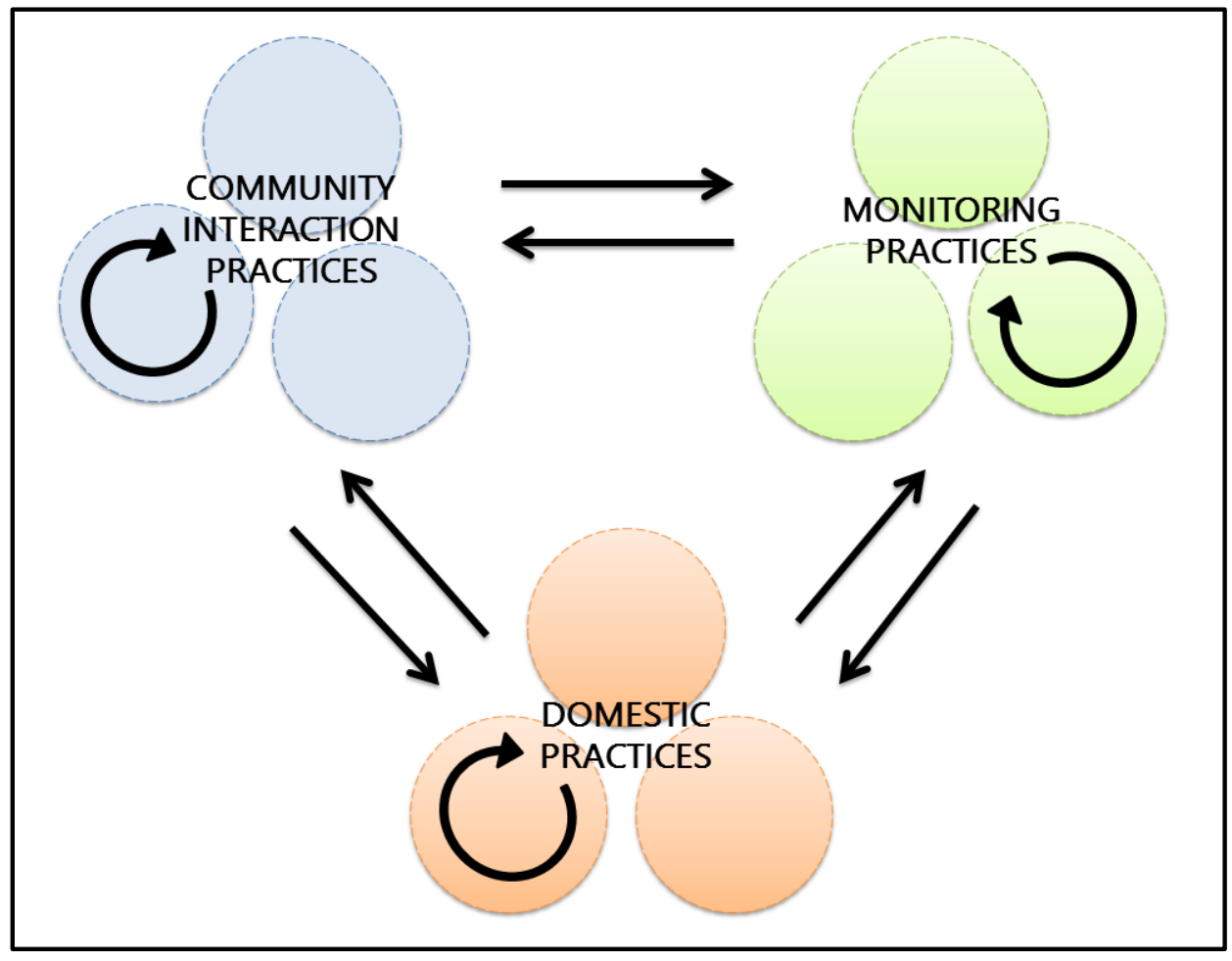

Figure 4.1: Accomplishing and using information (arrows) in relation to domestic practices, monitoring practices and community interaction practices (circles). 
The distinction between these sets of practices is necessarily a simplification of the complex array of practices taking place in the context of the pilot project. Moreover, while practices are characterised by a specific social organisation, they are not neatly bounded units (Nicolini, 2012). We have sought to account for this by formulating the categories in an open, tentative manner and by providing examples instead of strict definitions. In this sense, the distinction is as much an outcome of the data analysis as it is a starting point.

Each of these sets of practices is discussed in a separate sub-section. We start with an analysis of community interaction practices, then go on with monitoring practices and end with domestic practices. We do not want to suggest that there is a specific hierarchy or sequence in which they unfold. Rather, the analysis sheds light on the dynamic interrelations between the sets of practices. Figure 4.1 outlines how we proceed with the analysis. The circles indicate distinct practices (not practice-elements). They are grouped together with practices of the same category. The arrows indicate information flows. Information may be accomplished within a given practice, and influence its performance (the circular arrows), or 'travel' between practices and then effectuate change (the straight arrows).

\subsubsection{Community interaction practices}

The smart grid project gave rise to a variety of community interaction practices related to energy including workshops, demonstrations and symposia. Though energy functioned as a mutual focus of attention within these practices, the interviews revealed that the objective of collectivism - that is, the creation of a (sense of) community - was at least as important. Menno [WP9], one of the participants, clarified how this meaning of collectivism served as a starting point for his participation in the smart grid pilot:

"Well, the idea of a cooperative or an association is something that appeals to me. Joint responsibility for all kinds of matters, that's something I support." [WP9]

It was also with this outlook, of working together and learning from each other, that Menno and other project participants joined the workshop series on energy conservation. The workshops provided a platform to exchange data, ideas and experiences on energy monitoring and energy conservation. Workshop sessions usually started with a round of updates on the smart grid project and the energy cooperative, then continued with various discussion topics related to energy 
conservation, and ended with a drink. On some occasions, an energy or ICT expert was invited to provide extra information or assistance.

In pursuing the goal of energy conservation energy data and factual information were given particular prominence. This is most clearly indicated by the catchphrase to measure is to know is to save energy' [WEC3, WEC9], which was recurrently articulated during the workshop series as a rationale for monitoring energy consumption and production.

Energy data also played a central role in several workshop exercises. For the 'energy benchmark' [WEC1], for instance, participants were asked to report on variables such as yearly electricity use, average room temperatures and distances travelled by car. The benchmark allowed participants not only to compare energy use among each other, but also to keep track of progress towards the eventual goal of 'energy neutrality' [WEC1]. For a second workshop exercise, two of the more technically competent participants experimented with measurement tools at home to consider ways of reducing 'stand-by consumption' [WEC2]. The tests comprised several smart meter applications and a selfassembled manual tool that allowed for device-specific measurements. In reporting back to the group, the experimenters advised the others to examine all their domestic appliances in detail, to remove old electric rechargers from the sockets, and to install time-switches on appliances where possible [WEC4].

While energy data were clearly vital in these exercises, closer inspection reveals how meanings and materials implicated in domestic practice shaped the actual accomplishment of energy-information. Comfort expectations, for instance, functioned as an important condition to the central goal of energy conservation. Even though one of the participants initially criticised society's 'energy addiction' [WS1], there seemed to be a consensus on the dual goal of 'raising comfort levels, without using more energy' and/or 'maintaining comfort levels, while reducing energy use' [WS4]. For the calculation of stand-by consumption levels, furthermore, there was agreement on including all electric devices that are 'not really necessary' (e.g. TV's) and excluding all 'essential devices' that cannot be conveniently switched off (e.g. refrigerators) [WEC4]. Workshop participants thus established shared rules on how to approach the problem of energy saving, using elements and understandings of domestic practices as a point of reference.

In some cases, energy-information that was accomplished in the workshop sessions travelled to domestic practices; Menno [WP9], for instance, pulled the plug of the heating system after this was discussed as a way of reducing stand-by consumption during summer; and Carolien decided to switch from electricity to petrol when driving 
her hybrid car at high speeds, after learning that this is a more energy efficient way of driving. In these cases, energy-information took the form of hands-on lessons that could be applied with only small adaptations in (domestic) practice.

It was much harder to discern more demanding reconfigurations resulting from the workshops in such a direct and concrete manner, and workshops did not always result in directly usable energy-information. After a couple of sessions, for instance, participants experienced that the energy benchmark provided little more than an initial impression of the differences between households [WEC6]. As a consequence, the benchmark slowly moved to the background of the workshop and did not appear to inform any of the observed changes in domestic practices.

Unlike the workshop series, energy-information did not assume an important role in other community interaction practices related to the pilot project. Instead, events like the opening of the collective solar park on the town hall, a symposium on sustainable energy at the local church and a demonstration of electric vehicles at the marketplace were primarily directed at the creation of a (sense of) community and the recruitment of new participants for the cooperative and the smart grid pilot. Occasionally, nonetheless, energy-information would be accomplished as a kind of by-product. Tessa [NP1], for instance, who was more interested in local affairs than in energy matters per se, picked up the notion of energy neutrality at a symposium organised by LochemEnergie. Later, she used this notion of energy neutrality in an effort to convince her landlord of the benefits of installing solar panels on the roof of her rental house. This case not only shows how energy-related information can be accomplished without energy data but also that participation in community interaction practices does not have to start from a clear interest in energy.

Last but not least, energy-information and efforts to reconfigure domestic practices also emerged from informal interactions between project community members. This is apparent in the case of Sophie [PP1]. When she moved to Lochem, a few years ago, the energy cooperative initially functioned as a conversation topic that allowed her to bond with her new neighbours who were actively involved in the cooperative. However, through these conversations, she also developed a keen interest in local cooperation and small-scale renewables:

"It's so nice that everything is so close. You know, an offshore wind turbine is very far from the world you experience. But these little cars in the street and all the neighbours with solar panels on the rooftops...Then it also becomes much more tangible." [PP1] 
The fact that energy came to play a more visible and meaningful role in her life, also resulted in efforts to reconfigure domestic practices for instance laundry practices (as shown in 'Monitoring practices' and 'Domestic practices' sections).

In sum, this section has illuminated how community interaction practices produced new collective meanings around energy, how the workshops in particular inspired monitoring efforts, and how the participants accomplished useful as well as useless energy-information for reconfiguring domestic practices. It is also apparent that this is not a one-directional flow of information travelling from community interaction practices to monitoring practices and domestic practices, but a multi-directional flow in which there is no clear starting point (Naus et al., 2014). The next two sub-sections further explicate these interconnections.

\subsubsection{Monitoring practices}

Next to community interaction practices, the smart grid project initiated and promulgated monitoring practices. There were strong connections between both types of practices. To join the workshop exercise on stand-by consumption, for example, workshop participants had to use various smart meter applications. Thomas [WP1], who was an active participant in the workshop series, prepared a number of graphs based on the smart meter data that he had gathered in an effort to lower stand-by consumption:

"From here onwards it [the line] is quite stable. So that is the old situation. And here... [the line drops]... I went to find out what is still on stand-by; for instance, the cordless drill that is constantly recharging, while I am only a hobbyist, so I don't use that thing very often (...) And then an alarm clock somewhere in the boys' room, while they only stay overnight for two days a year. That's the kind of silly things you find out about." [WP1]

Monitoring practices thus resulted in a one-time effort to lower stand-by consumption. In the case of Jasper [WP2], monitoring practices rather resulted in the establishment of a new energy saving routine. After making an inventory, he installed switches for several groups of stand-by devices, which allowed him to conveniently switch off all devices in the evening. In both cases, the performance of monitoring practices, and subsequently, the lowering of stand-by consumption followed more or less directly from participation in the workshops.

Monitoring practices could also be performed relatively separate from the workshops. The daily monitoring routine of Floris [WP3] started long before the start of the workshop series, while Carolien [WP10] continued to carry out monitoring practices 
after she had lost interest in the workshops. Both Carolien and Floris, however, remained closely involved with the energy cooperative in other ways, suggesting that community interaction practices were still important in sustaining monitoring practices.

Regardless of the linkages between the workshops and other community interaction practices, monitoring practices comprised a variety of meanings, emotions and objectives. In the cases of Carolien, Floris and Peter, monitoring routines were not only geared towards energy conservation as such, but also towards sustaining a feeling of control and an ability to explain energy consumption patterns. Carolien [WP10] accessed smart meter applications on a daily basis to check for any 'deviations' from the 'fixed patterns' that she would normally encounter. In case of an unusually high peak in energy use, she would try to find an explanation:

"This one, for example (...) How is this possible? That's Tuesday, the full day, but ... reasoning backwards... my husband has been working until very late on Monday. He returned after midnight, connected the car to the grid ... Aha! And Tuesday he got home rather early. So that means we are recharging two times on one day. So that's how you reason back, so you can at least explain that peak." [WP10]

On some occasions, this information was also put-to-work, for instance, when Carolien asked her husband to shift the recharging routine towards daytime.

Also in the case of Floris [WP3], monitoring practices contained a variety of goals. First and foremost monitoring served as a method for keeping track of changing energy patterns throughout the years:

"Ever since we have the solar panels, that's two and a halfyears by now, I write down the meter data. I think that's pretty exceptional. I have almost 1100 meter readings by now (...) To measure is to know, right? Maybe it's a bit of a tic, but it's also quite funny." [WP3]

Next to the measuring and the knowing, which appear as goals in their own right here, the daily meter readings allowed Floris to keep a check on his energy bill and to occasionally show other people how much energy is really needed for living a comfortable life. It seems plausible to suggest that these kind of orientations become particularly significant in relation to community interaction practices, like workshops, where energy-related knowledgeability is a key competence and where the logic of 'to measure is to know (is to save energy)' is actively promoted. 
Finally, in the case of Peter [PP7], who was less involved in community interaction practices, monitoring practices were largely free of energy conservation goals. Instead, monitoring primarily served as a way to check upon the proper functioning of the rooftop solar panels:

"Sometimes I am afraid that they [the solar panels] are not working. If there is a wrong switch or if a fuse has blown out, they are simply not working, you know." [PP7]

Thus besides (positive) desires to save energy or to show competence, monitoring practices may also come along with more negative states of emotion.

Monitoring practices did not take hold in all cases however. Sometimes (initial) performances seemed to generate insufficient amounts of emotional energy for recurrent performance (Spaargaren, 2011); in other cases, monitoring practices were quickly discarded as too time-consuming or too complicated. In the case of Sophie [PP1], however, there was more at play than a lack of time and competence. While she had initially engaged with monitoring practices to align domestic laundry practices with collective solar panels on the town hall, this exercise became meaningless when she found out that there was no financial gain for her, as opposed to her neighbours who installed solar panels on their own house:

"Then I see I've used 5000 kilowatts. But most importantly it [the application] shows: Electricity returned to the grid; zero! Because I am not producing any energy myself, I also can't return anything to the grid. So, then I think, that information isn't very useful either. The most important difference, I think, is that I haven't become my own little energy source." [PP1]

This example demonstrates how the emergence and configuration of monitoring practices is intertwined, not only with community interaction practices and domestic practices but also with the configuration and logics of smart energy infrastructures (Bulkeley et al., 2016b).

In short, this section has explicated concrete instances of energy conservation as a result of monitoring practices. It has also revealed that engagements with monitoring were rather diverse, and that monitoring practices contained multiple meanings, emotions and objectives; feelings of being 'in control' and competences of understanding energy patterns can be just as relevant to monitoring practices as energy conservation objectives. This is important because it implies that energyinformation is not necessarily geared towards change. The final section takes up this 
multiplicity to further explicate both successful and unsuccessful attempts to reconfigure domestic practices.

\subsubsection{Domestic practices}

As compared with monitoring practices and community interaction practices, the first thing that stands out when considering domestic practices is the marginal role of energy-related information. Generally, energy seems to play an explicit role only when it comes to clearly noticeable deviations from long-established social conventions on resource efficiency and wastage, for instance, running a laundry program with just a few pieces of laundry, leaving the doors open on a cold winter's day or leaving the lights on in rooms that are not being used.

Rather than explicit conscious accomplishments of information, routine performances of domestic practice appear to be guided by implicit, bodily and sensory accomplishments of information (Strengers, 2013; Wallenborn and Wilhite, 2014). It is unsurprising, then, to find that domestic practices are typically geared towards implicit 'questions' like: Do I feel warm and comfortable? And, are all the devices and lights working properly? For David [NP3], the answers to such questions serve as a kind of shorthand for knowing that 'things relating to energy' are functioning as well. When functioning properly there appears to be no reason to start monitoring energy use or to change established ways of doing:

"We simply live here and, in my opinion, we use electricity and energy where we need it (...) I think I am a rather average householder who behaves properly, who uses the shower, who watches TV, who keeps his house warm and so on. No particularities or specific targets or whatever." [NP3]

This example alludes not only to the inconspicuous nature of energy consumption in everyday life but also to the normative character of community interaction practices and interventions like smart grid pilots. In portraying himself as an 'average householder who behaves properly', David indirectly referred to his uncomfortable encounters with members of LochemEnergie, who had repeatedly asked him to join the cooperative. He had turned down these membership offers; however, being wary of 'fights over energy bills' with his neighbours, and questioning the need for introducing new energy objectives at the household level [NP3].

Yet, even when householders welcomed the cooperative and the smart grid project, the integration of energy-related objectives into domestic practices was frequently unproductive or prone to reconsideration. The laundry practices of project participants are interesting in this regard. In the case of Hendrik and his wife Wilke [WP4], laundry 
practices remained untouched in spite of Hendrik's active participation in the workshops and Wilke's observation that team members at the sports club seemed to wash more efficiently, given that their originally white t-shirts were getting grey. Wilke, however, did not want to mix all kinds of laundry just to save energy. Instead the fabrics, the cleanliness and the whiteness of the laundry continued to function as the primary forms of 'feedback' in determining the course of action.

In the case of Sophie [PP1], attempts to reconfigure conventional ways of drying the laundry were regularly compromised by situational constraints, like unfavourable weather conditions or by the prospect of having guests coming over for a visit:

"This is dramatic of course, a dryer. I do use it, as in winter times you often have no other option. [But] mostly I try to dry outside or in a heated space (...) In the summer I rarely use it, unless, you know, if you have a house full of guests and then new guests are coming and you can't...well...the weather is bad, and you cannot hang it outside, and it has to be clean right away." [PP1]

Performances of laundry practices were thus constantly adapted to the specific 'demands' of the situation. Accordingly, some performances were more energyintensive than others.

In the case of Carolien [WP10], laundry practices were more reliant on the willingness of other family members to follow the new time-shifting strategies that she introduced. While her husband was usually quite willing to cooperate, her children would oftentimes resist her requests to shift their laundry practices to other times of the day:

"Sometimes my kids go crazy, haha! Then I tell them: now the sun is shining; switch on the laundry machine, because it's profitable right now! [The children would reply:] Well, I will decide for myself when to switch it on!" [WP10]

Together these three examples indicate that the dynamics of laundry practices are to a significant degree independent from enrolment in a smart grid project. Instead, efforts to reconfigure these practices proved to be subject to cooperating or counteracting household members, to collective meanings embedded in specific practices (e.g. whiteness, cleanliness), and to the wider time-space organisation of everyday life (Shove et al., 2012).

Yet, in spite of abundant difficulties in reconfiguring domestic practices, there were also concrete instances of change in which accomplishments of energy-information played an important role. The case of Hendrik and Wilke [WP4] is particularly interesting, because it illustrates how energy-information becomes intertwined with several forms of feedback originating from domestic practices. First, Hendrik and Wilke decided to 
replace various doors and windows in their house. This replacement occurred to them when Hendrik detected a defective window on the first floor. In further contemplating the replacement several memories and experiences came to their mind: they had sensed that there was an uncomfortable draft coming through the back door in winter times; they had experienced that it was difficult to take out their bikes through the narrow door in the garage; and they concluded that the hinges, locks and frames of the doors were getting out-dated. In the decision to install new doors and windows, then, various things came together: bodily experiences of cold drafts, social understandings of fashion and workshop practices that brought energy-conservation into focus.

The 'coincidental' character of change was even more apparent when Hendrik and Wilke started switching off the water boiler after showering to reduce stand-by consumption. Rather than starting from Hendrik's participation in the workshops where this issue was discussed, this process was set in motion when suddenly there was no hot water for showering anymore. When a mechanic found out that someone had accidentally hit the switch below the boiler - they did not know that the boiler contained a switch - Hendrik was reminded of the workshop where a participant had talked about installing a time-switch on the water boiler. So in this case energyinformation that was accomplished in the workshop became relevant only when something unexpected occurred that disrupted domestic practice.

In sum, this section has drawn attention to the routine character of domestic consumption practices (Spaargaren, 2011), the normativity involved in challenging such practices (Halkier, 2010), and the limited scope and partial character of change at times. On the other hand, it has shown how, in spite of the many complexities, new accomplishments of energy-information in policy-initiated practices can be decisive in specific instances of change.

\subsection{Conclusions and recommendations}

This article set out to acquire a better understanding of the role of energy-information in changing energy and carbon-intensive ways of living. For our analysis, we have adopted a practice theoretical perspective. This has allowed us to dismantle the linear logics implied in the 'information-deficit model' that guides many policy debates on behaviour change but also in the catchphrase 'to measure is to know is to save energy' that figured prominently in the smart grid pilot that was examined. As an alternative, we have explored a dynamic, practice-based understanding of information and intervention. Based on the analysis, we can formulate a number of conclusions and recommendations. 
First, we follow Macrorie et al. (2015) and Shove et al. (2015) in arguing that it is instructive to see interventions, such as the pilot of our study, as part of a configuration (or: system) of heterogeneous practices. In our case study, we distinguished between community interaction practices, monitoring practices and domestic practices and we treated them with the same practice analytical gaze. By doing so, we avoided positioning domestic practices at the receiving end of information flows. Instead, we showed how information was accomplished 'within' each of these practices, how information sometimes travelled between practices, and how in other instances information remained relevant only within the context of the practice in which it was accomplished (see Figure 4.1). In turn, our analysis exposed the need for a fuller consideration of the role and potential of energy-information in effectuating change. Rather than viewing in-home displays as the sole site for receiving energy feedback, future research on smart grid interventions could trace how energy-information is accomplished and put-to-work within a variety of practices and as part of larger configurations of practices.

Second, we argue along with Strengers (2013) and Hargreaves et al. (2013b) that, for energy-information to have an impact, energy first needs to be meaningful to householders. In the pilot we studied, energy-information appeared to be accomplished only when energy (or energy data) had some prior significance, for instance, due to an early engagement with solar PV or due to a professional interest in information technologies. When this kind of significance was absent, people did not accomplish energy-information in the first place and 'simply' went on with their lives.

Other practice-inspired studies of smart grid development have already suggested that energy can be made more meaningful by supporting on-site energy production, storage and use (Bulkeley et al., 2016b; Strengers, 2013) and by involving users in the development of shared visions of a sustainable energy future (Nyborg and Røpke, 2011). This article adds the insight that community energy initiatives can do the same. It seems unlikely, for instance, that monitoring practices and efforts to change domestic practices would have been so widespread without the organised and more spontaneous encounters between members of the project community. Clearly, this does not mean that community initiatives are a panacea or can be instigated at will (Heiskanen et al., 2010; Naus et al., 2015; Seyfang and Haxeltine, 2012). We showed that community practices may well run into normative resistance of householders who are unconvinced of the need to cooperate with their neighbours or to change their ways of doing. So, while there are good reasons for policy makers and project developers to further explore the possibilities of local embedding through cooperation with 
community energy initiatives, such a strategy may not necessarily take away the risk of resistance.

Third, we suggest that intervention programs could be (more) attentive to the multiplicity of meanings and objectives embedded in practices that are primarily initiated to generate energy-information and change. We showed that engagements with monitoring practices and energy conservation workshops were quite diverse, and that these practices were not only geared towards lowering energy bills or reducing carbon emissions; goals to increase energy-related knowledge and to enhance social cohesion between community members proved to be just as significant. In initiating monitoring practices and in organising community interaction practices, then, it seems important to provide room for multiple objectives and meanings, while at the same time sustaining a focus of attention on the reconfiguration of energy and carbonintensive ways of living. Further research on the multiplicity and layering of 'teleoaffective structures' (Schatzki, 2002: p80) in practices might help in this regard.

Fourth and final, we conclude that the effects of newly accomplished energyinformation are to a large extent determined by the existing organisation of domestic practices. In our analysis, successful attempts to put energy-information to work appeared to be comprised of those measures that could be fitted into the existing order of things relatively easily. We explicated, for instance, how new off-switching routines were integrated into daily practices, how laundry practices were shifted in time, and how old doors and windows were replaced by new ones. Yet, when changes interfered too much with, for instance, social conventions (e.g. cleanliness of the laundry), interpersonal relationships (e.g. between parents and children) or with other practices that demand time (e.g. having guests over) attempts would either fail or the 'information' would not be considered useful in the first place.

The fact that pathways of development, including ideas about what is possible and desirable, are (strongly) prefigured by existing configurations of practices is wellestablished in the practice literature (Schatzki, 2002; Shove et al., 2012; Spaargaren, 2011). Given the non-revolutionary character of the changes that were observed, it is unlikely that smart grid interventions will deviate from this. Yet, while large-scale reductions in the carbon or energy-intensity of domestic practices seem improbable in the short term, we think there is significant promise in policy strategies that see these interventions as part of a longer term trajectory in which new opportunities and ideas for change open up along the way. In any case, it is advisable to make use of strategies that target practices, their elements and their interconnections, instead of individuals (Spurling and McMeekin, 2015) and to monitor changes in their composition over time. 


\begin{abstract}
-
\end{abstract}




\section{Chapter 5}

Governing by Practices:

A practice-based approach

to sustainability transitions in smart grids 


\subsection{Introduction}

The development of smart grids features as key strategy for achieving climate targets and for realizing a transition to a more sustainable energy system. From a system perspective smart grids are typically seen as an enabler, or an infrastructural "backbone" (European Commission, 2011a: p2) for the widespread deployment of distributed renewables, fine-grained energy monitoring practices and local demand and supply matching programs. Yet, when engaging with this kind of innovation strategies, it becomes increasingly important to develop a better understanding of decentralised and domestic processes of change (Verbong et al., 2013; Wolsink, 2012) in addition to the strongly systemic understandings of energy transitions prevailing in academic literature and policy discourse (European Commission, 2011a; Geels and Schot, 2007). Following other scholars (e.g. Geels et al., 2015; Hargreaves et al., 2013a; McMeekin and Southerton, 2012), we suggest in this paper that practice theories can help to fulfil this demand for conceptualising decentralised sustainability transitions ${ }^{25}$ by connecting systemic changes with the dynamics of everyday life in and around households in a non-individualist manner.

This paper has two core aims. First, it will outline a conceptual framework for analysing sustainability transitions in decentralised smart energy systems ${ }^{1}$ that builds upon a social practice approach. Second, on the basis of this conceptual framework the paper seeks to inform future smart grid policies and discourses.

\section{$\underline{\text { Outline }}$}

Section 5.2 provides a brief discussion of transition research and transition policies to date. It also explicates the argument that the emergence of decentralised smart energy systems requires a new approach to sustainable energy transitions. In Section 5.3 we develop our conceptual framework. It defines and attributes a central role to so called Home Energy Management-practices (HEM-practices) which emerge, we argue, at the interface between the home and the energy grid. We provide some examples from the energy transition in the Netherlands to show that the use of this conceptual framework can enrich the discussion on the governance of decentralised energy transitions. Finally, Section 5.4 summarizes the main arguments and formulates key points of interest for policy and research.

\footnotetext{
25 As used here, the term smart energy transitions refers to different energy sources and functions, including electricity consumption and the (co)production and use of renewables, the use of natural gas, cooling and heating, showering, energy saving and energy storage.
} 


\subsection{Energy transitions in theory and (policy) practice}

Energy transitions are being pursued worldwide for the intricate linkages between energy consumption and climate change. In the European Union agendas on climate change and security of supply have been particularly important in establishing energy as a political priority (Nilsson, 2012). Even though firm targets have been put in place, it is still largely unclear how these are going to be achieved, especially the long-term targets of 2030 and 2050. This section sketches key developments, achievements and some deficiencies in transition policies and related research. An assessment of policies and research regarding the energy transition serves as a background to the next section, which looks more specifically into the role of smart grid development in the context of the energy transition.

An energy transition describes a process of systemic transformation involving fundamental changes in the organisation and design of the centralised, carbonintensive paradigm that is dominant today (Verbong and Loorbach, 2012). In debates on the energy transition there is explicit reference to the need to shift towards an energy paradigm that is more sustainable or climate friendly. This objective is also anchored in national and international policy in the form of long-term targets. The European Union (EU), for instance, has adopted climate and energy targets for 2020, 2030 and 2050, expressing progressively higher ambitions to reduce greenhouse gas emissions, to implement renewable energy sources and to improve energy efficiency (European Commission, 2015b). ${ }^{26}$

As for the scientific studies of (energy) transitions, considerable headway has been made since the 1990's. In our view, these studies have been successful in delivering a number of key insights on the dynamics of transitions. First, transitions are of a sociotechnical nature, indicating the fact that technological innovation and social change are inextricably linked through a process of co-evolution. Second, transitions are multiactor (state, market, civil society) and multi-level (niche, regime, landscape) processes, with special prominence for (market-)innovation at the niche level. And third, transitions can follow different transition pathways (transformation, reconfiguration, technological substitution, de- and re-alignment) which vary with respect to the speed, timing and profoundness of change.

\footnotetext{
26 The European Union has agreed upon a set of binding climate and energy targets for 2020 for 2030 $20 / 40 \%$ cut in greenhouse gas emissions, $20 / 27 \%$ energy from renewables, $20 / 27 \%$ improvement in energy efficiency, respectively (European Commission, 2015b).The ecological dimension should always be discussed in relation to the social and economic dimensions.
} 
For the Netherlands, it can be stated that transition policies and research have shown the relevance of a well-organised and well-funded program of change, involving widespread stakeholder dialogue in the context of explicit and intensive efforts to improve the governance of the energy transition (Kemp, 2010; Kern and Smith, 2008; Van der Loo and Loorbach, 2012). A wide range of so-called transition experiments made it possible to identify a diverse set of transition pathways, while also enhancing awareness about the need for an energy transition and the formulation of a clear set of long-term climate targets (Grin et al., 2010; Geels et al., 2015; Rotmans, 2012; Spaargaren et al., 2012). As a result, transition theories nowadays seem well equipped for analysing historically shaped patterns of change that are guided by a set of normative end-goals and that involve large numbers of actors operating at different levels of organisation (Verbong et al., 2013). Next to positive learning transpiring within policy and research, the Dutch transition experiments also generated knowledge on the shortcomings of transition policies, one of the most important critiques being the neglect of the social dimensions of the energy transition (Laes et al., 2014). In particular, only limited attention was paid to lifestyle changes on the side of end-users and the democratic involvement of citizens in decision-making procedures (Hendriks, 2008; Kern and Smith, 2008; Rotmans, 2012). As a consequence of this, a deficient understanding of social dynamics at the 'demand-side' of energy systems seems to persist (Verbong et al., 2013). Notwithstanding the load of social science studies indicating their shortcomings and ineffectiveness (Geels et al., 2015; Shove, 2010; Van der Loo and Loorbach, 2012), conventional methods of persuading and encouraging consumers through communication or financial incentives still reign in energy politics.

For a better understanding of the social dynamics at the demand side of energy systems, we argue that theories of social practices can be of great help. In line with earlier practice-theoretical accounts of social change (e.g. Schatzki, 2011, 2016a; Shove et al., 2012; Spaargaren et al., 2012, 2016) we elaborate in what ways householders and other decentral actors can be linked to energy transitions in a more specific, direct and analytically visible way.

When developing our practice-theoretical view of smart grid configurations, we build on the recommendation by McMeekin and Southerton (2012, p356) to develop "stronger conceptualisations of interdependencies between production and consumption processes", and in particular conceptualisations of the "nexus of practices" that occupies this in-between space. Second, we follow up on the propositions made by Geels et al. $(2015, \mathrm{p} 10)$ that both practice theories and transition theory can do more to address "the role of politics and power" as well as "the 
directionality of transitions". So what we try to establish in the end is a practice theoretical account of transitions in decentral energy systems which is sensitive to issues of power and responsibilities, connects energy production with energy consumption, and makes conceptual space for analysing the directionality - e.g. the orientation on sustainability - of different pathways of change.

In developing our conceptual framework in section 5.3, we take practices as the primary units of analysis. At the same time, we draw upon transition theory when elaborating two aspects that we consider to be of central importance for the energy transition: transition goals and transition pathways.

\subsection{A conceptual framework for smart grid transitions}

This section uses practice theories as starting point for analysing processes of social change in decentralised smart energy systems for three key reasons.

First, in theories of practices, individuals are approached not as rational decisionmakers or norm-followers, but as knowledgeable and capable participants in historically constructed and widely shared practices (Giddens, 1984; Nicolini, 2012). Even though individuals do matter in the reproduction of social life, the analytical focus within practice theories is not on individuals and their values and preferences but on bundles of organised activity (Schatzki, 2002) made possible by the instantaneous interplay of agency and (social) structure (Giddens, 1984). So by using practice theories as the basis for our conceptual framework, we depart from mainstream governance approaches that work with an analytical separation between individuals and 'context', and that take the decision-making of individuals as starting point for analysing social change (Shove, 2010; Spaargaren, 2011).

A second relevant aspect of social practice theories is their emphasis on materials, technologies and infrastructures as important elements co-constituting the social. This assumption of the social and the material being inherently interwoven, is one of the points that practice theories have in common with transition theories and Actor Network Theory (ANT) (Latour, 2005; Schatzki, 2016b). Because practices always go together with material arrangements, Schatzki suggests using 'practices-arrangement bundles' as the correct term for defining the units of analysis in practice theories (Schatzki, 2016b). We do concur with Schatzki's concept of practice-arrangement bundles and his assumption that analyses of social practices cannot and should not go without simultaneously considering related material arrangements and objects. By taking practices-arrangement bundles or - as transition theory would have it - sociotechnical systems as a starting point, our conceptual framework departs from 
approaches that neglect or underestimate the impacts of technologies on social change, such as governance approaches which put individual values, perceptions, and 'willingness to' centre stage (Geels et al., 2015; Shove et al., 2012). For reasons of convenience and readability however, we continue using 'practices' instead of 'practice-arrangement bundles' throughout the article.

A third element in our practice theoretical account concerns the emphasis on social change. This emphasis we borrow from transition theories which are developed for understanding transitions or transformations in (segments of) social life. Although Schatzki offers a discussion of becoming and change already in his earlier works (Schatzki, 1996, 2002), practice theories as used in the sociology of consumption do not offer an elaborate account of concepts like transitions, transformations, or episodic characterisations. The latter concept is used by Anthony Giddens (1984) to refer to processes of social change that happen within a delineated period of time and that proceed in a specific direction. Formulations of practice theory informed by Schatzki tend to emphasize the open and contingent character of the social, while not paying much attention to the steering or governance of social change. Only recently, practice theorists have started to confront the issue of (the steering of) social change in more elaborate ways, thereby also discussing the (in)compatibility of practice theory and transition theory (Schatzki, 2016b; Spaargaren et al., 2016) in some respects. Building upon this debate, we argue that specific elements of transition theory are of use when developing a practice theoretical account of social change (Geels et al., 2015; Hargreaves et al., 2013a; McMeekin and Southerton, 2012; Watson, 2012).

In what follows, we explicate the core elements of our conceptual framework for analysing social change in smart grid configurations. We start by discussing our unit of analysis: the type of social practices that compose the smart grid. In section 5.3.1 we attend to domestic consumption practices as the practice-arrangement bundles which are carried out by householders in and around the home, and to the new Home Energy Management-practices (HEM-practices) that emerge with the development of smart grids. We discuss in some detail the specific components of social practices - practical understandings, materials, rules and teleo-affective structures - and their role in analysing (the governance of) social change. In section 5.3.2 we go on to consider forms of social change in more detail. In order to clarify which practices are affected, in what ways, and to what extent, we pay special attention to different trajectories of change in ways similar to discussions on 'transition pathways' among transition theorists. In this section we also provide illustrations of how the conceptual framework could be used to organize empirical research on the governance of social change in decentralised (smart) energy systems. 


\subsubsection{Identifying and positioning relevant sets of practices for the energy transition}

When analysing social change with the help of practice theories, the units of analysis are not niches, regimes and landscapes but social practices or, following Schatzki (2011, 2016b), practice-arrangement bundles. Schatzki, whose ontological work serves as a reference point for many contemporary practice-theoretical accounts, defines practices as organized nexuses of doings and sayings performed by human agents (Schatzki, 2002). Examples are cooking practices, laundry practices and gardening practices. According to Schatzki, practices are always linked to material arrangements consisting of interconnected human bodies, organisms, artefacts, and things (Schatzki, 2016b). Cooking practices, for instance, typically involve foodstuffs, a fridge to store the food, a stove to prepare the food, tools to handle the food, and bodies to execute the actions (doings and sayings) that are required. Practices use, effect and

give meaning to material arrangements, while material arrangements enable and constrain practices in different ways (Schatzki, 2016b).

Bundles of practices and arrangements interconnect in many different ways to form larger bundles and constellations thereof. Bundles may interconnect for instance through linked material arrangements (the kitchen and the living room as spaces in the same house, or pans and cutleries for preparing food and for dining) or through action chains with shared ends (first buying food, then cooking it, having diner, and then washing the dishes). As such, human life transpires as part of a giant maze (or plenum) of smaller and larger practice-arrangement bundles (Schatzki, 2016b). Within this maze, both smaller and larger social phenomena unfold in particular ways, with larger social phenomena (e.g. energy systems, markets, fashions) referring to practicearrangement bundles of wider time-space scope in comparison with small social phenomena (e.g. gardening, showering, attending class).

This article concentrates on domestic consumption practices as a particular subset of practice-arrangement bundles and the constellations they are part of. They mostly take place in and around the home and, within that setting, acquire special significance in debates on smart grids and sustainable energy consumption (Bell et al, 2015; Christensen et al, 2013; Ellsworth-Krebs et al, 2015; Naus et al, 2014, 2015; Strengers, 2012). Table 5.1 specifies some of these practices, grouping them into together in categories representing more or less distinct domains of everyday life in and around the home. 
Table 5.1: Practices involved in the organisation of the home.

\begin{tabular}{|c|c|c|}
\hline Icon & $\begin{array}{l}\text { Domestic } \\
\text { consumption } \\
\text { practices } \\
\text { (categories): }\end{array}$ & Examples \\
\hline & Food & $\begin{array}{l}\text { Growing, buying, storing, cooling, cooking and conserving } \\
\text { food; having lunch or dinner; shopping for food; doing the } \\
\text { dishes; watering the kitchen garden; having a barbecue or a } \\
\text { pick-nick. }\end{array}$ \\
\hline & Mobility & $\begin{array}{l}\text { Walking to the bus-stop; storing and using a bike or a car; } \\
\text { repairing and maintaining bikes and cars; charging e-cars } \\
\text { or e-bikes; updating routing devices; planning a trip; using } \\
\text { the city-bike system; buying a car; commuting by train or } \\
\text { car. }\end{array}$ \\
\hline & Cleanliness & $\begin{array}{l}\text { Cleaning up the dwelling; vacuum cleaning the floor; doing } \\
\text { the laundry; ironing clothes; taking a shower or a bath; } \\
\text { doing the dishes/timing the dishwasher. }\end{array}$ \\
\hline & Leisure \& Work & $\begin{array}{l}\text { Watching TV; reading a book; playing a (online) game; } \\
\text { surfing the web; sending an email; making a phone-call; } \\
\text { gardening; booking a holiday; having a party. }\end{array}$ \\
\hline & Comfort \& Ambiance & $\begin{array}{l}\text { Heating, cooling, ventilating and lighting indoor and } \\
\text { outdoor spaces; shopping for appliances; DIY; having a } \\
\text { garage sale. }\end{array}$ \\
\hline
\end{tabular}

In the domestic consumption practices discerned, energy features as an 'ingredient' (Shove and Walker, 2014) or 'resource' (Spaargaren, 2011) that enables the performance of the practice. For the practice-participants, in this case the householders, energy - and its particular uses - is not normally an object of attention in and of itself (Ellsworth-Krebs et al., 2015; Shove and Walker, 2014). "People think warmth, coolness, freshness and light instead of energy" was the slogan used by one of the major Dutch energy companies early this century. Yet, by introducing new forms of micro-management of energy (Bulkeley et al., 2016b; Goulden et al., 2014; Strengers, 2012,2013 ) it seems to be precisely this goal - the singling out of energy as an explicit 'object' of attention and work - that smart grid development is foregrounding. 
When discussing domestic consumption practices and their dependence on energy however, we encounter the fact that domestic consumption practices are crucially different from practices in wider energy systems (Van Vliet et al., 2005; Van Vliet, 2012). The work of Habermas (1985) discusses in detail why and in what ways system rationalities, like those performed by energy producers and distributors, are different from the kind of rationalities that govern life-world practices, like those performed in and around the home. Taking the main argument of Habermas' into the smart grid debate helps to see that domestic consumption practices are not exclusively governed by system rationalities (e.g. optimizing profits, shaving energy peaks, reducing $\mathrm{CO}_{2}-$ emissions). When being involved in the reproduction of domestic consumption practices householders use wider life-world rationalities (e.g. getting comfortable, enjoying a dinner together, spending some time alone). To fully recognize and respect the life-world characteristics of the private, home-based consumption practices, we need to discern these practices from other kinds of practices, like those that are being introduced by smart grid development.

Building upon earlier accounts of the micro-management of domestic energy in smart grid environments (Naus et al., 2014, 2015; Naus and Van der Horst, 2017) Table 5.2 suggests a list of practices and technologies that are of special interest when considering the governance of domestic consumption practices. We refer to this emerging set of energy-related practices and technologies as Home Energy Management-practices, or in short HEM-practices. HEM-practices are emerging wherever smart grid developments gain empirical significance. ${ }^{27,28}$ Below, we discuss key characteristics of HEM-practices and formulate a number of research questions that come along with the 'governing by practices'-approach that HEM-practices make possible.

\footnotetext{
27 Strengers $(2012,2013)$ uses the persona of Resource Man to characterise and contest the dominant vision of domestic consumers as micro-managers of energy. We agree with this analysis insofar as the micro-management of energy is taken to refer to the rational behaviours of individuals or groups. In this paper, however, we conceptualise energy management as an emerging practice-arrangement bundle, thereby departing from such rationalist interpretations.

${ }^{28}$ Smart grid developments differ significantly around the world; domestic consumption practices, HEMpractices and energy systems show different contents and relationships, as illustrated by ongoing research in the UK (http://www.demand.ac.uk/) and in the Netherlands (http://www.energyinpractices.com/) for instance.
} 
Table 5.2: Home Energy Management (HEM)-practices emerging in the smart grids.

\begin{tabular}{|c|c|c|}
\hline Icon & $\begin{array}{c}\text { Home Energy } \\
\text { Management practices } \\
\text { (categories): }\end{array}$ & Examples \\
\hline & Energy monitoring & $\begin{array}{l}\text { Reading energy bills; using digital interfaces and apps; } \\
\text { comparing energy use-patterns over days, weeks, } \\
\text { years and in relation to other households; identifying } \\
\text { energy leakages; learning about stand-by uses; } \\
\text { comparing energy performances of appliances. }\end{array}$ \\
\hline & $\begin{array}{l}\text { Co-/self-production } \\
\text { of energy }\end{array}$ & $\begin{array}{l}\text { Having a set of PV-panels installed on the roof of the } \\
\text { house; participating in neighbourhood or apartment- } \\
\text { block related PV-panels as managed by citizen-groups } \\
\text { or local energy cooperatives. }\end{array}$ \\
\hline & $\begin{array}{l}\text { Energy sharing } \\
\quad \& \text { trading }\end{array}$ & $\begin{array}{l}\text { Sharing technologies and information with } \\
\text { neighbours, with residents of the apartment block, } \\
\text { with members of the housing cooperation or citizen- } \\
\text { committee; Buying and selling energy; participating in } \\
\text { a virtual energy company or community. }\end{array}$ \\
\hline & Timing of demand & $\begin{array}{l}\text { Flexible use; remote control of domestic appliances } \\
\text { (e.g. dish-washers, washing machines, dryers, boilers, } \\
\text { heating and cooling machines, coffee-machines, } \\
\text { lighting). }\end{array}$ \\
\hline & Energy storage & $\begin{array}{l}\text { Storage of renewable energy in particular in and } \\
\text { around the home; optimizing domestic energy } \\
\text { patterns for optimal use of self-produced and stored } \\
\text { renewables. }\end{array}$ \\
\hline & Energy conservation & $\begin{array}{l}\text { Improving the efficiency of energy infrastructures; } \\
\text { developing energy saving and thrifty routines. }\end{array}$ \\
\hline
\end{tabular}

\section{Home Energy Management-practices as instruments for (self-)governance}

What HEM-practices have in common, firstly, is the fact that they are specifically focused on the management, steering or governance of domestic energy flows, technologies and infrastructures. Their special relevance for the (self-)governance of the energy transition at decentralised levels is mirrored in the particular technologies (material arrangements) as well as in the (practical or practice) understandings, rules 
and teleo-affective structures which belong to these practices (Schatzki, 2002). ${ }^{29,30}$ Energy storage, for example, is made possible by a battery which - by its size, positioning and accompanying software - affects the forms of (self-)governance that are possible. Practical understandings with respect to storage practices relate to actors knowing how to go about storage, not being confused for instance by inquiries from neighbours. Rules are instructions and principles outlining how the practice of energy storage should be done in the first place. As such, rules direct and restrain people to perform certain actions (Schatzki, 2002). For the storage, trading and sharing of energy rather strict rules exist at the national levels. Finally, teleo-affective structures signify the directionality of social action. ${ }^{31}$ These structures 'tell' human agents 'what to do next', given their practical understanding of the situation and the emotions or affectivities attached to it. As teleo-affective structures they stipulate how the practitioners, through their doings and sayings, relate themselves to the tasks at hand and to the overall goals of, for example, the energy transition. As teleo-affective structures they involve a range of feelings and emotions, both positive and negative, that come along with working towards these goals.

Emotions and feelings can be seen as important drivers of the social. They are partly embodied in the actors, partly produced by and belonging to the social practices (Collins, 2004; Weenink and Spaargaren, 2016). With respect to energy storage, teleoaffective structures may refer to the drive of local actors to become 'independent' from the central energy grid for instance (Morris and Jungjohann, 2016). So far, empirical research on the teleo-affectivities of HEM-practices is limited however. Our own research (Naus et al., 2015; Naus and Van der Horst, 2017) indicates that economic 'motives' do not stand out as the singular and most important driver of HEM-practices as often suggested by energy companies and policy makers. Next to reducing the energy bill, the teleo-affective structures of HEM-practices may also relate to the pursuit of privacy, local cooperation and sustainability, for instance. This needs elaboration and specification in future empirical research on smart grids.

\footnotetext{
29 Schatzki (2002) discerns practical understandings, teleo-affective structures, rules and general understandings as the four organising components of practices.

30 Practice theorists use the concept of (shared or practical) 'understandings' in different ways. For Giddens, the most important connotation is the 'practical' in the sense of the non-discursive nature of the understandings. For Schatzki, understandings rather refer to how practices are understood, talked about and communicated among social actors in general. For a more detailed discussion see Spaargaren et al. (2016).

${ }^{31}$ Schatzki (2002: p80) defines teleo-affective structures as "a range of normativized and hierarchically ordered ends, projects and tasks to various degrees allied with normativised emotions and even moods".
} 


\section{Home Energy Management-practices as mediating practices}

A second important characteristic of HEM-practices is the fact that they are typically situated at the interface between households and the larger energy system. That is, they tend to emerge in-between domestic consumption practices on the one hand, and wider production and distribution practices on the other (Figure 5.1).

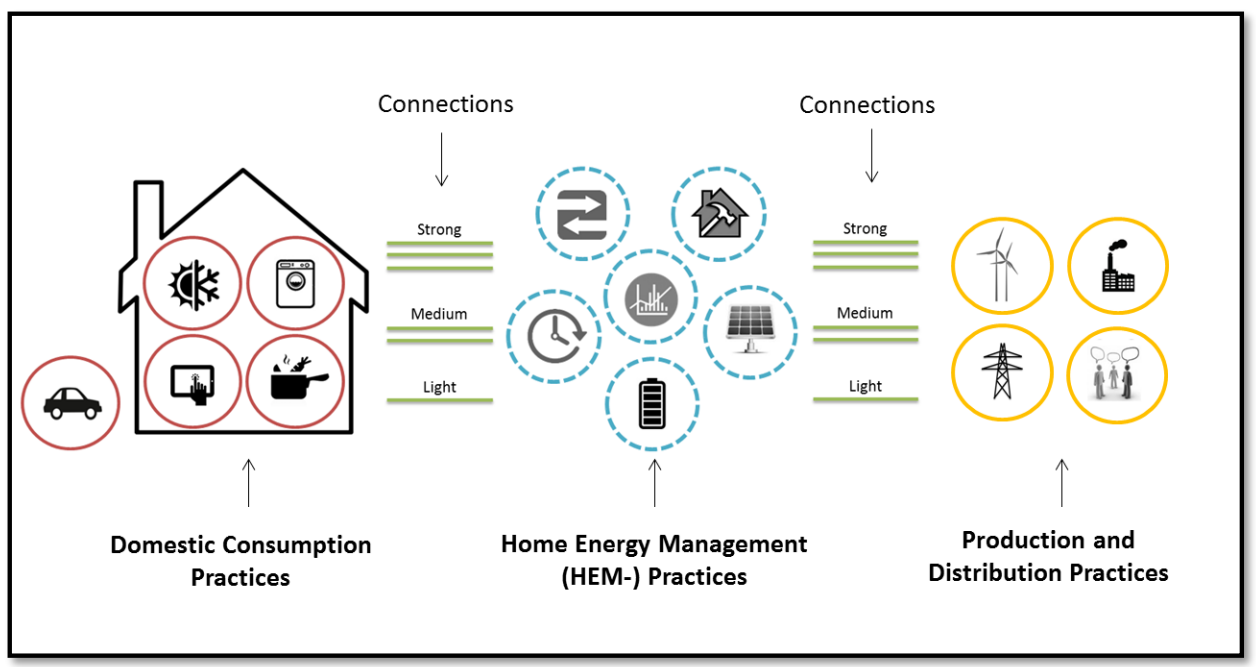

Figure 5.1: Emerging Home Energy Management-practices at the interface between the home and wider energy systems.

We argue that this intermediate position of the emerging HEM-practices is of great relevance when analysing the (self-)governance of social change in decentralised smart grids . First, as a dispersed set of doings, sayings and technologies (Gram-Hanssen, 2010), HEM-practices connect to and interlace with domestic consumption practices in various ways. This potentially alters the performance and organisation of domestic consumption practices (Bulkeley et al., 2016b). For example, when householders decide to turn on the laundry machine only at times when sufficient solar energy is available, energy production practices are being integrated into domestic laundry practices. However, in case the daughter or son 'needs' fresh clothes for the school party next day, life-world rationalities can intervene and be decisive for the laundry practices that are performed in the end.

Yet, as 'mediating practices' HEM-practices are not only involved in the reproduction and innovation of a range of domestic 'systems of systems' (Shove, 2003), but also in wider systems of energy production and distribution. Producing, storing and using 
local energy for instance also affects conventional centralised production and distribution practices. In terms of power relations, HEM-practices thus not only represent the transformative powers of (organized) households, but also the powers of energy companies and regulators. Accordingly, HEM-practices provide a central locus for analyses of power relations in smart grid configurations.

Home Energy Management-practices and research on (the governance of) social change

With the help of Figure 5.1, four sets of questions can be identified for investigating the (self-) governance of social change in smart grids.

The first set of questions concerns the emergence of HEM-practice-arrangement bundles: What kind of HEM-practice-arrangement bundles have emerged so far, at this particular time and place? Do we see a mature, fully developed set of HEM-practices, or is there a more limited set at work? What are the crucial components of the emerging HEM-practices in terms of the technologies, practice understandings, competences, portfolios, values, rules and teleo-affective structures involved in the performance of the practices? What makes it attractive for domestic actors to start participating in these practices? And is it possible to characterise HEM-practices in terms of their particular relationships with energy technologies, for example in the context of the high levels of automation and ICT-dependency? Who has the portfolios that best guarantee access to these smart information technologies?

A second set of research questions concerns the connections between practices: In what ways are HEM-practices becoming connected to domestic consumption practices on the one hand and to energy production and distribution practices on the other? One may consider the number and (power) direction of the connections as well as their strength; are there single, double or multiple bindings (Kuijer, 2014) at work among the different components of social practices. The more practice-components are involved, the stronger and more enduring the connections between practices tend to be. Connecting only the technologies, only the skills, only the values or only the teleoaffective structures produces weaker forms of connectivity and embeddedness compared to multiple bindings along all relevant components. Also the dynamics of change will differ as a result of differences in the strength of number of bindings.

Thirdly, we suggest investigating the set of HEM-practices with respect to their explicit role in the governance of practices in the smart grid. What kind of projects and programs do the HEM-practices put forward for the steering and directionality of both domestic consumption practices and wider production and distribution practices? In other words, what specific kinds of teleo-affective structures are involved in HEM- 
practices? Are the practices and their participants oriented towards optimising grid efficiency, enlarging the portfolios of renewables, increasing domestic autonomy and privacy, reducing energy bills, promoting local collaboration and sharing, or at particular combinations of these goals? When seeking to connect with HEM-practices, strategies for the governance of social change in smart grids will become more real and realistic given that it takes into account the complex interrelations between system and lifeworld rationalities.

Fourth and finally, in the context of governance, it is of special relevance to ask questions on the division of power and responsibilities. Who is in charge? And, who is (made) responsible for what kind of project or programme? The suggested distinction between domestic consumption practices and HEM-practices, as well as the mediating functions assigned to HEM-practices, make it possible to investigate issues of power, surveillance, empowerment and loss of autonomy involved in smart grid development in more detail. A seemingly simple question like "who is turning on the dishwasher, and at what time?" brings in not just strictly technical questions regarding the software of the dishwasher and the maximum use of renewables, but also questions regarding the changing relationship of power between households and energy providers.

\subsubsection{Discussing pathways of change in smart grids}

In the preceding section, practice theories have been used to conceptualise the dynamics of social change in decentralised smart energy systems. Social change is about human actors being involved in the performance of social practices, with technologies, skills, goals and motivations and emotions being assigned an important role in the analysis. To prevent naïve analyses of power and social change, new concepts were offered concerning the distribution of responsibilities among decentralised versus centralised (governance) actors. To conclude the discussion on a conceptual model for smart grid transitions, this section looks into different pathways of change that result from the active performances of the interrelated sets of practices implied in smart grids.

Transition theory (Geels and Schot, 2007; Geels, 2011; Grin et al., 2010) distinguishes four ideal-type transition pathways: transformation, technological substitution, reconfiguration and de- and re-alignment. Even though environmental outcomes $\left(\mathrm{CO}_{2}\right.$ emissions) can be quite similar in the end, these pathways differ in the timing and nature of the interactions between niche, regime and landscape levels. Accordingly, one might observe superficial or more radical, and gradual or more sudden changes in the socio-technical configuration (Foxon, 2013; Verbong and Geels, 2012). Moving 
from substitution to de- and re-alignment, the processes involved imply a more radical departure from the originally existing situation or regime. When radical, rupture-like dynamics of change arise, the demands on governance will be different than in the case of more smooth, gradual transformations that are characterized by 'muddling-through' (Lindblom, 1959) styles of governance.

Practice theories conceptualise patterns of change in terms of the emergence, persistence and dissolution of practices or practice-arrangement bundles (Schatzki, 2013; Shove et al., 2012). Examples of emergence are the coalescence of practicecomponents, the introduction of new (material) elements, and the hybridisation or bifurcation of existing practices. Compared to emergence, the persistence and the dissolution of practices involve processes that work in the opposite direction. The difference between persistence and dissolution, according to Schatzki (2013), is that the first refers to smaller, non-revolutionary changes, and the latter to larger, more disruptive ones. ${ }^{32}$

When zooming out on the wider maze of practices, there is at any moment a changing mix of emergence, persistence and dissolution at work, with some bundles moving more quickly and others moving more slowly. This creates an "uneven front of change" which, when compared to the concept of regime shifts in transition theory, shows a different, more differentiated and fine-grained picture of social change (Schatzki, 2011, 2016b; Walker, 2014).

For governance efforts that seek to effectuate change in energy production and consumption, however, it remains valuable to preserve an image of transition phenomena over larger swaths of time-space, as transition studies have convincingly pointed out. Accordingly, we suggest using an analytical scheme that encompasses both dimensions of transition dynamics at work in smaller and larger bundles of practices; a conceptual scheme that encompasses the idea of open-ended, patchy fronts of change (practice theories) as well as a view of longer term, historically traceable patterns or trajectories of transitions at large (transition theory).

Leaving aside for a moment the debate on hierarchical layers of the social as represented in the Multi-Level Perspective (MLP) of transition theory vis-à-vis the practice-theoretical understanding of all practices being spread out over just one 'level' of the social (the "flat ontology" assumption), 33 we argue that it is useful for empirical

\footnotetext{
32 For further patterns of change in practice-arrangement bundles see Schatzki (2016b).

33 For discussions on agency vs. structure, flat vs. layered ontology, and supply-side vs. demand-side dynamics see e.g. Geels (2011), Geels et al. (2015), Hargreaves et al. (2013a), McMeekin and Souterton (2012), Schatzki $(2011,2016 b)$, Shove and Walker $(2007,2010)$, Spaargaren et al. $(2012,2016)$.
} 
research on smart grid transitions to distinguish between different 'trajectories of change' of social practices as happening in the context of three 'orders of (sociotechnical) innovation' which can be distinguished in the plenum of practices. Figure 5.2 provides a visual presentation of our main argument as applied in the context of smart grids. In the following, we will discuss the trajectories of change and the orders of innovation with the help of examples that are illustrative for smart grid development.

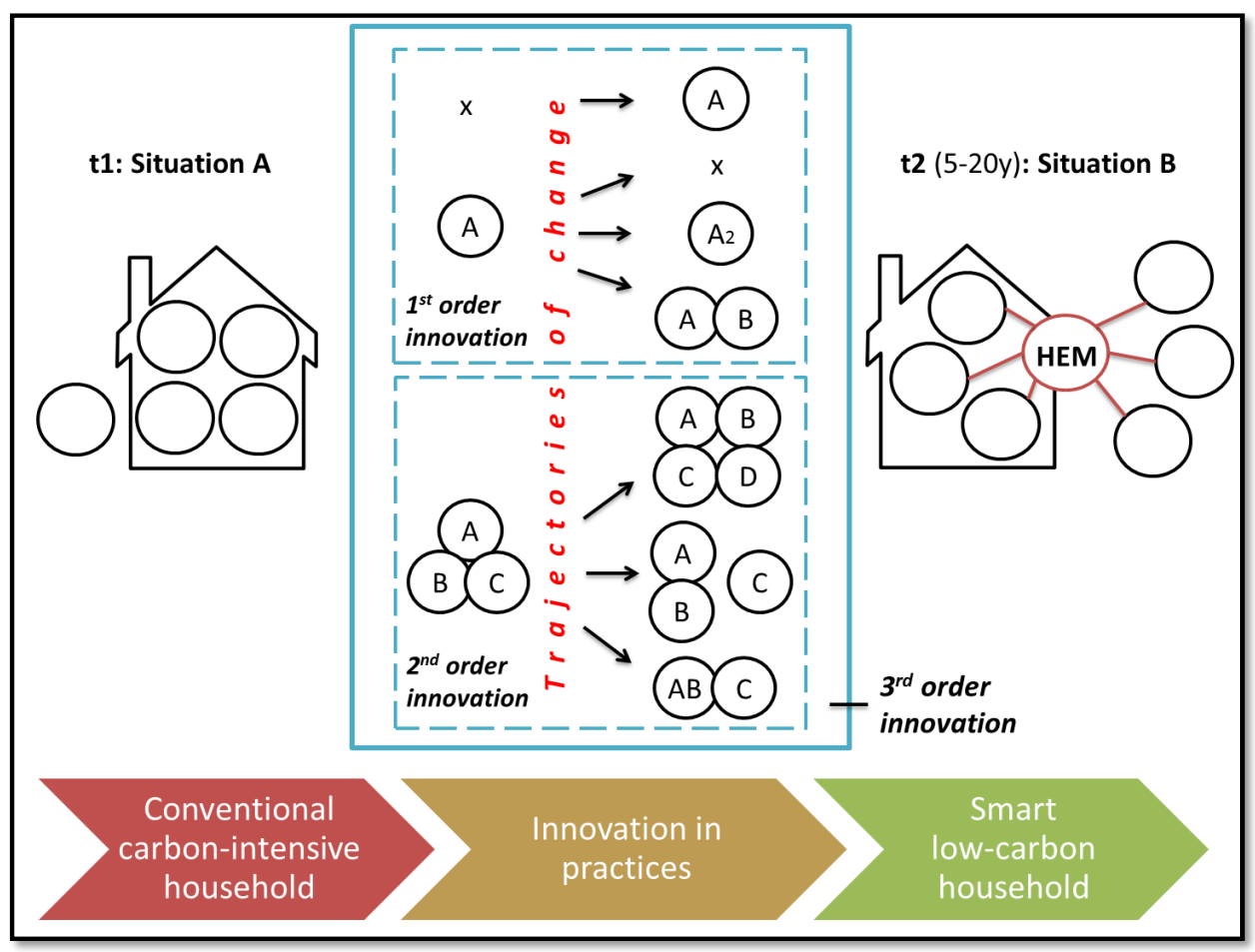

Figure 5.2: Trajectories of change for smart grid-related practices in the context of three orders of innovation.

\section{First order innovation: changes within situated practices}

\section{Characterisation of trajectories:}

This concerns changes in singular or relatively small social practices. The changes include the emergence, bifurcation and disintegration of a practice, and the addition, withdrawal, modification and substitution of practice-components. The methodological 
focus is on studying the 'life of the (individual) practice' (Shove et al., 2012) and alterations in its performance. When studying this order of innovation, the analytical lens will be in the zoomed-in position (Nicolini, 2012) most of the time.

\section{Examples:}

The emergence and extension of energy monitoring practices to include the use of an in-home energy display and the application of energy feedback from an expert service provider; the bifurcation of car-driving practices into (e-)biking practices for the shorter distances and (e-)car-driving practices for the longer distances; the substitution of an old gas-fuelled stove for a new, more efficient electric stove; the reconfiguration of on/off-switching routines with respect to the heating installation.

These examples illustrate the fact that first order innovations tend to leave the basic set-up of the household and its connection with the wider energy system intact. The innovations do not or hardly affect the ways in which domestic consumption practices are connected to HEM-practices and vice versa.

\section{Second order innovation: changes in the connections between practices}

\section{Characterisation of trajectories:}

In this case the trajectories of change refer primarily to changing relationships between practices. The trajectories include the hybridisation, the association and disassociation, the tightening and loosening of specific sets of practices. This takes place through the differential linking and de-linking of (shared) components. The analytical attention is on the ways in which situated practices are being (re)embedded in wider configurations of practices. When focusing on (sets of) social practices becoming linked or delinked via the emergence or loss of shared competences, rules, meanings and teleo-affective structures, the analytical lens alternates between the zoomed-in and zoomed-out position (Nicolini, 2012). By switching lenses, researchers can identify the hotspots that deserve closer inspection when seeking to specify the trajectories of change and the groups of agents carrying them out.

\section{Examples:}

The hybridisation of mobility practices and energy storage practices through carbatteries and, accordingly, the association of mobility practices with domestic lighting and cooling practices; the coupling of food, mobility and showering practices to monitoring practices and, accordingly, the affiliation of these practices through a shared orientation (teleo-affectivity) on minimizing carbon emissions; the linking of 
laundry and vacuum cleaning practices to local energy production practices through timing of demand and, accordingly, the de-linking of domestic consumption practices from carbon-intensive production and distribution practices; the linking of fresh food consumption practices to a food producing glasshouse in the smart grid in order to lower carbon footprints.

Second order innovations are made possible by newly emerging HEM-practices. These are becoming more strongly connected to domestic consumption practices on the one hand and to wider energy systems on the other.

\section{Third order innovation: changes in the wider constellation of practices}

\section{Characterisation of trajectories:}

The third order of innovation concerns a "synoptic overview" (Schatzki, 2016b) of the longer-term changes in single practices together with changes in the interconnections between practices. This overall process can be characterised in terms of transformation, reconfiguration or de-and re-alignment (Verbong and Geels, 2012), representing increasingly radical departures from the original configuration of practices. From Giddens' discussion of 'episodic characterisations' it becomes clear that these kinds of longer-term innovation processes can usually only be properly understood and assessed for their radicalness with hindsight. This requires the use of historical sociological analyses with the analytical lens on the (larger) practicearrangement bundles that are most deeply embedded in time-space. Alternatively, the concept of third order innovation can be used in the context of 'future studies' and in scenario analyses aimed at constructing realist utopias (Giddens, 1990) by opening up specific windows of innovation. With a view to governance, future studies are particularly helpful as smart grids are still a relatively new phenomenon with considerable room for manoeuvre. Building the transition pathways for smart grids discerned by Verbong and Geels (2012), practice-based scenarios of transformation, reconfiguration and de-and re-alignment might look as follows:

\section{Examples:}

Transformation could refer to a scenario in which HEM-practices become partially decentralised over the course of time, but remain primarily in the hands of established energy companies. Some changes in the timing of domestic consumption practices occur through the use of smart appliances and new tariff structures which allow key actors in the wider energy system to exercise control 'from a distance'. To cater for this transformation, large-scale renewable energy production, optimisation of existing 
local grids, and development of local energy storage capacity is needed. Through smart grids, households become linked to new, climate-modernized versions of existing production and distribution practices.

Reconfiguration could refer to a scenario in which HEM-practices steadily gain prominence and give rise to new, more balanced power relationships between (organized) households and key actors in the wider energy system. Tasks and responsibilities for energy production and distribution practices become increasingly shared between households, existing service providers and new intermediaries. Specific domestic consumption practices are being monitored and there is structural cooperation between the parties to lower carbon emissions resulting from these practices. Over time it becomes necessary to strengthen the local grid and to reconfigure the central grid and its services in order to better serve the energy system as a whole. The new system is not only climate neutral but also democratised for decisions that concern its social performance.

De- and realignment could refer to a scenario in which HEM-practices emerge and develop within a relatively short period of time, and come along with a (rapid) transfer of power from centralised to decentralised actors. This happens, for instance, when a neighbourhood or city district decides to detach from the central grid, and become selfsufficient and low-carbon within five or ten years' time. Households establish a local energy cooperative, engage in renewable energy production, and start participating in a personal carbon allowance and trading system. Over time, particular domestic consumption practices become shared instead of private (e.g. car-sharing, shared laundry service, joint cooking facilities). As domestic consumption practices become much more dependent on (seasonal) weather conditions, also anticipatory monitoring is required by default. The energy cooperative hires an Energy Service Company (ESCo) to store, locally distribute and trade the energy mix on their behalf. The new system differs from the old one in being not only climate neutral, but also radically decentralised both socially and technically.

Forms of de- and re-alignment can also be expected when large groups of households (neighbourhoods or even cities) are disconnected from the distribution grid for natural gas in a top-down manner. This is being discussed in the Dutch energy debate in terms of 'cold-turkey strategies' (Hier Klimaatbureau, 2016) which could be used by municipalities and energy companies to accelerate the transition to a future defossilised system of energy provision. 


\section{$\underline{\text { To conclude }}$}

Taken together, the 'trajectories of change' that occur within the three 'orders of innovation' can be used to analyse transition processes in emerging smart grid configurations. In this framework the emergence and embedding of new HEMpractices is crucial in determining the future of smart grids. HEM-practices and their teleo-affective structures together represent the overall direction of change as indicated by the long-term governance goals set for the energy transition at decentralised levels. In the discourse on smart grids however, the directionality and goals are not well elaborated (at least not in the Netherlands). The final section therefore discusses goal-setting in both analytical and political terms.

\subsection{Concluding discussion}

The need for ambitious climate targets that fuel a transition towards low-carbon systems for energy production and consumption seems to be acknowledged by ever more policy-makers, companies and citizens worldwide. At the international level and also at the national level, ambitious targets and policy strategies are being put in place to combat climate change. Although the general direction, the goal formulation and the basic trends seem to be clear (e.g. gradually phasing out fossil fuels; making use of renewable energy; paying for $\mathrm{CO}_{2}$ emissions), the energy transition has not yet delivered a (radically) new regime for energy consumption at the decentralised levels of households. Given that about one fourth of final energy consumption in the European Union is related to households (European Environment Agency, 2016), this level cannot be dismissed as being of less relevance for the energy transition. If it is true - as we and have argued - that the energy transition gets stuck at the local level because the top-down, technology-oriented approaches of centralised actors do not fit well with the decentralised dynamics of energy consumption in and around households, we are presented with a serious governance challenge.

An important step in confronting this challenge could be for cities to adopt a leading role in the energy transition (Bulkeley and Betsill, 2013; Lenhart, 2015). Climate governance at the level of cities and city networks like C-40 and ICLEI is promising because cities operate more closely to citizens and (energy) consumers. Around the world (smart) cities are indeed assuming a key role in climate governance by developing smart grids and other smart infrastructures to enable smarter lifestyles. This has resulted in new impulses for the energy transition at the local level, with solar PV and other climate smart technologies for the built environment becoming booming businesses. All kinds of formal (municipal authorities) and less formal (energy 
cooperatives and NGOs) organisations are making an effort to coordinate local transition dynamics by seeking to enrol 'ordinary citizens' into new, more decentralised modes of energy production and consumption. When doing so, however, they seem to run into obstacles that stand in the way of mainstreaming smart energy meters, smart networks and smart lifestyles. Some of these obstacles are created by policy makers themselves; for instance by relying on the idea that citizens only need to be 'nudged' into the right direction, or alternatively, by expecting that (smart) technologies will do the job by themselves.

In this article, we have taken up the challenge to rethink some of the main causes behind the lack of involvement of citizen-consumers into smart grids. Two arguments have been put forward in particular. First, for most of the time and for most of their consumption practices, householders do not 'think energy' as such. Instead, they pursue comfortable, sustainable and socially accepted lifestyles which materialise through sets of practices like cooking for friends, watching TV and doing the laundry (Ellsworth-Krebs et al, 2015; Spaargaren, 2011). To recognize and respect this way of living, governance actors are advised to make a distinction between two sets of social practices: domestic consumption practices and Home Energy Management-practices (HEM-practices). HEM-practices offer an anchor point for actors involved in the governance of smart grids to think about and act upon the climate and energy dimensions of domestic consumption. These practices are instrumental in showing the rationales behind and the general direction of energy transitions in smart grids.

Second, we argued that the lack of enrolment of citizen-consumers has to do with the historically grown divisions of power and responsibilities in energy systems. Although change is noticeable in various countries and regions, most of the decision making power is still in the hands of government and company actors (Verbong and Loorbach, 2012; Morris and Jungjohann, 2016). Against the background of this unequal division of power, householders are reluctant to be pulled into processes of (radical) change that they do not feel part of or responsible for. Energy transitions as envisaged by cityauthorities, national governments or the European Union are not 'their' pathways of change (Goulden et al., 2014; Wolsink, 2012), for instance when it comes to the goalsetting, the pace and scope of the transition. Citizens are insufficiently involved in debates about the risks of smart grid development, and also the (un)intended consequences of smart grid development for existing domestic routines are not well known.

To deal with this second obstacle, we argued that the division of power and the forms of socio-technical innovation should be made more transparent. The division of power 
can be made visible by analysing the emergence of Home Energy Managementpractices that operate at the interface between households and wider energy systems: Who is setting the goals for e-mobility, for the 'timing of demand', for energy storage etc.? What kind of smart technologies, infrastructural designs and services do householders feel comfortable with? And which of these technologies and services might attract householders to the innovation process? As regards socio-technical innovation, we argued that trajectories of change in social practices can and should be investigated in the context of three orders of innovation. Each trajectory and order involves different consequences and risks for householders and other stakeholders. With householders as a decisive group of stakeholders, their enrolment in HEMpractices will determine not only the kind of innovation processes taking place in smart grids, but also their success in realizing climate and energy goals. 'Governing by HEMpractices' therefore deserves the serious attention of both governmental and nongovernmental organisations involved in smart grid development. 


\section{Chapter 6}

Conclusions and discussion

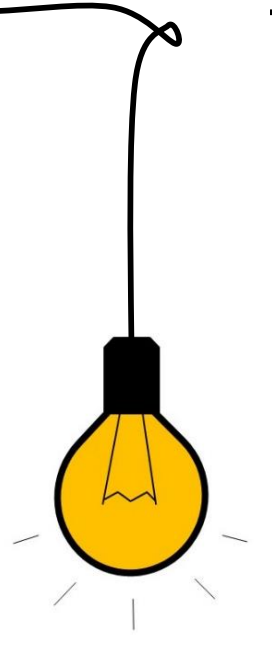




\subsection{Introduction}

The opening chapter of this thesis made clear that the contribution of smart grids to a sustainable energy transition cannot be taken for granted. Especially the actions, behaviours and decisions of end-users form a significant factor of uncertainty in smart grid development. There is for instance considerable uncertainty with respect to the flexibility that end-users will (be able to) provide as well as the energy savings that end-users will (be able to) realise with the help of smart energy technologies. Furthermore, groups of citizens have objected to the implementation of smart meters and smart grids, with some fearing an invasion of their privacy and autonomy.

The opening chapter related these observations to the individualistic, rationalistic and technology-focused approaches of established, centralised actors in the energy domain. To organise the thesis three research themes were singled out that are central to the problems at hand - the Household; Information flows; and the Sustainable energy transition. To come to grips with these themes, each theme was connected to a specialised body of theory - the Household to Social Practice Theories (SPT), Information flows to Informational Governance (IG), and the Sustainable energy transition to Transition Theories (TT). Together these themes and theories formed the basis for the formulation of the three central research questions:

1. How can we conceptualise the interplay between households and smart energy systems?

2. How do householders deal with new information flows in a context of emerging smart energy systems?

3. What are the implications of this analysis for (the governance of) householder participation in sustainable energy transitions that are enabled by smart energy systems?

In order to answer these questions this final chapter synthesises and discusses the findings of the different chapters. This will help fulfil the central aims of this thesis; a) to contribute to a better understanding of the social dynamics of smart energy systems, with a focus on the transformations taking place in and around the households of endusers; b) to develop concepts and analytical tools for studying these dynamics and transformations; and c) to formulate suggestions for the governance of sustainable energy transitions that involve smart energy systems. 


\section{Outline}

The next section (Section 6.2) addresses the central research questions. Subsequently, Section 6.3 reflects on theoretical and methodological choices and discusses the findings in relation to relevant academic literature. Finally, Section 6.4 presents a set of recommendations for policy and research.

\subsection{Questions \& answers}

\section{RQ\#1: How can we conceptualise the interplay between households and smart energy systems?}

This thesis has proposed to view the household as a particular set of social practices. More specifically, Chapter Two defined households as "hybrids of objects and people, which are implied in the (routine) performance of a set of interconnected practices (re-) produced in the domestic arena with the help of energy as a key resource". This definition of households contains a number of conceptual elements.

First, by understanding households as 'hybrids of objects and people' the definition attends to the intricate relationships between the social and the material. Understanding households as socio-material entities involves a move away from technology-focused perspectives (like engineering) that treat households as purely physical entities on the one hand, and individualistic perspectives (like psychology) that separate the social from the material and technical aspects on the other. Instead, social practice theories postulate that the social and the material interweave. Hence, Chapters Two and Five pointed out that the way in which end-users act is inseparable from, yet never fully determined by, material aspects like the physical lay-out of the house (e.g. the walls, windows and roofs) and the configurations of items within and around the house (e.g. couches, TV's and lamps).

Second, by referring to '(routine) performance' and '(re-)production' the definition brings to the fore the conventional and repetitive character of practices that take place in and around households. Different performances of dishwashing practices, for instance, tend to involve a specific set of materials (e.g. a dishwasher, detergent, a towel), a specific set of doings (e.g. gathering the dishes, sorting them) and a specific set of considerations on the part of end-users (e.g. what program to select, when to start). Yet, as Chapter Four pointed out, despite being organised in specific ways and tending towards reproduction, the organisation of practices is always provisional. In other words, the possibility of change is ever present in the moment of performance. Dishwashing practices may change, for instance, as a result of technological breakdown 
or replacement, along with changing styles of cooking or dining, or as a result of reflections on the environmental impacts.

Third, by understanding households as consisting of a 'set of interconnected practices' the definition makes clear that households are not of a single piece. Instead, households are (seen as) composed of a variety of practices, like cooking diner, heating and lighting the room, watching TV, doing the laundry (etc.) which, to some degree, have a character and logic of their own. Thus, the practice of having diner involves other actions and materials (e.g. using tables, chairs, cutleries) than practices of heating and lighting (e.g. handling thermostats, radiators, light switches). Yet, practices of cooking, heating and lighting also interconnect in different ways, for instance through co-location (in the same house or room) and through co-performance (at the same time, overlapping). So, while 'individual' domestic practices have some unique features to them, they do not exist in isolation; they are embedded in larger networks of practices with which they share particular features. Chapter Five suggested grouping domestic consumption practices into five categories of practices: Food, Mobility, Cleanliness, Leisure \& Work, and Comfort \& Ambiance.

Fourth, by referring to 'the domestic arena' the definition portrays the household as a meaningful geographical location. Chapter Three indicated that the household is not only a specific physical space that is shielded from other physical spaces (e.g. by walls or fences), but also a social space that is tied up with specific cultural meanings like privacy, freedom and comfort. Yet, given that practices are always embedded in larger networks of practices, there are no clear-cut (time-space) boundaries between the practices that take place in the domestic arena and those that happen elsewhere; working practices and sports practices, for instance, are likely to influence when and how laundry practices and dining practices are performed.

Fifth and final, the definition of households puts energy in the role of a resource (or ingredient) to domestic consumption practices. Chapter Two and Chapter Five drew attention to the fact that energy enables practices like dishwashing, showering and listening to music. Rather than being consumed as a product in its own right, energy is used in the course of performing such practices. Domestic energy consumption, then, is an outcome of all the practices performed in the domestic arena over a specific period of time.

Similar to the conceptualisation of households, (smart) energy systems can be thought of as particular sets of interconnected practices. As indicated in Chapter Five, energy systems can be said to consist of all energy-related practices - production practices, distribution practices, consumption practices, storage practices, monitoring practices, 
etc. - that are interconnected by an infrastructure of pipes, wires, energy flows, distribution stations, meters, electric devices, etc. Such a conception of energy systems considers households - or at least those domestic practices that involve energy - as part and parcel of energy systems, rather than as (strictly) separate entities. The advantage of such a conception is that it allows one to see how domestic consumption practices, and all the elements that are part of these practices, are actively involved in the reproduction and reconfiguration of energy infrastructures, which in turn make domestic consumption practices possible in the first place.

The transition from centralised fossil fuel based energy systems towards smart renewable energy based systems (potentially) embraces a wide variety of changes in the socio-technical fabric that makes up the energy system. This thesis has conceptualised these changes in terms of reconfigurations in practices and flows. ${ }^{34}$ Figure 6.1 provides a schematic presentation of the conceptual framework (adapted from earlier versions presented in Chapters Two and Five).

Figure 6.1 shows the different conceptual elements. First of all it depicts the emergence of bi-directional energy and information flows (central arrows). These flows emerge inbetween households and wider energy systems, replacing the one-directional flow of energy (and information) that characterises conventional, centralised energy systems. Chapter Two showed that new energy and information flows not only reconfigure and intensify interrelations between households and systemic actors ('vertical flows'), but also within households and between households ('horizontal flows'). The framework thus distinguishes three more or less distinct socio-technical contexts for handling energy and information within smart energy systems: within households, between households, and between households and systemic actors.

The second aspect that is central to Figure 6.1 is the emergence of a distinct set of Home Energy Management-practices (HEM-practices). Chapter Five listed six categories of emerging HEM-practices: Energy monitoring, Co-/self-production of energy, Energy trading/sharing, Timing of demand, Energy storage, and Energy conservation. The emergence of these practices (re-)configures the interconnections (or: the interface) between domestic consumption practices and systemic production and distribution practices. What sets HEM-practices apart from the other practices is that HEMpractices are centrally concerned with the management (or governance) of energy at a decentralised and domestic scale. This makes them distinct from, on the one hand,

\footnotetext{
34 See Section 6.3 for a discussion on the interrelations between the concepts of practices and (information) flows.
} 
domestic consumption practices which are oriented towards domestic 'purposes' (e.g. attaining a sense of comfort, cleanliness, privacy, etc.), and on the other hand, systemic production and distribution practices which are concerned with energy management at larger geographical scales (e.g. producing and distributing large-scale renewable energy; optimising interconnections between micro-grids).

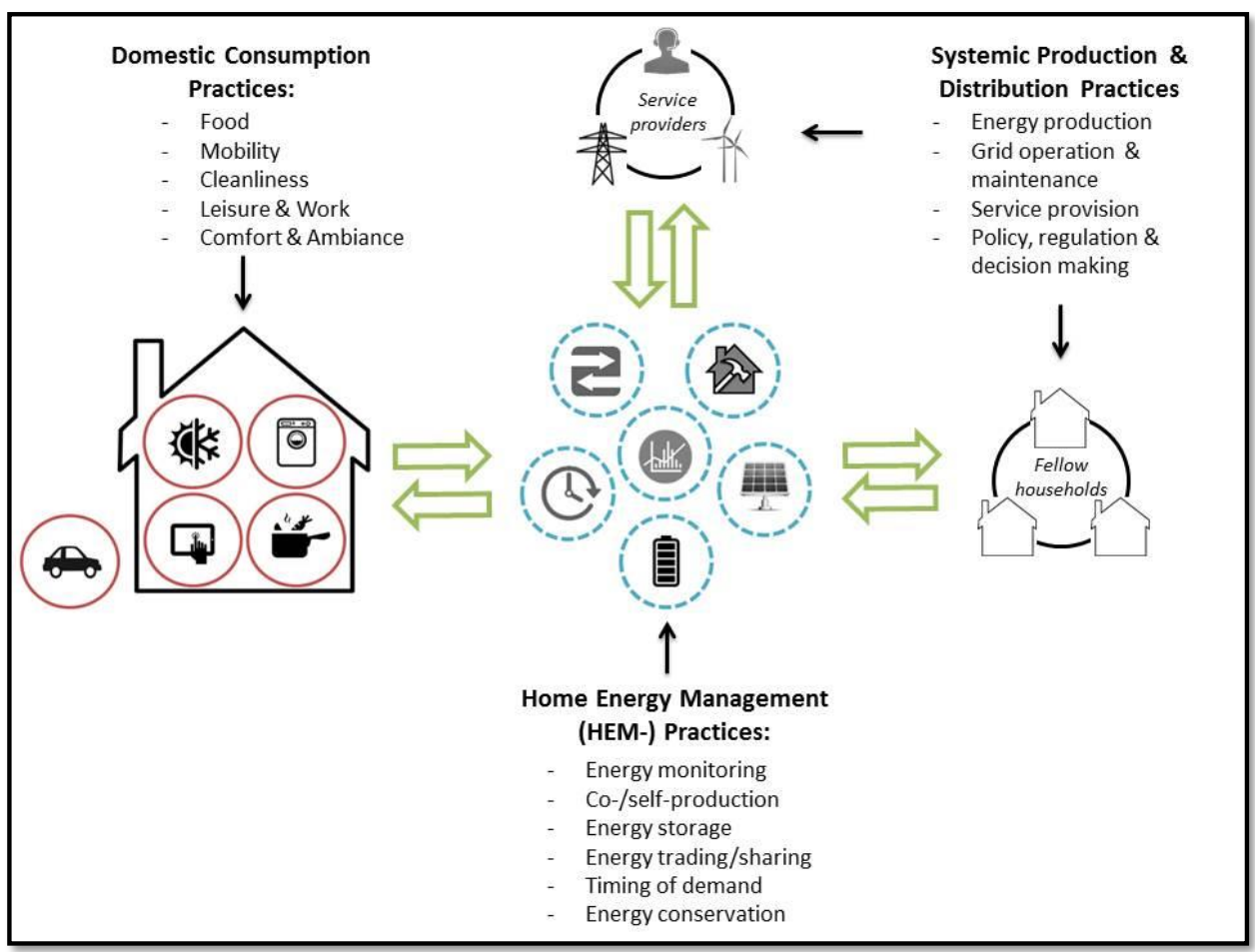

Figure 6.1: Conceptual framework on the interplay between households and smart energy systems.

To summarise, the interplay between households and smart energy systems can be understood in terms of the HEM-practices and the information flows that are emerging at the interface between households and wider energy infrastructures. The emergence of these new information flows and HEM-practices profoundly changes the ways in which households are "serving and being served by" (Otnes, 1988) the socio-material systems of energy provision. A new, more decentralised locus of change emerges which opens up space for the reconfiguration of vertical and horizontal relationships. To analyse the advent of smart energy systems it is suggested to examine the kind of HEMpractices that emerge, the ways in which these practices are organised (the practice- 
elements and participants), and the ways in which HEM-practices become connected to domestic consumption practices on the one hand, and to systemic production and distribution practices on the other.

\section{RQ\#2: How do householders deal with information flows in a context of emerging smart energy systems?}

As reflected in the set of HEM-practices explicated in Figure 6.1, monitoring practices are central to smart energy systems. Not only can monitoring be performed as a practice in its own right, also the other HEM-practices presume some form of monitoring. This thesis has investigated monitoring practices in two tracks. One track examined the considerations of end-users with respect to the disclosure of energyrelated information to outsiders (Chapter Three). The other track examined the ways in which end-users accomplish, handle and use energy-related information in relation to domestic consumption practices (Chapter Three). The analyses reveal several reasons why new information flows do not necessarily lead to more sustainable domestic consumption practices.

First, the participation of end-users in (self-)monitoring practices cannot be taken for granted. Chapters Two and Four showed that there is a range of motivations and objectives that are relevant for engaging in monitoring practices, including saving money, reducing carbon emissions, and participating in an energy community. However, it is also clear that not all end-users find smart meters (or monitoring more generally) equally interesting and worthwhile. Even for interested end-users it proved to be difficult to sustain an interest over time. As shown in Chapter Two, difficulties in accessing the data or in linking (aggregated) data to specific energy-consuming devices or practices complicated (continued) engagements in monitoring practices as well.

A second reason for why new information flows may not lead to more sustainable consumption practices is that monitoring practices are not necessarily directed towards sustainability or change. Chapter Four revealed several instances in which smart meter information was used for other purposes: in one case smart meter information provided a reassurance of the functioning of solar panels; in another case it was used as a check on the energy bill; and in a third case it helped to acquire new insight in energy consumption as a goal in its own right. This multiplicity of purposes (and emotions) involved in monitoring practices makes (sustainable) change in energy consumption patterns just one possible outcome among several others.

A third reason is that the effects of monitoring practices on energy consumption are prefigured by the existing organisation of domestic consumption practices; that is, the 
elements that practices are composed of and the ways in which practices interconnect. Chapter Four showed that when information runs counter to this organisation it is either dismissed as irrelevant, not accomplished in the first place, or impractical when put to the test. This can be the case, for instance, when the displayed information undermines social conventions of propriety, cleanliness or comfort embedded in domestic consumption practices, when it negates previous investments in technologies or infrastructures, or when it does not account for the time-dependence of practices. The layout of domestic consumption practices, and their historic trajectories, thus serve as a frame of reference for interpreting new information flows and structure the field of possibility for change. This tendency of domestic consumption practices to persist helped to explain why the energy-related measures ${ }^{35}$ taken by end-users often turned out to be non-revolutionary, at least when compared to the potentials that are sometimes attributed to smart grid development.

A key outcome of this analysis is to understand information and change as emergent outcomes of a dynamic interplay between practices. By conceiving of information flows as practical accomplishments, Chapter Four could trace the often unpredictable, nonlinear ways in which information flows were put-to-work in the context of a smart grid pilot. It revealed how energy-related information was accomplished within a variety of practices (in this case: domestic practices; monitoring practices and community interaction practices), how it travelled between these practices, and how it effectuated change as part of a specific local network of practices. Adopting such an embedded practice-based understanding of information and change offers an alternative to the linear cause-and-effect model which starts from information, goes through the minds of end-users and ends with behaviour change.

A fourth and final reason for why new information flows do not necessarily lead to more sustainable consumption practices has to do with the fact that end-users fend off some forms of information disclosure on the basis of privacy and autonomy concerns. This dynamic is relevant not only for relationships between households and the outside world, but also for relationships between household-members. Chapter Two presented a case in which a child was asked to explicate his behaviour to a parent after smart meter data had revealed unusual energy peaks at night. Similarly, Chapter Four presented a case in which children refused to conform to a parent's request to align

\footnotetext{
35 Energy-related measures included small adjustments in the performance of practices (e.g. switchingoff devices in stand-by mode; selecting eco-options), occasional adjustments in the timing of specific more 'flexible' practices (e.g. laundry practices, dishwashing practices), and one-off replacements of electric devices or material infrastructures (e.g. efficient boilers, better wall-insulation).
} 
laundry practices with domestic energy production. The observation that smart meters can be used as a new form of surveillance and control within households not only confirms the idea that smart meter information can serve a variety of purposes, but also shows that privacy and autonomy considerations can interfere with sustainability purposes.

Privacy and autonomy concerns also proved to be of significant importance to endusers when considering new forms of cooperation in a smart grid context. In Chapter Two it was mentioned that cooperation involves an opening up of end-users to new forms of surveillance and control by outsiders; a 'vertical opening up' to systemic actors as well as a 'horizontal opening up' to fellow householders. Chapter Three hypothesised that privacy and autonomy considerations would differ depending on the type of actor that one cooperates with (service providers, fellow householders) as well as the type of HEM-practice that one engages in (energy monitoring, co-production of energy, timing of demand).

The first part of the hypothesis could be confirmed; the difference between service providers and fellow householders provides a frame of reference for end-users when considering participation in emerging HEM-practices. In general, horizontally organised HEM-practices proved to be more attractive to than vertically organised HEM-practices. The main reason for this was the lack of trust in conventional energy providers. End-users who participated in the research criticised conventional energy providers for their involvement in carbon-intensive energy practices and their commercial interests. Horizontally organised HEM-practices provided a welcome alternative to many end-users, allowing them to acquire (a sense of) control over the energy transition. ${ }^{36}$ Yet, also horizontally organised practices proved to be subject to privacy and autonomy considerations. Especially the prospect of peer-pressure and personal conflict caused hesitance among end-users. Based on these findings it was concluded that new forms of decentralised cooperation that open up vertical as well as horizontal relationships for renegotiation provide a suitable way forward. This enables end-users to take (more) ownership of the sustainable energy transition, while at the same time allowing them to retain a sense of privacy and autonomy vis-à-vis service providers and other end-users.

It was also found that specific HEM-practices are prone to privacy and autonomy related concerns. Horizontally organised monitoring practices and co-production practices as

\footnotetext{
36 This critical stance towards conventional energy providers and the preference for horizontal forms of cooperation was also apparent in the smart grid pilot (discussed in Chapter Four) in which a local energy cooperative was a key actor.
} 
well as vertically organised monitoring and timing-of-demand practices proved to instigate such concerns. There was insufficient evidence, however, to support the (general) hypothesis that particular HEM-practices are more sensitive to the privacy and autonomy concerns than others. ${ }^{37}$

Taken together, it can be stated that the unpredictable, non-linear ways in which endusers deal with new information flows in smart grid contexts can be explained by referring to the character of monitoring practices and domestic consumption practices, as well as the complex ways in which these practices interconnect. End-users accomplish, handle and use new information flows not through an isolated engagement in new monitoring practices, but always and necessarily in relation to existing (sets of) domestic consumption practices. Changing energy consumption patterns is not straightforward as domestic consumption practices prefigure the field of possibility for change and have a tendency to persist. The conventionally private character of consumption practices, for instance, casts a shadow over engagements in new HEMpractices that imply some form of cooperation and information sharing with outsiders. Exposure to new horizontally and vertically arranged HEM-practices on the other hand seems to open the way for further engagements. If, however, new monitoring practices are not sufficiently attractive to end-users, or simply run counter to their interest, they do not engage in or accept monitoring practices in the first place. Therefore, as an alternative to existing models that relate feedback to behavioural changes in rather uncomplicated ways, a model of information handling and disclosure is suggested that puts the organisation and dynamics of social practices at the centre of the analysis.

\section{RQ\#3: What are the implications of this analysis for (the governance of) householder participation in sustainable energy transitions that are enabled by smart energy systems?}

From the answers to the previous research questions it is clear that the advent of smart energy systems requires an approach to the governance of sustainable energy transitions that resonates with the dynamics of social practices. More specifically, it was suggested that transition governance should focus on, adjust to, and seek to organise the dynamics of Home Energy Management-practices that are emerging at the interface between households and wider energy infrastructures. HEM-practices form the nexus for householder participation in smart energy systems.

\footnotetext{
${ }^{37} \mathrm{~A}$ key reason for this is that the analysis lacked a quantitative assessment of the impact of privacy or autonomy concerns on the dismissal of particular practices.
} 
The emergence of HEM-practices introduces a (distinctly) new set of opportunities and pitfalls for the governance of sustainable energy transitions. As explicated above, some of these relate to information handling and disclosure, some to the introduction of new technologies and infrastructures, and yet others to changes in the performances of social practices and the actor relationships involved in them more broadly. Based on the analysis, we argue that four focal points could be derived which are relevant when analysing and organising the (co-)governance of householder participation in smart energy systems:

\section{Putting HEM-practices centre stage:}

Transition governance would benefit from a focus on the development, organisation and embedding of HEM-practices at the decentralised level of households. Strategies that focus on HEM-practices serve as an alternative to strategies that concentrate on the deployment of energy technologies ('technology push') or on the persuasion of consumers ('mind-fix'). What this requires, first of all, is an understanding of the character of emerging HEM-practices and of the kind of changes that HEM-practices set in motion. The 'Governing-by-Practices' Approach (GPA) outlined in Chapter Five provides a starting point for getting to grips with HEM-practices and the trajectories of change that ensue from their introduction. The chapter identifies various categories of HEM-practices (that is; energy monitoring, co-production of energy, energy trading and sharing, timing of demand, energy storage, and energy conservation), it explicates the locus and characteristics of HEM-practices (that is; mediating between domestic consumption practices and systemic production and distribution practices), and it spells out different trajectories of change in practices (that is; in the components of practices and the connection between practices). By adopting a practice-based approach and putting HEM-practices centre stage, transition governance becomes part of the decentralised energy configurations themselves. Governing actors, in other words, deal with sustainable energy transitions from the 'inside' rather than 'from the outside'.

\section{Developing sustainability goals for HEM-practices:}

Transition governance could benefit from developing a set of sustainability goals for HEM-practices in dialogue with end-users. Developing sustainability goals for HEMpractices is a way to structurally embed sustainability goals in decentralised smart energy systems, without giving these goals and criteria absolute or isolated primacy over other goals and criteria. Chapters Three and Four showed that there is a range of goals and motivations for engaging with HEM-practices, from the side of end-users (e.g. 
reducing energy bills, increasing local autonomy, improving home comfort, contributing to sustainability) as well as from the side of energy companies and governments (e.g. improving business strategies, reducing labour costs, saving on infrastructural investment, achieving sustainability goals). While HEM-practices can serve multiple goals and engagements at the same time, Chapter Five suggested that sustainability goals for HEM-practices can guide household-level changes similar to the ways in which long-term goals direct system-level changes (e.g. the EU climate and energy targets for 2020, 2030 and 2050). Compared to the existing situation, this would link end-users to the sustainable energy transition in a more direct and explicit manner. Sustainability goals could take the form of 'hard' quantitative goals (e.g. carbon budgets) or more 'soft' qualitative goals, criteria or engagements (e.g. practicespecific rules and teleo-affective structures). Hard sustainability goals can direct and condition the change trajectories of HEM-practices over the medium and long term. Soft sustainability goals rather take the form of a lived directionality that guides the performance of HEM-practices in real-time. Analysing the configurations of HEMpractices can reveal and help to organise different (hard and soft) goals, interests and motivations in smart grid enabled energy transitions.

\section{Making room for local innovation trajectories in HEM-practices:}

Transition governance would benefit from the development of strategies that allow (groups of) end-users to (co-)determine local and domestic innovation trajectories. Chapters Three and Four suggested that (some) end-users are quite willing to take (coJownership of the energy transition as long as there is considerable freedom to organise HEM-practices and their innovation trajectories on their own terms and conditions. $^{38}$ The chapters also showed that social and technical decentralisation of energy configurations can make the sustainable energy transition more meaningful to end-users and help address some of the 'dark sides' of smart grid development, such as threats to end-user privacy and autonomy. Indeed, by engaging in new HEMpractices end-users not only affect, but are also exposed to shifting power balances between providers and consumers in energy systems. The Governing-by-Practices Approach is therefore best developed as a locally adaptive governance approach that allows end-users to, at a minimum, co-determine local transition trajectories. A starting point could be to let end-users articulate what are, in their view and in their

\footnotetext{
${ }^{38}$ Although never intended as a representative sample, the selection of cases and respondents may have caused some bias. Only few respondents were explicitly opposed to sustainable energy transitions and initiatives. A more representative selection of cases is likely to produce a more ambiguous picture.
} 
specific situation, the most practical, affordable and acceptable ways of organising HEM-practices (e.g. privately, horizontally or vertically). Governing-by-Practices can be seen as an adaptive governance strategy for providers as well; engaging in HEMpractices allows companies and regulatory agencies to learn about and adapt to (changing) lifeworld dynamics that set specific conditions for (fruitful) governance strategies and business models in smart grid configurations.

\section{Providing long-term support to end-user participation in HEM-practices:}

Transition governance would benefit from investments in a trustworthy organisational environment that can support end-user engagement in HEM-practices over the long term. End-users (as well as energy companies) need to be able to rely on the new smart energy configurations they become dependent on. Chapters Three, Four and Five suggested that new intermediary organisations like municipal governments, local energy cooperatives and ESCO's are in a particularly good position to facilitate local and domestic innovation trajectories. Intermediary organisations (and other providers) could support end-users, for instance by explicating different options for organising HEM-practices, by engaging end-users in the formulation of sustainability goals for HEM-practices, and by facilitating the development and embedding of new HEM-practices over time. More concretely, intermediaries could take up specific HEMrelated tasks such as trading the local energy mix on behalf of end-users, taking care of administrative issues, organising and guiding energy-related workshops, and familiarising end-users with new technologies and new ways to use these as part of daily life. Established energy companies and technology-related SMEs, on the other hand, might need to reinvent themselves in order to connect to the decentralised dynamics of HEM-practices. An intermediary support infrastructure could help here as well, for instance by assisting in the generation of new business models that combine the creation of economic value with the creation and safeguarding of environmental and social values.

Together these four focal points form the basis of the Governing-by-Practices Approach that is suggested for analysing and organising householder participation in smart energy systems. Analyses based on these focal points can help to see how smart grid development is organised, for instance; as a resourceful and well-balanced sustainability transition in which end-users and systemic actors share the opportunities, risks and responsibilities; as a conventional top-down transition in which established actors remain firmly in power, or; as a disruptive transition which involves a significant transfer of power and responsibilities for environmental change from systemic actors to end-users. 


\subsection{Discussion \& reflection}

The concluding discussion and reflection is organised into three subsections. The first subsection discusses the development of the conceptual framework, in particular the interrelation between two key conceptual elements: social practices and information flows. The second subsection reflects on the methodological and analytical choices that have been made in investigating social practices. Finally, the third subsection discusses the Governing-by-Practices Approach developed for analysing and governing sustainable energy transitions in a context of smart grids.

\subsubsection{Coming to grips with practices and flows}

In developing a conceptual understanding of the interplay between households and smart energy systems, the different chapters of this thesis have variously emphasised and dealt with the concepts of social practices and information flows. The initial conceptual framework, developed in Chapter Two, differentiated between various sets of domestic consumption practices (the household) on the one hand, and between three sets of energy and information flows that connect the household to (other actors in) the smart grid on the other (Figure 2.2). Subsequently, in focusing on information flows, Chapter Three considered new information flows first and foremost in terms of the new social relationships between actors they produce: between householders and systemic actors (vertical) and between householders and fellow-householders (horizontal) (Table 3.1). Chapter Four, on the other hand, treated information not as a flow or relationship between actors, but as a social accomplishment that emerges from, travels between, and is used within practices (Figure 4.1). In Chapter Five, finally, the concept of information (flows) was given less explicit attention. Instead, Chapter Five explicated a set of Home Energy Management-practices (HEM-practices), with monitoring practices featuring as one type of HEM-practices (Figure 5.1). ${ }^{39}$ HEMpractices also form the core of the conceptual framework presented in this concluding chapter (Figure 6.1), but this time monitoring practices are brought into the limelight again (see answer to research question 2). This section extends the discussion on the key elements of the conceptual framework based on two questions that have remained underexplored so far.

The first question is how to understand the role of information flows in relation to (consumption) practices. Together with existing practice-based accounts of the topic (Foulds et al., 2015; Royston, 2014; Strengers, 2013; Wallenborn and Wilhite, 2014)

\footnotetext{
${ }^{39}$ An initial set of HEM-practices was identified in Chapter Three.
} 
this thesis has drawn attention to different forms of feedback that are involved in social practices, such as sensory feedback (e.g. related to the weather), social feedback (e.g. from the neighbours) and material feedback (e.g. from technologies). Tracing the role of these forms of feedback has helped to see that domestic consumption practices are not uninformed or unconscious routines, nor deliberate courses of action resulting from conscious reflections by end-users, as sometimes assumed in smart metering discourse. Nonetheless, some (parts of) practices seem to be more specifically geared towards the accomplishing and use of information than others (Cox, 2013). In energy monitoring practices and community energy workshops, for instance, the creation and use of energy-related information proved to serve as a key objective (Chapter Three). ${ }^{40}$ It seems analytically helpful, therefore, to distinguish between two information-related concepts: 'information-in-practice' (Cox, 2013), which refers to generic, mostly implicit acts of information seeking and use in social practices and, second, 'informational practices', which refers to those practices that are geared towards the creation, processing and use of information itself. Linking this idea back to the case at hand, it could be stated that HEM-practices are most like informational practices (they involve at least some form of monitoring), while domestic consumption practices are more accurately described with the concept of information-in-practice.

Such an understanding of information is not only relevant for Social Practice Theories, but also for Informational Governance. At least in its original formulations, IG uses the concept of information flows as a common denominator for all kinds of exchanges of data, information and knowledge (Mol, 2006, 2008). In doing so, it is (intentionally) unspecific about the concept of information, and rather draws attention to the actors, networks and institutions that process, use and exchange the information. This aligns well with the idea of a network society in which networks are conceived as communicative structures that process information flows (Castells, 1996, 2009). However, by presenting Informational Governance as a mode of governance in which "(environmental) information gains transformative powers" (Mol, 2006: p497), IG seems to attribute powers of determination to information itself.41 In line with other (practice-based) accounts of information and knowledge (Labanca, 2016; Orlikowski, 2002), this thesis suggests that, to do so, is to erroneously abstract information from the practice(s) in which it is generated, processed and used. One way to integrate this

\footnotetext{
40 This is not to deny that monitoring practices and workshop practices serve multiple objectives at the same time.

${ }^{41}$ A similar tendency can be found in the statement that "ICT ... has the power to accelerate irreversible transformative change" (Termeer and Bruinsma, 2016: p96). In this case powers of determination are attributed to ICT, rather than to information flows.
} 
understanding into IG could be to shift from the idea of 'networks of actors' to 'networks of practices'. This would generate new types of questions for IG, such as: In what ways does information emerge from, travel between, and affect existing networks of practices? And, how do new informational practices affect existing forms of environmental governance?

The second question with respect to the conceptual framework is to what extent HEMpractices can be seen as a set of social practices in their own right. This thesis has argued that HEM-practices are central to the analysis of emerging smart energy systems. HEM-practices, so it is argued in Chapter Five, have a character and dynamic of their own that sets them apart from other types of practices, primarily domestic consumption practices and systemic production and distribution practices. In part, the discerning of HEM-practices is an analytical finding elicited from SPT literature on smart energy systems. Several scholars have referred to the emergence of new (smart) technologies and new forms of (smart) energy conduct: When discussing the use of smart meters and feedback devices Hargreaves et al. (2013b) identify 'new forms of monitoring' employed by end-users. Pullinger et al. (2014: p1149) introduce the term 'reflection practice' to refer to a "process of mindfully thinking about one's routines". In analysing a project on the reduction of standby consumption, Gram-Hanssen (2010) suggests that the initially (simple) 'dispersed practice' of standby-consumption (or energy saving) developed into a more comprehensive 'integrated practice' during the course of the project. When discussing on-site energy production, Strengers (2013) refers to 'energy-making practices'. And, finally, in their account of a smart grid project Bulkeley et al. (2016b) find that 'forms of smart energy practice' and 'new forms of electricity conduct' are being introduced into the household. Chapter Five has brought these ideas together and expanded the list of relevant technologies and activities, arguing that there is common ground in the fact that all these technologies and activities are geared towards the management of energy flows at household level.

However, these findings do not yet amount to the conclusion that HEM-practices form a category of practices of their own nor that they assume an intermediary position inbetween the household and wider energy systems. Rather than seeing local energymaking practices as intermediary practices, Strengers (2011) for instance considers energy-making practices as part of energy infrastructures, and analyses how these intersect with 'practices-that-use-energy'. Similarly, Bulkeley et al. (2016b: p7) investigate how governmental rationales, smart technologies and new forms of energy conduct are being "appropriated, normalised, incorporated into or domesticated within existing [everyday] practice". The differences are subtle and not necessarily contradictory. This thesis does not refute the idea that HEM-practices are (also) part of 
domestic consumption practices or energy systems. Rather, it draws the analytical 'line' differently in order to discern between two spheres of the social - system and lifeworld - that use different types of logic in their functioning. Doing so is to invite more nuanced approaches to sustainability transitions. It helps to see the development of smart energy systems not necessarily as a series of one-sided top-down (or bottomup) interventions, but rather as a more complex, two-sided process in which (power) relationships between end-users and systemic actors are being reconfigured. Setting all HEM-practices apart and assigning them the function of intermediary practices allows one to see the multifaceted space for renegotiation that is opening up inbetween households and energy grids.

In part, however, the discerning of HEM-practices remains an open empirical question. Even though the contours are becoming increasingly visible, only the future will reveal how smart energy systems take root, and thus to what extent it makes sense to speak of HEM-practices as a distinct and analytically helpful set of (intermediary) practices. The discussion on the need for intermediary organisations and arrangements to support households and companies in the sustainable energy transition suggests that bundles of HEM-practices can become institutionalised - that is, anchored in time and space - in particular organisational forms. This gives rise to new research questions, like: What kind of HEM-practices are emerging? Are these relatively isolated or part of a more integrated set of HEM-practices? What kind of interconnections with domestic consumption practices and systemic practices are being formed? And, what particular organisational forms would fit best for intermediaries?

\subsubsection{Researching social practices and their networks}

Social Practice Theories have served as the primary frame of reference in this thesis. This section seeks to contribute to on-going discussions on the development of practice theories and methodologies (e.g. Bueger, 2012; Nicolini, 2012) by eliciting three points of interest for approaching social practices and their networks.

The first point concerns the discerning of practice components. As mentioned in Section 1.6, this thesis has not adopted a particular set of components for analysing practices. On the one hand, this has helped to create an open view on what a social practice is about, providing room for exploring different aspects, dimensions and components of social practices. In Chapter Four for instance the components specified by Reckwitz 
(2002) and Shove et al. (2012) 42 $^{42}$ were used as sensitizing statements on what practices might embrace, rather than as (rigid) analytical schemes. This allowed for a more explorative type of analysis and a more selective focus on the role of information in practices. In Chapter Five the practice-arrangement model of Schatzki (2002) ${ }^{43}$ was taken as the primary point of reference. This helped to (re)consider the material dimensions of practices (i.e. as part of practice-arrangement bundles) and it allowed for a more explicit discussion of the directionality of practices (i.e. using Schatki's concepts of rules and teleo-affective structures).

Not adopting a (single) scheme, however, also implied that there was less guidance in empirical research and analysis. In Chapter Three, for instance, energy monitoring, energy production and time-shifting were initially presented as emerging (HEMJpractices, without much thought being given to their empirical and analytical status; that is, as practices, practice-components or otherwise. This did not seem to hinder the ability of the respondents to relate to the matter, but it prompted some reflection in the concluding part of Chapter Three, and a more detailed explication of HEM-practices in Chapter Five. To alleviate the risk of analyses becoming either too open-ended or too narrow and simplistic (Nicolini, 2012; Spaargaren et al., 2016) one could start the analysis from a particular scheme that suits the purpose of the study, while remaining open to other schemes and possible adaptations along the way.

A second, closely related point relates to the delineation, differentiation and labelling of practices. In general, this thesis has taken theory (that is, abstract reasoning), rather than concrete empirical situations, as a starting point for analysis. This has resulted, among other things, in a general categorisation of practices that are relevant for analysing the interplay between households and smart energy systems. In particular, Chapter Five discerned five sets of domestic consumption practices (Food, Mobility, Cleanliness, Leisure \& Work, and Comfort \& Ambiance) and six sets of emerging HEMpractices (Energy monitoring, Co-/self-production of energy, Energy trading/sharing, Timing of demand, Energy storage, and Energy conservation). Each category of practices (potentially) embraces a multitude of 'smaller' practices.

Categorising and labelling practices in this way is a delicate issue that involves some trade-offs. On the one hand, in reflecting more or less distinct consumption domains (Spaargaren, 2003) the categories of domestic practices and HEM-practices that have

\footnotetext{
42 Reckwitz (2002): forms of bodily activities, forms of mental activities, 'things' and their use, a background knowledge in the form of understanding, know-how, states of emotion, and motivational knowledge. Shove et al. (2012): materials, competences and meanings.

43 Schatzki (2002, 2016b): practices (practical understandings, rules, teleo-affective structures, and general understandings) and arrangements (human bodies, organisms, artefacts, and things)
} 
been discerned seem useful for empirical analysis. On the other hand, however, this categorisation also invites a reduction of complexity by emphasising some interrelations between practices (e.g. spatial, teleo-affective), while downplaying other interrelations between practices (e.g. rhythmic, material). Especially with respect to households, several other networks of domestic consumption practices, that are either more tightly integrated or more loosely associated (Higginson et al., 2015; Shove et al., 2012) than the categories discerned here could be identified, depending on the kind of linkages that are being highlighted. In the end, however, any attempt at categorising and labelling seems artificial as practices and their networks are always embedded in wider networks of practices (Bueger, 2012; Nicolini, 2012; Schatzki, 2016). Similar to the schemes on practice components, then, the categories of practices suggested in this thesis are not intended as rigid analytical schemes, but as an open analytical device that can serve as a starting point for analysis of smart grid development.

The third and final point concerns the methods for researching social practices and their networks. This thesis has employed and combined a variety of methods. Chapter Four used participant observation in combination with interviews and house tours. This approach aligns quite well with Nicolini's practice-methodology of zooming in and out (Nicolini, 2012) in starting from the action (that is, zooming in on workshop practices) and subsequently exploring the interconnections with other practices (that is, zooming out on the larger networks of practices). For exploring domestic consumption practices however, it seems both unpractical and unethical to use the kind of ethnomethodological and ethnographic methods that practice scholars generally prefer (Browne, 2016; Bueger, 2012). In this sense, methods like interviews and house tours (as used here), can provide valid alternatives even though they rely on post-hoc accounts of practices.

The methods used in Chapter Three - a quantitative survey in combination with a focus group - seem less compatible with a practice-based approach. Both of these methods carry connotations of the 'methodological individualism' that SPT seeks to contest (Shove et al., 2012; Spaargaren et al., 2016). Yet, rather than relying solely on the intentions, values and motivations of individuals, both the survey and the focus group started from and referred as much as possible to actual decisions and practices in order to explore future configurations of practices. While this may not fully address the critiques on these methods, other research shows that there is significant potential in using such methods for revealing aspects of practices. It has been shown, for instance, that 'talk-based methods' like focus groups and interviews can help reveal what matters most in practices and thus say something about the likeliness of particular future trajectories of practices (Browne, 2016; Goulden et al., 2014; Hitchings, 2012). 
Similarly, the focus group (and the survey) proved to be helpful in exploring the relevance of autonomy and privacy considerations for specific future configurations of HEM-practices. Also quantitative surveys have proven to be useful for practice-based research, especially in tracing frequencies, rhythmic qualities and varieties in performances of practices (Bartiaux, 2008; Browne et al., 2013; Higginson et al., 2015; Nicholls and Strengers, 2015). So, while methods should always be critically assessed with respect to their suitability to practice-based research, there seems to be sufficient room for manoeuvre and exploration. Much depends on how methods like focus groups, surveys and interviews are being used and interpreted (Browne et al., 2013; 2016). More generally, it can be stated that SPT could benefit from the development of more systematic research approaches that alternate between the zoomed in and zoomed out modality of social scientific analysis.

\subsubsection{Approaching sustainable energy transitions}

The Governing-by-Practices Approach developed in this thesis promotes a particular way of analysing smart grid development as well as a particular way of governing sustainable energy transitions. This final section of the discussion highlights four issues that are relevant for reflecting on the development of this approach, and discussing the risks and affordances involved.

A first point concerns the concept of 'Home Energy Management-practices' (HEMpractices). There is a risk that this term reinforces an image of end-users as (individual) micro-energy managers, when used in the context of existing, mostly individualistic and rationalistic approaches to sustainable energy transitions. Doing so, would imply a return to 'Resource Man', a term coined by Strengers (2013) to denote the rational, tech-savvy, male individual that features prominently in smart grid discourse. Rather, as explicated in Chapter Five, the point is to see energy management at the household level as an (emerging) bundle of practices, and to use this term as part of a Governingby-Practices Approach.

There is also a risk that a focus on HEM-practices directs attention away from policy measures that are not readily associated with smart energy systems. This may include 'non-smart' measures like altering (and rethinking) building codes and technology standards to lower energy consumption (Shove, 2003), changing working times and daily rhythms to accommodate fluctuations in energy production (Walker, 2014), and nurturing (knowledge and know-how of) low-carbon and low-energy practices to prevent a rise in energy demand in the first place (Royston, 2014; Strengers and Maller, 2012). The focus on HEM-practices in the Governing-by-Practice Approach, then, is not 
to exclude any 'non-smart' measures or trajectories towards a more sustainable energy future, but rather to signal a particular development within the energy transition.

The second issue concerns the position of the human agent vis-à-vis the (material dimension off social practices. To describe the role of end-users in relation to (their) social practices, this thesis has mainly used the 'participant'-concept, rather than the 'carrier'-concept (Reckwitz, 2002; Shove et al., 2012). Even though both concepts are used to decentre individuals and their minds, an individual who participates in a social practice denotes a more prominent agential role for the individual vis-à-vis the practice than an individual who (merely) carries it on. Conceiving of end-users as 'change agents' however, might overstate the primacy of the individual (Chapter Three). ${ }^{44}$ From an SPT perspective (or, at least some SPT perspectives) this conceptualisation is problematic insofar as it reproduces a focus on individuals rather than on the social practices that make agency possible in the first place (Shove et al., 2012; Strengers, 2012). In close resemblance with Actor Network Theory, moreover, SPT scholars are arguing that agency is not exclusive to the individual, but distributed (or networked) between the human and non-human elements of practices (Schatzki, 2002; Strengers et al., 2016). At the same time, the agential powers of humans and non-humans are not the same; agential qualities like intelligibility, intentionality and affectivity - as manifested in networks of practices - 'belong' to human beings, not to things or technologies (Nicolini, 2012; Schatzki, 2002; Spaargaren et al., 2016). ${ }^{45}$ From this discussion it can be concluded that smart grid development can never fully rely on human agency (e.g. in the form of consumer engagement strategies) nor on non-human agency (e.g. in the form of home automation strategies). Rather, smart grid policy and interventions should account for both human and non-human agency in a way that reflects their respective agential qualities.

The third issue concerns the directionality of social change. The Governing-by-Practices Approach contains an assumption that the emergence of HEM-practices, and the linking of sustainability goals to HEM-practices, is a desirable and necessary development. From a Foucauldian perspective however, HEM-practices can also be seen as a new form of disciplinary power (or: green governmentality) through which governments (or corporations) seek to subject end-users to their rationales, goals and ideals - be it sustainability or something else. HEM-practices, in that case, normalise end-user practices and impede their freedom of choice and conduct (see e.g. Bulkeley

\footnotetext{
44 To do so, was to foreground the shift in responsibility for change from systemic (energy) actors to domestic actors in smart energy transitions.

${ }^{45}$ Reckwitz (2012), by contrast, sees affectivity, perceptiveness and sensuality as part of social practices. Individuals, in this account, feature as the 'sensual-perceptive agents'.
} 
et al., 2016b; Marres, 2011). Disciplinary power, and power more generally, can be exercised in overt and direct ways - e.g. through the top-down organisation of HEMpractices - as well as in more indirect and hidden ways - e.g. through the promotion of self-discipline or self-governance.

With respect to the more overt, direct exercise of control, this thesis has drawn attention to the need to involve end-users in decision-making processes on sustainability goals, HEM-practices and decentralised innovation trajectories. As indicated in Chapter Three, HEM-practices can, at least in principle, be organised in such a way that system actors have little direct influence on the practices of end-users, for instance through private and horizontal arrangements. What can be questioned, nevertheless, is the extent to which such an open-ended (theoretical) approach to power reflects the actual distribution of power in smart grid development. Historically, governments and energy companies hold more powerful positions vis-à-vis end-users, and it is unlikely that this will simply dissolve. Indeed, in the energy transition at large the continuing dominance of centralised actors is often considered to be a key reason for the slow pace of change (Verbong and Loorbach, 2012; Verbong et al., 2013). So rather than implying that smart grid development starts from a clean slate, the suggestion is that the emergence of HEM-practices opens up new possibilities for the redistribution of power between conventional, centralised actors and more unconventional, decentralised actors, including (groups of) end-users.

With respect to (the threat of) self-discipline/self-governance, the thesis draws attention to two aspects of HEM-practices. First, this thesis concurs with Bulkeley et al. (2016b) and Halkier (2010) that governmental programs, rather than functioning as blueprints for end-user conduct, are subject to adaptation, mediation, contestation (etc.) when put into practice. SPT thus helps to see that the effects of HEM-practices are always dependent on the particular ways in which, and the extent to which, elements of these programs are incorporated into existing practices and their networks. Next to that, Chapter Three and Chapter Four have also indicated that the emergence of HEM-practices is not solely a top-down governmental (or corporate) program, but also reflects and incorporates bottom-up developments such as the growth of collective energy production initiatives, collective acquisition of solar panels, and car-sharing schemes. Acknowledging (and facilitating) this bottom-up movement may help in (re)positioning smart grid development as a collective societal endeavor, instead of as a particularistic undertaking for which only systemic actors or end-users bear ultimate responsibility. Taken together, these points imply that the Governing-byPractice Approach that is proposed in this thesis, rather than being a one-sided normative program, opens up new (conceptual) space for analysing the power 
dynamics of sustainable energy transitions, an aspect which has received relatively little attention both in Social Practice Theories as well as in Transition Theories (Smith et al., 2005; Geels et al., 2015; Sayer, 2013).

The fourth and final aspect concerns the commensurability of Social Practice Theories (SPT) and Transition Theories (TT). In developing the Governing-by-Practice approach this thesis has engaged with and drawn upon TT (Chapter Five). There are, however, different positions with respect to the commensurability of the two bodies of theory. Scholars who highlight complementarity and possibilities for cross-over refer to the joint emphasis on process, to the heterogeneous composition of the analytical units (practices and levels), and to the joint conceptualisation of change as co-evolutionary in nature (Geels et al., 2015; Hargreaves et al., 2013a; McMeekin and Southerton, 2012; Spaargaren et al., 2012; Watson, 2012; Welch and Warde, 2015). Scholars who accentuate difference and incommensurability, on the other hand, point to the differences in the ontologies of both bodies of theory. In that case SPT's 'flat ontology' - which assumes that 'all' is spread out on one plain of the social - is contrasted with TT's (suspected) 'multi-level ontology' - which assumes a specific hierarchy in the social or, at a minimum, different degrees of institutionalisation (Schatzki, 2016b; Shove and Walker, 2010; Geels, 2011).

The Governing-by-Practices Approach assumes a special position within the SPT-TT debate by endorsing specific elements of TT without abandoning the flat ontology of SPT. It offers a way of crossing the SPT-TT divide by connecting the small(er)-scale phenomena of energy consumption that are usually at the centre of attention in SPT studies, to the large(r)-scale phenomena of technological innovation in production systems that are typically at the centre of TT studies. This approach has resulted in a number of additions to the debate on sustainability transitions. First, following a suggestion by McMeekin and Southerton (2012) to conceptualise the space in-between the spheres of production and consumption, Chapter Five has identified HEM-practices as mediating entities in-between households and wider energy systems. Understanding HEM-practices as mediating practices not only helps to understand shifting power relations in the energy transition, but also broadens the concept of '(inter)mediation' beyond intermediary actors and organisations (Moss, 2009; Rohracher, 2009) and intermediary technologies and material infrastructures (Marvin and Medd, 2004; Strengers, 2011b). Second, Chapter Five has pointed to the directionality of HEM-practices, in particular the 'rules' and the 'teleo-affective structures' (Schatzki, 2002). Such a practice-based understanding of directionality offers a way of connecting the long-term goals of systemic change in the energy transition to the myriad of small-scale changes taking place in the everyday lives of 
end-users. Third, Chapter Five suggests that the typology of transition pathways for systemic change, as specified in TT (Geels and Schot, 2007), is also relevant for SPT frameworks. When understood as the sum-total of changes in practices and their networks over long periods of time, this typology can serve either as a starting point for a more detailed analysis of changes in practices or as a summary of its outcomes.

The points mentioned in this section form a bundle of thoughts (in progress) that reflect the diversity of ideas that have been explored, considered, reconsidered and occasionally discarded in the course of the thesis trajectory. The final section draws some of these ideas together in order to formulate an agenda for future policy and research.

\subsection{Recommendations}

On the basis of the conclusions and the discussion presented in this concluding chapter a number of recommendations for policy and research can be formulated. This section starts with the policy recommendations and ends with the research recommendations.

\subsubsection{Recommendations for policy}

First, with respect to policy, this thesis has formulated a set of four focal points for the governance of householder participation in sustainable energy transitions that are enabled by smart energy systems. In short, these four focal points can be reiterated as follows: 46

1. Focus on the development and embedding of Home Energy Management-practices (HEM-practices) that emerge at the interface between households and wider energy infrastructures.

2. Develop sustainability goals for HEM-practices in dialogue with end-users to make sure that smart grid development contributes to a sustainable energy transition.

3. Make room for local innovation trajectories in HEM-practices to adapt to personal preferences and local circumstances, while safeguarding end-users against unwanted invasions of their privacy and autonomy.

4. Provide long-term support to end-user participation in HEM-practices by investing in trustworthy intermediary organisations that (re-)connect end-users and systemic actors in innovative and well-balanced ways.

\footnotetext{
${ }^{46}$ For a more elaborate version of these focal points see Section 6.2.
} 
Together these focal points form the basis of a Governing-by-Practices Approach (GPA). When further explicated in a policy context, GPA could serve as a sociological alternative to the individualist and technology-focused approaches that prevail in energy-related policy and practice.

\subsubsection{Recommendations for research}

Finally, with a view to future research on smart grids and end-users, this thesis has given rise to a variety of theoretical and methodological ideas. These ideas can be boiled down to the following set of research recommendations: 47

\section{Start mapping the emergence, embedding and effects of HEM-Practices}

This thesis has outlined a conceptual framework for studying Home Energy Management-practices (Chapter 5). Future research could empirically trace the composition of (specific) HEM-practices, their development and decay trajectories, and consequently the effects on domestic and systemic practices. It could also examine how different actors (seek to) shape the composition of HEM-practices and direct their trajectories. Both comparative research (comparing HEM-practices between different sites) and longitudinal research (following HEM-practices over time) are instrumental in this regard. Empirical investigations into HEM-practices could strengthen the empirical basis of the framework, and help reflect on and improve its ability to describe, understand and organise sustainable energy transitions that are enabled by smart energy systems.

\section{Further explore the notion of 'intermediary practices'}

This thesis has suggested that HEM-practices can be seen as intermediary practices that emerge at the interface between households and wider energy systems. Future research could delve into the notion of intermediary practices by comparing and contrasting it with existing notions of intermediaries which refer either to actors or to objects. Considering the potentially high degrees of automation that come along with smart grid development, such research may also help to (re)consider the different agential powers of humans and non-humans, as expressed in HEM-practices. Finally, the notion of intermediary practices may be relevant not only for the domain of energy, but for water, food, waste and air quality issues as well, with the increasing emphasis on decentralised monitoring in each of these domains (e.g. Smart Cities).

\footnotetext{
${ }^{47}$ For background and more details see Section 6.3.
} 
Refine the body of literature on methodologies for practice-based research

With the work on social practice theories and methodologies in progress, future research could bring together and expand the fragmented but growing literature on methodologies for researching practices and their networks. Such an overview is useful as a starting point and guide for scholars who want to use social practice theories, or consider doing so. There is particular promise in developing approaches that systematically alternate between the zoomed-in modus and the zoomed-out modus, focusing on the details of specific performances and on the larger network of practices respectively. Also in terms of concrete methods there is room for manoeuvre and exploration. Rather than dismissing specific methods beforehand, future research could further explore (and critically assess) how such methods can be put to work in practice-based research.

Further investigate alliances between theories that are relevant for the governance of sustainability transitions

This thesis has explored alliances between Social Practices Theories (SPT) and Informational Governance (IG), and between SPT and Transition Theories (TT). In both cases there proved to be possibilities for learning and adjustment that do not undermine the distinct character of SPT. Alliances between SPT and IG could build on the suggested distinction between 'informational practices' and 'information-inpractices'. This distinction may help in evaluating the effects of (environmental) policies, programs and initiatives that centre on information or information technologies. Alliances between SPT and TT could further explore the linkages between (the governance of) short-term, small-scale change and long-term, systemic change. Of particular merit to transition governance are differences and alignments in directionality between these two time-space extensions. Finally, the Governing-byPractices Approach (GPA) could be inspected and expanded. GPA promotes an idea of governance that is rooted in SPT, but also provides room for transition theories and theories of (informational) governance to contribute to the discussion.

Together these points form a research agenda for further investigating the social dynamics of smart grids. With the research agenda and the policy recommendations in place, this thesis comes to a close. I hope you have enjoyed reading the thesis, and I hope it has generated some inspiring and useful new ideas. 


\section{References}

Amsterdam Smart City (2016) About Amsterdam Smart City. Available at: https://amsterdamsmartcity.com/p/about (accessed 15 November 2016).

Bailey M, Bush SR, Miller A, et al. (2016) The role of traceability in transforming seafood governance in the global South. Current Opinion in Environmental Sustainability 18: 2532.

Bartiaux F (2008) Does environmental information overcome practice compartmentalisation and change consumers' behaviours? Journal of Cleaner Production 16: 1170-1180.

Beaulieu A (2016) What Are Smart Grids? Epistemology, Interdisciplinarity and Getting Things Done. In: Beaulieu A, De Wilde J and Scherpen J (eds) Smart Grids from a Global Perspective: Bridging Old and New Energy Systems. Cham: Springer, pp.63-73.

Beaulieu A, de Wilde J and Scherpen J (2016) Smart Grids from a Global Perspective: Bridging Old and New Energy Systems. Cham: Springer.

Bell S, Judson E, Bulkeley H, et al. (2015) Sociality and electricity in the United Kingdom: the influence of household dynamics on everyday consumption. Energy research \& social science 9: 98-106.

Bertoldo R, Poumadère M and Rodrigues LC Jr (2015) When meters start to talk: The public's encounter with smart meters in France. Energy research \& social science 9: 146-156.

Beyea J (2010) The smart electricity grid and scientific research. Science 328: 979-980.

BigThink (2015) Jeremy Rifkin on the Energy Internet. Available at: http://bigthink.com/think-tank/jeremy-rifkin-on-the-energy-internet (accessed 8 December 2016)

BigThink (2016) About Us. Available at: http://bigthink.com/about (accessed 8 December 2016)

Blumsack S and Fernandez A (2012) Ready or not, here comes the smart grid! Energy 37: 6168.

Boon FP and Dieperink C (2014) Local civil society based renewable energy organisations in the Netherlands: Exploring the factors that stimulate their emergence and development. Energy Policy 69: 297-307.

Bosmans (2013) Streetwise smart grid: De vierde fase in de evolutie van het smart grid debat. Report for DRIFT, Erasmus University Rotterdam, The Netherlands, March.

Bourdieu P (1977) Outline of a Theory of Practice. Cambridge: Cambridge University Press. 
Breukers S and Mourik R (2013) End-user engagement for flexible energy consumption patterns: Towards tailored interventions for shifting and reducing household energy demand. In: Proceedings of SCORAI Europe \& InContext Workshop, Rotterdam, The Netherlands, 7-8 October 2013, pp.294-315.

Browne AL (2016) Can people talk together about their practices? Focus groups, humour and the sensitive dynamics of everyday life. Area 48(2): 198-205

Browne AL, Medd W and Anderson B (2013) Developing novel approaches to tracking domestic water demand under uncertainty-A reflection on the "up scaling" of social science approaches in the United Kingdom. Water Resources Management 27: 10131035 .

Browne AL, Medd W, Anderson B, et al. (2014) Method as intervention: intervening in practice through quantitative and mixed methodologies. In: Strengers Y and Maller C (eds) Social Practices, Interventions and Sustainability: Beyond Behaviour Change. London: Routledge, pp.179-195

Bueger C (2014) Pathways to practice: praxiography and international politics. European political science review 6: 383-406.

Bulkeley H and Betsill MM (2013) Revisiting the urban politics of climate change. Environmental politics 22: 136-154.

Bulkeley H, McGuirk PM and Dowling R (2016a) Making a smart city for the smart grid? The urban material politics of actualising smart electricity networks. Environment and planning A 48: 1709-1726.

Bulkeley H, Powells G and Bell S (2016b) Smart grids and the constitution of solar electricity conduct. Environment and planning A 48: 7-23.

Bullis (2009) Dumb meters get smarter. MIT Technology Review. Available at: https://www.technologyreview.com/s/412798/dumb-meters-get-smarter/(accessed 28 April 2017)

Burgess J and Nye M (2008) Re-materialising energy use through transparent monitoring systems. Energy Policy 36: 4454-4459.

Castells M (1996) The rise of the network society: The information age: Economy, society, and culture (Vol. 1). Massachusetts: Blackwell Publishers Inc.

Castells M (1996-1998) The Information Age: Economy, Society and Culture. Oxford: Blackwell Publishing Ltd.

Castells M (2009) Communication power. Oxford: Oxford University Press. 
Cavoukian A, Polonetsky J and Wolf C (2010) Smartprivacy for the smart grid: embedding privacy into the design of electricity conservation. Identity in the Information Society 3: 275-294.

CBS - Centraal Bureau voor de Statistiek (2013) Figures by theme. Available at: http://www.cbs.nl/en-GB/menu/ cijfers/cijfers-perthema/default.htm?Languageswitch=on (accessed 10 September 2013).

Christensen TH, Ascarza A, Throndsen W, et al. (2013) The role of households in the smart grid: a comparative study. In: ECEEE 2013 Summer Study - Rethink, Renew, Restart, Toulon, France, 3-8 June 2013, pp.2285-2296. Stockholm: ABA Intercopy.

Clastres C (2011) Smart grids: Another step towards competition, energy security and climate change objectives. Energy Policy 39: 5399-5408.

Collins R (2004) Interaction Ritual Chains. Princeton: Princeton University Press.

Coll-Mayor D, Paget M and Lightner E (2007) Future intelligent power grids: Analysis of the vision in the European Union and the United States. Energy Policy 35: 2453-2465.

Cook W, van Bommel S and Turnhout E (2016) Inside environmental auditing: effectiveness, objectivity, and transparency. Current Opinion in Environmental Sustainability 18: 33-39.

Cotton M and Devine-Wright P (2012) Making electricity networks "visible": Industry actor representations of "publics" and public engagement in infrastructure planning. Public Understanding of Science 21: 17-35.

Covrig CF, Ardelean M, Vasiljevska J, et al. (2014) Smart grid projects outlook 2014. JRC Science and Policy Reports, European Commission. Luxembourg: Publications Office of the European Union.

Cowan RS (1983) More work for mother: The ironies of household technology from the open hearth to the microwave (Vol. 5131). New York: Basic Books.

Cox AM (2013) Information in social practice: A practice approach to understanding information activities in personal photography. Journal of Information Science 39: 6172.

Creswell JW (2013) Research design: Qualitative, quantitative, and mixed methods approaches. London: Sage.

Cuijpers C and Koops BJ (2008) Het wetsvoorstel 'slimme meters': een privacytoets op basis van art. 8 EVRM. Report for the Consumentenbond, University of Tilburg, The Netherlands, October.

D’Oca S, Corgnati SP and Buso T (2014) Smart meters and energy savings in Italy: Determining the effectiveness of persuasive communication in dwellings. Energy research \& social science $3:$ 131-142. 
Darby S (2006) The effectiveness of feedback on energy consumption. Report for DEFRA, University of Oxford, UK, April.

Darby S (2010) Smart metering: what potential for householder engagement? Building Research \& Information 38: 442-457.

Doyle R and Davies AR (2013) Towards sustainable household consumption: exploring a practice oriented, participatory backcasting approach for sustainable home heating practices in Ireland. Journal of Cleaner Production 48: 260-271.

Dutch Central Government (2013) Slimme Meter. Available at: http://www. rijksoverheid.nl/onderwerpen/gas-en-elektriciteit-thuis/slimme-meter (accessed 03 July 2013).

Dutch Central Government (2016) Kabinet schetst route naar CO2-arme energievoorziening. Available at: https://www.rijksoverheid.nl/actueel/nieuws/2016/12/07/kabinetschetst-route-naar-co2-arme-energievoorziening (accessed 07 December 2016).

Dutch Ministry of Economic Affairs (2014) Besluit grootschalige uitrol slimme meters. Directoraat-generaal Energie, Telecom \& Mededinging, Directie Energiemarkt, 10 March.

ECN (2014) Energie Trends 2014. Report by ECN, Energie Nederland and Netbeheer Nederland. Report No. ECN-O--14-041, September.

Elliott D (2013) Emergence of European supergrids - Essay on strategy issues. Energy Strategy Reviews 1: 171-173.

Ellsworth-Krebs K, Reid L and Hunter CJ (2015) Home-ing in on domestic energy research: "House,"'home," and the importance of ontology. Energy research \& social science 6: 100108.

Energiekaart (2015) Projecten. Available at: http://energiekaart.net/ (accessed 5 November 2015).

Enexis (2016) Enexis huis. Available at: https://www.enexishuis.nl/\# (accessed 20 April 2016).

Erlinghagen S and Markard J (2012) Smart grids and the transformation of the electricity sector: ICT firms as potential catalysts for sectoral change. Energy Policy 51: 895-906.

ETP Smart Grids (2016) Mission and Objectives. Available at: http://www.smartgrids.eu/node/5 (accessed 5 December 2016).

European Commission (2011a) Smart grids: from innovation to deployment. Communication from the Commission to the European Parliament, the Council, the European Economic and Social Committee and the Committee of the Regions. COM(2011) 202 final, Brussels, 12 April. 
European Commission (2011b) Smart grids: from innovation to deployment: Definition, expected services, functionalities and benefits from smart grids. Communication from the Commission to the European Parliament, the Council, the European Economic and Social Committee and the Committee of the Regions. SEC(2011) 463 final, Brussels, 12 April.

European Commission (2012) Commission Recommendation of 9 March 2012 on preparations for the roll-out of smart metering systems. Official Journal of the European Union, 13 March 2012.

European Commission (2014) A policy framework for climate and energy in the period from 2020 to 2030. Communication from the Commission to the European Parliament, the Council, the European Economic and Social Committee and the Committee of the Regions. COM(2014) 15 final, Brussels, 22 January.

European Commission (2015a) Energy Union Package: A framework Strategy for a Resilient Energy Union with a Forward-Looking Climate Policy. Communication from the Commission to the European Parliament, the council, the European economic and social committee, the Committee of the Regions and the European Investment Bank. $\operatorname{COM(2015)~} 80$ final, Brussels, 25 February.

European Commission (2015b) 2020 Climate \& Energy Package. Available at: http://ec.europa.eu/clima/policies/strategies/2020/index en.htm (accessed 10 November 2015).

European Commission (2016) Smart grids and meters. Available at: https://ec.europa.eu/energy/en/topics/markets-and-consumers/smart-grids-andmeters (accessed 15 November 2016).

European Environment Agency (2016) Final Energy Consumption by Sector and Fuel. Available at: http://www.eea.europa.eu/data-and-maps/indicators/final-energyconsumption-by-sector-9/assessment-1 (accessed 15 November 2016).

Faruqui A and Sergici S (2010) Household response to dynamic pricing of electricity: a survey of 15 experiments. Journal of regulatory Economics 38: 193-225.

Faruqui A, Sergici S and Sharif A (2010) The impact of informational feedback on energy consumption-A survey of the experimental evidence. Energy 35: 1598-1608.

Fell MJ, Shipworth D, Huebner GM, et al. (2015) Public acceptability of domestic demand-side response in Great Britain: The role of automation and direct load control. Energy research \& social science 9: 72-84.

Field A (2013) Discovering statistics using IBM SPSS statistics. London: Sage.

Fischer C (2008) Feedback on household electricity consumption: a tool for saving energy? Energy efficiency 1: 79-104. 
Foucault M (1995) Discipline \& Punish: The Birth of the Prison. New York: Vintage Books.

Foulds C, Royston S, Buchanan K, et al. (2014) The many faces of feedback: Beyond the kWh. In: Foulds C and Jensen CL (eds) Practices, the Built Environment and Sustainability - A Thinking Note Collection. Cambridge, Copenhagen, London: GSI, DIST, BSA CCSG, pp.1921.

Foxon TJ (2013) Transition pathways for a UK low carbon electricity future. Energy Policy 52: $10-24$.

Gangale F, Mengolini A and Onyeji I (2013) Consumer engagement: An insight from smart grid projects in Europe. Energy Policy 60: 621-628.

Gawel E, Strunz S and Lehmann P (2013) Germany's Energy Transition Under Attack: Is There an Inscrutable German Sonderweg? Nature and Culture 8: 121-133.

Geelen DV (2014) Empowering end-users in the energy transition: An exploration of products and services to support changes in household energy management. $\mathrm{PhD}$ thesis, Delft University of Technology, The Netherlands.

Geels F, Kemp R, Dudley G, et al. (2012) Automobility in transition? A socio-technical analysis of sustainable transport. London: Routledge.

Geels FW (2002) Technological transitions as evolutionary reconfiguration processes: a multi-level perspective and a case-study. Research policy 31: 1257-1274.

Geels FW (2010) Ontologies, socio-technical transitions (to sustainability), and the multilevel perspective. Research policy 39: 495-510.

Geels FW (2011) The multi-level perspective on sustainability transitions: Responses to seven criticisms. Environmental innovation and societal transitions 1: 24-40.

Geels FW and Schot J (2007) Typology of sociotechnical transition pathways. Research policy 36: 399-417.

Geels FW, McMeekin A, Mylan J, et al. (2015) A critical appraisal of Sustainable Consumption and Production research: The reformist, revolutionary and reconfiguration positions. Global Environmental Change 34: 1-12.

Geisler K (2013) The relationship between smart grids and smart cities. IEEE newsletter, May.

Giddens A (1984) The constitution of society: Outline of the theory of structuration. Berkeley: University of California Press.

Giordano V, Gangale F, Fulli G, et al. (2011) Smart Grid projects in Europe: lessons learned and current developments. JRC Reference Reports, European Commission. Luxembourg: Publications Office of the European Union. 
Goulden M, Bedwell B, Rennick-Egglestone S, et al. (2014) Smart grids, smart users? The role of the user in demand side management. Energy research \& social science 2: 21-29.

Graham S (1998) Spaces of surveillant simulation: new technologies, digital representations, and material geographies. Environment and Planning D: Society and Space 16: 483-504.

Gram-Hanssen K (2010) Standby consumption in households analyzed with a practice theory approach. Journal of Industrial Ecology 14: 150-165.

Gregson N, Metcalfe A and Crewe L (2007) Moving things along: the conduits and practices of divestment in consumption. Transactions of the Institute of British Geographers 32: 187200.

GridWise Alliance (2016) GridWise Alliance: joining forces to realize a smart grid. Available at: http://www.gridwise.org/gridwisealli_about.asp (accessed 03 February 2016).

Grin J (2010) Understanding transitions from a governance perspective, Part III. In: Grin J, Rotmans J and Schot J (eds) T Transitions to Sustainable Development: New Directions in the Study of Long Term Transformative Change. London: Routledge, pp.223-319.

Grin J, Rotmans J and Schot J (2010) Transitions to Sustainable Development: New Directions in the Study of Long Term Transformative Change. London: Routledge.

Grin J, Rotmans J and Schot J (2011) On patterns and agency in transition dynamics: Some key insights from the KSI programme. Environmental innovation and societal transitions 1: 76-81.

Gupta A and Mason M (2016) Disclosing or obscuring? The politics of transparency in global climate governance. Current Opinion in Environmental Sustainability 18: 82-90.

Guy S, Marvin S and Moss T (2001) Urban infrastructure in transition: networks, buildings, plans. Abingdon: Earthscan Publication.

Habermas J (1985) The theory of communicative action, Volume 2: Lifeworld and system: A critique of functionalist reason. Boston: Beacon Press.

Hakvoort R and Huygen A (2012) Sturen op het gebruik van lokale energienetten. Report for the Ministry of Economic Affairs, Agriculture and Innovation, D-Cision B.V. and TNO, 5 October.

Halkier B (2010) Consumption challenged: Food in medialised everyday lives. London: Ashgate Publishing Ltd.

Halkier B and Jensen I (2011) Methodological challenges in using practice theory in consumption research. Examples from a study on handling nutritional contestations of food consumption. Journal of Consumer Culture 11: 101-123. 
Hargreaves T (2010) Putting Foucault to work on the environment: Exploring proenvironmental behaviour change as a form of discipline. CSERGE working paper EDM, No. 10-11, University of East Anglia, UK, June.

Hargreaves T (2012) Governing energy use at home: smart meters, governmentality and resistance. 3S Working paper, Science, Society and Sustainability Research Group, University of East Anglia, UK, January.

Hargreaves T, Longhurst N and Seyfang G (2013a) Up, down, round and round: connecting regimes and practices in innovation for sustainability. Environment and planning $A 45$ : 402-420.

Hargreaves T, Nye M and Burgess J (2010) Making energy visible: A qualitative field study of how householders interact with feedback from smart energy monitors. Energy Policy 38: 6111-6119.

Hargreaves T, Nye M and Burgess J (2013b) Keeping energy visible? Exploring how householders interact with feedback from smart energy monitors in the longer term. Energy Policy 52: 126-134.

Hegger D, Spaargaren G, Van Vliet BJM, et al. (2011) Consumer-inclusive innovation strategies for the Dutch water supply sector: Opportunities for more sustainable products and services. NJAS-Wageningen Journal of Life Sciences 58: 49-56.

Heiskanen E, Johnson M, Robinson S, et al. (2010) Low-carbon communities as a context for individual behavioural change. Energy Policy 38: 7586-7595.

Hendriks CM (2008) On inclusion and network governance: the democratic disconnect of Dutch energy transitions. Public Administration 86: 1009-1031.

Hess DJ (2014) Smart meters and public acceptance: comparative analysis and governance implications. Health, Risk \& Society 16: 243-258.

Hier Klimaatbureau (2016) 12 visies op wonen zonder aardgas. Available at: https://hier.nu/klimaatbureau/nieuws/12-visies-op-wonen-zonder-aardgas (accessed 15 December 2016).

HierOpgewekt (2014) Inventarisatie initiatieven Available at: https://www.hieropgewekt.nl/initiatieven (accessed 12 November 2014).

Higginson S, Thomson M and Bhamra T (2014) "For the times they are a-changin": the impact of shifting energy-use practices in time and space. Local Environment 19: 520-538.

Hitchings R (2012) People can talk about their practices. Area 44: 61-67.

Hoefnagel E, de Vos B and Buisman E (2013) Marine informational governance, a conceptual framework. Marine Policy 42: 150-156. 
Hoenkamp R, Huitema GB and de Moor-van Vugt AJ. (2011) The neglected consumer: the case of the smart meter rollout in the Netherlands. Renewable Energy L. \& Pol'y Rev.: 269.

Hoppe T, Graf A, Warbroek B, et al. (2015) Local governments supporting local energy initiatives: lessons from the best practices of Saerbeck (Germany) and Lochem (The Netherlands). Sustainability 7: 1900-1931.

Jacobsson S and Lauber V (2006) The politics and policy of energy system transformationexplaining the German diffusion of renewable energy technology. Energy Policy 34: 256276.

Jay SA and Toonen HM (2015) The power of the offshore (super-) grid in advancing marine regionalization. Ocean \& Coastal Management 117: 32-42.

Jefferson M (2008) Accelerating the transition to sustainable energy systems. Energy Policy 36: 4116-4125.

Jolivet E and Heiskanen E (2010) Blowing against the wind-An exploratory application of actor network theory to the analysis of local controversies and participation processes in wind energy. Energy Policy 38: 6746-6754.

JRC Project Maps (2016) Smart Electricity Systems and Interoperability: Project maps. Available at: http://ses.jrc.ec.europa.eu/project-maps (accessed 16 December 2016).

JRC Smart Metering (2016) Smart Metering Deployment in the European Union. Available at: http://ses.jrc.ec.europa.eu/smart-metering-deployment-european-union (accessed 15 November 2016)

Juntunen JK (2014) Prosuming energy-User innovation and new energy communities in renewable micro-generation. $\mathrm{PhD}$ thesis, Aalto University, Finland.

Kawulich BB (2005) Participant observation as a data collection method. Forum: Qualitative Social Research 6(2): 1-19

Kemp R (2010) The Dutch energy transition approach. International Economics and Economic Policy 7: 291-316.

Kemp R, Schot J and Hoogma R (1998) Regime shifts to sustainability through processes of niche formation: the approach of strategic niche management. Technology Analysis \& Strategic Management 10: 175-198.

Kern F and Smith A (2008) Restructuring energy systems for sustainability? Energy transition policy in the Netherlands. Energy Policy 36: 4093-4103.

Kester J (2016) Conducting a Smarter Grid: Reflecting on the Power and Security Behind Smart Grids with Foucault. In: Beaulieu A, De Wilde J and Scherpen J (eds) Smart Grids from a Global Perspective: Bridging Old and New Energy Systems. Cham: Springer, pp.197213. 
Klopfert F and Wallenborn G (2011) Empowering consumers through smart metering. Report for BEUC (the European Consumer Organisation), Université Libre de Bruxelles, Belgium, December.

Kobus C (2016) A switch by design: user-centred design of smart energy technologies to change habits of using energy at home. PhD Thesis, Delft University of Technology, The Netherlands.

Kuijer SC (2014) Implications of Social Practice Theory for Sustainable Design. PhD Thesis, Delft University of Technology, The Netherlands.

Kumar R (2014) Research methodology: A step-by-step guide for beginners. London: Sage.

Labanca N (2016) Response to the Discussion Paper on Change. In: DEMAND Conference 2016, DEMAND Centre, Lancaster University, UK, 13-15 April 2016.

Laes E, Gorissen L and Nevens F (2014) A comparison of energy transition governance in Germany, the Netherlands and the United Kingdom. Sustainability 6: 1129-1152.

Lamers M and Van der Duim R (2016) Connecting practices: Conservation tourism partnerships in Kenya. In: Spaargaren G, Weenink D and Lamers M (eds) Practice Theory and Research: Exploring the Dynamics of Social Life. London: Routledge, pp.179-201.

Lamers M, Pristupa A, Amelung B, et al. (2016) The changing role of environmental information in Arctic marine governance. Current Opinion in Environmental Sustainability 18: 49-55.

Latour B (2005) Reassembling the social: An introduction to actor-network-theory. Oxford: Oxford University Press.

Lehtonen M, Sébastien L and Bauler T (2016) The multiple roles of sustainability indicators in informational governance: between intended use and unanticipated influence. Current Opinion in Environmental Sustainability 18: 1-9.

Lenhart J (2015) Urban climate governance: the role of local authorities. PhD Thesis, Wageningen University, The Netherlands.

Lin CC, Yang CH and Shyua JZ (2013) A comparison of innovation policy in the smart grid industry across the pacific: China and the USA. Energy Policy 57: 119-132.

Lindblom CE (1959) The science of" muddling through". Public administration review 19(2): 79-88.

Locamation (2011) Proeftuin LochemEnergie: Intelligent Net in Duurzaam Lochem. Report of consortium partners (Locamation, LochemEnergie, Alliander, Eaton, Trianel, Technical University of Twente) to the Ministry of Economic Affairs, The Netherlands, [date unknown]. 
LochemEnergie (2016) Homepage. Available at: https://www.lochemenergie.net/ (accesssed 15 December 2016).

Longhurst R (2003) Semi-structured interviews and focus groups. In: Clifford N, Cope M, Gillespie T, et al. (eds) Key methods in geography (third edition). London: Sage, pp.117132.

Loorbach D and Rotmans J (2010) The practice of transition management: Examples and lessons from four distinct cases. Futures 42: 237-246.

Macrorie R, Daly M and Spurling N (2014) Can 'systems of practice' help to analyse wide-scale sociotechnical change? In: Foulds C and Jensen CL (eds) Practices, the Built Environment and Sustainability - A Thinking Note Collection Cambridge, Copenhagen, London: GSI, DIST, BSA CCSG, pp.16-18.

Macrorie R, Foulds C and Hargreaves T (2015) Governing and governed by practices: Exploring interventions in low-carbon housing policy and practice. In: Strengers Y and Maller C (eds) Social Practices, Intervention and Sustainability: Beyond Behaviour Change. London: Routledge, pp.95-111.

Markard J, Raven R and Truffer B (2012) Sustainability transitions: An emerging field of research and its prospects. Research policy 41: 955-967.

Markovic D, Cvetkovic D, Zivkovic D, et al. (2012) Challenges of information and communication technology in energy efficient smart homes. Renewable and Sustainable Energy Reviews 16: 1210-1216.

Marres N (2011) The costs of public involvement: everyday devices of carbon accounting and the materialization of participation. Economy and society 40: 510-533.

Marres N (2012) Material participation: technology, the environment and everyday publics. Basingstoke: Palgrave Macmillan.

Marris (2008) Energy: Upgrading the Grid. Nature 454: 570-573. Available at: http://www.nature.com/news/2008/080730/full/454570a/box/1.html

Marvin S and Guy S (1997) Infrastructure provision, development processes and the coproduction of environmental value. Urban studies 34: 2023-2036.

Marvin S and Medd W (2004) Sustainable infrastructures by proxy? Intermediation beyond the production-consumption nexus. In: Southerton D, Chappells H and Van Vliet BJM (eds) Sustainable consumption: The implications of changing infrastructures of provision. Cheltenham: Edward Elgar, pp.81-96.

Marvin S, Chappells H and Guy S (1999a) Pathways of smart metering development: shaping environmental innovation. Computers, Environment and Urban Systems 23: 109-126. 
Marvin S, Graham S and Guy S (1999b) Cities, regions and privatised utilities. Progress in Planning 51: 91-165.

McKenna E, Richardson I and Thomson M (2012) Smart meter data: Balancing consumer privacy concerns with legitimate applications. Energy Policy 41: 807-814.

McMeekin A and Southerton D (2012) Sustainability transitions and final consumption: practices and socio-technical systems. Technology Analysis \& Strategic Management 24: 345-361.

Merriam-Webster Dictionary (2016) Ontology. Available at: https://www.merriamwebster.com/dictionary/ontology (accessed 22 December 2016).

Missaoui R, Joumaa H, Ploix S, et al. (2014) Managing energy Smart Homes according to energy prices: Analysis of a Building Energy Management System. Energy and buildings 71: 155-167.

Mol APJ (2006) Environmental governance in the Information Age: the emergence of informational governance. Environment and Planning C: Government and Policy 24: 497514.

Mol APJ (2008) Environmental reform in the information age. The Contours of Informational Governance. Cambridge: Cambridge University Press.

Mol APJ and Spaargaren G (2000) Ecological modernisation theory in debate: a review. Environmental politics 9: 17-49.

Mol APJ, Sonnenfeld D and Spaargaren G (2009) The ecological modernization reader. London: Routledge.

Moreno M, Úbeda B, Skarmeta AF, et al. (2014) How can we tackle energy efficiency in iot basedsmart buildings? Sensors 14: 9582-9614.

Morris C and Jungjohann A (2016) Energy Democracy: Germany's Energiewende to Renewables: Basingstoke: Palgrave Macmillan.

Moss T (2009) Intermediaries and the governance of sociotechnical networks in transition. Environment and planning A 41: 1480-1495.

Naus J and Van der Horst HM (2017) Accomplishing information and change in a smart grid pilot: Linking domestic practices with policy interventions. Environment and Planning: Politics and Space 35: 379-396.

Naus J, Spaargaren G, Van Vliet BJM, et al. (2014) Smart grids, information flows and emerging domestic energy practices. Energy Policy 68: 436-446.

Naus J, Van Vliet BJM and Hendriksen A (2015) Households as change agents in a Dutch smart energy transition: On power, privacy and participation. Energy research \& social science 9: 125-136. 
Netherlands Enterprise Agency (2013) Intelligente netten. Available at: http://www.rvo.nl/subsidies-regelingen/intelligente-netten (accessed 23 December 2013).

Netherlands Enterprise Agency (2015a) Factsheets ENG 2015. Available at: http://www.rvo.nl/onderwerpen/duurzaam-ondernemen/energie-en-milieuinnovaties/smart-grids/publicaties/factsheets-eng-2015 (accessed 5 November 2015).

Netherlands Enterprise Agency (2015b) Innovatieprogramma Intelligente Netten (IPIN): Position paper kennis- en leertraject - Thema gebruikersbenadering en gebruikersonderzoek. Report for the Ministry of Economic Affairs, Report no. RVO-2001501/BR-DUZA, September 2015.

Nicholls L and Strengers Y (2015) Peak demand and the 'family peak' period in Australia: Understanding practice (in) flexibility in households with children. Energy research \& social science 9: 116-124.

Nicolini D (2012) Practice theory, work, and organization: An introduction. Oxford: Oxford University Press.

Nilsson M (2012) Energy Governance in the European Union: enabling conditions for a low carbon transition?. In: Verbong GPJ and Loorbach D (eds) Governing the Energy Transition. Reality, Illusion or Necessity. London: Routledge, pp.296-316.

Noppers EH, Keizer K, Milovanovic M, et al. (2016) The importance of instrumental, symbolic, and environmental attributes for the adoption of smart energy systems. Energy Policy 98: 12-18.

NorthSeaGrid (2016) Project Description. Available at: http://northseagrid.info/projectdescription (accessed 20 November 2016)

Nyborg S and Røpke I (2011) Energy impacts of the smart home-conflicting visions. In: Energy efficiency first: The foundation of a low-carbon society, Belambra Presquile de Giens, France, 6-11 June 2011, pp.1849-1860. Stockholm: ABA Intercopy.

Nyborg S and Røpke I (2013) Constructing users in the smart grid-insights from the Danish eFlex project. Energy efficiency 6: 655-670.

Opdam P, Coninx I, Dewulf A, et al. (2016) Does information on landscape benefits influence collective action in landscape governance? Current Opinion in Environmental Sustainability 18: 107-114.

Orlikowski WJ (2002) Knowing in practice: Enacting a collective capability in distributed organizing. Organization science 13: 249-273. 
Ornetzeder M and Rohracher H (2013) Of solar collectors, wind power, and car sharing: comparing and understanding successful cases of grassroots innovations. Global Environmental Change 23: 856-867.

Otnes P (1988) The Sociology of Consumption: An Anthology. Atlantic Highlands: Humanities Press.

Ozaki R and Shaw I (2014) Entangled practices: governance, sustainable technologies, and energy consumption. Sociology 48: 590-605.

Pierce J, Odom W and Blevis E (2008) Energy aware dwelling: a critical survey of interaction design for eco-visualizations. In: Proceedings of the 20th Australasian Conference on Computer-Human Interaction: Designing for Habitus and Habitat, Cairns, Australia, 8-12 December 2008, pp.1-8.

Pixabay (2017) Smart Home. Date unknown. Available at: https://pixabay.com/nl/smarthome-home-technologie-2005993/

Powells G, Bulkeley H, Bell S, et al. (2014) Peak electricity demand and the flexibility of everyday life. Geoforum 55: 43-52.

Pullinger M, Lovell H and Webb J (2014) Influencing household energy practices: a critical review of UK smart metering standards and commercial feedback devices. Technology Analysis \& Strategic Management 26: 1144-1162.

Reckwitz A (2002) Toward a theory of social practices: A development in culturalist theorizing. European journal of social theory 5: 243-263.

Reckwitz A (2012) Affective spaces: a praxeological outlook. Rethinking history 16: 241-258.

REScoop (2014) REScoop map. Available at: https://rescoop.eu/renewable-energy-citizeninitiatives/map (accessed 1 November 2014).

Rifkin J (2015) The Energy Internet Explained, with Jeremy Rifkin. Available on: https://youtu.be/XtQoPcscFts.

Rip A and Kemp R (1998) Technological change. In: Rayner S and Malone EL (eds) Human choice and climate change, Vol. II: Resources and technology. Columbus: Battelle Press, pp.327-399.

Rohracher H (2009) Intermediaries and the governance of choice: the case of green electricity labelling. Environment and planning A 41: 2014-2028.

Røpke I (2009) Theories of practice-New inspiration for ecological economic studies on consumption. Ecological Economics 68: 2490-2497.

Røpke I and Christensen TH (2012) Energy impacts of ICT-Insights from an everyday life perspective. Telematics and Informatics 29: 348-361. 
Rotmans J and Horsten H (2012) In het oog van de orkaan: Nederland in transitie. Boxtel: Aeneas.

Rotmans J and Loorbach D (2009) Complexity and transition management. Journal of Industrial Ecology 13: 184-196.

Royston S (2014) Dragon-breath and snow-melt: Know-how, experience and heat flows in the home. Energy research \& social science 2: 148-158.

Sahakian M and Wilhite H (2014) Making practice theory practicable: Towards more sustainable forms of consumption. Journal of Consumer Culture 14: 25-44.

Sayer A (2013) Power, sustainability and well-being: An outsider's view. In: Shove E and Spurling N (eds) Sustainable practices: Social theory and climate change. London: Routledge, pp.292-317.

Schatzki TR (1996) Social practices: A Wittgensteinian approach to human activity and the social. Cambridge: Cambridge University Press.

Schatzki TR (2002) The site of the social: A philosophical account of the constitution of social life and change. Pennsylvania: Penn State Press.

Schatzki TR (2010) The timespace of human activity: On performance, society, and history as indeterminate teleological events. New York: Lexington Books.

Schatzki TR (2011) Where the action is (on large social phenomena such as sociotechnical regimes). In: SPRG Summer School: Working Paper 1, Manchester, UK, 14-16 September 2011.

Schatzki TR (2013) On the edge of change: On the emergence, persistence and dissolution of practices. In: Shove E, Spurling N (eds) Sustainable practices: Social theory and climate change. London: Routledge, pp.31-46.

Schatzki TR (2016a) Practice Theory as Flat Ontology. In: Spaargaren G, Weenink D and Lamers M (eds) Practice Theory and Research: Exploring the dynamics of social life. London: Routledge, pp. 28-43.

Schatzki TR (2016b) Keeping Track of large phenomena. Geographische Zeitschrift 104(1): 424.

Schatzki TR, Knorr-Cetina KK and Von Savigny E (2001) The practice turn in contemporary theory. London: Routledge.

Schot J and Geels FW (2008) Strategic niche management and sustainable innovation journeys: theory, findings, research agenda, and policy. Technology Analysis \& Strategic Management 20: 537-554.

Schwencke AM (2012) De Energieke BottumUp in Lage Landen: De Energietransitie van Onderaf. AS I-Search, 21 August. 
Seyfang G and Haxeltine A (2012) Growing grassroots innovations: exploring the role of community-based initiatives in governing sustainable energy transitions. Environment and Planning C: Government and Policy 30: 381-400.

Seyfang G, Park JJ and Smith A (2013) A thousand flowers blooming? An examination of community energy in the UK. Energy Policy 61: 977-989.

Shove E (2003) Converging conventions of comfort, cleanliness and convenience. Journal of Consumer policy 26: 395-418.

Shove E (2010) Beyond the ABC: climate change policy and theories of social change. Environment and planning A 42: 1273-1285.

Shove E and Spurling N (2013) Sustainable practices: Social theory and climate change. London: Routledge.

Shove E and Walker G (2007) CAUTION! Transitions ahead: politics, practice, and sustainable transition management. Environment and planning A 39: 763-770.

Shove E and Walker G (2010) Governing transitions in the sustainability of everyday life. Research policy 39: 471-476.

Shove E and Walker G (2014) What is energy for? Social practice and energy demand. Theory, Culture \& Society 31: 41-58.

Shove E, Pantzar M and Watson M (2012) The dynamics of social practice: Everyday life and how it changes. London: Sage.

Shove E, Watson M, Spurling N, et al. (2015) Conceptualizing connections: Energy demand, infrastructures and social practices. European journal of social theory 18: 274-287.

Shove E. (1998) Gaps, barriers and conceptual chasms: theories of technology transfer and energy in buildings. Energy Policy 26: 1105-1112.

Skjølsvold TM and Lindkvist C (2015) Ambivalence, designing users and user imaginaries in the European smart grid: insights from an interdisciplinary demonstration project. Energy research \& social science 9: 43-50.

Skjølsvold TM, Ryghaug M and Berker T (2015) A traveler's guide to smart grids and the social sciences. Energy research \& social science 9: 1-8.

Smart Grids Task Force (2011) European Task Force for the Implementation of Smart Grids into the European Internal Market: Mission and Work programme. European Commission, Brussels, [date unknonwn].

Smith A, Stirling A and Berkhout F (2005) The governance of sustainable socio-technical transitions. Research policy 34: 1491-1510. 
Smith A, Voß JP and Grin J (2010) Innovation studies and sustainability transitions: The allure of the multi-level perspective and its challenges. Research policy 39: 435-448.

Social Economic Council (2013) Summary of: Energy Agreement for Sustainable Growth. Socio Economic Council (SER), The Netherlands, 06 September.

Solove DJ (2002) Conceptualizing privacy. California Law Review: 1087-1155.

Solove DJ (2008) Understanding Privacy. Cambridge: Harvard University Press.

Soma K, MacDonald BH, Termeer CJ, et al. (2016a) Introduction article: Informational governance and environmental sustainability. Current Opinion in Environmental Sustainability 18: 131-139.

Soma K, Termeer CJ and Opdam P (2016b) Informational governance-A systematic literature review of governance for sustainability in the Information Age. Environmental Science \& Policy 56: 89-99.

Southerton D (2013) Habits, routines and temporalities of consumption: From individual behaviours to the reproduction of everyday practices. Time \& Society 22: 335-355.

Southerton D, Chappells H and Van Vliet BJM (2004) Sustainable consumption: The implications of changing infrastructures of provision. Cheltenham: Edward Elgar.

Sovacool BK (2014) What are we doing here? Analyzing fifteen years of energy scholarship and proposing a social science research agenda. Energy research \& social science 1: 1-29.

Spaargaren G (2003) Sustainable consumption: a theoretical and environmental policy perspective. Society \& Natural Resources 16: 687-701.

Spaargaren G (2011) Theories of practices: Agency, technology, and culture: Exploring the relevance of practice theories for the governance of sustainable consumption practices in the new world-order. Global Environmental Change 21: 813-822.

Spaargaren G and Mol APJ (2008) Greening global consumption: Redefining politics and authority. Global Environmental Change 18: 350-359.

Spaargaren G and Van Vliet BJM (2000) Lifestyles, consumption and the environment: The ecological modernization of domestic consumption. Environmental politics 9: 50-76.

Spaargaren G, Oosterveer P and Loeber A (2012) Sustainability transitions in food consumption, retail and production. In: Spaargaren G, Oosterveer P and Loeber A (eds) Food Practices in Transition: Changing food consumption, retail and production in the age of reflexive modernity. London: Routledge, pp.1-33.

Spaargaren G, Weenink D and Lamers M (2016) Practice Theory and Research: Exploring the dynamics of social life. London: Routledge. 
Spurling N and McMeekin A (2015) Interventions in practices: Sustainable mobility policies in England. In: Strengers Y and Maller C (eds) Social Practices, Intervention and Sustainability: Beyond Behaviour Change. London: Routledge, pp.78-94.

Steg L (2008) Promoting household energy conservation. Energy Policy 36: 4449-4453.

Steinheimer M, Trick U and Ruhrig P (2012) Energy communities in Smart Markets for optimisation of peer-to-peer interconnected Smart Homes. In: 2012 8th International Symposium on Communication Systems, Networks \& Digital Signal Processing (CSNDSP), Poznan, Poland, 18-20 July, pp.1-6. IEEE Xplore.

Stephens JC, Wilson EJ and Peterson TR (2015) Smart Grid (R) Evolution. Cambridge: Cambridge University Press.

Stephens JC, Wilson EJ, Peterson TR, et al. (2013) Getting smart? Climate change and the electric grid. Challenges 4: 201-216.

Stern PC (2014) Individual and household interactions with energy systems: toward integrated understanding. Energy research \& social science 1: 41-48.

Stevens T, Aarts N, Termeer C, et al. (2016) Social media as a new playing field for the governance of agro-food sustainability. Current Opinion in Environmental Sustainability 18: 99-106.

Strengers Y (2011a) Negotiating everyday life: The role of energy and water consumption feedback. Journal of Consumer Culture 11: 319-338.

Strengers Y (2011b) Beyond demand management: co-managing energy and water practices with Australian households. Policy Studies 32: 35-58.

Strengers Y (2012) Peak electricity demand and social practice theories: Reframing the role of change agents in the energy sector. Energy Policy 44: 226-234.

Strengers Y (2013) Smart energy technologies in everyday life: Smart Utopia?. Basingstoke: Palgrave Macmillan.

Strengers Y and Maller C (2014) Social practices, Intervention and Sustainability: Beyond behaviour change. London: Routledge.

Strengers Y, Moloney S, Maller C, et al. (2015) Beyond behaviour change: Practical applications of social practice theory in behaviour change programs. In: Strengers $Y$ and Maller C (eds) Social Practices, Intervention and Sustainability: Beyond Behaviour Change. London: Routledge, pp.63-77.

Strengers Y, Nicholls L and Maller C (2016) Curious energy consumers: Humans and nonhumans in assemblages of household practice. Journal of Consumer Culture 16: 761780. 
Stromback J, Dromacque C and Yassin MH (2011) The potential of smart meter enabled programs to increase energy and systems efficiency: a mass pilot comparison. Vaasa ETT Global Energy Think Tank, Helsinki, Finland.

Taskforce Intelligente Netten (2011) Op weg naar intelligente netten in Nederland: einddocument van de Taskforce Intelligente Netten. Report for the Ministry of Economic Affairs, May.

Termeer CJ and Bruinsma A (2016) ICT-enabled boundary spanning arrangements in collaborative sustainability governance. Current Opinion in Environmental Sustainability 18: 91-98.

Throndsen W and Ryghaug M (2015) Material participation and the smart grid: exploring different modes of articulation. Energy research \& social science 9: 157-165.

TKI Urban Energy (2016) Visie, missie en strategie. Available at: http://topsectorenergie.nl/urban-energy/onze-visie/ (accessed 19 November 2016).

Toonen HM and Lindeboom HJ (2015) Dark green electricity comes from the sea: Capitalizing on ecological merits of offshore wind power? Renewable and Sustainable Energy Reviews 42: 1023-1033.

Toonen HM and Mol APJ (2013) Putting sustainable fisheries on the map? Establishing notake zones for North Sea plaice fisheries through MSC certification. Marine Policy 37: 294-304.

Topteam Energie (2012) Innovatie contract Smart Grids: Headlines of a public private partnership and Innovation Agenda 2012. Report by Topteam Energie, The Netherlands, 20 August.

Tuballa ML and Abundo ML (2016) A review of the development of Smart Grid technologies. Renewable and Sustainable Energy Reviews 59: 710-725.

US Department of Energy (2016) How the smart grid promotes a greener future. Report for the US Department of Energy, Litos Strategic Communication, Contract No. DE-AC2604NT41817 Subtask 500.01.02, [date unknown].

Van den Burg S (2006) Governance through information: environmental monitoring from a citizen-consumer perspective. PhD Thesis, Wageningen University, The Netherlands.

Van den Burg S, Mol APJ and Spaargaren G (2003) Consumer-oriented monitoring and environmental reform. Environment and Planning C: Government and Policy 21: 371-388.

Van der Loo F and Loorbach D (2012) The Dutch Energy Transition Project (2000-2009). In: Verbong GPJ and Loorbach D (eds) Governing the Energy Transition. Reality, Illusion or Necessity. London: Routledge, pp.220-250. 
Van der Werff E and Steg L (2016) The psychology of participation and interest in smart energy systems: Comparing the value-belief-norm theory and the value-identitypersonal norm model. Energy research \& social science 22: 107-114.

Van der Werff E, Perlaviciute G and Steg L (2016) Transition to smart grids: A psychological perspective. Smart Grids from a Global Perspective: Bridging Old and New Energy Systems. Cham: Springer, pp.43-62.

Van Vliet BJM (2002) Greening the Grid: The Ecological Modernisation of Network-bound Systems. PhD Thesis, Wageningen University, The Netherlands.

Van Vliet BJM (2012) Sustainable innovation in network-bound systems: implications for the consumption of water, waste water and electricity services. Journal of Environmental Policy \& Planning 14: 263-278.

Van Vliet BJM, Shove E and Chappells H (2005) Infrastructures of consumption: Environmental innovation in the utility industries. London: Earthscan.

Verbong GPJ and Geels F (2012) Future electricity systems: Vision, Scenario's and Transition Pathways. In: Verbong GPJ and Loorbach D (eds) Governing the Energy Transition. Reality, Illusion or Necessity. London: Routledge, pp.203-219.

Verbong GPJ and Geels FW (2010) Exploring sustainability transitions in the electricity sector with socio-technical pathways. Technological Forecasting and Social Change 77: 12141221.

Verbong GPJ and Loorbach D (2012) Governing the energy transition: reality, illusion or necessity? London: Routledge.

Verbong GPJ, Beemsterboer S and Sengers F (2013) Smart grids or smart users? Involving users in developing a low carbon electricity economy. Energy Policy 52: 117-125.

Verbong GPJ, Verkade N, Verhees B, et al. (2016) Smart Business for Smart Users: A Social Agenda for Developing Smart Grids. Smart Grids from a Global Perspective: Bridging Old and New Energy Systems. Cham: Springer, pp.27-42.

Voß JP, Smith A and Grin J (2009) Designing long-term policy: rethinking transition management. Policy sciences 42: 275-302.

Vringer K and Dassen T (2016) Slimme meter, uitgelezen energie(k)?. Planbureau voor de Leefomgeving (PBL), Report no. 2122, Den Haag, The Netherlands, 17 November.

Walker G (2014) The dynamics of energy demand: change, rhythm and synchronicity. Energy research \& social science 1: 49-55.

Wallenborn G and Wilhite H (2014) Rethinking embodied knowledge and household consumption. Energy research \& social science 1: 56-64. 
Wallenborn G, Orsini M and Vanhaverbeke J (2011) Household appropriation of electricity monitors. International Journal of Consumer Studies 35: 146-152.

Warde A (2005) Consumption and theories of practice. Journal of Consumer Culture 5: 131153.

Warde A (2014) After taste: Culture, consumption and theories of practice. Journal of Consumer Culture 14: 279-303.

Watson M (2012) How theories of practice can inform transition to a decarbonised transport system. Journal of Transport Geography 24: 488-496.

Webb TL, Benn Y and Chang BP (2014) Antecedents and consequences of monitoring domestic electricity consumption. Journal of Environmental Psychology 40: 228-238.

Weenink D and Spaargaren G (2016) Emotional agency navigates a world of practices. In: Spaargaren G, Weenink D and Lamers M (eds) Practice Theory and Research: Exploring the Dynamics of Social Life. London: Routledge, pp.60-84.

Welch D and Warde A (2015) Theories of practice and sustainable consumption. In: Reisch LA and Thøgersen J (eds) Handbook of research on sustainable consumption. Cheltenham: Edward Elgar, pp.84-100.

Westskog H, Winther T and Sæle H (2015) The Effects of In-Home Displays-Revisiting the Context. Sustainability 7: 5431-5451.

Wikimedia (2008) Sketch of possible infrastructure for a sustainable supply of power to Europe, the Middle East and North Africa (EU-MENA). December 2008. Available at: https://upload.wikimedia.org/wikipedia/commons/0/0a/TREC-Map-en.jpg.

Wilhite $\mathrm{H}$ and Ling R (1995) Measured energy savings from a more informative energy bill. Energy and buildings 22: 145-155.

Wilson C, Hargreaves T and Hauxwell-Baldwin R (2015). Smart homes and their users: a systematic analysis and key challenges. Personal and Ubiquitous Computing 19: 463-476.

Wissner M (2011) The Smart Grid-A saucerful of secrets? Applied Energy 88: 2509-2518.

Wolsink M (2012) The research agenda on social acceptance of distributed generation in smart grids: Renewable as common pool resources. Renewable and Sustainable Energy Reviews 16: 822-835.

World Energy Council (2014) Global Energy Transitions A comparative analysis of key countries and implications for the international energy debate. Extraction and translation from “Energie für Deutschland 2014”, Berlin, Germany, October 2014.

Yuan J, Shen J, Pan L, et al. (2014) Smart grids in China. Renewable and Sustainable Energy Reviews 37: 896-906. 


\section{Annex A: Interviews with householders (Ch.2)}

\section{Annex A1: List of interviewees}

\begin{tabular}{|c|c|c|c|c|c|c|}
\hline Name & Age & Employment & $\begin{array}{l}\text { Household } \\
\text { composition }\end{array}$ & $\begin{array}{l}\text { Type of } \\
\text { residence }\end{array}$ & Trial & $\begin{array}{l}\text { Monitoring } \\
\text { tool(s) }\end{array}$ \\
\hline $\begin{array}{l}\text { Ms. } \\
\text { Visser }\end{array}$ & 52 & $\begin{array}{l}\text { Environmental } \\
\text { NGO }\end{array}$ & $\begin{array}{l}\text { Couple, } \\
2 \text { children }\end{array}$ & $\begin{array}{l}\text { Corner } \\
\text { house }\end{array}$ & $\begin{array}{l}\text { Pre-test for } \\
\text { eNGO }\end{array}$ & $\begin{array}{l}\text { Online portal } \\
\text { (5weeks) / } \\
\text { Coloured } \\
\text { device \& PC } \\
\text { software } \\
\text { (2 months) }\end{array}$ \\
\hline $\begin{array}{l}\text { Ms. } \\
\text { Dijkstra }\end{array}$ & 53 & In horticulture & $\begin{array}{l}\text { Couple, } \\
2 \text { children }\end{array}$ & Apartment & $\begin{array}{l}\text { 1-year trial } \\
\text { of consumer } \\
\text { organisation }\end{array}$ & $\begin{array}{l}\text { Monthly e- } \\
\text { mail } \\
\text { (6 months) / } \\
\text { online portal } \\
\text { (6 months) }\end{array}$ \\
\hline $\begin{array}{l}\text { Ms. } \\
\text { Martens }\end{array}$ & 65 & $\begin{array}{l}\text { Supplementary } \\
\text { benefit }\end{array}$ & Single & $\begin{array}{l}\text { Corner } \\
\text { house }\end{array}$ & $\begin{array}{l}\text { 1-year trial } \\
\text { of consumer } \\
\text { organisation }\end{array}$ & $\begin{array}{l}\text { Monthly e- } \\
\text { mail } \\
\text { (6 months) / } \\
\text { online portal } \\
\text { (6 months) }\end{array}$ \\
\hline $\begin{array}{l}\text { Mr. } \\
\text { Kuipers }\end{array}$ & 43 & $\begin{array}{l}\text { In sales and } \\
\text { advice }\end{array}$ & $\begin{array}{l}\text { Couple, } \\
2 \text { children }\end{array}$ & $\begin{array}{l}\text { Semi- } \\
\text { detached } \\
\text { house }\end{array}$ & $\begin{array}{l}\text { 1-year trial } \\
\text { of consumer } \\
\text { organisation }\end{array}$ & $\begin{array}{l}\text { In-home } \\
\text { display } \\
\text { (1 year) }\end{array}$ \\
\hline $\begin{array}{l}\text { Mr. } \\
\text { Peters }\end{array}$ & 60 & In ICT sector & Couple & $\begin{array}{l}\text { Terraced } \\
\text { house }\end{array}$ & $\begin{array}{l}\text { 1-year trial } \\
\text { of consumer } \\
\text { organisation }\end{array}$ & $\begin{array}{l}\text { In-home } \\
\text { display } \\
\text { (1 year) }\end{array}$ \\
\hline
\end{tabular}




\section{Annex A2: Interview guide (in Dutch)}

Note: this interview guide represents a basic outline that has been adapted on case-by-case basis.

\section{Doel interview}

Inzicht krijgen in (dagelijkse) bezigheden, handelingen en beslissingen van huishoudens omtrent energie consumptie, productie en monitoring, en de veranderingen door de introductie van de slimme meter.

\section{Vragenlijst}

1. Energieverbruik: Wat kunt u me vertellen over uw energieverbruik?

- Verbruik (hoeveelheid)

- Verbruiksposten

- Technische maatregelen

○ Gedragsmaatregelen

2. Energieopwekking: Hoe is de beslissing tot stand gekomen om [opwekker] aan te schaffen?

○ Type opwekking (zon, wind, etc)

- Verkoper (wie, welk initiatief)

- Overleg (wie, wanneer, hoe vaak)

○ Belangrijke overwegingen/keuzes

- Informatie (wat, waar)

○ Veranderingen/consequenties verbruik

○ Monitoring/afrekening opwekking

3. Energiemonitoring: Wat kunt u me vertellen over het bijhouden van energieverbruik (en productie)?

○ Wie houdt wat bij, hoe vaak?

- Methode (slimme meter, apparaten meter, EPA)

- Reden voor monitoring

- Rol slimme meter

- Totstandkoming beslissing slimme meter

- Veranderingen monitoring t.o.v. analoge meter

○ Beschrijving van 'practice': wat doet u precies?

○ Vergelijken (wie, wat, hoe vaak)

4. Energiebedrijven: Wat kunt u me vertellen over uw energieleverancier?

○ Naam leverancier

○ Type energiecontract

- Beslissing om over te stappen (vergelijkingen)

- Contact en relatie met leverancier (onderwerp, frequentie)

Informatie over productie (bron, kwaliteit, performance) 


\section{Annex B: Interviews with institutional actors (Ch.2)}

Annex B1: List of interviewees

\begin{tabular}{|l|l|l|}
\hline Organisation & Position & Date \\
\hline AgentschapNL & Project advisor & 22 Jun. 2012 \\
\hline Alliander & $\begin{array}{l}\text { Technology manager \& } \\
\text { Research scientist }\end{array}$ & 08 Nov. 2011 \\
\hline Alliander & Innovation manager & $\begin{array}{l}\text { 22 May 2012 \& } \\
\text { 07 Nov. 2012 }\end{array}$ \\
\hline Consumentenbond & Manager public affairs & 09 May 2012 \\
\hline Essent & Innovation manager & 24 Aug. 2012 \\
\hline Greenchoice & Marketing manager & 03 Sep. 2012 \\
\hline Qurrent & Company lawyer & 30 Jan. 2013 \\
\hline TNO & Senior research scientist & 08 Aug. 2012 \\
\hline TNO & Senior scientist & 24 Sep. 2012 \\
\hline $\begin{array}{l}\text { Vereniging Eigen } \\
\text { Huis }\end{array}$ & Policy advisor & 23 Aug. 2012 \\
\hline
\end{tabular}




\section{Annex B2: Interview guide (in Dutch)}

Note: this interview guide represents a basic outline that has been adapted on a case-by-case basis.

\section{Doel interview:}

1) Meer zicht te krijgen op het speelveld omtrent slimme meters en slimme netten

2) Beter doorgronden wat privacy en duurzaamheid in deze context betekenen

3) Beter begrijpen wat de rol en visie van [organisatie] is t.a.v. ontwikkelingen rond slimme meter en slimme netten.

\section{Vragenlijst:}

\section{Betrokkenheid organisatie}

- Op welke manier is [organisatie] betrokken bij de ontwikkeling van slimme netten/meters? (bijv. eigen initiatieven / strategieën / discussies)

\section{Slimme meters en slimme netten}

- Wat is een slimme meter in de kern? Waartoe dient het?

- Wat is het verschil tussen de slimme meter die er gaat komen en de slimme meter die jullie graag zouden willen?

- Wat is een slim net in de kern? Waartoe dient het?

- Welke functies dragen, volgens $\mathrm{u}$, bij aan duurzaamheid?

- Wat is volgens u de link tussen een slim net en een slimme meter?

- Welke partijen zijn leidend in ontwikkelingen omtrent slimme meters en slimme netten? En zijn dit volgens u de logische partijen?

\section{De consument}

- Wat weet de consument van energieverbruik en opwekking?

- Wat weet de consument van slimme netten en slimme meters?

- Wat is de rol van de consument t.a.v. slimme meters en slimme netten?

- Welke belangen heeft de consument bij de ontwikkeling van slimme meters/netten?

- Wie vertegenwoordigt de belangen van de consument?

\section{Privacy discussie}

- Wat is, volgens u, de kern van de privacy discussie?

- Wat is de opvatting van [organisatie] in deze discussie?

- Welke betrokken partijen hadden (duidelijk) een andere visie?

- Wat waren de beslissende momenten in de privacy discussie?

- Wat zijn de belangrijkste uitkomsten, volgens u?

- Leeft privacy onder consumenten?

- Is de privacy discussie nu opgelost? Wat zijn de alternatieven?

- Wat weet u over discussies in andere landen of op Europees niveau omtrent privacy en slimme meters? 


\section{Annex C: Online survey (Ch.3)}

\section{Annex C1: Questionnaire (in Dutch)}

\section{Enquête: De energie-toekomst in beeld}

Er zijn de laatste jaren interessante ontwikkelingen gaande op energiegebied. Zo zijn er steeds meer huizen en apparaten voorzien van een energielabel, wekken steeds meer mensen zelf energie op, en is ook het monitoren van energieverbruik in opkomst. Wageningen Universiteit probeert met een uitgebreide enquête in kaart te brengen 1) op welke manieren mensen thuis bezig zijn met energie, en 2) voor welke nieuwe energieontwikkelingen ze openstaan en voor welke juist niet.

De enquête is onderdeel van een onafhankelijk onderzoek aan Wageningen Universiteit. De resultaten worden gebruikt om wetenschappelijke kennis op het gebied van energie en huishoudens te vergroten. Door deze enquête in te vullen, draagt $u$ hier ook aan bij en kunt $u$ op een leuke manier een kijkje nemen in energiehuishouding van de nabije toekomst. Bovendien maakt $u$ kans op 1 van de 4 PODIUM cadeaukaarten ter waarde van €30,-

Duurzaamnieuws.nl zal de resultaten publiceren.

De vragen en stellingen in de enquête zijn verdeeld over vijf onderdelen. Het invullen duurt naar schatting 20 minuten. De enquête wordt automatisch opgeslagen, zodat u (indien nodig) kunt afsluiten om op een later moment weer verder te gaan. Uw gegevens worden uiteraard vertrouwelijk behandeld.

Hartelijk dank voor uw deelname

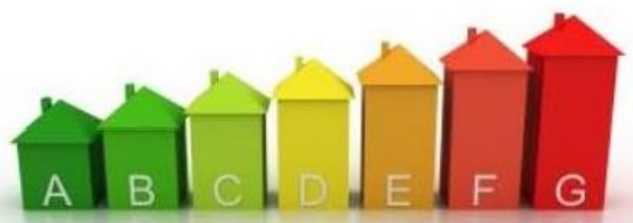

\section{Energie meten}

Er zijn verschillende manieren om energieverbruik in huis in kaart te brengen. De vragen in dit onderdeel gaan hierover.

leder huishouden ontvangt jaarlijks een energierekening. Neemt $u$ de energierekening door? 


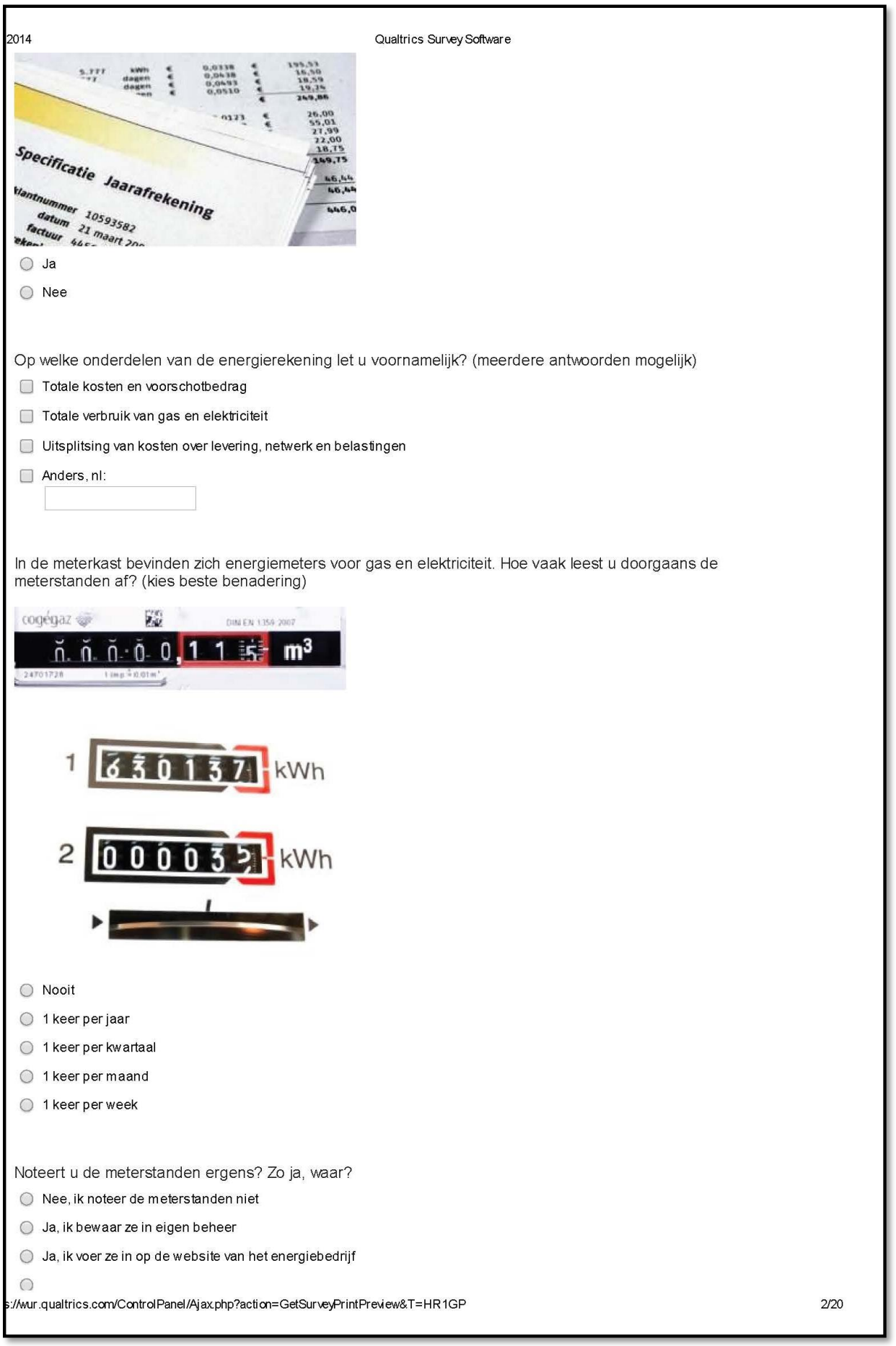




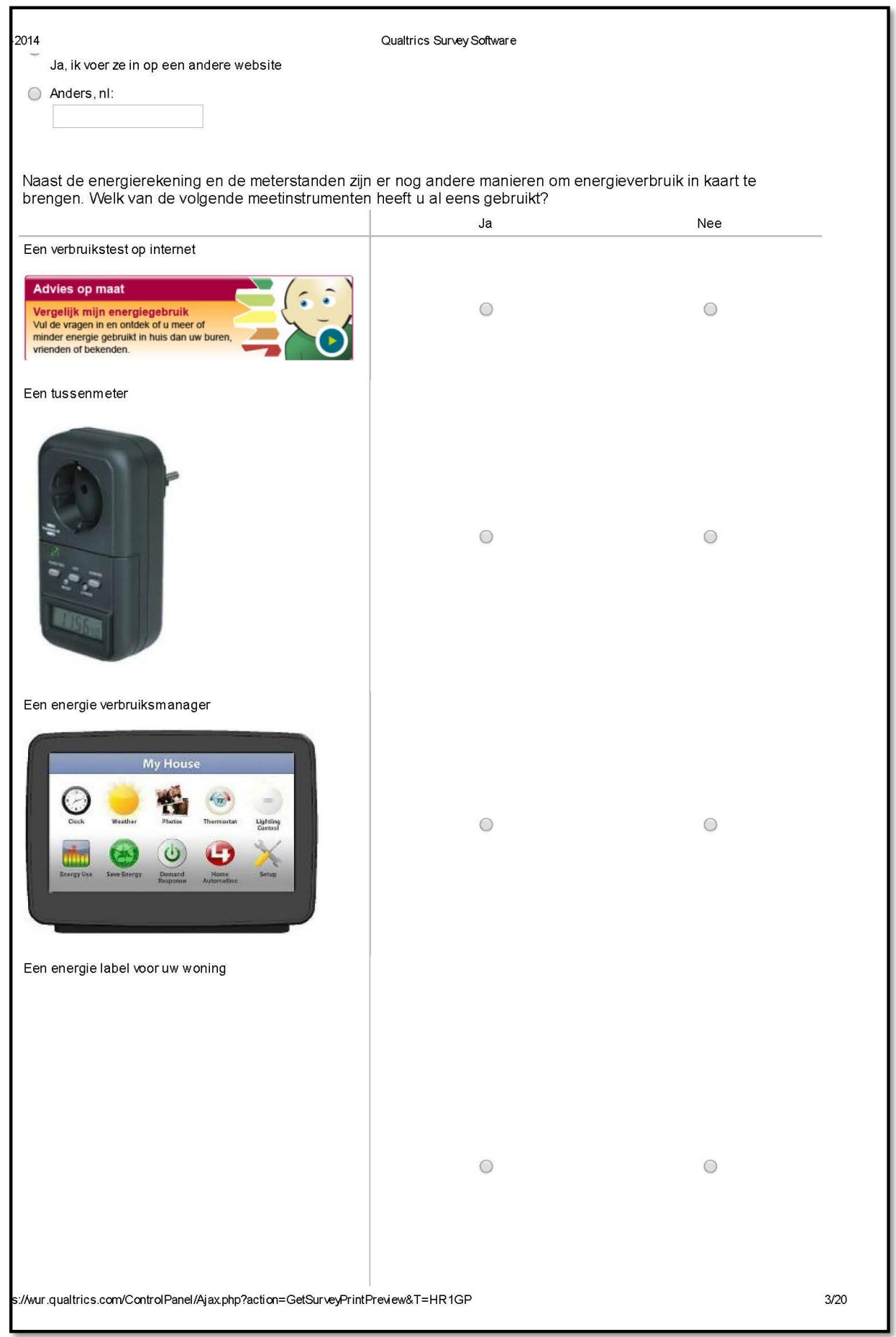




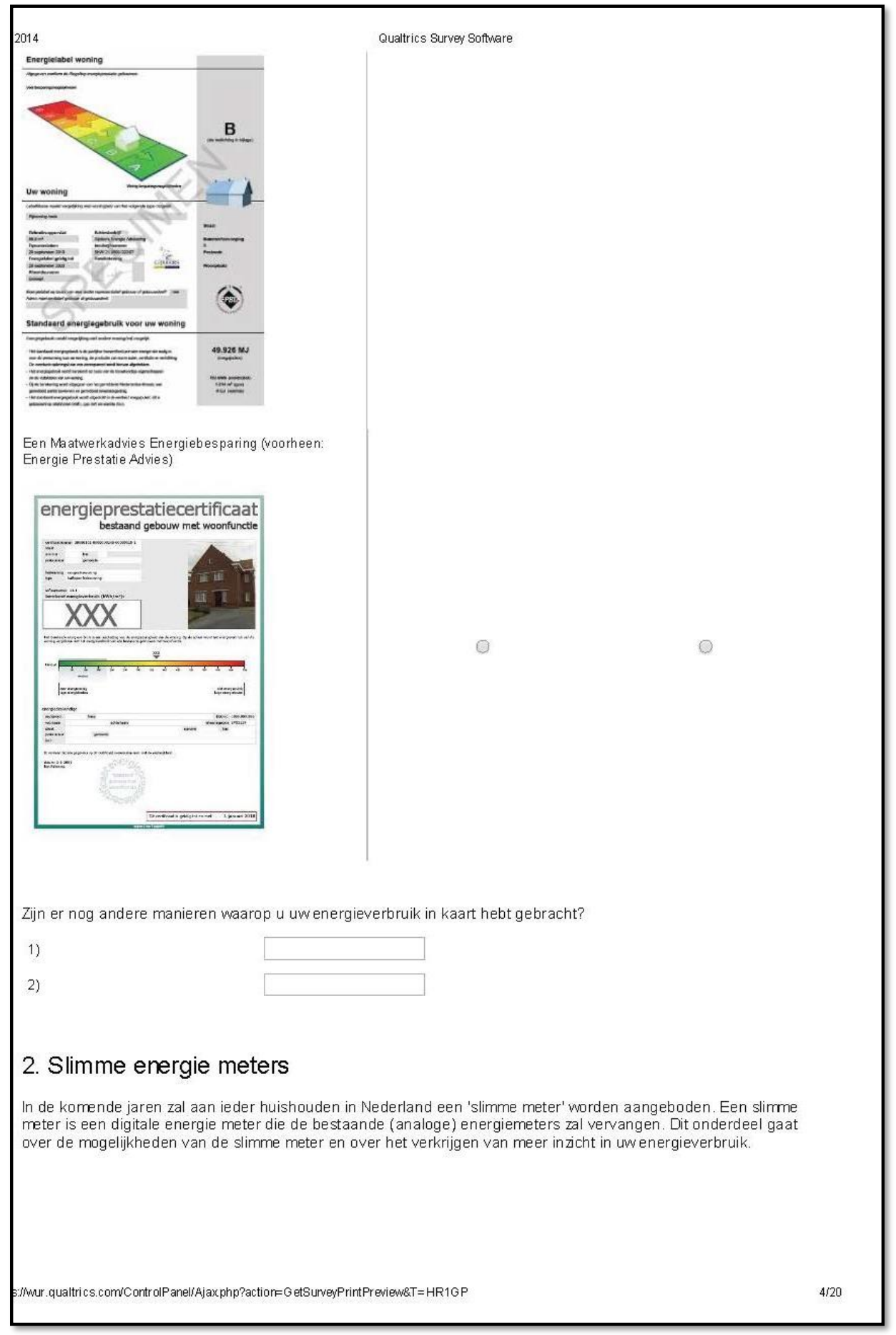




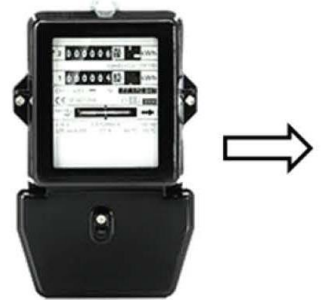

Analoge meter

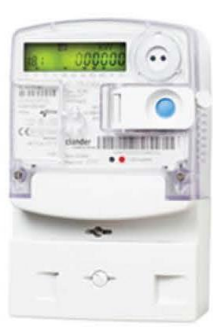

Slimme meter

Hebt $u$ al een slimme meter in huis?

O Ja

Nee

Weet ikniet

De slimme meter kan uw meterstanden automatisch doorsturen naar het meetbedrijf. Bij de installatie van de slimme meter kunt u kiezen hoe vaak de meterstanden door het meetbedrijf worden uitgelezen. Voor welk van onderstaande uitlees-opties heeft u gekozen?

De meter staat uit en geeft de standen niet automatisch door

Elke twee maanden (standaard)

Dagelijks / continue

Weetik niet

De slimme meter kan uw meterstanden automatisch doorsturen naar het meetbedrijf. U ontvangt dan standaard elke twee maanden een verbruiksoverzicht. Op afspraak kunt u ook vaker uw meterstanden laten uitlezen voor gedetailleerder inzicht in uw energieverbruik. Stel, u krijgt de slimme meter aangeboden. Voor welk van onderstaande opties zou u kiezen?

Ik weiger de slimme meter

Ik accepteer de slimme meter, maar laat de meterstanden niet automatisch doorsturen

Ik accepteer de slimme meter en laat de meterstanden elke twee maanden automatisch doorsturen

Ik accepteer de slimme meter en laat de meterstanden dagelijks automatisch doorsturen

Waarom kiest u voor deze optie?

Er zijn in Nederland verschillende proefprojecten waarin de slimme meter wordt ingezet om de gebruiker meer inzicht te geven in zijn/haar energieverbruik. In 2012 is er bijvoorbeeld een test uitgevoerd met 45 huishoudens in de regio's Arnhem en Amsterdam. De meetgegevens uit de slimme meter werden gedurende een jaar digitaal aan de gebruiker getoond. Probeer u eens voor te stellen dat u meedoet aan zo'n proef. Op welk van onderstaande manieren zou u de meetgegevens willen ontvangen?

Via een maandelijkse e-mail van het energiebedrijf 


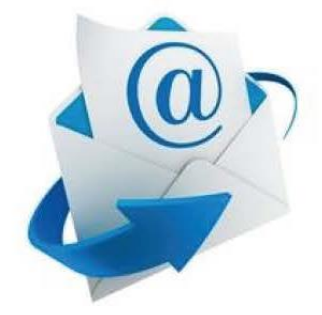

Via een website van het energiebedrijf met een inlogcode

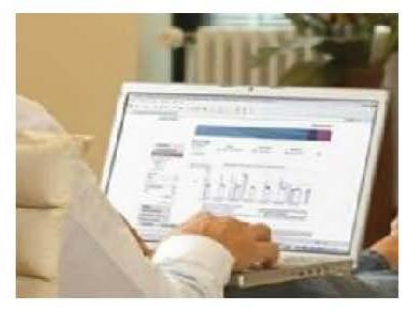

Vla een eigen energie display in de huiskamer

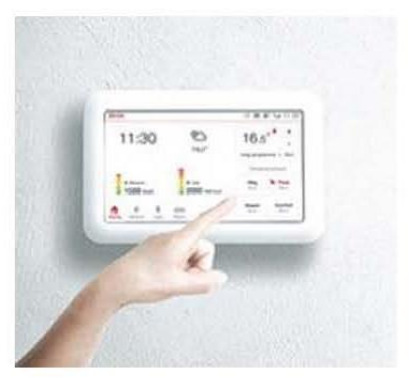

Kunt u deze keuze kort toelichten?

Uw energiegebruik kan in verschillende eenheden aan u worden getoond. Welke eenheden geven u inzicht in uw verbruik?

\begin{tabular}{|c|c|c|c|}
\hline & Wel & Een beetje & Niet \\
\hline kWh en $\mathrm{m}^{3}$ & 0 & 0 & 0 \\
\hline$€$ & 0 & 0 & 0 \\
\hline $\mathrm{CO}_{2}$ & 0 & 0 & 0 \\
\hline
\end{tabular}

Met behulp van een slimme meter kunt u meer te weten komen over energieverbruik in huis. Welke verbruiksposten zjjn voor u het meest interessant? (selecteer er maximaal 3) 


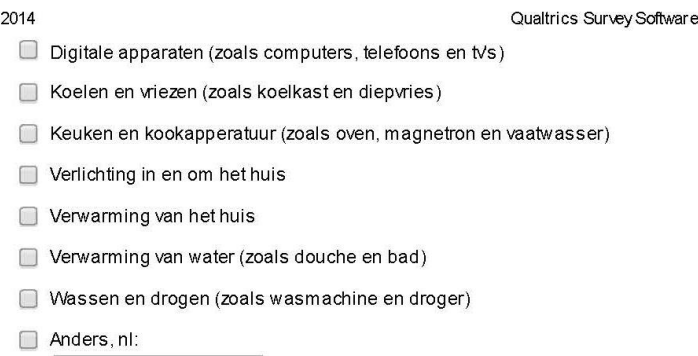

Een slimme meter kan u meer inzicht geven uwenergieverbruik. Het is echter niet altijd makkelijk te achterhalen om welke specifieke verbruiksposten het gaat en wat u het beste kunt doen om uw energieverbruik te verminderen.

Specialisten kunnen u hierbij helpen door gebruik te maken van gegevens uit uw slimme meter. In hoeverre spreken de volgende slimme meter diensten u aan?

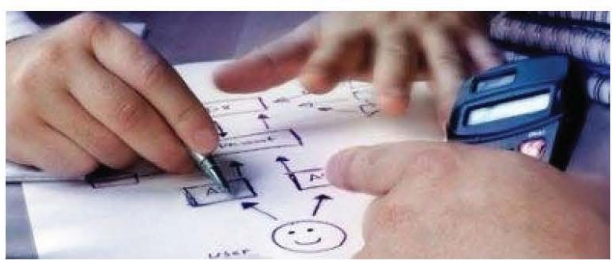

Wel

Een beetje

Niet

Hulp bij het inzichtelijk maken

van energieverbruik door

vers chillende verbruiksposten

Besparingstips op maat

(specifiek voor uw situatie)

Meldingen bij mogelijk defect

of ongew oon verbruik van

specifieke apparaten

Persoonlijke aanbiedingen

voor energiebesparende

maatregelen en energiezuinige

apparatuur

Kunt u deze keuze kort toelichten?

Van welk type dienstverlener zou u deze slimme meter diensten willen ontvangen? (kies bij elke dienstverlener 'ja' of 'nee')

\begin{tabular}{l|cc} 
Commercieel & Ja & Nee \\
s:/Mur.qualtrics.com/ControlPanel/Ajax.php?action=GetSurveyPrintPreview\&.T=HR 1GP & 0 & 0
\end{tabular}


2014

besparingsadviseur

Uw energieleverancier

Fabrikant van energie-zuinige

apparaten

Consumenten organistatie

Milieu organistatie
Qualtrics Survey Software

O

Waarom kiest u juist voor deze dienstverlener(s)?

Met behulp van een slimme meter wordt het makkelijker om uw energieverbruik te vergelijken met andere huishoudens. Hebt u uw energieverbruik al eens vergeleken met ... (kies telkens 'ja' of 'nee')

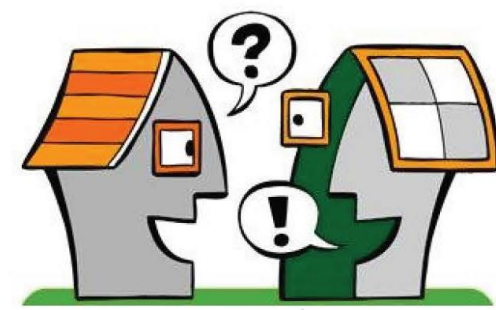

$\mathrm{Ja} \quad \mathrm{Nee}$

Met het landelijk gemiddelde

(bv. via internet)

O 0

Met buurtgenoten

Met vienden/collega'sffamilie

Energiegegevens kunnen ook eenvoudig online uitgewisseld en vergeleken worden, bijvoorbeeld op een internet forum of via sociale media. Als $u$ dat gevraagd zou worden, met wie zou u uw energieprestatie dan online willen delen?

\begin{tabular}{l|cc} 
& Wel & Niet \\
\hline Familie & 0 & 0 \\
Vrienden & 0 & 0 \\
Buurtgenoten & 0 & 0 \\
Collega's & 0 & 0 \\
Onbekenden & 0 & 0
\end{tabular}

Er zijn verschillende initiatieven waarin mensen samen aan de slag gaan met energiegegevens. Als u hiervoor uitgenodigd zou worden, aan welk van onderstaande initiatieven zou u dan meedoen?

Wel

Niet

Een buurtinitiatief waarin u

samen met uw buurtgenoten

probeert uw energieverbruik te

O

0

Een besparingscompetitie

waarin $u$ het opneemt tegen

viienden en bekenden

Een internet forum voor het

s:/Wur .qualtrics.com/ControlPanel/Ajax.php?action=GetSurveyPrintPreview\& $T=H R$ 1GP 
2014

online bespreken van

energiekwesties
Qualtrics Survey Software

O

Kunt u dit kort toelichten?

\section{Energie in ontwikkeling}

Naast de slimme meter wordt er in Nederland ook geëxperimenteerd met andere energie-toepassingen in en om het huis. De verwachting is dat in de komende 10 jaar steeds meer van deze toepassingen voor een breed publiek beschikbaar komen. Dit onderdeel gaat over deze energie toepassingen.

Steeds meer mensen wekken thuis energie op, bijvoorbeeld met behulp van zonnepanelen, een zonneboiler of een windmolen. Wekt $u$ thuis energie op?

Ja, nl:

Als $u$ de mogelijkheid zou hebben, zou u dan in de komende jaren zelf (nog meer) energie willen opwekken?

Ja

Nee

Naast het zelf opwekken van energie wordt er ook geexperimenteerd met collectie ve opwek van energie. Zo is er in de Lochem (Gelderland) de mogelijkheid om een set panelen op het dak van het gemeentehuis te huren. Maakt $\mathrm{u}$ al gebruik van collectieve opwek?

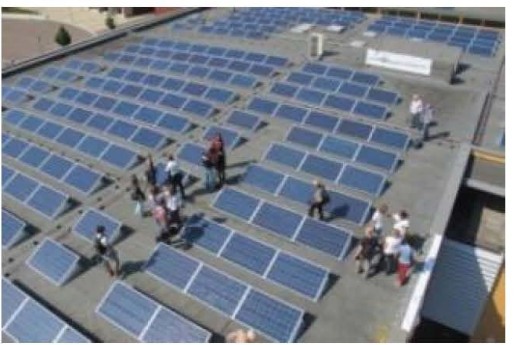

Ja, nl

Nee

Als u gevraagd zou worden om mee te doen, voor welk van de volgende collectieve opwek-mogelijkheden zou $u$ dan openstaan?

\begin{tabular}{l|cc} 
& Wel & Een beetje \\
\hline $\begin{array}{l}\text { Samen met een vriend of } \\
\text { goede bekende, in }\end{array}$ \\
$\begin{array}{l}\text { onderling overleg } \\
\text { bv: gedeelde zonnepanelen op } \\
\text { eigen dak ofop het dak van }\end{array}$
\end{tabular}

s://Mur.qualtrics.com/ControlPanel/Ajax.php?action=GetSurveyPrintPreviews:T=HR $1 \mathrm{GP}$ 
2014

vrienden

Samen met buurtgenoten

in een lokale

energiecooperatie

bv gedeelde zonnepanelen op

het dak van het buurthuis of

van de lokale school

Samen met landgenoten

in een grootschaliger

energieproject

bv: participatie in een

windmolenpark of zonnepark

elders in Nederland

Kunt u uw keuze kort toelichten?

Ook in auto's kunnen verschillende type energiebronnen worden toegepast. Hebt u een eigen auto? Zoja, waar rijdt uw auto op?

Ja, op benzine / diesel / LPG

Ja, op elekriciteit/hyoride

$\bigcirc \mathrm{Ja}$, op groen gas

Nee, lk heb geen auto

Er zijn steeds vaker elektrische auto's in het verkeer te zien. Als u de mogelijkheid zou hebben, zou u dan in de komende jaren ook een elektrische auto willen aanschaffen?

Ja

Nee

Naast (of in plaats van) een eigen auto, is het ook mogelijk gebruik te maken van deelauto's. In Amsterdam en Utrecht kunnen mensen sinds kort ook kiezen voor elektrische deel-auto's. Hebt u al eens gebruik gemaakt van een deelauto (elektrisch of niet-elektrisch)?

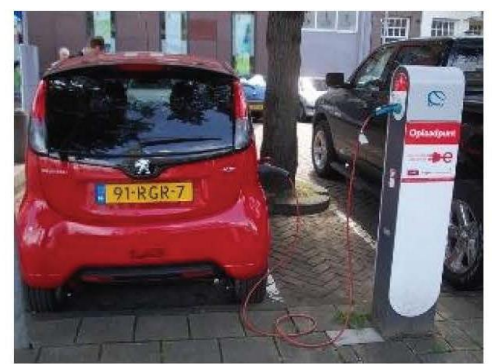

$\mathrm{Ja}$, een elektrische deel-auto

Ja, een niet-elektrische deel-auto

Nee

Met de opkomst van elektrische auto's wordt het interessanter om gebruik te maken van deelauto's. Zo kan s:/Mur. qualtrics.com/ControlPanel/Ajax.php?action=GetSurveyPrintPreview\& $T=H R 1 G P$ 
bijvoorbeeld een elektrische deel-auto gebruikt worden voor de kortere afstanden, of een niet-elektrische deelauto voor de langere afstanden. Als u gevraagd zou worden om mee te doen, voor welk van de volgende deelautomogelijkheden zou u dan openstaan?

We

Samen met een vriend of

bekende, in onderling overleg

Hierbij wordt een auto samen

aangeschaftgeleased en in

ondering overleg gebruikt

Samen met buurtgenoten in een lokaal

samenwerkingsverband

Hierbij is er een klein lokaa

wagenpark beheerd dooren

voor buutbewoners

Samen met landgenoten, in

een landelijk netwerk

Hierbij zijn er auto's

beschikbaardoor het hele land

voor iedereen met een

abonnement

Kunt u uw keuze kort toelichten?

0
Een beetje

Niet et

(n)

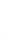

0

Met de opkomst van wind- en zonne-energie wordt de beschikbaarheid van elektriciteit meer afhankelijk van het weer. Een windmolen draait immers alleen als het waait en zonnepanelen leveren alleen bij voldoende licht.

Hierdoor is er op sommige momenten veel elektriciteit goedkoop beschikbaar (zogenaamde: gunstige momenten).

Op andere momenten is elektriciteit juist schaars en duur (zogenaamde: ongunstige momenten). De komende paar vragen gaan over deze gunstige en ongunstige momenten.

Om energiegebruik op gunstige momenten te stimuleren, en op ongunstige momenten te ontmoedigen, wil men variabele tariefstelsels invoeren. Hierbij betaalt u relatief weinig op gunstige momenten, en relatief veel op ongunstige momenten. Deze variabele tarieven vervangen het huidige vaste tarief, waarbij u altijd evenveel betaalt voor uw elektriciteit. Stel, u staat binnenkort voor deze keuze. Voor welk van onderstaande opties zou u kiezen?

Vast tarief: Elektriciteit kost altijd evenveel (gemiddelde prijs).

Meerdere tariefblokken per dag: De dag wordt opgedeeld in een aantal goedkopere en duurdere tjdsblokken. leder tijdsblok krijgt een ander vaststaand tarief (dit is een uitbreiding op het dag- en nachttarief).

Actueel tarief: De kosten kunnen elk kwartier variëren en geven actuele kosten van opwek en levering weer.

Weetik niet

Kunt u deze keuze kort toelichten?

Een andere mogelijkheid is om in overleg met de energieleverancier een verbruikslimiet voor ongunstige momenten af te spreken. Als de leverancier dan moeite heeft om aan de energievraag te voldoen omdat er weinig duurzame energie beschikbaar is, kan die u vragen om tijdelijk minder energie af te nemen.

\section{Zou u een tijdelijke}

verbruikslimiet accepteren als

dat de inzet van duurzame
Ja

Nee 
energie ten goede komt?

Wat is de belangrijkste voorwaarde voor u om deze verbruikslimiet te accepteren?

Zijn er voorwaarden waarbij u een verbruikslimiet wel zou accepteren?

Ja

Nee

Wat zijn deze voorwaarden?

Een derde manier om energieverbruik op gunstige momenten te stimuleren is door gebruik te maken van slimme huishoudelijke apparaten. Een voorbeeld is een slimme wasmachine. Deze kan zelf een gunstig moment herkennen en ook buitenshuis aangezet worden (bijvoorbeeld met een smartphone). Stel dat $u$ een slimme wasmachine tot uw beschikking heeft. Voor welk van onderstaande opties zou u dan kiezen?

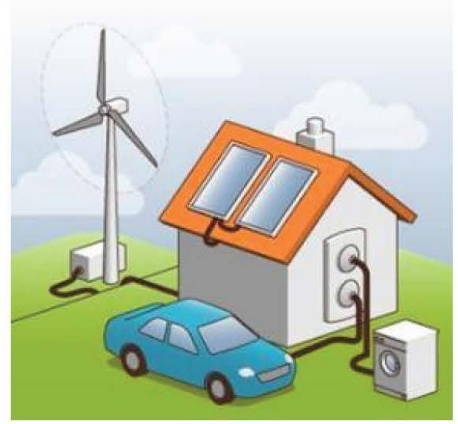

Ik wil zelf een gunstig moment uitkiezen op basis van actuele informatie over het energie-aanbod en de kosten

Het energiebedrijf mag een aantal opties voorselecteren, maar ik beslis zelf.

Het energiebedrijf mag het meest gunstige moment selecteren binnen een door mij gestelde tijdslimiet

Ik wil geen slimme wasmachine

Weet ik niet

Kunt u deze keuze toelichten?

Het energiebedrijf kan ook helpen bij de aansturing van diverse andere slimme apparaten. Zo kan een slimme vriezer of koelkast bijvoorbeeld meer gekoeld worden op een gunstig moment, en juist minder op een ongunstig 
2014 Qualtrics Survey Software

moment (zonder de kwaliteit van het voedsel in gevaar te brengen). Zou het energiebedrijf de aansturing van uw vriezer en koelkast mogen verzorgen?

Ja

Nee

Kunt $\mathrm{u}$ de deze keuze toelichten?

\section{Energie: stand van zaken}

Tot zover de toekomst van energiegebruik en opwekking. Dit onderdeel gaat in op uw huidige situatie.

Eens of oneens? Thuis denken wij bij alles wat energie kost aan mogelijkheden om te energiegebruik te beperken..

Eens

Niet eens/niet oneens

Oneens

Energiebesparing kan worden gerealiseerd door zowel technische maatregelen (bijv. zuinige apparatuur) als door energiebesparend gedrag. Waar ligt bij u thuis de nadruk op?

\begin{tabular}{l|ccc} 
& Vooral technische maatregelen & $50 / 50$ & Vooral besparend gedrag \\
\hline Energiebesparing & 0 & 0 & 0 \\
& & & \\
Is kostenbesparing of milieubesparing uw belangrijkste motivatie om & energieverbruik te beperken? \\
& Vooral kosten & $50 / 50$ & Vooral milieu \\
\hline Belangrijkste motivatie & 0 & 0 & 0
\end{tabular}

Welk van de volgende isolatie-technieken zijn toegepast in uw huis?

(vul bij elke regel een antwoord in; vul 'niet van toepassing' in als u bjvoorbeeld geen eigen dak heeft)

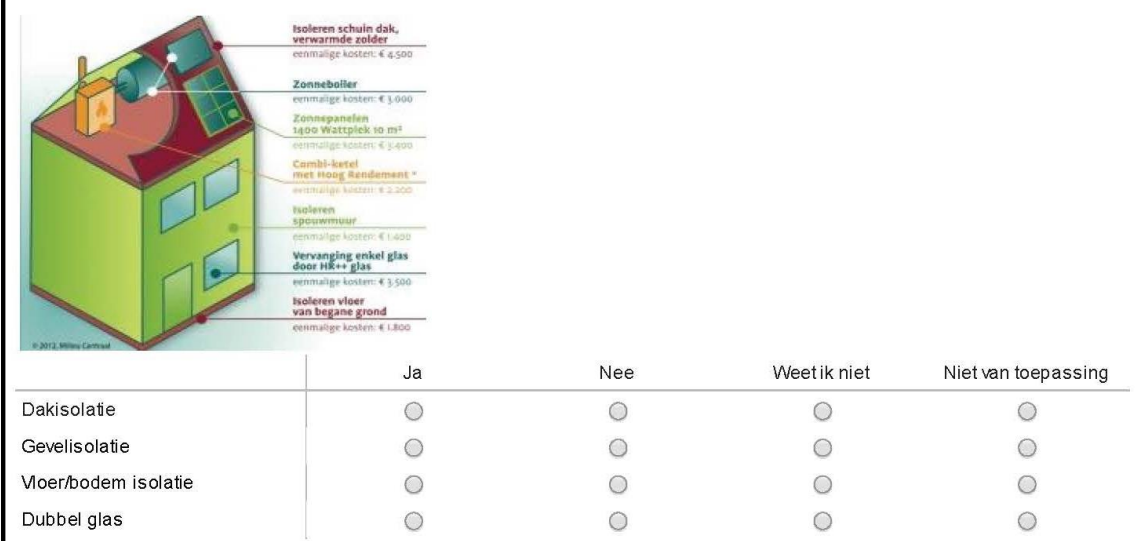

s:/Mur. qualtrics.com/ControlPanel/Ajax.php?action=GetSurveyPrintPreview\& $T=H R 1 G P$ 


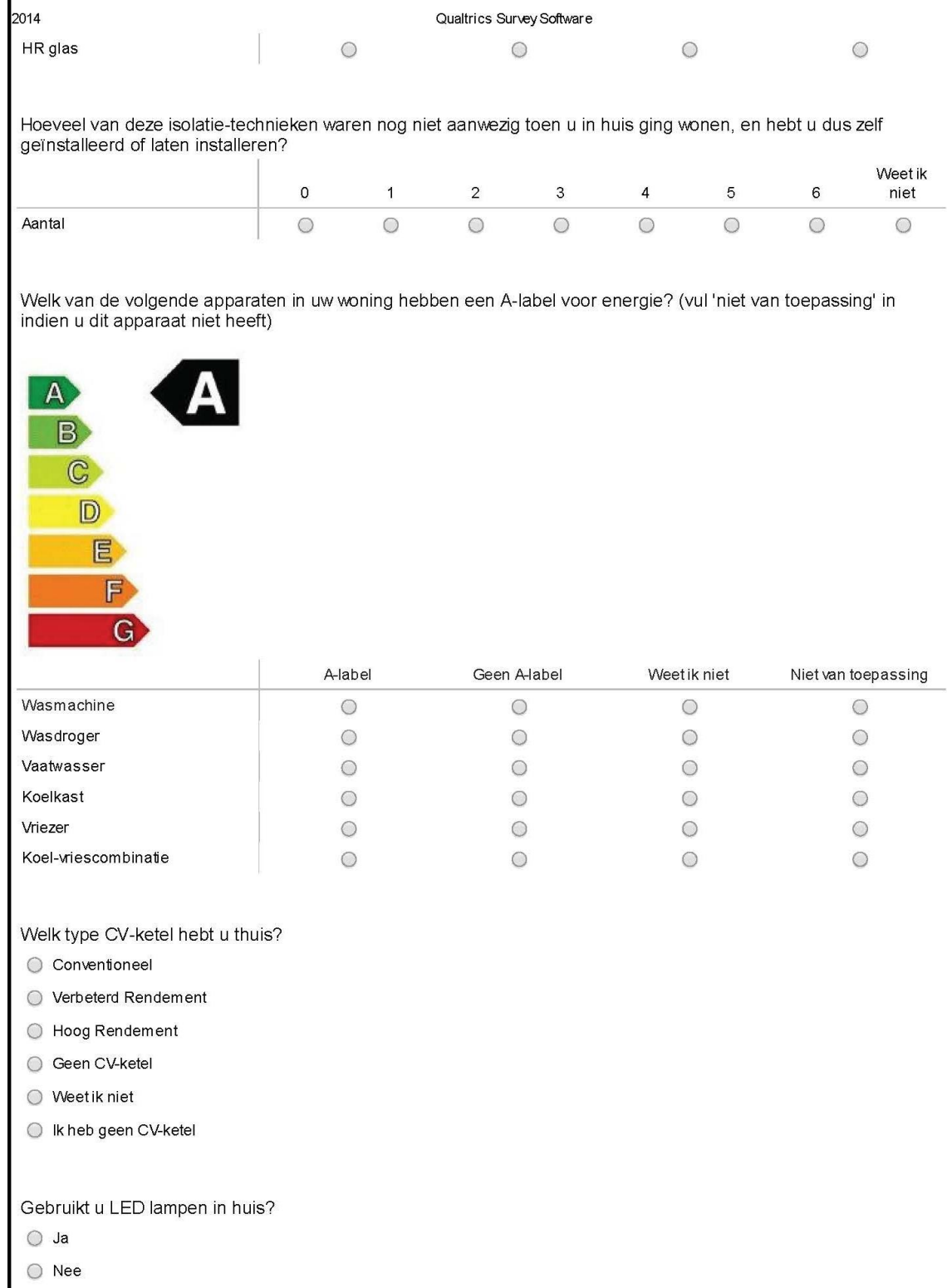

Welk van de volgende apparaten in uw woning hebben een A-label voor energie? (vul 'niet van toepassing' in indien u dit apparaat niet heeft)

G

\begin{tabular}{l|cccc} 
& A-label & Geen A-label & Weetik niet & Niet van toepassing \\
\hline Wasmachine & 0 & 0 & 0 & 0 \\
Wasdroger & 0 & 0 & 0 & 0 \\
Vaatwasser & 0 & 0 & 0 & 0 \\
Koelkast & 0 & 0 & 0 & 0 \\
Vriezer & 0 & 0 & 0 & 0 \\
Koel-riescombinatie & 0 & 0 & 0 & 0
\end{tabular}

Welk type CV-ketel hebt u thuis?

Conventioneel

Verbeterd Rendement

Hoog Rendement

Geen CV-ketel

Weetik niet

Ik heb geen CV-ketel

Gebruikt u LED lampen in huis?

O Ja

Nee

Hebt u nog andere maatregelen genomen om uw energiegebruik te verminderen? 
Wat voor energie-contract hebt u?

- Eigen contractm et energieleverancier

Via collectieve inkoop

via verhuurder

Weetik niet

Anders, $\mathrm{nl}$ :

Wat voor soort stroom krijgt u geleverd van uw energieleverancier?

Atoom stroom

O Gewone/grijze stroom

Groene stroom

Weetik niet

Waar wordt de stroom opgewekt die u krijgt geleverd?

Lokaal

In Nederland

Internationaal

Weetik niet

Hebt $u$ wel eens contact met uw energieleverancier, anders dan het opnemen van de meterstand en het toesturen van de energierekeningen?

O Ja

Nee

Waarover hebt u in zo'n geval contact met uw leverancier?

1)

2)

Hoe vaak bent $u$ in de afgelopen 5 jaar van energieleverancier overgestapt?

\begin{tabular}{l|ccccccc} 
& 0 & 1 & 2 & 3 & 4 & 5 & Weetik niet \\
\hline Aantal keren overgestapt & 0 & 0 & 0 & 0 & 0 & 0 & 0
\end{tabular}

Op internet zijn er verschillende websites waarop energieleveranciers met elkaar vergeleken kunnen worden. Kijkt u wel eens op zo'n vergelijkings-site? 


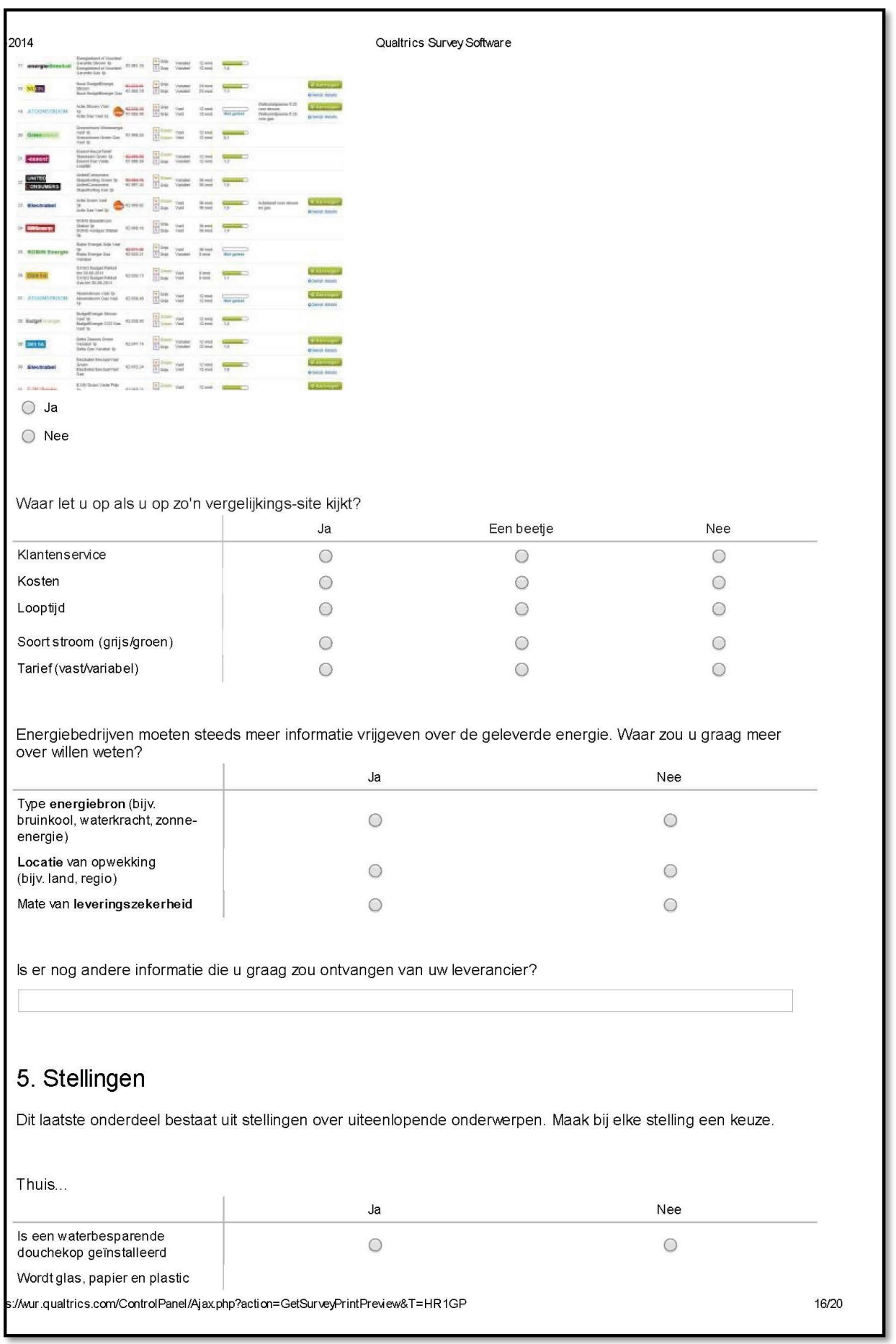




\begin{tabular}{|c|c|c|}
\hline 2014 & & \\
\hline afval gescheiden & 0 & 0 \\
\hline $\begin{array}{l}\text { Staat de verwarming laag als } \\
\text { er niemand thuis is }\end{array}$ & 0 & 0 \\
\hline $\begin{array}{l}\text { Wordt zoveel mogelijk de fiets } \\
\text { gebruikt voor korte afstanden }\end{array}$ & 0 & 0 \\
\hline $\begin{array}{l}\text { Wordt zoveel mogelijk op lage } \\
\text { temperaturen gewassen }\end{array}$ & 0 & 0 \\
\hline \multicolumn{3}{|l|}{ Als het even kan, kies ik voor... } \\
\hline & $\mathrm{Ja}$ & Nee \\
\hline Lokaal geproduceerd voedsel & 0 & 0 \\
\hline Biologische voedingsmiddelen & 0 & 0 \\
\hline $\begin{array}{l}\text { Minstens twee dagen in de } \\
\text { week zonder vees }\end{array}$ & 0 & 0 \\
\hline $\begin{array}{l}\text { Openbaar vervoer voor lange } \\
\text { afstanden }\end{array}$ & 0 & 0 \\
\hline $\begin{array}{l}\text { FSC gecertificeerd hout en } \\
\text { papier }\end{array}$ & 0 & 0 \\
\hline
\end{tabular}

Worden de volgende taken bij $u$ thuis doorgaans zelf gedaan of uitbesteed aan bekenden/een bedrijf? (vul 'niet van toepassing' in als u het gevraagde voorwerp niet heeft)

\begin{tabular}{l|cccc} 
& Zelf gedaan & $50 / 50$ & Uitbesteed & Niet van toepassing \\
\hline $\begin{array}{l}\text { Kleine klussen in en om het } \\
\text { huis }\end{array}$ & 0 & 0 & 0 & 0 \\
$\begin{array}{l}\text { De tuin onderhouden } \\
\text { Kleine technische problemen }\end{array}$ & 0 & 0 & 0 & 0 \\
met computers oplossen & 0 & 0 & 0 & 0 \\
Hethuis schilderen & 0 & 0 & 0 & 0 \\
Reparaties aan de fiets & 0 & 0 & 0 & 0
\end{tabular}

In mijn vrije tijd ben ik betrokken bij verenigingen of georganiseerde activiteiten op het gebied van (vul 'niet van toepassing' in als u geen deelnemer/lid of organisator/vrijwilliger bent)

\begin{tabular}{l|ccc} 
& As deelnemer/lid & Als organisator/vrijwilliger & Niet van toepassing \\
\hline Cultuur (zoals muziek, kunst) & 0 & 0 & 0 \\
Natuur en Milieu & 0 & 0 & 0 \\
Religie & 0 & 0 & 0 \\
Sport & 0 & 0 & 0 \\
Zorg & 0 & 0 & 0 \\
Anders, nl: & 0 & 0 & 0
\end{tabular}

Mogelijke aantasting van mijn privacy is voor mij een reden om te twijfelen over deelname aan...

\begin{tabular}{l|cc} 
& Ja & Nee \\
\hline OVchipkaart & 0 & 0 \\
DigiD & 0 & 0 \\
Elektronisch Patienten Dossier & 0 & 0 \\
Digitale klantenkaarten in de & 0 & 0 \\
supermarkt & 0 & 0 \\
Sociale media & 0 & $17 / 20$ \\
s:/Mur.qualtrics.com/ControlPanel/Ajaxphp?action=GetSurveyPrintPreview/T=HR1GP & \\
\hline
\end{tabular}




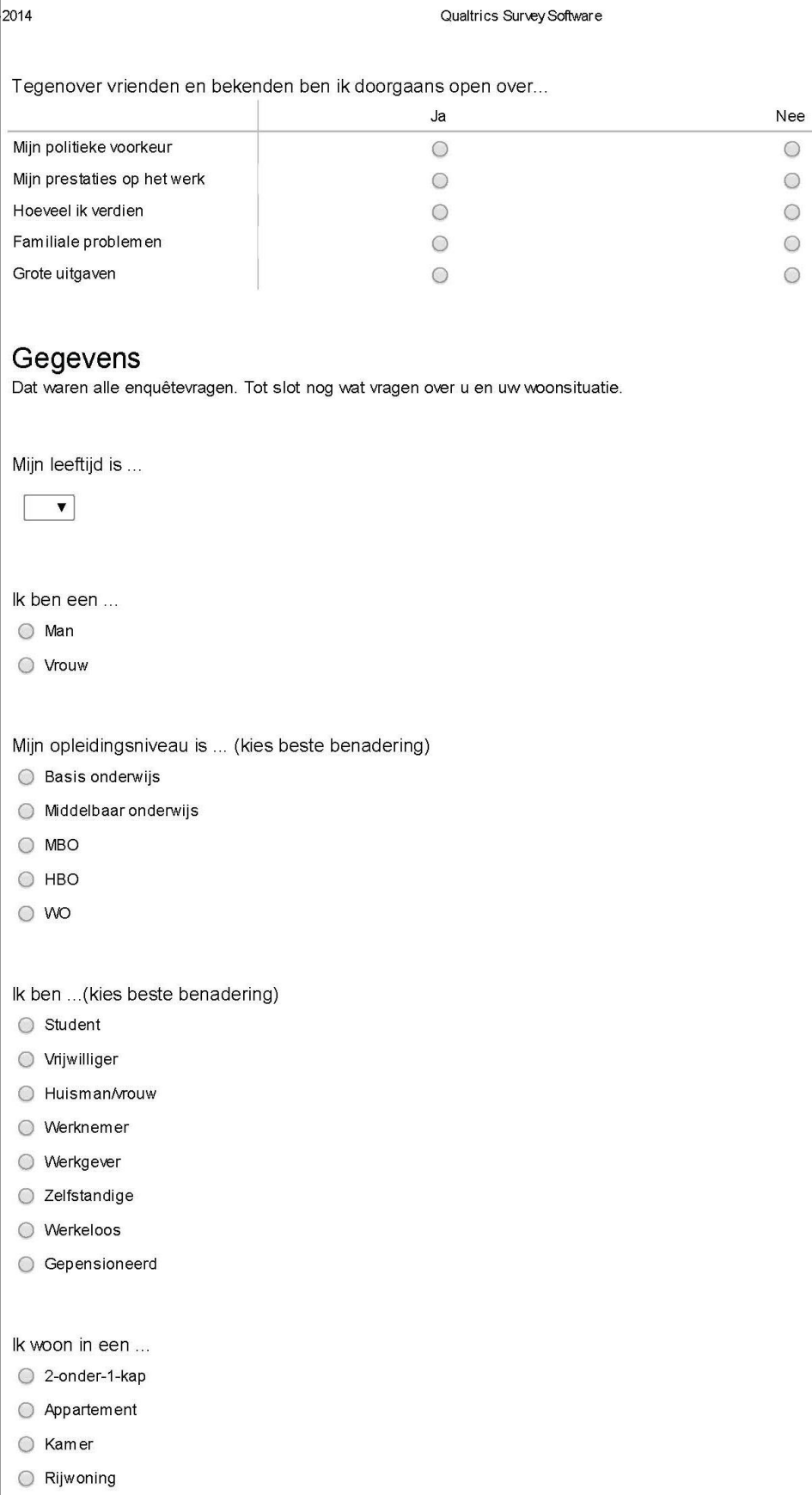




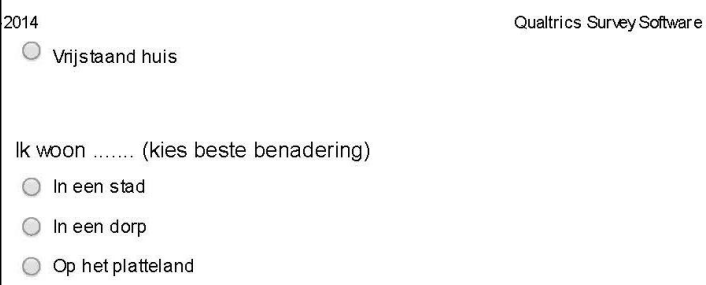

Het verzameld jaarinkomen van het huishouden is... (modaal is ca. €33.000) $\checkmark$

Dit verzameld inkomen bestaat uit .... individuele inkomens

$$
\nabla
$$

Tot zover de enquête en de gegevens. Hebt u nog op- of aanmerkingen naar aanleiding van de enquête?

Wilt u kans maken op 1 van de 4 PODIUM cadeaukaarten ter waarde van $€ 30$,- of heeft $u$ interesse in een groepsdiscussie op basis van de resultaten van de enquête? Vul dan uw email adres in op de volgende pagina.

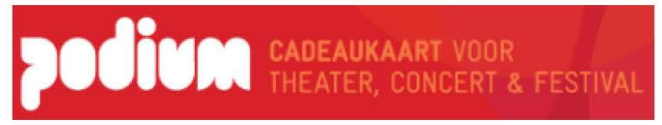




\section{Annex C2: Constructs and items}

\section{Practice arrangements}

\section{Feedback \& advice (construct)}

Q: Based on smart meter data, experts can provide support to save energy. To what extent do the following smart meter services appeal to you?

Get assistance in making energy use transparent (item 1)

Receive tailored energy saving tips (item 2)

Receive notifications in case of unusual energy use (item 3)

Receive tailored advertisements (item 4)

\section{Information sharing}

Q: There are different kinds of initiatives in which people make use of energy data. When invited to participate, for which of the following initiatives would you sign up?

Share energy performance through social media

Join energy saving initiative with neighbours

Join energy saving competition with friends

Online forum for discussing energy topics

\section{Collective energy production}

Q: Besides domestic energy production, there are also experiments around collective energy production. When asked to participate, to which of the following collective arrangements would you be open?

With a friend or acquaintance, in mutual agreement

With neighbours in a local energy cooperative

With other Dutch householders in a larger scale project

\section{Demand control}

Q: With the advent of renewables the availability of energy becomes more dependent on weather conditions. To promote the use of renewable energy, for what smart technology applications would you sign up?

Dynamic tariff structures

Temporary limit to energy demand

Remotely controlled washing machine

Remotely controlled refrigerator/freezer

\section{Privacy}

\begin{tabular}{|l|}
\hline Horizontal privacy \\
Q: I am generally open towards friends and acquaintances about... \\
\hline Political preference \\
\hline Performance at work \\
\hline Level of income \\
\hline Family issues \\
\hline Big expenses \\
\hline Vertical privacy \\
Q: Possible violation of privacy is a reason for me to doubt about using... \\
\hline Digital public transportation card \\
\hline Digital public administration system \\
\hline Electronic health record \\
\hline Digital customers card at the supermarket \\
\hline Social media \\
\hline
\end{tabular}




\section{Annex C3: Score accounting scheme}

\section{Scoring on items}

For each item scores are attributed to answer categories on a scale of $0-2$, with 1 as an intermediate value (if applicable). For some of the items answer categories are merged in order to fit the scale.

\section{Scoring on constructs}

For each respondent the scores on items are aggregated to form construct scores. This is done by adding up item scores and then averaging over the number of items. In case of a missing value the average is calculated over the remaining items.

\section{Dividing high and low scores}

New variables are created by dividing each construct into two groups (rank cases); one with a relatively low score and one with a relatively high score. As each unique construct score is included in either the high or low score group, groups are generally similar in size but not necessarily equal (see Annex 4).

\section{Correlating constructs}

Correlation tests are performed with the new construct variables. That is, between the practice arrangements items/constructs and the privacy constructs. 2-sided Pearson Chi-square tests are used to measure the significance of the correlation: below 0.05 is a significant correlation, between $0.05-0.10$ is considered a trend.

\section{Interpreting correlation}

In case of a significant correlation or a trend, graphs are created to visualise the relation between the two variables and to find out whether the relation is positive (more of $A$ is more of $B$ ) or negative (more of A is less of $B$ ). 


\section{Annex C4: Correlation test results}

Overview of correlations (Pearson Chi-square; 2-sided significance)

\begin{tabular}{|c|c|c|}
\hline $\begin{array}{l}\text { Privacy } \\
\text { Constructs } \\
\text { arrangements } \downarrow\end{array}$ & $\begin{array}{c}\text { Horizontal } \\
\text { Privacy } \\
(\alpha=0.709)\end{array}$ & $\begin{array}{l}\text { Vertical Privacy } \\
\qquad(\alpha=0.664)\end{array}$ \\
\hline Feedback \& Advice $(\alpha=0.794)$ & $0.045^{*}$ & $0.068 * *$ \\
\hline $\begin{array}{l}\text { Get assistance in making energy use } \\
\text { transparent }\end{array}$ & 0.828 & 0.299 \\
\hline Receive tailored energy saving tips & 0.354 & 0.105 \\
\hline $\begin{array}{l}\text { Receive notifications in case of } \\
\text { unusual energy use }\end{array}$ & 0.163 & 0.417 \\
\hline Receive tailored advertisements & $0.074 * *$ & 0.117 \\
\hline Information Sharing $(\alpha=0.620)$ & 0.286 & 0.499 \\
\hline $\begin{array}{l}\text { Share energy performance through } \\
\text { social media }\end{array}$ & $0.002 *$ & 0.698 \\
\hline $\begin{array}{l}\text { Join energy saving initiative with } \\
\text { neighbours }\end{array}$ & 0.473 & 0.266 \\
\hline $\begin{array}{l}\text { Join energy saving competition with } \\
\text { friends }\end{array}$ & 0.227 & 0.506 \\
\hline $\begin{array}{l}\text { Online forum for discussing energy } \\
\text { topics }\end{array}$ & 0.871 & 0.362 \\
\hline $\begin{array}{l}\text { Collective Energy Production }(\alpha= \\
0.680)\end{array}$ & $0.091^{* *}$ & 0.750 \\
\hline $\begin{array}{l}\text { With a friend or acquaintance, in } \\
\text { mutual agreement }\end{array}$ & $0.023^{*}$ & 0.821 \\
\hline $\begin{array}{l}\text { With neighbours in a local energy } \\
\text { cooperative }\end{array}$ & 0.254 & 0.925 \\
\hline $\begin{array}{l}\text { With other Dutch householders in a } \\
\text { larger scale project }\end{array}$ & $0.025^{*}$ & 0.585 \\
\hline Demand Control $(\alpha=0.501)$ & 0.122 & 0.283 \\
\hline Apply dynamic tariff structures & 0.430 & 0.845 \\
\hline $\begin{array}{l}\text { Apply temporary limit to energy } \\
\text { demand }\end{array}$ & 0.285 & 0.235 \\
\hline $\begin{array}{l}\text { Use remotely controlled washing } \\
\text { machine }\end{array}$ & $0.075^{* *}$ & $0.014 *$ \\
\hline $\begin{array}{l}\text { Use remotely controlled } \\
\text { refrigerator/freezer }\end{array}$ & 0.860 & 0.328 \\
\hline
\end{tabular}

* Significant correlation - 2-sided significance below 0.05

** Trend (non-significant) - 2-sided significance between 0.05-0.10 
Annex C5: Dividing high and low scores groups

\section{Example of procedure}

\section{$\underline{\text { Horizontal privacy }}$}

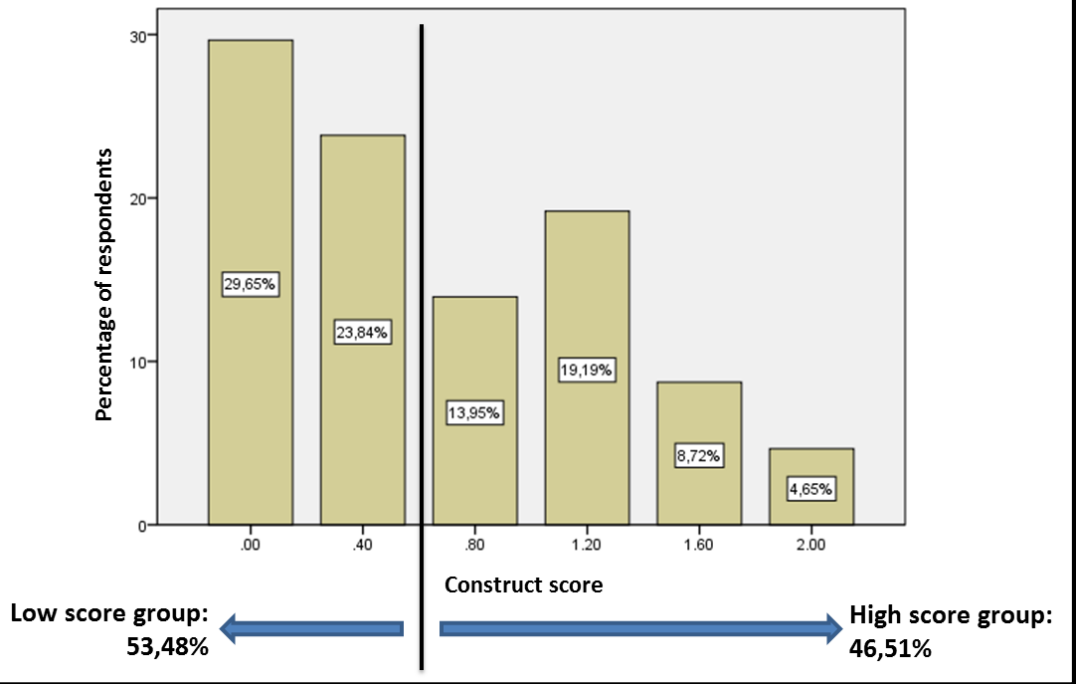




\section{Annex D: Focus group (Ch.3)}

Annex D1: Slides provided to participants

$\underline{\text { Round } 1}$

\section{Vragen}

1. Hoe zijn jullie thuis bezig met dit thema?

2. Hoe zou dit thema in 2020 georganiseerd kunnen worden?

a) Welke organisatievormen zijn mogelijk?

b) Welke partijen zijn daarvoor nodig?

c) Wat zijn de belangrijkste voor-en nadelen?

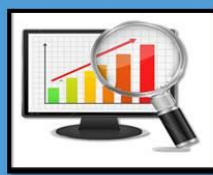

Energie Monitoren
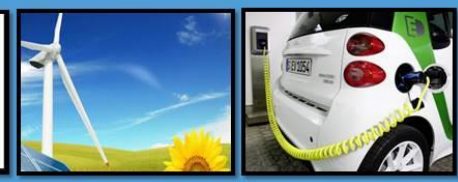

Elektrisch

Duurzaam
Opwekken Vervoer

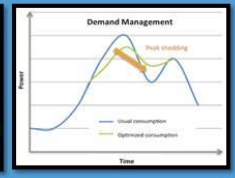

Timing Energievraag

WAGENINGEN UNIVERSITY

Round 2

\section{Vragen}

Per thema, wat betekent deze organisatievorm voor:

a) Gebruik van informatie

b) Autonomie en controle

c) Maatschappelijke betrokkenheid

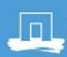

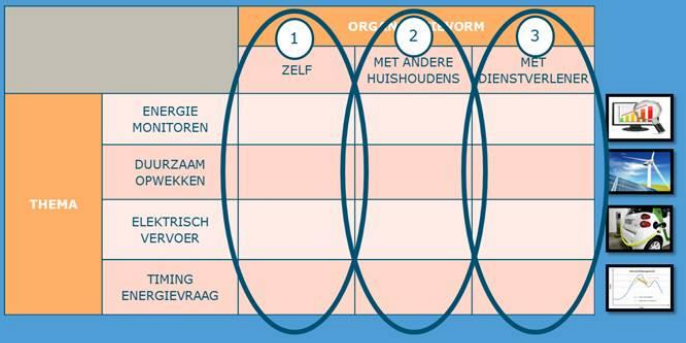


Round 3

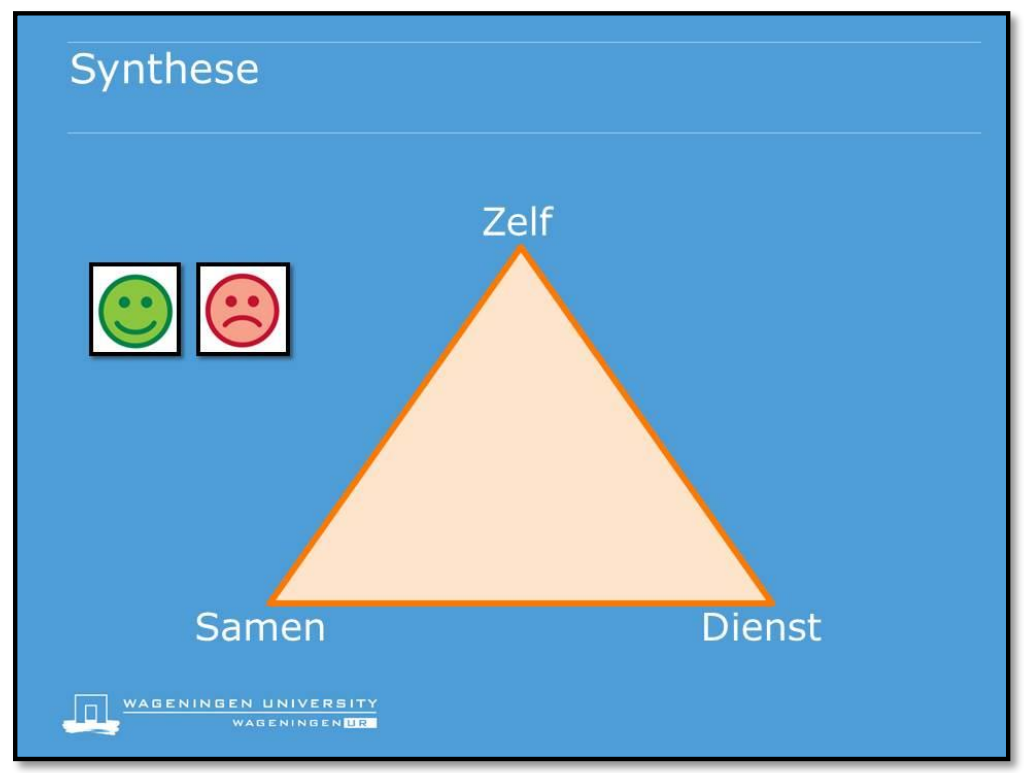




\section{Annex E: Workshops on Energy Conservation (Ch.4)}

Annex E1: List of workshop sessions

\begin{tabular}{|l|l|l|}
\hline Code & $\begin{array}{l}\text { Number of } \\
\text { Participants }\end{array}$ & Date \\
\hline WEC1 & 16 & 27 Jun 2013 \\
\hline WEC2 & 13 & 05 Sep 2013 \\
\hline WEC3 & 18 & 20 Nov 2013 \\
\hline WEC4 & 10 & 15 Jan 2014 \\
\hline WEC5 & 8 & 20 Feb 2014 \\
\hline WEC6 & 9 & 16 Apr 2014 \\
\hline WEC7 & 10 & 11 Jun 2014 \\
\hline WEC8 & 6 & 03 Sep 2014 \\
\hline WEC9 & 10 & 22 Oct 2014 \\
\hline
\end{tabular}




\section{Annex F: Interviews with householders (Ch.4)}

\section{Annex F1: List of interviewees}

\begin{tabular}{|c|c|c|c|c|c|}
\hline Code & $\begin{array}{l}\text { Name } \\
\text { interviewees } \\
\text { (pseudonyms) }\end{array}$ & $\begin{array}{l}\text { Man / } \\
\text { Woman }\end{array}$ & $\begin{array}{l}\text { Household } \\
\text { composition }\end{array}$ & $\begin{array}{l}\text { Participant in } \\
\text { the smart } \\
\text { grid project }\end{array}$ & $\begin{array}{l}\text { Participant } \\
\text { in the } \\
\text { workshop }\end{array}$ \\
\hline WP1 & Thomas & Man & Couple, 1 child & $\mathrm{X}$ & $\mathrm{X}$ \\
\hline WP2 & $\begin{array}{l}\text { Jasper \& } \\
\text { Claudia }\end{array}$ & Man \& Woman & Couple & $\mathrm{X}$ & $\mathrm{X}$ \\
\hline WP3 & Floris & Man & Couple & $\mathrm{X}$ & $\mathrm{X}$ \\
\hline WP4 & $\begin{array}{l}\text { Hendrik \& } \\
\text { Wilma }\end{array}$ & Man \& Woman & Couple, 1 child & $\mathrm{X}$ & $\mathrm{X}$ \\
\hline WP5 & Henk & Man & Couple, 1 child & $\mathrm{X}$ & $\mathrm{X}$ \\
\hline WP6 & Ben \& Ilse & Man \& Woman & Couple & $\mathrm{X}$ & $\mathrm{X}$ \\
\hline WP7 & Derk & Man & Couple & $\mathrm{X}$ & $\mathrm{X}$ \\
\hline WP8 & Jakob & Man & Single & $\mathrm{X}$ & $\mathrm{X}$ \\
\hline WP9 & Menno \& Stella & Man \& Woman & Couple & $\mathrm{X}$ & $\mathrm{X}$ \\
\hline WP10 & Carolien & Woman & Couple, 4 children & $\mathrm{X}$ & $\mathrm{X}$ \\
\hline PP1 & Sophie & Woman & Single & $\mathrm{X}$ & \\
\hline PP2 & Ellis \& Jaap & Woman \& Man & Couple & $\mathrm{X}$ & \\
\hline PP3 & Maria \& Frank & Woman \& Man & Couple, 1 child & $\mathrm{X}$ & \\
\hline PP4 & Wendy \& Boris & Woman \& Man & Couple, 3 children & $\mathrm{X}$ & \\
\hline PP5 & Brenda & Woman & Couple & $\mathrm{X}$ & \\
\hline PP6 & Jack & Man & Couple, 2 children & $\mathrm{X}$ & \\
\hline PP7 & Emma \& Peter & Woman \& Man & Couple, 3 children & $\mathrm{X}$ & \\
\hline NP1 & Tessa & Woman & Couple, 2 children & & \\
\hline NP2 & Niels & Man & Couple, 2 children & & \\
\hline NP3 & David & Man & Couple & & \\
\hline NP4 & Linda & Woman & Couple, 2 children & & \\
\hline
\end{tabular}




\section{Annex F2: Interview guide (in Dutch)}

Note: this interview guide represents a basic outline that has been adapted on a case-by-case basis.

\section{Introductie}

- Introductie: onderzoek naar de verduurzaming van energiegebruik in huishoudens.

Lochem interessant vanwege Lochem Energie en het slim net project.

- Doel: Inzicht krijgen in dagelijkse bezigheden en beslissingen omtrent energie, en betrokkenheid bij Lochem Energie (LE) en het slim net project (IPIN).

\section{Vragenlijst}

\section{Lochem Energie / IPIN project}

- Kun je me vertellen hoe je bij LE/IPIN betrokken bent geraakt?

- Waarom ben je lid/deelnemer geworden?

- Ben je wel eens naar bijeenkomsten, workshops of vergaderingen van LE/IPIN geweest? Hoe heb je dit ervaren?

- Wat heb je geleerd uit bijeenkomsten of bronnen rondom LE...?

○ Over jezelf

- Over anderen

- Over energieopwekking en duurzaamheid

- Wat vind je van de informatie zoals je die krijgt: is die toepasbaar in je dagelijks leven?

- Welke informatie heb je thuis toegepast?

- Welke informatie mis je?

- Wordt er thuis overlegd over energie? En over de informatie die je verkrijgt? Hoe?

- Deel je wel eens informatie met anderen? Met wie? Hoe? Heb je al eerder informatie gedeeld over energie? Wat deel je liever niet?

\section{Dagelijkse praktijken}

Ik zou ik graag een beter beeld willen krijgen van een aantal alledaagse bezigheden. Het gaat hierbij om de was doen, het huis verwarmen en verlichting.

- De was doen: zou je me mee kunnen nemen naar de wasmachine en me laten zien hoe je doorgaans de was doet?

- Hoe bepaal je het juiste wasprogramma? Wanneer draai je een volle en wanneer een halfvolle trommel? Wanneer een kort en wanneer een lang programma? Wat zijn de overwegingen daarbij?

- De wasmachine geeft informatie over o.a. het wasprogramma en de duur van de was. Is er informatie die je mist en graag extra zou willen hebben?

- Kun je je herinneren wat het laatste is dat je hebt veranderd in het doen van de was? Waarom heb je dat veranderd? Speelt je deelname aan LE/IPIN hier een rol in? 
○ Wat weet je over het energiegebruik van verschillende programma's? Hoe weet je dat? Wat mis je nog?

○ Denk je wel eens na over alternatieven of programma's die minder energie gebruiken? Speelt je deelname aan LE/IPIN hier een rol in?

- Verwarmen: Kun je me eens laten zien hoe je de temperatuur in huis bepaald?

- Hoe bepaal je wat de juiste temperatuur is overdag en 's nachts? Wat zijn daarin de overwegingen? Wat staat aan en wat staat uit?

○ De thermostaat geeft informatie over o.a. [de actuele temperatuur in huis en de ingestelde temperatuur]. Is er informatie die je mist en graag extra zou willen hebben?

- Wat is het laatste dat je veranderd hebt in het verwarmen van het huis? Wat waren de overwegingen daarbij? Speelt LE/IPIN hier een rol in?

- Wat weet je over energieverbruik bij het verwarmen van het huis? Hoe weet je dat?

- Denk je wel eens na over manieren van verwarmen die minder energie gebruiken? Speelt LE/IPIN hier een rol in?

- Verlichten: kun je eens laten zien welke verlichting je aanzet in de woonkamer wanneer het 's avonds donker wordt?

- Hoe bepaal je welke lampen er aan en welke niet?

- Een lamp geeft o.a. het wattage aan en het aantal branduren. Is er nog informatie die je mist en graag extra zou willen hebben?

- Wat is het laatste dat je hebt veranderd in het verlichten van de woonkamer? Wat waren de overwegingen hierbij? Speelt LE/IPIN hier een rol in?

- Wat weet je over het energieverbruik van verschillende soorten verlichting? Hoe weet je dat?

- Denk je wel eens na over alternatieven of verlichting die minder energie gebruikt? Speelt LE/IPIN hier een rol in?

\section{Nieuwe energie praktijken}

- Monitoren: Zijn er manieren waarop je je energieverbruik probeert bij te houden?

○ Waar let je dan op? Waarom?

○ Is deze informatie toepasbaar? Hoe pas je die toe? Heb je die informatie al eens toegepast voor de wasmachine, de verwarming of verlichting?

- Welke informatie zou je nog graag willen hebben?

○ Wie gebruikt de informatie uit de slimme meter denk je? En waarvoor?

○ Is er informatie die je liever niet vrijgeeft?

- Opwekken: Kun je me vertellen hoe de beslissing om zonnepanelen te nemen tot stand is gekomen?

○ Wat weet je over de opbrengst? Hoe weet je dat?

○ Is dat bruikbare informatie? Welke informatie zou je nog willen hebben? 
○ Denk je wel eens na over andere manieren van energie opwekken?

- Elektrisch vervoer: Maak je wel eens gebruik van de elektrische deelauto's, of heb je zelf een elektrische auto?

○ Waarom maak je (geen) gebruik van EV/deelauto's? Wanneer wel, wanneer niet?

- Hoe ervaar je het gebruik van de (deel)auto?

- Wat weet je over het energieverbruik van elektrische auto's? Hoe weet je dat? 


\section{Annex G: Interviews with project organisations (Ch.4)}

Annex G1: List of interviewees

\begin{tabular}{|l|l|l|}
\hline Organisation & Position & Date \\
\hline Alliander & Project leader & 20 Oct 2014 \\
\hline LochemEnergie & Board member & 13 Oct 2014 \\
\hline LochemEnergie & Advisor, founder & 13 Oct 2014 \\
\hline LochemEnergie & Advisor, founder & 20 Oct 2014 \\
\hline LochemEnergie & $\begin{array}{l}\text { Project leader, } \\
\text { founder }\end{array}$ & 21 Oct 2014 \\
\hline $\begin{array}{l}\text { Lochem Energie } \\
\text { Board member }\end{array}$ & 03 Nov 2014 \\
\hline Mpare & Account manager & 03 Nov 2014 \\
\hline $\begin{array}{l}\text { Technical University } \\
\text { of Twente }\end{array}$ & $\begin{array}{l}\text { Computer } \\
\text { scientist }\end{array}$ & 29 Oct 2014 \\
\hline
\end{tabular}




\section{Annex G2: Interview guide (in Dutch)}

Note: this interview guide represents a basic outline that has been adapted on a case-by-case basis.

\section{$\underline{\text { Introductie }}$}

- Introductie: onderzoek naar de nieuwe mogelijkheden tot verduurzaming van huishoudelijk energiegebruik met de opkomst van slimme energie netwerken. Ik let met name de rol van bewoners en interactie tussen verschillende partijen. IPIN project te Lochem.

- Doel: Inzicht krijgen in beslissingen omtrent energie en informatie voorziening, alsmede interacties tussen verschillende betrokken partijen.

\section{Vragenlijst}

\section{Rol binnen Slim Net project}

- Wat is de rol van de organisatie binnen het project?

- Kun je eens beschrijven hoe [organisatie] bij IPIN betrokken is geraakt?

- Wat is jouw rol precies binnen [organisatie]? En binnen het IPIN project?

\section{Proces en ervaringen}

- Wat is volgens u de belangrijkste doelstelling van het IPIN project?

- Is er, volgens u, tot nu toe aan deze doelstelling voldaan? Wat zou daar nog voor moeten gebeuren?

- Wat zijn volgens u de belangrijkste momenten geweest binnen het IPIN project? Waarom zijn juist deze belangrijk?

- Wat zijn de belangrijkste lessen die u zelf, en [organisatie], hebben geleerd uit dit project?

\section{Informatiestromen}

- Welke rol speelt informatie in de doelstelling die u zojuist noemde?

- Welke informatie t.a.v. energie wordt er verzameld? En hoe?

- Hoe wordt deze informatie gebruikt?

- Hoe belangrijk is deze informatie voor:

- [Organisatie]

○ Bewoners

- Het slagen van het project

- Wat zijn de belangrijkste overwegingen in de selectie van te verzamelen informatie?

- Hoe wordt de verzamelde informatie verwerkt?

- Blijft er ook informatie liggen die niet gebruikt wordt?

- Wat weet u over de effectiviteit van informatie? Hoe weet $\mathrm{u}$ dat?

- Worden er wel eens vragen gesteld over informatieverzameling? Wat voor vragen? Door wie? 
- Welke informatie wordt teruggekoppeld naar bewoners? Hoe? In welke vorm? Welk schaalniveau (individueel/ groep)? Welke informatie wordt niet teruggekoppeld?

- Wat denk je dat bewoners met de informatie kunnen doen? Bijvoorbeeld bij:

- Het doen van de was

- Het verwarmen van het huis

○ Het verlichten van het huis

- Snappen bewoners de informatie die ze krijgen? Wat doen jullie er aan om het begrijpelijk en bruikbaar te maken?

- Welke informatie wordt er uitgewisseld met partners? Wie? Welke informatie niet? Wat is het belang van deze informatie?

\section{Interactie met partners}

- Hoe is de interactie met andere partijen in het IPIN project bevallen? Kun je hier een voorbeeld van geven?

- Is er iets in de samenwerking met partners dat u achteraf liever anders zou hebben gedaan? En wat zou u in een vervolgproject juist op dezelfde manier aanpakken? 


\section{Summary}

In climate and energy policy the development of ICT-based energy systems, or smart grids, features as a critical new step in the transition towards a sustainable energy future. The application of ICT enables detailed monitoring of energy flows at household level, two-way communication between households and energy providers, and realtime balancing of demand and supply. This can help in organising energy systems that contain increasing amounts of decentralised renewable energy sources. Not only energy providers, but also end-users are expected to benefit from the application of ICT; new monitoring technologies and smart appliances are assumed to put end-users in a better position to reduce their energy bills, lower their carbon footprints, and actively participate in the energy market.

The opening chapter of the thesis shows that the smart grid landscape in the European Union and in the Netherlands is rapidly evolving. Most countries have made considerable headway in the roll-out of smart meters, and all kinds of new technologies are being tested in real-life pilot projects. Smart grid configurations are emerging at different levels of organisation, from the local to the international level. However, from discussions on smart grid development it is clear that not everything is running smoothly. Pilot projects have shown that energy savings are often lower than expected, and that the flexibility that end-users can provide is uncertain. Also the roll-out of smart meters is not always proceeding as planned, with groups of consumers objecting against a potential invasion of their privacy and autonomy (among other things). These observations show why end-users are becoming an increasing source of uncertainty and concern for policy makers and businesses pursuing smart grid development and a sustainable energy transition.

The central aims of this thesis are: a) to contribute to a better understanding of the social dynamics of emerging smart energy systems, with a focus on the transformations taking place in and around the households of end-users; b) to develop concepts and analytical tools for studying these dynamics and transformations, and; c) to formulate suggestions for the governance of sustainable energy transitions that involve smart energy systems. To organise the discussion on smart grids and end-users the opening chapter draws out three (interrelated) research themes: the Household, which serves as a key site of intervention and change in smart energy systems; Information flows, which act as a means of organising change in smart energy systems; and, finally, the Sustainable energy transition, which refers to the long-term process of change that smart energy systems are expected to contribute to. To come to grips with these three research themes, each theme is matched with a specialised theoretical perspective: the 
Household is matched with Social Practice Theories (SPT); the theme of Information flows is matched with Informational Governance (IG); and the Sustainable energy transition is matched with Transition Theories (TT). Social Practice Theories form the primary frame of reference. Informational Governance and Transition Theories are brought in to assist in the analysis of specific research themes and to develop a dialogue between the theories.

The central research questions (RQ's) of the thesis are:

1. How can we conceptualise the interplay between households and smart energy systems?

2. How do householders deal with new information flows in a context of emerging smart energy systems?

3. What are the implications of this analysis for (the governance of) householder participation in sustainable energy transitions that are enabled by smart energy systems?

The thesis addresses these research questions with the help of four chapters that focus on specific research themes and a concluding chapter that synthesises and discusses the main outcomes.

Chapter Two outlines a conceptual framework for understanding the interrelations between households and emerging smart energy systems. Drawing upon Social Practice Theories and Informational Governance, the framework discerns three categories of energy and information flows: flows between household-members, flows between households and energy service providers (vertical), and flows between local and distant households (horizontal). For each set of energy and information flows, the chapter examines the changes that occur in domestic consumption practices and social relationships based on a set of exploratory interviews with Dutch households and institutional actors. The analysis reveals that changes in domestic consumption practices are contextual and emergent, rather than linear and predictable. The chapter also argues for seeing information disclosure between householders and energy providers as a two-way process and, secondly, for examining the new terrain of practices that is opening up as a result of information exchange between households.

Chapter Three further examines the privacy and autonomy concerns of end-users in relation to their participation in smart grids. Based on an online survey and a focus group discussion among Dutch end-users who have some experience with sustainable energy practices, the chapter seeks to understand the nature of privacy and autonomy concerns as well as the significance of these concerns. The analysis is organised with the help of a conceptual scheme that discerns three types of energy management 
practices that are typical for smart grids - energy monitoring, co-production of energy and time-shifting - and three social arrangements that refer to different forms of participation and information disclosure in smart energy systems - private, horizontal and vertical arrangements. The analysis shows that privacy and autonomy concerns are relevant for different kinds of energy management practices and for different social arrangements, and that these concerns shape and may sometimes impede the participation of end-users in smart energy systems. Finally, it is suggested that decentralised smart energy systems can help in making privacy and autonomy concerns explicit, and open up space for renegotiating vertical and horizontal relationships.

Chapter Four further investigates the role of information in reconfiguring domestic consumption practices. To do so, it examines a smart grid pilot project (Smart Grid Lochem) in the Netherlands. Data are drawn from a set of interviews and house tours with end-users, and from participant observation in a series of workshops on energy conservation organised by a local energy cooperative. To guide the analysis the chapter discerns between three sets of social practices that reflect the particularities of the pilot project: community interaction practices, monitoring practices and domestic (consumption) practices. The analysis explicates the ways in which information is accomplished as part of these practices, how information 'moves' between practices, and how it does or does not lead to the reconfiguration of domestic consumption practices. It is argued that smart grid interventions like pilot projects, which are usually inspired by rationalistic and individualistic models of behaviour change, would benefit from a practice-based model of social change that considers interventions and information as part of specific local configurations of practices.

Chapter Five outlines a practice-based approach to the governance of sustainable energy transitions in the context of smart grids. Starting from a discussion on Transition Theories and transition policies, the chapter argues that Social Practice Theories can help analyse the decentralised dynamics of smart energy systems. Home Energy Management-practices (HEM-practices) form the central components of the conceptual framework that is introduced. Emerging HEM-practices play a key role in smart grids as mediating practices in-between domestic consumption practices and systemic production and distribution practices. After specifying a set of six HEMpractices (Energy monitoring, Co-production of energy, Energy trading and sharing, Timing of demand, Energy storage, and Energy conservation), the chapter discusses the trajectories of social change that are set in motion by the introduction of HEMpractices. Social change in smart grids is conceptualised as the emergence of new HEMpractices, the reconfiguration of existing domestic and systemic practices, and the 
linking and delinking of networks of practices. Examples illustrate how this understanding of social change helps in analysing small-scale, short-term change as well as long-term, large-scale change. The concluding discussion argues that the suggested approach - referred to as 'Governing-by-Practices' - can be used to rethink existing approaches to the governance of smart grid-related energy transitions.

The final chapter, Chapter Six, synthesises the findings of the different chapters and draws general conclusions. Firstly, it is concluded that the interplay between households and smart energy systems (RQ\#1) can be understood in terms of the HEMpractices and the information flows that are emerging at the interface between households and wider energy systems. This interplay is defined by the type(s) of HEMpractices that are emerging, the ways in which these HEM-practices are organised, and the ways in which HEM-practices become connected to domestic consumption practices as well as systemic practices of energy provision. Secondly, it is concluded that the unpredictable, non-linear ways in which end-users deal with new information flows in smart grid contexts (RQ\#2) stem from the complex ways in which monitoring practices and domestic consumption practices become connected, as well as the tendency of (privately organised) consumption practices to persist. Based on these findings, finally, the chapter distils four focal points for analysing and organising the governance of householder participation in sustainable energy transitions that involve smart energy systems (RQ\#3):

1. Putting HEM-practices centre stage.

2. Developing sustainability goals for HEM-practices in dialogue with end-users.

3. Making room for local innovation trajectories in HEM-practices.

4. Providing long-term support to end-user participation in HEM-practices.

Together these four focal points form the basis of the Governing-by-Practice Approach (GPA). The remainder of the chapter contains a discussion of the research process and its outcomes, as well as a set of recommendations for future policy and research on end-users and smart energy systems. 


\section{SENSE}

Netherlands Research School for the

Socio-Economic and Natural Sciences of the Environment

\section{I P L O M A}

For specialised PhD training

The Netherlands Research School for the

Socio-Economic and Natural Sciences of the Environment

(SENSE) declares that

\section{Joeri Naus}

born on 23 January 1986 in Deurne, the Netherlands

has successfully fulfilled all requirements of the

Educational Programme of SENSE.

Wageningen, 1 November 2017

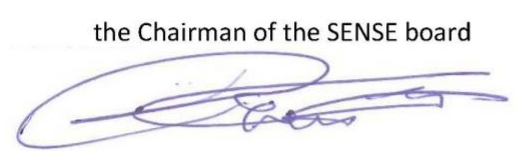

Prof. dr. Huub Rijnaarts the SENSE Director of Education

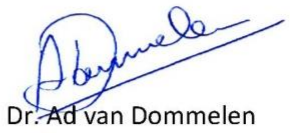

The SENSE Research School has been accredited by the Royal Netherlands Academy of Arts and Sciences (KNAW)

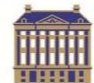

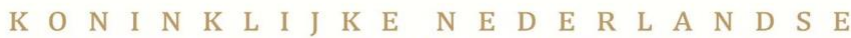

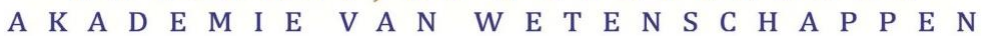




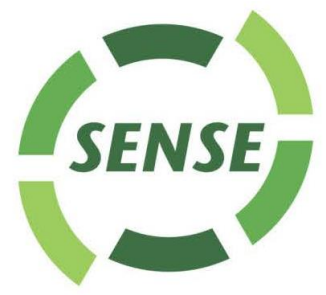

The SENSE Research School declares that Mr Joeri Naus has successfully fulfilled all requirements of the Educational PhD Programme of SENSE with a work load of $56 \mathrm{EC}$, including the following activities:

\section{SENSE PhD Courses}

- Environmental research in context (2012)

- Research in context activity: 'Organizing workshop series on energy conservation for a citizen-based energy cooperative and writing a popularizing article on consumer privacy and autonomy in smart grids for Duurzaamnieuws.nl' (2014 and 2015)

\section{Other PhD and Advanced MSc Courses}

- Social theory and the environment: an introduction to ecological modernization theory, Wageningen University (2011)

- Interviewing techniques, Wageningen University (2012)

- Pitch training, Wageningen University (2014)

- Groningen Energy Summer school 'Smart Grids from a Global Perspective: bridging old and new energy systems', Groningen University (2014)

- Summer Training Seminar: Science, Technology, Society (STS) \& Environmental Sociology and Policy, by Prof. David Hess, Vanderbilt University (2014)

- Career Orientation, Wageningen University (2015)

\section{Management and Didactic Skills Training}

- Supervising the MSc theses of three MSc students (2012-2014)

- Lecturing in the MSc course 'Consumers and Technology' (2014-2015)

- Lecturing and supervision of group work in the BSc/MSc course 'Sustainable Technology Development' (2014-2016)

- PhD representative at Daily Board of Environmental Policy Group (2013-2015)

- Co-organising three PhD trips; to Denmark \& Sweden (2012), to Belgium (2014) and to Germany \& Switzerland (2016)

\section{Selection of Oral Presentations}

- Householder participation in the future smart grid: A study among environmentallyengaged householders in the Netheriands. Workshop Smart Grids and the Social Sciences, 10-11 April 2014, Trondheim, Norway

- Governing by Practices: Sustainability goals for social change in decentralised smart energy systems. DEMAND Conference - What energy is for: The making and dynamics of demand, 13-15 April 2016, Lancaster, UK

- Smartening energy consumption: A practice-based approach to households, information and sustainability. International Transparency Conference - Disclosing Sustainability: The transformative power of transparency, 24-25 June 2016, Wageningen, the Netherlands

SENSE Coordinator PhD Education

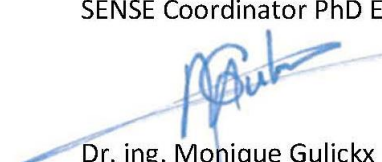




\section{About the author}

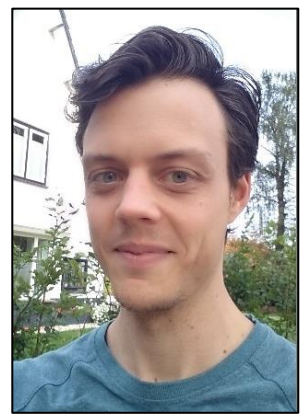

Joeri Naus (born in Deurne on 23 January 1986) grew up and went to school in Panningen, the Netherlands. After secondary school he studied Environmental Sciences at Wageningen University (the Netherlands). In 2008 he obtained a BSc degree in Environmental Sciences with a specialisation in Environmental Systems Analysis. Two years later, in 2010, he obtained a MSc degree with a specialisation in Environmental Policy and a minor in Urban Environmental Management.

During the MSc program he did an internship at European Environmental Bureau in Brussels, Belgium. He worked on an assessment of the River Basin Management Plans in the context of the European water policy, and on Indirect Land Use Change in the context of European biofuel policy. To finalise the MSc program he wrote an MSc thesis on the implementation of the Clean Development Mechanism in Uganda, Africa.

In 2011 Joeri started working at Environmental Policy Group (Wageningen University). As a Junior Researcher he participated in a research project on innovation in sanitation technology, and he assisted teaching staff in education activities. In coordination with ENP staff he also developed a PhD proposal, which was granted in 2012 under the Informational Governance research program of Wageningen University.

During the PhD he published several peer-reviewed articles (see next page) and engaged in a variety of educational tasks and management activities (see SENSE Diploma). He also participated in three international PhD study trips - to Denmark and Sweden (2012) to Belgium (2014) and to in Germany and Switzerland (2016) - and took part in two international summer schools - an interdisciplinary summer school on smart grids at Groningen University (the Netherlands), and a summer seminar on STS \& environmental sociology at Vanderbilt University (Nashville, USA). 


\section{Journal publications}

- Naus J, Spaargaren G and Verbong JPG (under review) Governing by practices: a practicebased approach to sustainability transitions in smart grids.

- Naus J and Van der Horst HM (2017) Accomplishing information and change in a smart grid pilot: Linking domestic practices with policy interventions. Environment and Planning: Politics and Space 35: 379-396.

- $\quad$ Naus J, Van Vliet BJM and Hendriksen A (2015) Households as change agents in a Dutch smart energy transition: On power, privacy and participation. Energy research \& social science 9: 125-136.

- Naus J, Spaargaren G, Van Vliet BJM and Van der Horst HM (2014) Smart grids, information flows and emerging domestic energy practices. Energy Policy 68: 436-446.

\section{Other publications}

- Van Vliet BJM, Naus J, Smale R and Spaargaren G (2016) Emerging e-practices, information flows and the home: a (sociological) research agenda on smart energy systems. In: Beaulieu A, De Wilde J and Scherpen J (eds) Smart Grids from a Global Perspective: Bridging Old and New Energy Systems. Cham: Springer, pp.217-234.

- $\quad$ Naus J, Spaargaren G, Van Vliet BJM and Van der Horst HM (2016) Will smart energy systems inspire a turnaround in sustainable energy consumption? In: Potters J, Termeer K and Opdam P (eds) Organising Sustainability in the Digital Age Results of the research programme Informational Governance for Sustainability 2012-2016, Wageningen University, June. Available at: http://edepot.wur.nl/387053

- Naus J, Van Vliet BJM and Hendriksen A (2015) Onderzoek: Privacy en autonomie cruciaal in duurzame energie-toekomst. Duurzaamnieuws.nl, October 19. Available at: http://www.duurzaamnieuws.nl/onderzoek-privacy-en-autonomie-cruciaal-induurzame-energie-toekomst/

- $\quad$ Naus J and Van Vliet BJM (2012) Over Spoelen en Vermalen: bewonersonderzoek naar percepties en gebruikerservaringen van het project Waterschoon in Sneek. Wageningen University, The Netherlands, March. Available at: http://edepot.wur.nl/211059

- Naus J (2010) The Clean Development Mechanism (CDM): an analysis of the state of play in Uganda. MSc Thesis, Wageningen University, The Netherlands. Available at: http://edepot.wur.nl/158015 


\section{Acknowledgements}

A supportive environment is essential for completing a $\mathrm{PhD}$ thesis. I would like to express my gratitude to everyone who contributed to this thesis, directly or indirectly, intentionally or unintentionally. It has been a challenge to come to grips with the wealth of new ideas, theories and research approaches, and also on a personal level the $\mathrm{PhD}$ trajectory has been challenging at times. I greatly appreciate all the support I have received.

First of all, I would like to thank my promotor and co-promotors; Gert Spaargaren, Bas van Vliet and Hilje van der Horst. I am very grateful for your guidance during the PhD trajectory and for your contributions to the different chapters of this thesis. Gert, thank you for endorsing me as a PhD student, and for the many inspiring discussions on social theory. Some of the core ideas presented in the thesis are as much yours as they are mine. Bas, thank you for your ever-constructive feedback and for the support in times of need. Any PhD student would be lucky to have you as a supervisor and co-promotor. Hilje, thank you for your interest and support in the fieldwork, and for helping me see and question my assumptions. This has not only advanced my understanding of the topic, but also aided my development as a researcher.

Second, I would like to thank the staff members and PhD students of the Environmental Policy Group (ENP). With so many nationalities and high-quality researchers it has been a truly enriching experience. I greatly appreciate the opportunity to work at ENP, and I want to thank the group for the financial support to organise a focus group discussion and to participate in two excellent summer schools. There are some people that I want to thank in particular: Peter Oosterveer for helping me discover my potential as a researcher during the MSc thesis, and for his suggestion to develop a PhD proposal in the first place; Astrid Hendriksen for her eagerness to help out with the online survey and the focus group, and for being a co-author to Chapter Three of the thesis ("Households as Change Agents in a Smart Energy Transition"); and Corry Rothuizen for her tireless help solving administrative struggles, for all the nice chats about cats, and for occasionally reminding me of the irrationalities of science and its practitioners.

It was also a delight to be part of the PhD-community at ENP. It is difficult to imagine what $\mathrm{PhD}$ life would have been like without such a nice, active and diverse group of colleagues and friends. Next to the frequent PhD dinners and drinks, I particularly enjoyed the PhD study trips to Denmark and Sweden (2012), to Belgium (2014), and to Germany and Switzerland (2016). These study trips were not only a great learning experience, but also a great way to get to know many of you on a much more personal 
level. A special thanks furthermore to Alexey Pristupa and Harry Barnes-Dabban for assisting me as paranymphs at the defence of my theses, and to all the PhDs that have shared an office with me: Natapol Thongplew, Debasish Kundu, Belay Mengistie, Eira Carballo Cardenas, Judith Floor, Terrence Lee, Moises Covarrubias Perez, Mandy Doddema and Mariska Bottema. Thank you for all the nice chats, shared laughs and concerns and inspiring conversations. I will definitely miss having you around.

Furthermore, I want to express my gratitude to several scholars located elsewhere in academia: to Katrien Termeer, Paul Opdam, Katrine Soma, Jorieke Potters and others for having me as a participant in the Informational Governance Research Programme of Wageningen University; to David Hess for accepting me as a participant in the summer seminar on STS \& Environmental Sociology at VanderBilt University (Nashville, USA); to Anne Beaulieu, Jaap de Wilde and others for allowing me to join the interdisciplinary Summer School on Smart Grids at Groningen University (the Netherlands), and for inviting me to write a chapter in their book ("Smart Grids from a Global Perspective"); and, finally, to Geert Verbong for his contributions as a co-author to Chapter Five of this thesis ("Governing by Practices").

There are also a number of people outside of academia that I want to mention. First, I would like to acknowledge the contributions of all the respondents. Without their voluntary participation in my research, this thesis would not have been possible. Thank you to all the interviewees, survey respondents and focus group participants. Next, I would like to thank the people who have facilitated my research in various other way: Peter van Vliet for providing a platform for distributing the online survey and publishing the results (duurzaamnieuws.nl); Tonnie Tekelenburg for facilitating my research in Lochem and for giving me access to the energy workshops; and Klaas Hallenga and Willem Beekman for kindly allowing me to stay in their homes during fieldwork in Lochem.

Finally, I would like to thank family and friends. I want to express my gratitude to my parents Mat and El Naus and my sisters Malou and Myrthe for their support, patience and understanding; to the family Van Bets for the nice weekend breakaways in Belgium and the magnificent trip to Peru; to Joep Keijsers for the wonderful time as roommates and PhD colleagues; and to Christan Buurstee for the refreshing and enjoyable trips to Milan. Most of all I want to express my deep appreciation to my partner Linde. I am so fortunate the have you by my side. In times of need you were always there to pick me up. Thank you so much for all the love and support. I am greatly indebted to you. 
The research described in this thesis was financially supported by the Informational Governance Research Program of Wageningen University \& Research (WUR), to contribute to solutions for the most pressing global environmental problems.

Cover design by: Joeri Naus

Printed by: Digiforce 